\title{
Análise de custo-efetividade de teste rápido para o diagnóstico de casos novos de malária em doze municípios endêmicos do Estado do Pará
}

Maria Regina Fernandes de Oliveira

Tese apresentada ao Programa de Pós Graduação em Saúde Pública da Faculdade de Saúde Pública da Universidade de São Paulo para obtenção do título de Doutora em Saúde Pública.

Área de Concentração: Epidemiologia

Orientador: Prof. Dr. Almério de Castro Gomes Co - orientadora: Dra. Cristiana Toscano

São Paulo 
É expressamente proibida a comercialização deste documento tanto na sua forma impressa como eletrônica. Sua reprodução total ou parcial é permitida, exclusivamente, para fins acadêmicos e científicos, desde que na reprodução figure a identificação do autor, título, instituição e ano da tese. 
Aos meus pais e irmãs - começo de tudo

Ao Gustavo - amor e companheiro incondicional 


\section{AGRADECIMENTOS}

Esta tese não teria sido viável sem a inestimável colaboração, amizade, apoio e orientação de várias pessoas muito especiais a quem serei eternamente grata: Almério de Castro Gomes, que foi o meu maior incentivador e, acredito, que sem o seu constante estímulo para a minha entrada no doutorado, eu não teria dado o primeiro passo; Cristiana Toscano, mestre e co-orientadora, responsável por ter iluminado o meu conhecimento na área de avaliação econômica; Cor Jesus Fontes, Marcus Lacerda, Maria Novaes e Pedro Tauil, sempre disponíveis para o aporte de informações, discussões, buscas de dados e resolução de dúvidas durante a elaboração do estudo; a equipe do Programa Nacional de Controle de Malária da Secretaria de Vigilância em Saúde, o seu coordenador José Ladislau, Maria da Paz Luna e Rui Moreira Braz, que com total abertura facilitaram todos os dados do Programa, sempre amigos e colaboradores, sendo absolutamente fundamentais para o desenvolvimento do estudo e grandes exemplos do verdadeiro interesse coletivo; Marinete Póvoa, do laboratório de malária do Instituto Evandro Chagas, pelas informações de custos ligados à microscopia e pela opinião especializada na área de diagnóstico; Sérgio Abucater, Alberto Coutinho, Cristiane Maia, Lina Alencar e Willian Gomes da Silva, pela disponibilização dos dados da Secretaria de Vigilância em Saúde para a composição dos custos de transporte e medicamentos e valiosas orientações técnicas específicas da área financeira; Roberto Montoya, da Organização Pan Americana da Saúde, pela orientação inicial no tema e informações técnicas; Ana Rosa Bosi e Josileno Duarte Nogueira, profissionais atuantes no Município do Novo Repartimento, cujas prestimosas e detalhadas informações foram básicas para o delineamento do modelo do estudo; Valdir Amoras, da Secretaria de Estado da Saúde do Pará, pelos dados relativos à implantação do TR no estado; Lorrin Pang e Fabiana Piovesan Alves pela discussão via internet sobre dados cruciais de custos da microscopia, mesmo sem nunca termos 
nos conhecido pessoalmente; meus chefes na Secretaria de Vigilância em Saúde nos quatro anos do doutorado - Jarbas Barbosa, Fabiano Pimenta e Gerson Penna - pelo inestimável apoio e grande compreensão em todas as fases do curso; amigas e colegas de trabalho - Margarita Urdaneta e Ana Johnson - que de forma bastante profissional e, principalmente, generosa, não mediram esforços para assumir as minhas funções na Secretaria de Vigilância em Saúde nos momentos de afastamento para a realização dos créditos em São Paulo e para a conclusão da tese; Ana Maria, Edite, Elza, Gyl, Heloiza, Lydiane, Marta, Rejane e Roseane da nossa Coordenação Geral de Desenvolvimento da Epidemiologia em Serviço pela amizade, competência e apoio a mim, Margarita e Ana Johnson na condução e execução das metas de trabalho.

$\mathrm{Na}$ minha formação em epidemiologia, agradeço de forma muito especial aos mestres da USP, das duas casas - Faculdade de Saúde Pública e Departamento de Medicina Preventiva - cujos ensinamentos e afetuoso acolhimento estão comigo; ao amigo Eliseu Waldman, pelo grande apoio em todas as fases.

Às colegas da nossa turma de 2005: Christine, Flávia, Lúcia, Miriam, Mônica e Paula - meu grande carinho e amizade.

Enfim, o trabalho leva o meu nome, mas não é meu somente, é um pouco de cada uma destas pessoas, é fruto de trabalhos coletivos; a experiência da tese me ensinou, e muito, o grande valor da cooperação entre nós. 
"Segue-se agora o tratamento das febres, uma classe de doenças que acometem o corpo como um todo, além de serem extremamente comuns. Dessas febres, uma é cotidiana, a outra é terçã e a terceira, quartã" - Aulus Cornelius Celsus (25 A.C. - 50 D.C.). Primeiro Tratado de Medicina.

"Not everything that can be counted, counts, and not everything that counts, can be counted" - Albert Einstein (1879-1955). 
Fernandes de Oliveira, MR. Análise de custo-efetividade de teste rápido para o diagnóstico de casos novos de malária em doze municípios endêmicos do Estado do Pará [Tese de Doutorado]. São Paulo: Faculdade de Saúde Pública da Universidade de São Paulo; 2008.

Palavras - chave: Malária; Teste Rápido; Custo-efetividade; Diagnóstico; Modelo econômico.

\section{RESUMO}

Introdução: A malária humana apresenta sintomas inespecíficos e exige diagnóstico laboratorial e identificação da espécie para o seu manejo. 0 diagnóstico baseia-se na microscopia, exame barato, que exige profissionais experientes. Nos últimos anos surgiram testes imunocromatográficos de execução rápida e custo mais elevado em comparação à microscopia. Estudos de validação demonstraram sensibilidade e especificidade comparáveis à microscopia, podendo ser alternativa confiável em áreas sem laboratório. Objetivo: Realizar análise de custo-efetividade do uso do OptiMAL $\circledast$ - teste rápido (TR) registrado no Brasil e validado em áreas endêmicas - comparado à microscopia. Métodos: A perspectiva da análise foi a do sistema público de saúde brasileiro - SUS, o horizonte analítico de seis meses e o ano de 2006, a referência temporal. Doze municípios do Estado do Pará constituíram a área de estudo. Foi construído modelo de decisão considerando dois desfechos: casos diagnosticados adequadamente e casos conduzidos adequadamente em três cenários: o cenário 1 corresponde a 100\% dos exames realizados, o cenário 2 considera somente os exames feitos nas áreas com laboratório e o cenário 3 corresponde a $30 \%$ dos exames, realizados em áreas isoladas. Os parâmetros epidemiológicos principais foram prevalência da malária entre indivíduos sintomáticos e acurácia - sensibilidade e especificidade - dos métodos diagnósticos, cujas estimativas foram obtidas a partir do Sistema de Informação de Vigilância Epidemiológica da Malária e literatura científica. Foram estimados custos diretos médicos e não-médicos, considerando diretrizes nacionais e dados municipais. Fontes de dados de custos 
incluíram o Sistema de Informação de Insumos Estratégicos, a Tabela de Procedimentos do SUS e o Sistema de Informação Hospitalar do SUS. Foram estimadas as razões média e adicional de custo-efetividade (RCEA) e realizada análise de sensibilidade. O software utilizado foi o TreeAge Pro 2005. Resultados: O TR foi dominado pela microscopia nos cenários 1 e 2 . Em áreas isoladas a estratégia microscopia apresentou RCEA de $\mathrm{R} \$ 1.193,00$ por caso diagnosticado adequadamente e de $\mathrm{R} \$ 1.016,67$ por caso conduzido adequadamente quando comparada com o OptiMAL $\circledast$. O TR tornou-se mais custo-efetivo nos dois desfechos dos três cenários com a redução da acurácia da gota espessa, na análise de sensibilidade. Conclusões: O TR foi menos custo-efetivo em todos os cenários, quando a acurácia da microscopia manteve-se elevada. 
Fernandes de Oliveira, MR. Cost-effectiveness analysis of rapid test for the diagnosis of new malaria cases in twelve endemic municipalities of the State of Pará, Brazil [Tese de Doutorado]. São Paulo: Faculdade de Saúde Pública da Universidade de São Paulo; 2008.

Keywords - Malaria; Rapid test; Cost-effectiveness; Diagnosis; Economic Model.

\section{ABSTRACT}

Introduction: Diagnosis of malaria is based on blood microscopy, a lowcost procedure that requires experienced technicians. Rapid immunochromatography tests (RDT) were developed with the advantage of being easy-to-use tools but with higher costs. RDT validation showed similar accuracy compared to microscopy suggesting that the RDT could be a reliable alternative in areas without lab facilities. Objective: To perform costeffectiveness analysis for the use of OptiMAL $\AA$ in comparison with the thick blood smear microscopy. Methods: The study was conducted from the perspective of the Brazilian Public Health System, the analytic horizon was of six months, and the time frame was 2006. The analysis was performed through a decision tree with two outcomes: "properly diagnosed cases" and "properly conducted cases". There were defined three scenarios in 12 municipalities of the State of Pará: the scenario 1 considered the whole malaria tests performed in 2006; the scenario 2 considered the malaria tests performed in the endemic areas with access to lab facilities; and the scenario 3 considered the $30 \%$ malaria tests performed in areas without lab facilities. The main epidemiological measures were the prevalence of malaria and the accuracy of the diagnostic methods. Epidemiological estimates were obtained from the Brazilian Malaria Surveillance Information System and the scientific literature. Direct medical and non-medical costs were estimated taking into consideration the national guidelines and the data obtained from the municipalities. Cost data sources were the Information System for Strategic Resources from the Health Surveillance Secretariat, the Reimbursement Values Table and the Hospital Information System of the 
Brazilian Public Health System. The average and the incremental costeffectiveness ratio (ICER) were estimated and it was conducted a sensitivity analysis. Data were analyzed with the TreeAge Pro 2005 software. Results: RDT strategy was dominated by the microscopy strategy in the scenarios 1 and 2. The ICER for the microscopy strategy in the scenario 3 was $\mathrm{R} \$ 1,193.00$ per properly diagnosed case and it was $\mathrm{R} \$ 1,016.67$ per properly conducted case compared with the OptiMAL® strategy. The sensitivity analysis showed that the RDT was cost-effective for both outcomes in all the scenarios when the thick blood smear accuracy was reduced. Conclusions: The RDT is the least cost effective strategy, providing that microscopy accuracy is high. 


\section{ÍNDICE}

1. INTRODUÇÃO 24

2. REVISÃO DA LITERATURA 28

2.1. MALÁRIA 28

2.1.1. A Situação Epidemiológica da Malária no 28

Brasil, Estratégias de Controle e Financiamento das Ações

2.1.2. A Clínica da Malária e Malária Grave 34

2.1.3. O Tratamento Atual da Malária no Brasil 41

2.1.4. O Diagnóstico da Malária 43

2.2. AVALIAÇÃO ECONÔMICA EM SAÚDE 63

2.2.1. A Análise de Custo-Efetividade 66

2.3. TESTE RÁPIDO PARA O DIAGNÓSTICO DA 72

MALÁRIA NO BRASIL E AVALIAÇÃO

ECONÔMICA

3. OBJETIVOS 75

4. MÉTODOS 76

4.1. TIPO DE ESTUDO E MODELO DE ANÁLISE DE 76 CUSTO-EFETIVIDADE

4.2. ESTRATÉGIAS AVALIADAS 76

4.3. PERSPECTIVA DA ANÁLISE 76

4.4. PERÍODO DE INTERVENÇÃO 77

4.5. DESFECHOS DE INTERESSE 77

4.6. HORIZONTE ANALÍTICO 77

4.7. DESCRIÇÃO DA ÁREA DE ESTUDO 80

4.7.1. Descrição Geral dos Municípios 80

4.7.2. Características da Organização dos Serviços 82

de Atenção Básica e de Diagnóstico de Malária

dos 12 Municípios

4.7.3. População sob Risco 84

4.8. PARÂMETROS EPIDEMIOLÓGICOS DO MODELO 84 
4.9.FONTE DOS DADOS EPIDEMIOLÓGICOS DE

MALÁRIA DOS 12 MUNICÍPIOS

4.10. DEFINIÇÃO DE CASOS DE MALÁRIA

UTILIZADOS NA ANÁLISE E RELAÇÃO COM OS CUSTOS

4.11. ANÁLISE DO BANCO DE DADOS DE

MALÁRIA SIVEP/MALÁRIA E DO BANCO DE

MORBIDADE HOSPITALAR - DATASUS

4.11.1. Preparação do Banco de Dados do

89

SIVEP/malária com os Casos de Malária Vivax e Malária

Falciparum para a Estratificação das Idades para Estimar o

Custo dos Medicamentos

4.11.2. Estratificação dos Casos de acordo com as

Faixas Etárias Relevantes para o Tratamento da Malária

Vivax e Malária Falciparum Grave e Não-Grave

4.11.3. Organização do Banco para o Cálculo da

92

Prevalência da Malária (Probabilidade pré-teste)

e a Probabilidade de Resultados Positivos para Plasmodium

falciparum e Plasmodium vivax.

4.11.4. Estratificação dos Municípios segundo o

Risco Epidemiológico.

4.11.5. Morbidade Hospitalar

4.12. AVALIAÇÃO DOS ESTUDOS DE ACURÁCIA

DA GOTA ESPESSA E DO TESTE RÁPIDO

4.13. BUSCA E SELEÇÃO DE ARTIGOS PARA

ESTIMAR OS PARÂMETROS DE RESULTADOS DO

TRATAMENTO ANTIMALÁRICO

4.13.1. Estimativa do Parâmetro Proporção de

Cura com Coartem $\AA$, para Malária Falciparum

Não-grave 
4.13.2. Estimativa do Parâmetro Proporção de

Cura com Artesunato ou Artemeter para

Malária Falciparum grave

4.13.3. Estimativa do Parâmetro Proporção de Cura

com Cloroquina e Primaquina para Malária Vivax

4.14. LEVANTAMENTO DE CUSTOS

4.14.1.Custos Diretos do Diagnóstico da Malária

4.14.2. Custos Diretos do Cuidado da Doença

4.15. PRESSUPOSTOS DO MODELO

124

4.16. RAZÕES DE CUSTO-EFETIVIDADE

4.17. ANÁLISE DE SENSIBILIDADE

4.18. ANÁLISE DOS DADOS DE CUSTO-EFETIVIDADE

4.19. CONSIDERAÇÕES ÉTICAS

5.1. CENÁRIOS DA ANÁLISE DE CUSTO-EFETIVIDADE 129

5.2. ANÁLISE DE CUSTO-EFETIVIDADE 129

5.3. ANÁLISE DE SENSIBILIDADE 132

5.4. ANÁLISE DE BREAK-EVEN 148

6. DISCUSSÃO 149

7. CONCLUSÕES 170

8. REFERÊNCIAS 171

ANEXOS 187 


\section{ABREVIATURAS E SIGLAS UTILIZADAS}

ACE

ACS

ANP

ANVISA

ATS

AVAI

BIREME

CAPES

CDC

CE

CENADI

CIF

DATASUS

DHL

FUNASA

HRP-2

HTA

IBGE

IDH-M
Análise de Custo-Efetividade

Agentes Comunitários de Saúde

Agência Nacional do Petróleo, Gás Natural e Biocombustíveis

Agência Nacional de Vigilância Sanitária

Avaliação de Tecnologias em Saúde

Anos de Vida Ajustados por Incapacidade

Biblioteca Regional de Medicina

Coordenação de Aperfeiçoamento de Pessoal de Nível Superior

Centers for Disease Control and Prevention

Custo-Efetividade

Centro Nacional de Armazenamento e

Distribuição de Imunobiológicos

Costs, insurance and freight

Departamento de Informática do Sistema Único de Saúde

Desidrogenase Lática

Fundação Nacional de Saúde

Proteína 2 rica em histidina

Health Technology Assessment Programme

Fundação Instituto Brasileiro de Geografia e Estatística

Índice de Desenvolvimento Humano - Municipal 
IFA

IPA

IPCA

LACEN

LVC

MS

OMS

OPAS

PAB

PCR

PIACM

PIB

pLDH

PNCM

PNUD

PPT

QBC

QUADAS

RAVREDA

RCEA

RR
Proporção de casos de malária por Plasmodium falciparum

Incidência Parasitária Anual

Índice Nacional de Preços ao Consumidor Amplo

Laboratórios Centrais de Saúde Pública

Lâminas de Verificação de Cura

Ministério da Saúde

Organização Mundial da Saúde

Organização Pan Americana da Saúde

Piso de Atenção Básica

Reação em cadeia pela polimerase

Plano de Intensificação das Ações de Controle da Malária na Amazônia Legal

Produto Interno Bruto

Lactato desidrogenase parasito-específica

Programa Nacional de Prevenção e Controle da Malária

Programa das Nações Unidas para o desenvolvimento

Probabilidade Pré-Teste

Quantitative Buffy Coat

Quality Assessment of Diagnostic Accuracy studies

Rede Amazônica de Vigilância da Resistência às Drogas Antimaláricas no Brasil

Razão de Custo-Efetividade Adicional

Risco Relativo 
SES

SESPA

SIES

SIH-SUS

SIVEP/Malária

SMS

SUS

SVS

SVS/MS

TFVS

TGO

TGP

TR

UNICEF

UTI
Secretaria de Estado da Saúde

Secretaria de Estado da Saúde do Pará

Sistema de Informação de Insumos Estratégicos

Sistema de Informações Hospitalares do Sistema Único de Saúde

Sistema de Informação de Vigilância Epidemiológica da Malária

Secretaria Municipal de Saúde

Sistema Único de Saúde

Secretaria de Vigilância em Saúde

Secretaria de Vigilância em Saúde do Ministério da Saúde

Teto Financeiro de Vigilância em Saúde

Transaminase Glutâmico-Oxalacética

Transaminase Glutâmico-Pirúvica

Testes Rápidos

Fundo das Nações Unidas para a Infância

Unidade de Terapia Intensiva 


\section{LISTA DE TABELAS}

Tabela 1 - Distribuição dos 21 países endêmicos para malária na Região das Américas, segundo variação no número de casos relatados em relação ao ano de 2000. Região das Américas, 2006.

Tabela 2 - Esquemas de tratamento antimalárico de primeira linha preconizados pelo Programa Nacional de Controle de Malária, Ministério da Saúde, Brasil.

Tabela 3 - Diagnóstico da malária - Testes Rápidos e Microscopia segundo algumas características e requerimentos.

Tabela 4 - Resultados de estudos de validação de testes rápidos, segundo tipo de teste, características da população e espécie de plasmodium.

Tabela 5 - Distribuição dos 12 municípios do Estado do Pará de acordo com o número de laboratórios ativos para diagnóstico de malária. Pará, 2006.

Tabela 6 - Parâmetros epidemiológicos do modelo de custo-efetividade segundo valores do caso-base, variação e fontes de informação.

Tabela 7 - Distribuição dos 12 municípios segundo Índice Parasitário Anual (IPA), proporção de malária falciparum (IFA) e Probabilidade Pré-Teste (PPT) e divisão por estratos de risco. Pará, Brasil, 2006.

Tabela 8 - Instrumento de avaliação de qualidade de artigos de acurácia QUADAS.

Tabela 9 - Distribuição dos 13 artigos publicados e do relatório da OPAS, segundo os critérios do QUADAS, 2007.

Tabela 10 - Distribuição dos 13 artigos publicados e do relatório da OPAS, segundo critérios definidos para a avaliação pela autora. 2007. 
Tabela 11 - Parâmetros de custos diretos do diagnóstico da malária para modelo de custo- efetividade da área global dos 12 municípios, segundo valores básicos, variação dos valores e fontes consultadas.

Tabela 12 - Parâmetros de custos diretos de cuidados com a doença para o modelo de custo-efetividade da área global dos 12 municípios, segundo valores básicos, variação dos valores e fontes consultadas.

Tabela 13 - Ajuste do custo da microscopia a partir de referências da WHO (2000), Pang \& Piovesan-Alves (2001) e Macauley (2005) por meio da conversão para reais pela taxa média de conversão do dólar para os anos 2000 e 2001, e pela aplicação do Índice Nacional de Preços ao Consumidor Amplo - IPCA até 2005.

Tabela 14 - Custos estimados de combustíveis usados no controle de malária no ano de 2006 por município, a partir da área territorial e número de laboratórios, tomando como referência o Município do Novo Repartimento. 12 Municípios do Estado do Pará, 2006.

Tabela 15 - Custos, custos adicionais, efeitos, efeitos adicionais, razão média de custo-efetividade e razão de custo-efetividade adicional das estratégias "microscopia" e "teste rápido", segundo o desfecho "caso diagnosticado adequadamente" e para os três cenários de análise. 12 municípios do Estado do Pará, 2006.

Tabela 16 - Custos, custos adicionais, efeitos, efeitos adicionais, razão média de custo-efetividade e razão de custo-efetividade adicional das estratégias "microscopia" e "teste rápido", segundo o desfecho "caso conduzido adequadamente" e para os três cenários de análise. 12 municípios do Estado do Pará, 2006. 2006.

Tabela 17 - Resultados da análise de sensibilidade para o desfecho "caso diagnosticado adequadamente" no cenário 1: áreas com laboratórios mais áreas isoladas. 12 municípios do Estado do Pará, 2006.

Tabela 18 - Resultados da análise de sensibilidade para o desfecho "caso conduzido adequadamente" no cenário 1: áreas com laboratórios mais áreas isoladas. 12 municípios do Estado do Pará, 2006. 
Tabela 19 - Resultados da análise de sensibilidade para o desfecho "caso diagnosticado adequadamente" no cenário 2: áreas com laboratórios. 12 municípios do Estado do Pará, 2006.

Tabela 20 - Resultados da análise de sensibilidade para o desfecho "caso conduzido adequadamente" no cenário 2: áreas com laboratórios.

12 municípios do Estado do Pará, 2006.

Tabela 21 - Resultados da análise de sensibilidade para o desfecho "caso diagnosticado adequadamente" no cenário 3: áreas isoladas. 12 municípios do Estado do Pará, 2006.

Tabela 22 - Resultados da análise de sensibilidade para o desfecho "caso conduzido adequadamente" no cenário 3: áreas isoladas. 12 municípios do Estado do Pará, 2006.

Tabela 23 - Análise de break-even para os cenários 1 e 2 e os desfechos: "casos diagnosticados adequadamente" e "casos conduzidos adequadamente". 12 municípios do Estado do Pará, 2006. 


\section{LISTA DE TABELAS DA SEÇÃO “ANEXOS”}

Tabela A1 - Distribuição dos 12 municípios quanto à população estimada em 01 de julho de 2006, extensão territorial, Produto Interno Bruto (PIB) e Produto Interno Bruto per capita. Municípios do Estado do Pará, Brasil, 2006.

Tabela A2 - Distribuição dos 12 municípios quanto à população total e sua respectiva distribuição percentual, por sexo e situação do domicílio, e proporção de pessoas naturais dos municípios. Municípios do Estado do Pará, Brasil, 2000.

Tabela A3 - Distribuição dos 12 municípios segundo percentual da população residente, por grupos de idade, Municípios do Estado do Pará, 2000.

Tabela A4 - Distribuição dos 12 municípios segundo percentual dos domicílios particulares permanentes, por classes de rendimento médio mensal domiciliar per capita em salários mínimos, Municípios do Estado do Pará, 2000.

Tabela A5 - Distribuição dos 12 municípios segundo a proporção de pessoas de 15 anos ou mais de idade com menos de 4 anos de estudo e por sexo, Municípios do Estado do Pará, 2000.

Tabela A6 - Distribuição dos 12 municípios de interesse segundo Índice de desenvolvimento Humano - Municipal - IDH-M1991 e 2000.

Tabela A7 - Distribuição dos 13 artigos publicados e do relatório da OPAS, segundo todos os critérios definidos para a avaliação e resultados individuais. 2007.

Tabela A8 - Parâmetros de custos diretos do diagnóstico da malária para o modelo de custo- efetividade do cenário 2 - área cobertas por laboratórios nos 12 municípios - segundo valores básicos, variação dos valores e fontes consultadas.

Tabela A9 - Parâmetros de custos diretos de cuidados com a doença para o modelo de custo-efetividade do cenário 2 - área cobertas com laboratórios nos 12 municípios - segundo valores básicos, variação dos valores e fontes consultadas.

Tabela A10 - Parâmetros de custos diretos do diagnóstico da malária para o modelo de custo - efetividade do cenário 3 - áreas isoladas dos 12 municípios - segundo valores básicos, variação dos valores e fontes consultadas. 
Tabela A11 - Parâmetros de custos diretos de cuidados com a doença para o modelo de custo-efetividade do cenário 3 - áreas isoladas dos 12 municípios - segundo valores básicos, variação dos valores e fontes consultadas.

Tabela A12 - Memória de cálculo para o custo final de um exame de gota espessa, a partir dos custos de insumos para a técnica de coloração de lâmina, para a técnica de leitura e para a coleta do sangue.

Tabela A13 - Memória de cálculo do custo de tratamento específico para malária vivax, segundo ponderações pelas proporções de casos nas faixas etárias e gravidez a partir das notificações de casos de 2006 e esquemas preconizados pelo PNCM/SVS/MS.

Tabela A14 - Memória de cálculo do custo de tratamento específico para malária falciparum não-grave, segundo ponderações pelas proporções de casos nas faixas etárias e gravidez a partir das notificações de casos de 2006 e esquemas preconizados pelo PNCM/SVS/MS.

Tabela A15 - Memória de cálculo do custo de tratamento específico para malária falciparum grave, segundo ponderações pelas proporções de casos nas faixas etárias e gravidez a partir das notificações de casos de 2006 e esquemas preconizados pelo PNCM/SVS/MS.

Tabela A16 - Memória de cálculo do custo de tratamento específico para malária mista (falciparum e vivax) para prevenção de recaída da malária vivax, segundo ponderações pelas proporções de casos nas faixas etárias a partir das notificações de casos de 2006e esquemas preconizados pelo PNCM/SVS/MS.

Tabela A17 - Memória de cálculo para a estimativa de custo do salário do microscopista de acordo com o número de lâminas examinadas em cada estrato e com o número de profissionais necessários no cenário 1 - área global dos municípios.

Tabela A18 - Memória de cálculo para a estimativa de custo do salário do agente comunitário de saúde que realiza o teste rápido de acordo com o número de testes realizados em cada estrato e com 0 número de profissionais necessários no cenário 1 - área global dos municípios. 
Tabela A19 - Memória de cálculo para a estimativa de custo do salário anual do microscopista e do agente comunitário de saúde que realiza o teste rápido segundo os cenários de análise: cenário 1 - área global, cenário 2 - áreas com laboratórios e cenário 3 - áreas isoladas.

Tabela A20 - Memória de cálculo do salário global para realização de uma microscopia, considerando dois cenários de análise: cenário 1 - área global dos 12 municípios que contém 30\% dos exames realizados em áreas isoladas e cenário 3 - áreas isoladas.

Tabela A21 - Memória de cálculo para a estimativa de custo de microscópio e de manutenção de microscópio segundo o número de profissionais necessários no cenário 1 - área global dos municípios.

Tabela A22 - Memória de cálculo para a estimativa de custo de transporte para a realização de teste rápido em áreas isoladas que correspondem a $30 \%$ dos casos examinados no cenário 1 - área global dos municípios, segundo a necessidade por estratos.

Tabela A23 - Memória de cálculo para a estimativa de custo de transporte para a realização da gota espessa em áreas isoladas que correspondem a $30 \%$ dos casos examinados no cenário 1 - área global dos municípios, segundo a necessidade por estratos.

Tabela A24 - Memória de cálculo para a estimativa de custo de internação hospitalar, considerando custos conjuntos de diárias de enfermaria e diárias de UTI em três possibilidades de tempo de internação e para o conjunto dos casos positivos. 


\section{LISTA DE FIGURAS}

Figura 1 - Distribuição da Incidência Parasitária Anual (IPA) por 1.000 hab. no período de 2003 a 2007. Amazônia Legal, Brasil, 2003-2007.

Figura 2 - Distribuição do número de casos de malária registrados no período de 2003 a 2007. Amazônia Legal, Brasil, 2003-2007.

Figura 3 - Estrutura da árvore de decisão para o desfecho "casos diagnosticados adequadamente".

Figura 4 - Estrutura da árvore de decisão para o desfecho "casos conduzidos adequadamente".

Figura 5 - Mapa do Estado do Pará com a localização geográfica dos 12 municípios do estudo. Pará, 2006.

Figura 6 - Fluxograma de descrição do preparo do banco de dados de malária, para a análise dos esquemas de tratamento estratificados pelas faixas etárias de interesse - Estado do Pará, Brasil, 2006. 


\section{INTRODUÇÃO}

A malária é uma protozoose causada por parasitos do gênero Plasmodium e transmitida ao homem por mosquitos do gênero Anopheles. No Brasil é causada pelas espécies Plasmodium vivax e Plasmodium falciparum e com menor freqüência pelo Plasmodium malariae (91). Os sintomas são febre paroxística, calafrios, sudorese, anemia e astenia. $O$ Plasmodium falciparum é o responsável pela maioria dos casos graves e complicados de malária que podem evoluir a óbito, especialmente, ao atingir populações e indivíduos parcialmente imunes ou com ausência de imunidade adquirida contra a doença. A resposta imune é mais conhecida e estudada para o Plasmodium falciparum e a imunidade clínica parcial desenvolve-se somente depois de infecções repetidas com a mesma espécie de parasito e caracteriza-se pela ausência de sintomas clínicos apesar da manutenção da parasitemia (38). A malária por Plasmodium vivax apresenta evolução clínica mais benigna, porém é responsável por grande perda de dias de trabalho e de produtividade.

No final do ano de 2004, 107 países e territórios do mundo apresentavam transmissão de malária (176) e estima-se que mais de $50 \%$ da população mundial esteja exposta ao risco de adoecer (19). No mundo, uma criança morre de malária a cada 30 segundos, ocorrem 350-500 milhões de casos clínicos anuais e mais de um milhão de pessoas morrem vítimas de malária por Plasmodium falciparum a cada ano, principalmente crianças e mulheres grávidas, a maioria na África (175). Na África Subsaaariana ocorrem cerca de $60 \%$ dos casos de malária, $75 \%$ dos casos de malária por Plasmodium falciparum e mais de $80 \%$ das mortes por malária, em relação aos casos mundiais e a grande maioria dos casos é causada por Plasmodium falciparum com cerca de $18 \%$ das mortes em crianças abaixo de 5 anos (176). 
$\mathrm{Na}$ África, a malária na gravidez é responsável por $60 \%$ de perda fetal e $10 \%$ de mortes maternas, além de desenvolvimento fetal prejudicado devido à anemia grave $(175,176,176)$.

A transmissão da malária é variável em intensidade e regularidade nas várias partes do mundo e depende de fatores locais como padrões climáticos - especialmente períodos de chuvas - proximidade de fontes alimentares para os mosquitos transmissores e peculiaridades do comportamento das diferentes espécies de vetores que predominam em cada região (175).

Considerando a carga da doença em anos de vida ajustados por incapacidade (AVAl), que sumariza a mortalidade e incapacidade produzidas por determinado agravo, o continente africano contribui com mais de $90 \%$ da carga da doença atribuída à malária no mundo, seguido pelo Sudeste Asiático com mais de $9 \%$ da carga. As mortes por malária são responsáveis por quase $3 \%$ dos AVAl do mundo, dos quais mais de $10 \%$ na África. Ainda, estima-se que, anualmente, pelo menos 1.300 a 7.800 indivíduos terão seqüelas neurológicas após malária cerebral em áreas endêmicas africanas (19).

Em termos de impactos sociais e econômicos existem menos estudos e as estimativas são mais imprecisas. Sabe-se que a malária tem um alto custo, globalmente, e em especial para os países africanos, retardando consideravelmente o desenvolvimento econômico. Estimou-se uma perda de 1,3\% no crescimento econômico anual nos países com elevada transmissão de malária, a qual ao longo dos anos leva a diferenças substanciais no Produto Interno Bruto (PIB) nos países com malária, quando comparados a países sem ocorrência de malária. Uma família africana pode gastar até $25 \%$ de seus recursos em prevenção e controle da doença, o que piora o círculo da pobreza já que atinge as populações mais pobres e com menos acesso à atenção em saúde $(19,175)$. Em países com alta carga de malária o setor 
saúde pode dispor mais de $40 \%$ do seu orçamento em despesas com a prevenção e tratamento da doença (175).

Estima-se que, globalmente, $4 \%$ dos casos e entre 12 e $25 \%$ das mortes por malária em todas as idades, incluindo até $50 \%$ dos óbitos mundiais estimados em menores de 15 anos ocorrem em decorrência de epidemias de malária. Embora os dados disponíveis sobre epidemias de malária no mundo sejam limitados, estima-se que na África ocorreriam mais de 12 milhões de episódios de malária por ano e entre 155.000 a 310.000 mortes por malária atribuíveis a epidemias quando as medidas de controle não são aplicadas oportunamente (178).

Nas Américas, 21 países têm áreas com transmissão ativa de malária: Argentina, Belize, Bolívia, Brasil, Colômbia, Costa Rica, Equador, El Salvador, Guiana Francesa, Guatemala, Guiana, Haití, Honduras, México, Nicarágua, Panamá, Paraguai, Peru, República Dominicana, Suriname e Venezuela (127). No ano de 2006, estes 21 países tinham uma população total estimada de 508,452 milhões de pessoas, dos quais 274,647 milhões (54\%) viviam em áreas com transmissão de malária. Destas, 39 milhões de pessoas viviam em áreas de moderado a elevado risco (131). Entre os países da América do Sul, $25 \%$ dos casos são causados por Plasmodium falciparum e na América Central e Caribe, 10\%; e o restante, predominantemente, por Plasmodium vivax (176), já que menos de 0,01\% dos casos são causados por Plasmodium malariae, que está focalizado em algumas áreas do Brasil, Guiana Francesa, Guiana e Suriname (132).

Um total de 902.373 casos de malária foram relatados no ano de 2006 na Região das Américas (dados preliminares), representando uma diminuição de $22 \%$ no número de casos em relação ao ano 2000 (132). A redução ocorreu em 15 dos 21 países endêmicos, oito dos quais tiveram redução acima de 50\%: Argentina, Equador, El Salvador, Honduras, México, Nicarágua, Paraguai e Suriname. Seis países, no entanto, apresentaram 
aumento no número de casos variando entre 10 a 211\%: Costa Rica, Guiana Francesa, Haiti, Panamá, República Dominicana e Venezuela (132) (Tabela 1). Os países com maiores incidências nas Américas em 2006 foram Guiana e Guiana Francesa. Em relação à mortalidade, o número de óbitos por malária relatados em 2005, na Região, apresentou uma redução da ordem de $69 \%$ em relação a 2000 (132).

Tabela 1 - Distribuição dos 21 países endêmicos para malária na Região das Américas, segundo variação no número de casos relatados em relação ao ano de 2000. Região das Américas, 2006.

\begin{tabular}{crc}
\hline País & Último ano de referência & $\begin{array}{c}\text { Variação } \\
\%\end{array}$ \\
\hline Argentina & 2004 & -74 \\
Belize & (1) 2006 & -43 \\
Bolívia & 2006 & -40 \\
Brasil & 2006 & -11 \\
Colômbia & 2006 & -9 \\
Costa Rica & (1) 2006 & +55 \\
Dominicana (República & 2005 & +211 \\
Dominicana) & 2006 & -93 \\
Equador & 2006 & -93 \\
El Salvador & 2006 & +10 \\
Guiana Francesa & 2006 & -42 \\
Guatemala & 2006 & -12 \\
Guiana & 2005 & +29 \\
Haiti & 2006 & -67 \\
Honduras & (1) 2006 & -67 \\
México & (1) 2006 & -88 \\
Nicarágua & 2006 & +61 \\
Panamá & 2005 & -95 \\
Paraguai & 2006 & -5 \\
Peru & (1) & -70 \\
Suriname & (1) 2006 & +25 \\
Venezuela & &
\end{tabular}

Fonte: Adaptado de dados da Organização Pan Americana da Saúde, 2008.

Notas: (1) Dados preliminares 
Os avanços e sucessos no controle da malária no Brasil foram importantes entre as décadas de 40 e 70 , principalmente fora da área amazônica. A área receptiva para a doença, no entanto, é extensa, devido a presença do mosquito transmissor em $80 \%$ do território do país, correspondendo a 6,8 milhões de $\mathrm{km}^{2}$. $(71,81)$.

\section{REVISÃO DA LITERATURA}

\subsection{MALÁRIA}

2.1.1. A Situação Epidemiológica da Malária no Brasil, Estratégias de Controle e Financiamento das Ações

A partir dos registros oficiais e regulares de casos de malária com confirmação parasitoscópica, verifica-se que o ano de 1962 foi o que notificou o menor número de casos no Brasil - 36,9 mil (81) - em toda a história da endemia. Nos anos 70 , os esforços empreendidos pela Superintendência de Campanhas de Saúde Púbica (SUCAM) foram interrompendo, gradativamente, a transmissão da malária nas Regiões Nordeste, Sudeste, Sul e em parte do Centro-Oeste e a incidência passou a concentrar-se cada vez mais na Região da Amazônia Legal, hoje composta pelos Estados do Amapá, Acre, Amazonas, Pará, Roraima, Rondônia, Tocantins, Mato Grosso e da área ocidental do Estado do Maranhão (71, 81). Os processos de expansão desenvolvimentista da Região ocorridos a partir da segunda metade da década de 70 , com projetos de desmatamento para a construção de grandes rodovias e obras, e ainda a expansão da agropecuária e exploração de minérios, levaram à Amazônia pessoas vindas das Regiões do Centro-Sul em busca de trabalho (153). Dados da Fundação Instituto Brasileiro de Geografia e Estatística (IBGE) demonstram que no período entre 1970 e 1995 o crescimento da população desses Estados foi 
de $127 \%$ em contraste ao crescimento nacional de $57,6 \%$ no mesmo período (42).

Vários fatores agravaram as condições favoráveis para a expansão da malária na Região Amazônica, como a ocupação desordenada e rápida, as drásticas alterações ambientais, a migração composta por populações nãoimunes e a organização precária dos serviços locais. Em 1999, 40\% dos casos do continente americano - 632.800 casos - foram registrados na Região Amazônica (154), o que correspondia a um aumento de $26 \%$ em relação ao ano anterior, acompanhado também de aumento de $19 \%$ na proporção de casos por Plasmodium falciparum: de 102.700 para 117.500 casos (71).

Atualmente, 99,8\% dos casos de malária no Brasil concentram-se na Região da Amazônia Legal (em 807 municípios) dos quais, mais de 70\% são causados por Plasmodium vivax (103). A distribuição dos casos na Amazônia Legal não é homogênea e as áreas são estratificadas em alto, médio e baixo risco de acordo com a Incidência Parasitária Anual (IPA) (71, 153). A IPA é calculada como o número de casos confirmados dividido pela população em risco e multiplicado por 1.000. Os critérios para a classificação de risco consideram níveis de IPA sendo alto risco: IPA > 49,9/1.000 habitantes; médio risco: IPA entre 10 - 49,9/1.000 habitantes e baixo risco: IPA até 9,9/1.000 habitantes. (103).

Face ao problema crescente da malária na Amazônia Legal, no ano 2000 foi elaborado e implantado o Plano de Intensificação das Ações de Controle da Malária na Amazônia Legal (PIACM) pela Fundação Nacional de Saúde - FUNASA - responsável até então pelas ações de prevenção e controle (43). O plano governamental foi uma resposta às estratégias e compromissos entre os governos que se desenhavam internacionalmente desde 1998, quando a Organização Mundial da Saúde (OMS) - em parceria com o Programa das Nações Unidas para o Desenvolvimento (PNUD), o 
Fundo das Nações Unidas para a Infância (UNICEF) e o Banco Mundial lançou a estratégia "Roll Back Malaria" $(51,120)$. O "Roll Back Malaria" tem como objetivo controlar a malária no mundo com uma meta de redução de 50\% da carga da doença até 2010 e prioriza quatro estratégias: 1) acesso fácil ao tratamento efetivo; 2) promoção de intervenções para controle de vetores como o uso de mosquiteiros impregnados; 3 ) prevenção e manejo da malária em grávidas; e 4) fortalecimento da prevenção e da resposta às epidemias de malária (50), com ênfase no fortalecimento dos serviços de saúde de modo que o tratamento efetivo e as medidas de prevenção sejam acessíveis a todos e adaptados às necessidades das diferentes regiões (51, 120). A resposta brasileira era necessária devido à incidência crescente e à descontinuidade em algumas estratégias de controle como o abastecimento de medicamentos e inseticidas (154).

Como fato histórico no processo de descentralização da saúde, em dezembro de 1999 o Ministério da Saúde publicou as portarias 1399 e 950 $(17,18)$ que consolidavam a descentralização das ações de vigilância, prevenção e controle de doenças por meio do estabelecimento de tetos de financiamento das ações e definição das atribuições de cada esfera de governo. Os recursos financeiros passaram a ser transferidos do Fundo Nacional de Saúde para os Fundos Estaduais e Municipais, fato que gerou agilidade administrativa e contribuiu para a implantação das ações de controle de forma mais efetiva (154), favorecendo a aplicação das ações do PIACM.

No ano de 2003 institucionalizou-se, no Ministério da Saúde (MS) na Secretaria de Vigilância em Saúde (SVS), o Programa Nacional de Prevenção e Controle da Malária (PNCM) que estabeleceu uma política permanente para a prevenção e controle da endemia, continuando os avanços alcançados pelo PIACM e agregando atividades adicionais recomendadas na sua avaliação (100). O PNCM tem como objetivos: 1) reduzir a incidência da malária; 2) reduzir a mortalidade por malária; 3) 
reduzir as formas graves da doença; 4) eliminar a transmissão da malária em áreas urbanas nas capitais; e 5) manter a ausência da transmissão da doença nos locais onde tiver sido interrompida a sua transmissão. Os componentes principais do PNCM são: vigilância; diagnóstico e tratamento; capacitação de recursos humanos; controle seletivo de vetores; educação em saúde, comunicação e mobilização social; e apoio à estruturação dos serviços locais de saúde (100).

No primeiro ano de implantação do PIACM já puderam ser percebidos os seus efeitos, com uma redução de $39 \%$ no número total de casos em relação a 1999, que se manteve de forma consistente até $2002(71,103)$. A partir de 2003 o número de casos voltou novamente a ascender, porém com redução no número de municípios classificados como "alto risco" e no número de internações hospitalares, o que pode refletir alterações na dinâmica da transmissão da doença e melhora na atenção (103). O aumento da incidência a partir de 2003 deveu-se à ocupação desordenada e intensa na periferia de cidades como Manaus (AM), Porto Velho (RO), e Cruzeiro do Sul (AC), que concentravam no período um quarto dos casos da Região, além de outros fatores como o desmatamento de novas áreas e o aumento do número de criadouros do vetor, devido à crescente atividade econômica de piscicultura em várias cidades (103). Existe atualmente uma concentração de casos da doença em 19 municípios que são responsáveis por 50\% dos casos notificados na Amazônia Legal (105).

No período de 2003 a 2007, a IPA da Amazônia Legal variou entre 18,3 a 26,6 casos por mil habitantes, sendo de 19,24 casos por mil habitantes no ano de 2007 (103) (Figura 1). A variação no número bruto de casos no período de 2003 a 2007 pode ser observada na figura 2.

No ano de 2007 foram registrados 457.659 casos na Amazônia Legal, com IPA de 19,24 casos por mil habitantes, representando uma redução de $24,7 \%$ do número de casos em relação a 2006. Destes, foram registradas 
5.901 internações hospitalares que correspondem a 1,3\% dos casos, representando uma redução de $31 \%$ do número de internações em relação a 2006 (90, 91, 105). A redução no número de internações em 2007 foi proporcional à redução de casos por Plasmodium falciparum, a qual foi de $36,6 \%$ em relação ao ano anterior. O Estado do Amazonas foi responsável pela notificação de $43,2 \%$ dos casos do ano de 2007, seguido pelos Estados de Rondônia e do Pará, que notificaram 18,0 e 16,5\% dos casos, respectivamente.

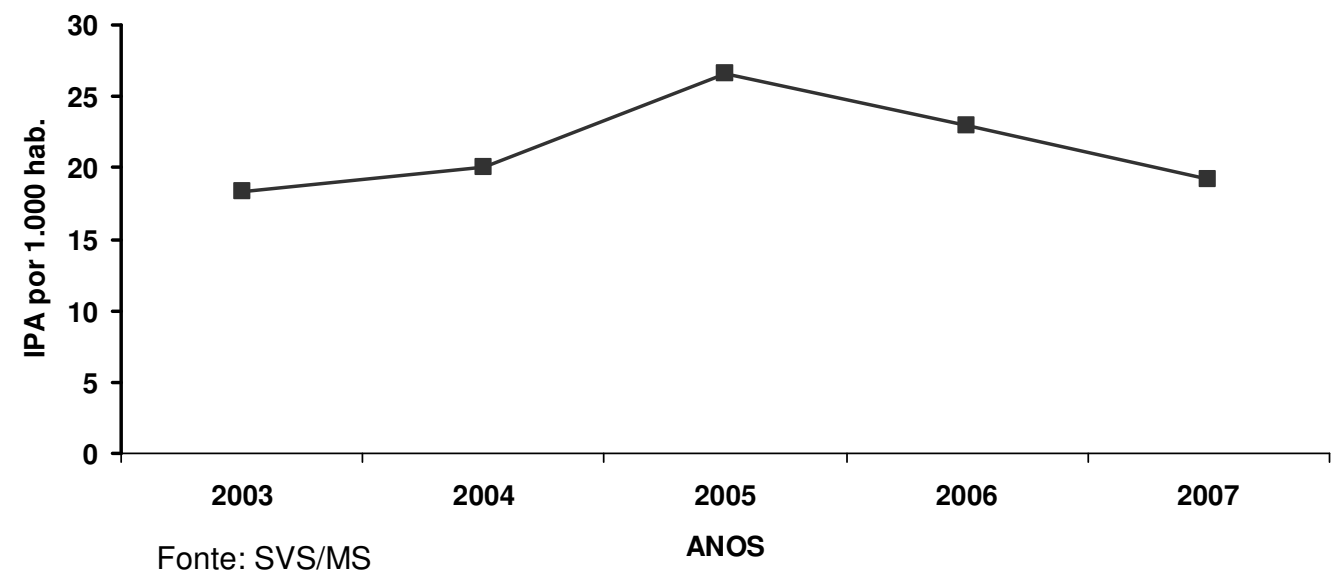

Figura 1 - Distribuição da Incidência Parasitária Anual (IPA) por 1.000 hab. no período de 2003 a 2007. Amazônia Legal, Brasil, 2003-2007 


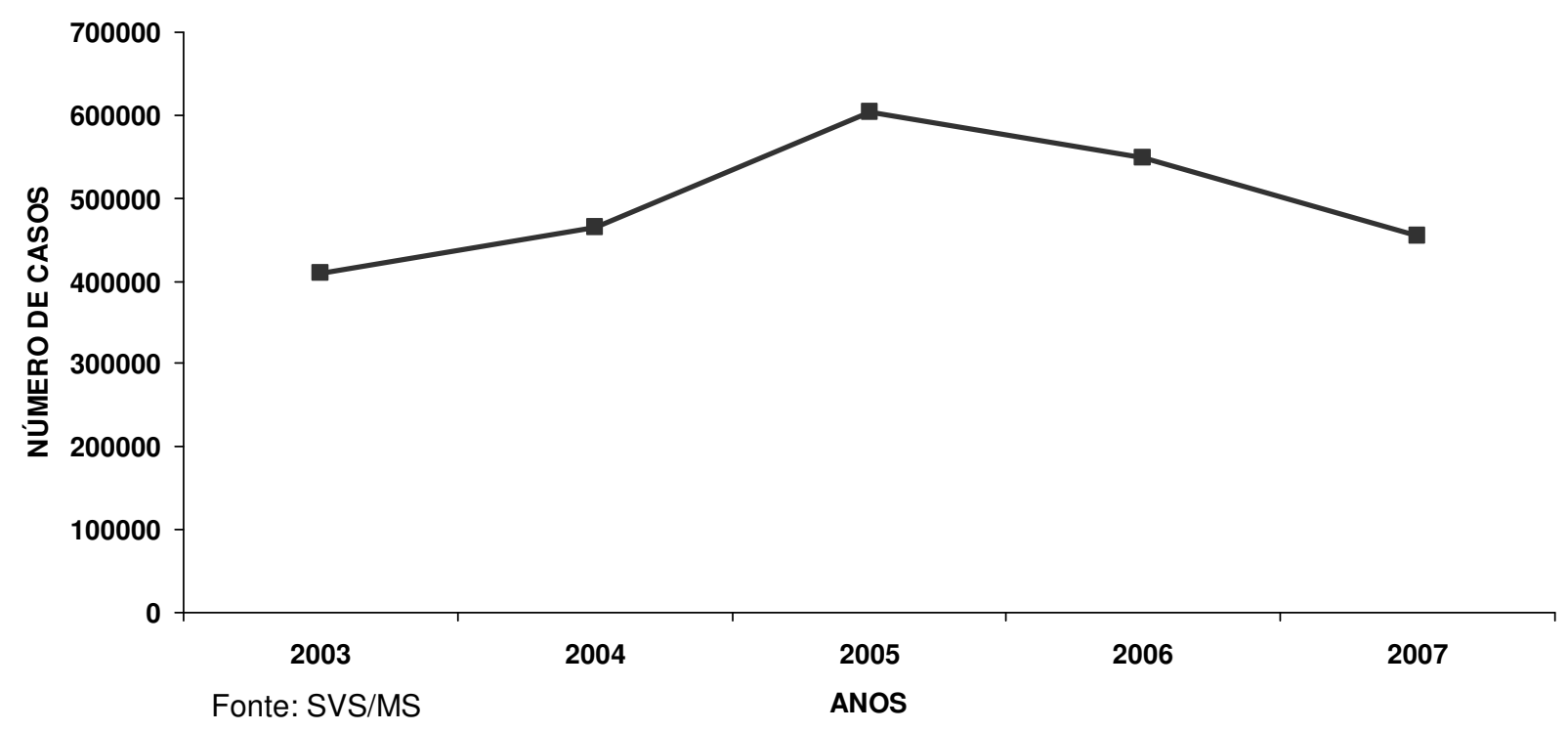

Figura 2 - Distribuição do número de casos de malária registrados no período de 2003 a 2007. Amazônia Legal, Brasil, 2003-2007

Na Região Amazônica, 79 municípios foram classificados em 2007 como de alto risco, dos quais 11 apresentaram incidência acima de 300 casos por 1.000 hab., a saber: Rodrigues Alves, Mâncio Lima e Cruzeiro do Sul, no Estado do Acre; Santa Isabel do Rio Negro, Careiro, Atalaia do Norte e Novo Airão, no Estado do Amazonas; Oiapoque e Calçoene, no Estado do Amapá; Anajás, no Estado do Pará; e Cujubim, no Estado de Rondônia (105).

Na região extra-Amazônica, não endêmica para malária, no período de 1999 a 2006 houve uma média anual de 211 casos autóctones e no ano de 2006 foram notificados 135 casos autóctones em 47 municípios. Paraná, São Paulo e Espírito Santo responderam por $88 \%$ dos casos no ano de 2007. O intenso e constante fluxo de pessoas provenientes de áreas endêmicas pode ser um dos fatores para o surgimento de surtos de malária fora da área endêmica $(103,105)$. 
O financiamento nacional das ações de prevenção e controle de malária, coordenado pela SVS/MS, ocorre por meio da rubrica orçamentária: "vigilância, prevenção e controle da malária", que no ano de 2008 foi da ordem de $\mathrm{R} \$ 12.847 .033,00$ e representa cerca de $39 \%$ de todo o orçamento da SVS. Além desses recursos, que são de aplicação pelo nível federal, foram repassados a partir do Fundo Nacional de Saúde para os Fundos Estaduais e Municipais, por meio do Teto Financeiro de Vigilância em Saúde (TFVS), cerca de 145 milhões de reais para ações de vigilância em toda a região da Amazônia Legal, que são aplicados pelas esferas descentralizadas. Estima-se que pelo menos $50 \%$ desses recursos descentralizados fundo a fundo sejam destinados pelos Estados e Municípios para as ações em malária (informações repassadas pelo PNCM, dados não publicados). Uma outra fonte de recursos para a malária é o Piso da Atenção Básica (PAB), onde está incorporado o custo do exame de gota espessa, sem a individualização do seu valor (96). As Secretarias Estaduais e Municipais de Saúde também investem recursos próprios que são utilizados, principalmente, para custeio de pagamento de pessoal, infraestrutura, insumos de laboratório e para manutenção de veículos. O financiamento das ações, portanto, é complexo, pois provém de várias fontes que não permitem, muitas vezes, a individualização do valor dispendido exclusivamente com a malária. Não existem, até o momento, estudos de custos do programa e de suas ações.

\subsubsection{A Clínica da Malária e Malária Grave}

As manifestações clínicas da malária não complicada são variadas e inespecíficas, assemelhando-se a muitos outros quadros infecciosos. A febre é freqüente, mas pode não ocorrer em raros casos. A febre pode ser acompanhada de calafrios e são usuais queixas de cefaléia e dores generalizadas no corpo, podendo ocorrrer hepatoesplenomegalia (169). 
Estudo de prevalência realizado em quatro municípios da Amazônia Legal demonstrou que os sinais e sintomas clássicos da malária - febre, dor de cabeça e calafrios - foram significativamente mais freqüentes nas infecções por Plasmodium falciparum de forma isolada, quando em comparação com as infecções mistas de Plasmodium falciparum associado com qualquer outra espécie de plasmódio. Não são conhecidos, porém, os mecanismos fisiopatogênicos que poderiam explicar os diferentes achados clínicos entre as duas formas de infecção, os quais também foram demonstrados em outras partes do mundo (76).

Devido à forte presença da malária no continente africano, a maior parte dos estudos clínicos é realizada na África, principalmente os estudos sobre as características e manejo da forma grave, já que acima de $90 \%$ dos casos de malária notificados no mundo ocorre em crianças africanas (169). Há escassez de estudos da forma grave na Região das Américas, onde predomina o Plasmodium vivax, espécie responsável pela forma benigna da doença $(66,157)$.

Cinco fatores têm sido descritos como relevantes na virulência dos plasmódios e no desenvolvimento de formas graves da doença (66): 1) a capacidade de multiplicação, que é maior no Plasmodium falciparum; 2) a preferência por determinado estágio de vida do eritrócito - o Plasmodium vivax invade apenas reticulócitos, o Plasmodium malariae apenas eritrócitos mais velhos e o Plasmodium falciparum parasita eritrócitos de diferentes idades; 3) a capacidade do Plasmodium falciparum de produzir citoaderência; 4) a indução da produção de citocinas; e 5) a capacidade de induzir a resposta imune no hospedeiro vertebrado.

A malária falciparum é mais estudada quanto à gravidade clínica, já que casos com evolução grave por Plasmodium vivax são mais raros (66). Os critérios de malária grave por Plasmodium falciparum foram estabelecidos pela OMS. De acordo com aqueles critérios, deve ser 
classificado como caso de malária grave um paciente com Plasmodium falciparum detectado pela presença de formas assexuadas no sangue periférico e sem nenhuma outra causa confirmada para os sintomas; e com a presença de um ou mais dos seguintes achados clínicos ou laboratoriais: hipertermia contínua; prostração; alteração do nível de consciência; disfunção respiratória; convulsões múltiplas; colapso circulatório; edema pulmonar; sangramento anormal; icterícia; hemoglobinúria; insuficiência renal; hipoglicemia; distúrbios hidroeletrolíticos; acidose metabólica; anemia grave; plaquetopenia; alteração das provas de coagulação e hiperparasitemia (acima de 10\% dos eritrócitos circulantes parasitados em pacientes não-imunes) (169).

Até o momento, não existem critérios para classificação de casos graves por Plasmodium vivax, portanto os estudos têm usado os mesmos critérios da OMS, acima citados, para a classificação dos casos de malária vivax com evolução grave $(9,66)$. Também se conhece pouco sobre a fisiopatologia de processos graves causados por Plasmodium vivax, embora já tenha sido demonstrada in vitro a sua capacidade de induzir a formação de rosetas de hemácias parasitadas ou não, fenômeno já largamente descrito para o Plasmodium falciparum. Não se evidenciou, no entanto, em infecções por Plasmodium vivax, o mecanismo de sequestro das hemáceas parasitadas e o fenômeno de citoaderência não foi observado. Não foi demonstrada a associação entre a formação de rosetas na malária vivax e a ocorrência de febre, trombocitopenia, anemia ou reticulocitose. Como a formação de rosetas de forma isolada, sem o fenômeno de citoaderência, não parece ser suficiente para causar formas graves como a malária cerebral, os achados podem ajudar a explicar a benignidade da doença (160).

$\mathrm{Na}$ Índia, no entanto, foram relatados 11 casos graves de malária vivax exclusiva - diagnosticados por reação em cadeia pela polimerase (PCR) - que evoluíram com malária cerebral, insuficiência renal, colapso 
circulatório, anemia grave, hemoglobinúria, sangramento anormal, disfunção respiratória aguda e icterícia, com letalidade de 18\% (60). O trabalho não detalha mecanismos parasitários e fisiopatogênicos que possam explicar estes achados incomuns na malária vivax, como a malária cerebral, que são associados à citoaderência.

No Brasil, estudo conduzido no Estado do Maranhão identificou 11 pacientes com malária vivax grave, os quais apresentavam os seguintes achados clínicos: palidez, icterícia, alteração do nível de consciência e com plaquetopenia inferior a 100.000 plaquetas $/ \mathrm{mm}^{3}$, que foi a alteração laboratorial mais comum. Os pacientes considerados graves eram todos primoinfectados, tiveram demora no diagnóstico e evoluíram favoravelmente após a instituição do tratamento (143).

Um dos mais comuns sinais de gravidade da malária vivax é a plaquetopenia, associada ou não a sangramentos $(58,66,143,145)$. Outras complicações já foram descritas na literatura nacional e internacional no curso da malária vivax, mas são de ocorrência rara como a púrpura trombocitopênica idiopática (67), a sínfrome nefrótica (16), a insuficiência respiratória grave devido a edema pulmonar não-cardiogênico $(72,142,158)$ e a coagulação intravascular disseminada com malária álgida (61).

Como os casos de malária vivax grave são de mais baixa frequência, o termo "malária grave" será utilizado a partir deste ponto do texto como sinônimo de "malária falciparum grave", fazendo-se referência à malária vivax, apenas quando pertinente.

Em áreas onde a endemicidade da malária por Plamodium falciparum é estável, a forma grave ocorre principalmente em crianças nos primeiros meses de vida e até os cinco anos, sendo menos comum em outras faixas etárias, devido à aquisição de imunidade parcial. Na África Subsaariana a malária cerebral afeta, anualmente, 575.000 crianças com menos de cinco 
anos de idade, com letalidade de 19\% (117). Em estudo epidemiológico realizado no Malawi, crianças menores de um ano apresentaram maior risco de evoluir para óbito quando comparadas a crianças entre 10 - 14 anos, com risco relativo (RR) de 3,74 (IC 95\% 2,52 - 5,39). A letalidade global no estudo foi de $7,6 \%$, sendo de $8,5 \%$ abaixo de seis meses de idade (59). Estudo realizado no Quênia identificou os seguintes sintomas como fatores associados a óbito em crianças: insuficiência respiratória ( $R R=3,9$, IC $95 \%$ 2,0 - 7,7) e alterações de consciência (RR de 3,3, IC 95\% 1,6 - 7,0) (82).

Em áreas de mais baixa endemicidade, embora a malária grave possa ocorrer tanto em adultos como em crianças, há diferenças no espectro clínico apresentado em função da idade do paciente. Nos adultos é mais comum o edema pulmonar, icterícia e insuficiência renal do que nas crianças. Nessas, são mais comuns a anemia e convulsões. Hipoglicemia é mais comum nas crianças e em mulheres grávidas, principalmente em associação ao uso do quinino na gravidez $(112,169)$. Em alguns países, como Índia, Tailândia e Vietnã, a malária cerebral foi descrita como sendo a apresentação clínica mais comum da forma grave e a causa de morte mais freqüente em adultos com malária, estimando-se coeficientes de $20 \%$ de letalidade em adultos e $15 \%$ em crianças $(113,169)$. Na índia, a malária cerebral foi a principal causa de óbito em uma coorte de 242 crianças com malária complicada (147). Um estudo epidemiológico de caso-controle sobre a malária complicada, realizado em duas áreas endêmicas da Colômbia, estudou 64 casos graves com 77 complicações e encontrou em $84 \%$ dos casos a presença de apenas uma complicação clínica dentre os critérios de gravidade da OMS. Entre todas as complicações detectadas foi encontrado 40\% (31/77) de hiperparasitemia, 36\% (28/77) de insuficiência hepática, 7\% de síndrome de insuficiência respiratória aguda (6/77), 5\% de insuficiência renal (4/77), 4\% (3/77) de trombocitopenia grave, 3\% (2/77) de anemia grave e de malária cerebral e $2 \%$ (1/77) de hipoglicemia grave (157). 
No Estado do Amazonas, Brasil, relatos retrospectivos de casos graves de malária falciparum internados em hospital de referência no período de 1996 a 1999, demonstraram que entre os adultos, as principais complicações foram: plaquetopenia (38\%), insuficiência renal $(11,7 \%)$, insuficiência respiratória $(9,5 \%)$ e hemorragias $(4,1 \%)$. Entre os 222 casos avaliados, apenas um óbito $(0,4 \%)$ foi observado no período (69). Entre 255 crianças avaliadas, com média de idades de 3,8 anos, os principais achados foram plaquetopenia $(27,6 \%)$, alterações neurológicas $(17,3 \%)$, alterações metabólicas $(13,8 \%)$, insuficiência respiratória $(12,6 \%)$ alterações da função renal $(1,9 \%)$ e apenas dois casos $(0,8 \%)$ evoluíram a óbito (116).

A baixa letalidade observada em área endêmica de baixa transmissão na Tailândia foi atribuída ao acesso e à qualidade da atenção na área de estudo (79), que provê diagnóstico e tratamento precoces e gratuitos, atenção adequada ao pré-natal e acesso universal à população sob risco. Persiste incerteza se as diferentes freqüências das manifestações da malária grave e de óbito estão associadas somente à idade ou se outros fatores tais como a diversidade entre as populações afetadas, características do parasito, características da exposição, acesso e provisão de serviços médicos podem estar relacionados (169).

Pessoas que viajam para áreas endêmicas e não possuem imunidade são bastante vulneráveis ao desenvolvimento de manifestações de gravidade $(23,169)$. A gravidez aumenta a suscetibilidade à malaria, principalmente quando se trata da primigrávidas, e as gestantes têm maior risco de desenvolver manifestações graves do que as não-gestantes da mesma idade $(2,40)$.

Não há sempre relação direta entre as manifestações graves da doença e a parasitemia. Em crianças não-imunes vivendo em áreas de endemicidade instável uma parasitemia periférica de $4 \%$ dos eritrócitos circulantes pode ser considerada um sinal de malária grave, já em áreas de 
endemicidade estável, este risco pode ser considerado com parasitemias iguais ou maiores de $20 \%$ (169).

A malária grave pode ainda evoluir com a associação de infecções bacterianas, tais como: broncopneumonia (sobretudo em pacientes que apresentam convulsões generalizadas); infecções urinárias associadas à cateterização vesical; infecção de úlceras de decúbito; infecções associadas a cateteres venosos; e ainda septicemia sem focos aparentes (169).

Estudo conduzido na cidade de Manaus, Estado do Amazonas, Brasil, no período de 2004 a 2006, utilizou amostra probabilística representativa da população com malária que é atendida no hospital de referência do município, com o objetivo de estimar a freqüência, manifestações clínicas e patogênese da plaquetopenia em pacientes com malária. Foram estudados 168 pacientes, sendo 142 com malária vivax e 26 com malária falciparum. Dentre os pacientes com malária falciparum, 11,54\% (3/26) (IC95\%: 3,219,9) tiveram manifestações de doença grave e com malária vivax, 1,4\% (2/142) (IC95\%: 0,0 - 4,6) dos casos. Os critérios da OMS foram utilizados para a classificação de ambas as formas de malária (169). Todos os casos de malária grave apresentaram plaquetopenia grave $(<50.000$ plaquetas $/ \mu \mathrm{L})$. Entre os dois pacientes com malária vivax grave, o outro achado clínico foi a hiperbilirrubinemia. Entre os três pacientes com malária falciparum foram observadas também insuficiência renal aguda, malária cerebral e malária álgida, com um caso evoluindo a óbito. O tempo de doença dos pacientes graves variou de cinco a 11 dias e quatro dentre os cinco casos eram primoinfectados (66). 


\subsubsection{O Tratamento Atual da Malária no Brasil}

O tratamento específico da malária por meio de quimioterápicos tem um papel indispensável na atenção à doença por quatro grandes objetivos: 1) a assistência aos indivíduos que contraem a doença, abortando as manifestações clínicas provenientes da esquizogonia sanguínea (processo de desenvolvimento do parasito no interior do eritrócito, que resulta na liberação de formas assexuadas que invadirão outros eritrócitos); 2) a prevenção das formas graves, especialmente, por Plasmodium falcipraum, evitáveis pelo tratamento eficaz e precoce; 3) a prevenção de recaídas (reaparecimento das manifestações clínicas a partir de formas parasitárias de origem hepática, que invadem eritrócitos) causadas pelo Plasmodium vivax, pela erradicação de formas teciduais do parasito; e 4) a quebra da cadeia de transmissão, sendo uma ação do controle em saúde pública, por eliminar as formas sexuadas - os gametócitos - no sangue periférico, que são as fontes de infecção para o mosquito transmissor (93).

A cloroquina era a droga eficaz, no passado, para todas as quatro espécies de Plasmodium. O desenvolvimento da resistência pelo Plasmodium falciparum a esse quimioterápico, assim como a vários outros que o sucederam, tornou o tratamento da malária um constante desafio, exigindo o monitaramento contínuo da resistência do parasito aos antimaláricos, assim como desenvolvimento de estudos de novas drogas ou de novas formulações, visando ao alcance dos quatro objetivos propostos $(93,171)$. A decisão pelo esquema de tratamento mais adequado leva em conta a espécie infectante, a gravidade da doença, a idade do paciente e condições clínicas subjacentes como a presença de gravidez $(93,171)$.

O esquema de tratamento de primeira linha atualmente adotado pelo PNCM está descrito na tabela 2. Na segunda linha de tratamento são preconizados esquemas com quinino, doxiciclina, mefloquina e formulações 
fixas de artesunato com mefloquina, indicados, principalmente, para situações em que exista contra-indicação às drogas de primeira escolha (88, 102, 125).

Tabela 2 - Esquemas de tratamento antimalárico de primeira linha preconizados pelo Programa Nacional de Controle de Malária, Ministério da Saúde, Brasil.

\begin{tabular}{|c|c|}
\hline Formas de Malária & Esquemas terapêuticos de primeira linha \\
\hline $\begin{array}{l}\text { Malária por Plasmodium } \\
\text { vivax }\end{array}$ & $\begin{array}{l}\text { Cloroquina: Comprimidos contendo } 250 \mathrm{mg} \text { de sal, equivalente } \\
\text { a } 150 \mathrm{mg} \text { de base. Crianças e adultos: dose total de } 25 \mathrm{mg} \text { de } \\
\text { base } / \mathrm{kg} \text {, administrada no transcorrer de três dias - administrar } \\
10 \mathrm{mg} \text { de base } / \mathrm{kg} \text { no primeiro dia, seguida de } 7,5 \mathrm{mg} / \mathrm{de} \text { base } / \mathrm{kg} \\
\text { no segundo e terceiro dias. Gestantes utilizam } 5 \mathrm{mg} / \mathrm{kg} / \mathrm{semana} \\
\text { até o final da gestação e menores de } 6 \text { meses, } 1 / 4 \mathrm{de} \text { comprimido } \\
\text { em dose semanal, por três meses, para evitar recaídas. } \\
\text { Primaquina: Comprimidos contendo } 5,0 \mathrm{mg} \text { e } 15,0 \mathrm{mg} \text { de base } \\
\text { como difosfato, equivalendo a } 8,8 \mathrm{mg} \text { e } 26,4 \mathrm{mg} \text { do sal, } \\
\text { respectivamente. Dose de } 0,50 \mathrm{mg} \text { de base } / \mathrm{kg} \text { de peso, } \\
\text { diariamente, durante sete dias. Não utilizar em gestantes e } \\
\text { crianças menores de } 6 \text { meses. }\end{array}$ \\
\hline
\end{tabular}

Malária por Plasmodium falciparum não-grave

\section{Artemeter + Lumefantrina (Coartem $\AA)$ :}

Comprimidos contendo uma combinação fixa com artemeter 20 mg e lumefantrina120 mg. Não administrar a gestantes durante o primeiro trimestre de gravidez nem a menores de 6 meses. Vem em embalagens individuais contendo 6,12, 18 ou 24 comprimidos, de acordo com as diversas faixas etárias. Quinina - Comprimidos com $500 \mathrm{mg}$ do sal de quinina, equivalendo a $325 \mathrm{mg}$ da base. Administrar $30 \mathrm{mg}$ do sal de quinina/ $\mathrm{kg} /$ dia durante três dias. Uso em crianças menores de 6 meses e gestantes no primeiro trimestre de gravidez.

Clindamicina - $20 \mathrm{mg} / \mathrm{kg} / \mathrm{dia}$, duas a quatro vezes ao dia, durante 05 dias. Associar à quinina para uso em gestantes no primeiro trimestre da gravidez.

Malária grave por Artesunato: 2,4 mg/kg (ataque), seguidos de 1,2 mg/kg após 12 Plasmodium falciparum e 24 horas da dose inicial. Manter uma dose diária de $1,2 \mathrm{mg} / \mathrm{kg}$ durante 6 dias. $60 \mathrm{mg}$ por ampola, diluir o pó no diluente próprio e em $5 \mathrm{ml}$ de SG $5 \%$, via EV.

OU

Artemeter: 3,2 mg/kg (ataque), seguidos por $1,6 \mathrm{mg} / \mathrm{kg}$ por dia, durante 6 dias. $80 \mathrm{mg}$. por ampola, via IM

Mefloquina: 15 a $20 \mathrm{mg} / \mathrm{kg}$ em dose única - administrar após os três primeiros dias de uso de artesunato ou artemeter. ${ }^{(1}$

Primaquina - Como gametocitocida, na dose de 0,5-0,75 mg

de base/kg em uma única dose, i.e., 30 - $45 \mathrm{mg}$ de base para um adulto. Uso após o quinto dia de tratamento. ${ }^{(2)}$

Quinino + Clindamicina - injetáveis, para o tratamento da malária grave em gestantes, nas mesmas doses acima citadas. Fontes: Ministério da Saúde; Organização Mundial da Saúde; Fundação de Medicina Tropical do Amazonas Notas:

(1) Sequencialmente ao uso de artemeter ou artesunato, estão indicados como alternativas, além da mefloquina, antibióticos como doxiciclina ou clindamicina.

(2) Indicada quando há presença de gametócitos (68). 


\subsubsection{O Diagnóstico da Malária}

O diagnóstico clínico da malária é insuficiente para o correto manejo da doença, que exige diagnóstico precoce e acurado, uma vez que a malária apresenta sintomas clínicos inespecíficos que são comuns a várias doenças infecciosas agudas.

Todos os países endêmicos para a malária compartilham, na área da saúde, a necessidade de manter um sistema de diagnóstico confiável e eficiente que seja a base para a introdução de terapêutica antimalárica racional e para a informação epidemiológica confiável e oportuna (167).

\subsubsection{Microscopia}

O método convencional estabelecido para o diagnóstico é a microscopia por meio da visualização direta do parasito. Os dois métodos de exame são: esfregaço delgado e esfregaço espesso, denominados mais comumente de "esfregaço" e "gota espessa", respectivamente, terminologia que se adotará nesta tese. Entre os dois, o método da gota espessa é o mais largamente empregado (114). A microscopia requer condições técnicas para a sua execução e exige pessoal capacitado, porém é barata e permite a diferenciação de todas as espécies do Plasmodium e a quantificação da parasitemia (167).

A técnica baseia-se na visualização do parasito por meio de microscopia ótica, após coloração com corante vital (azul de metileno e Giemsa), permitindo a diferenciação específica dos parasitos a partir da análise da sua morfologia e dos seus estádios de desenvolvimento encontrados no sangue periférico. A determinação da densidade parasitária, útil para a avaliação prognóstica, deve ser realizada em todo paciente com malária, especialmente nos portadores de Plasmodium falciparum. Para tal, 
o exame padrão da gota espessa deve ser realizado em 100 campos microscópicos, examinados com aumento de 600-700 vezes, o que equivale a $0,25 \mu \mathrm{l}$ de sangue. Um método semiquantitativo de avaliação da parasitemia, expresso em "cruzes", pode ser aplicado. Uma forma mais precisa de quantificar a parasitemia é realizada pela contagem simultânea de parasitos e de leucócitos em 200-500 campos da gota espessa. Se a contagem global de leucócitos é conhecida, a razão parasitos/leucócitos da lâmina permitirá a estimação da parasitemia por $\mathrm{mm}^{3}$ de sangue (101).

A gota espessa proporciona maior acurácia aos métodos microscópicos, especialmente, em casos com baixa parasitemia e durante a recrudescência ou recidiva. Por outro lado, o esfregaço provê melhor identificação da espécie dos parasitos (114). As exigências técnicas para o exame microscópico nem sempre são facilmente cumpridas, particularmente, em áreas periféricas ou de baixa endemicidade, o que gera atraso no diagnóstico e na decisão clínica quanto ao tratamento (168).

Apesar de a microscopia ser o método tradicional, é uma referência padrão imperfeita, com muitas limitações inerentes à técnica, como: a necessidade de profissionais altamente experientes e motivados; variabilidade na qualidade do esfregaço; a inabilidade para determinar a espécie do parasito quando a parasitemia é muito baixa e a perda da qualidade da lâmina com o passar do tempo (123). Além disto, os procedimentos para a preparação das lâminas e para a quantificação dos parasitos podem ser variados e inconsistentes e os diversos métodos para medição da parasitemia dificultam a comparação dos resultados $(114,129$, 130).

Os resultados falsos positivos da microscopia podem ser conseqüência de artefatos - como precipitação de corantes ou debris celulares - ou de confundimento com plaquetas e são mais freqüentes quando os microscopistas têm menos experiência. A probabilidade de 
resultados falsos negativos aumenta com a redução da densidade parasitária; este tipo de erro pode ser reduzido quando se examinam mais campos com maior tempo por exame de cada campo (167).

Revisão da OMS sobre métodos diagnósticos (168) destaca as seguintes vantagens da microscopia:

- É bastante sensível e permite a quantificação da densidade parasitária. Quando executada por técnicos habilitados pode detectar densidades tão baixas quanto 5-10 parasitos por $\mu \mathrm{l}$ de sangue; em condições de campo, entretanto, a detecção mais realista é a de 100 parasitos por $\mu \mathrm{l}$ de sangue para um microscopista experiente.

- Fornece diagnóstico espécie-específico dos estádios circulantes no sangue; microscopistas muito experientes ainda conseguem detectar alterações morfológicas induzidas por tratamento recente.

- É relativamente barata; o custo estimado para países endêmicos varia de US $\$ 0,12$ a US $\$ 0,40$ por lâmina examinada. Estes custos não refletem, porém, o verdadeiro custo para o sistema de saúde ou para o paciente, o qual pode ser substancialmente maior, considerando custos de estrutura, treinamento e transporte, entre outros. O custo por teste aumenta se a utilização for baixa ou se a estrutura do serviço de saúde for usada exclusivamente para o diagnóstico da malária.

- Exige infra-estrutura para o diagnóstico que pode ser compartilhada com outros programas de controle como o da tuberculose ou de doenças sexualmente transmissíveis.

- Fornece um registro permanente do achado diagnóstico, pela possibilidade de arquivamento e releitura posterior da lâmina. 
As seguintes desvantagens da microscopia como teste diagnóstico são apresentadas na revisão da OMS(168):

- Consome esforço e tempo, requerendo, normalmente, cerca de 60 minutos entre a coleta e o resultado de cada exame realizado.

- Depende diretamente de boa técnica, reagentes, microscópios e, principalmente, de pessoal muito bem treinado e experiente.

- O resultado pode demorar muito em ser disponibilizado para o médico clínico, retardando o tratamento.

Existem poucos estudos que avaliaram a sensibilidade $e$ especificidade da microscopia como teste diagnóstico. Na Tailândia, a microscopia feita em campo - que foi definida como exame que lê 50-100 campos da gota espessa, durante cinco minutos, usando fonte de luz natural (devido a localidade ser de difícil acesso e desprovida de energia elétrica) para diagnóstico de pacientes assintomáticos, demonstrou sensibilidade muito baixa quando comparada com o exame feito em laboratório especializado (padrão-ouro). A sensibilidade para diagnóstico de Plasmodium falciparum foi de $10 \%$ e para Plasmodium vivax de $7,1 \%$, sendo a especificidade do método para ambas as espécies de 99\% (30). A técnica de campo, de uso corrente no país, não foi recomendada para a vigilância ativa, considerando que os indivíduos têm baixas cargas parasitárias (30).

No Afeganistão, a microscopia feita em laboratórios locais de campo quando comparada com a do laboratório de referência (padrão-ouro) demonstrou sensibilidade para diagnóstico de Plasmodium falciparum de 85,2\% e a especificidade de 99,7\%; para Plasmodium vivax a sensibilidade foi de $90,4 \%$ e a especificidade de $98,7 \%$ (62). Estudo no Haiti comparou a expertise do diagnóstico local com um laboratório de referência nos Centers for Disease Control and Prevention (CDC, Atlanta), como padrão-ouro, obtendo sensibilidade de $83,6 \%$ e especificidade de $88,6 \%$, para o 
diagnóstico global de malária com um baixo valor preditivo positivo $(22,2 \%)$ (57). No Kuwait, em população migrante provinda de áreas endêmicas, a microscopia foi comparada à reação de PCR, como padrão-ouro, com sensibilidade de $86 \%$ para diagnóstico da infecção malárica global (56). Estudo na Indonésia comparou a microscopia com a PCR (padrão-ouro) em duas situações: 1) por um microscopista menos experiente e 2) por um microscopista com mais de 40 anos de experiência. Os resultados mostraram que para a primeira situação a sensibilidade para $P$. falciparum foi de $77 \%$ e para Plasmodium vivax de $90 \%$. Já para os resultados fornecidos pelo microscopista experiente a sensibilidade foi de $92 \%$ para Plasmodium falciparum e de $95 \%$ para Plasmodium vivax (123). Estudo realizado em Toronto, com doentes febris que retornaram de áreas endêmicas, estimou sensibilidade de $83 \%$ e especificidade de $99 \%$ para Plasmodium falciparum, comparando a microscopia com a PCR (padrãoouro) (54). Outro estudo do Canadá, com refugiados africanos assintomáticos e considerando como padrão-ouro o diagnóstico de Plasmodium falciparum pela PCR, estimou a sensibilidade da microscopia em $50 \%$ e a especificidade em $100 \%$; a baixa sensibilidade do exame pode estar associada à baixa parasitemia encontrada nas infecções assintomáticas (121). No Irã, foi validada a microscopia, comparando-a com a PCR para diagnóstico de infecções causadas por Plasmodium vivax, com resultados de sensibilidade de $77 \%$ (IC 95\%: 46-94) e especificidade de 100\% (IC 95\%: 95-100) (49).

O Brasil possui ampla estrutura para o diagnóstico microscópico da malária. Na Amazônia Legal estão sediados 3.240 laboratórios ativos (número de janeiro de 2008), distribuídos entre os nove Estados. No ano de 2006, a Região contava com 3.187 serviços de diagnóstico ativos (91). Apesar desta estrutura, devido à extensão territorial da Região, nas áreas endêmicas da malária ainda persistem limitações de acesso e disponibilidade dos serviços de saúde, relacionadas à dificuldade de acesso, 
mobilidade e instabilidade da população e ao alto custo da prestação de serviços em áreas dispersas (104).

\subsubsection{Testes Rápidos}

Nos últimos 10 anos foram introduzidos como alternativa para o diagnóstico da malária os testes rápidos (TR) com pelo menos 25 diferentes produtos disponíveis no mercado, a maioria exclusivamente para 0 diagnóstico de Plasmodium falciparum (168).

Os TR, que utilizam métodos imunocromatográficos, detectam antígenos específicos de Plasmodium em uma amostra de sangue colhida por punção digital. Podem ser realizados em aproximadamente 15 minutos, por indivíduos com treinamento mínimo na técnica, usando kits que não requerem energia elétrica e nem equipamento especial (168).

Em se tratando de uma nova tecnologia, é estipulado que os TR para diagnóstico de malária devem ter sensibilidade acima de 95\% quando comparados à microscopia, capacidade de detectar a infecção em níveis de 100 parasitos/ $\mu$ l do gênero Plasmodium, habilidade para realizar medições semiquantitativas para monitorar o tratamento - esta última característica ainda não foi alcançada nos testes disponíveis - e ainda, que sejam validados considerando métodos adequados para padrão-ouro e que sejam tão acurados quanto a microscopia feita por um técnico em condições normais de campo (114). Ressalta-se que testes que requerem mais de uma hora para prover um diagnóstico objetivo de malária não são considerados testes rápidos (114).

O desenvolvimento e uso de TR na malária envolve, ainda, algumas dificuldades e necessidades que se relacionam com a distribuição e apresentação clínica da doença (174). O uso de TR em áreas remotas e tropicais - onde estariam mais indicados devido à falta de acesso ao 
diagnóstico microscópico - limita, por exemplo, o controle da temperatura ambiente adequada para 0 armazenamento dos kits, que exigem, idealmente, o uso de cadeias de frio para o seu transporte e estocagem (174). Muitas vezes, devido às longas distâncias, também pode ocorrer limitada supervisão da sua aplicação em áreas remotas. Soma-se a estes desafios, o fato de a malária causada pelo Plasmodium falciparum apresentar risco de evolução grave e fatal, o que exige alta sensibilidade para o seu diagnóstico (174).

A técnica utilizada na maioria dos TR disponíveis para o diagnóstico da malária é a imunocromatográfica com anticorpos monoclonais conjugados. Os antígenos-alvo de preferência são aqueles mais abundantes nos estágios sexuados e assexuados do parasito e usualmente o interesse é focalizado na detecção da Proteína 2 rica em histidina (histidine-rich protein 2 - HRP-2) do Plasmodium falciparum, na lactato desidrogenase parasitoespecífica (pLDH) ou na aldolase, as duas últimas presentes no processo glicolítico do parasito e em todas as espécies (114). Os testes que utilizam a pLDH são mais apropriados para monitorar o tratamento, pois a enzima persiste por menor tempo no sangue periférico, em comparação à HRP-2; no entanto a pLDH também é produzida por gametócitos, podendo ser detectada quando já não há formas assexuadas no sangue periférico (167).

Os antígenos-alvo e algumas apresentações comerciais de TR disponíveis são:

- HRP - 2: proteína hidrossolúvel produzida pelos trofozoítos e gametócitos jovens do Plasmodium falciparum. Os kits comerciais disponíveis detectam HRP-2I somente de Plasmodium falciparum; alguns testes vêm conjugados com a aldolase (114), o que amplia o diagnóstico do teste para outras espécies. Entre as apresentações comerciais estão ParaSight $\AA$, ICT $\AA$, ICT Pf/Pv $\AA$, Malar-check ${ }^{\circledR}$ e o NOW ICT Pf/Pv® $(11,29,36,114,130,139)$. 
- pLDH: enzima glicolítica produzida em níveis elevados pelos estádios assexuados dos parasitos e em menores níveis pelos estádios sexuados e é encontrada nas quatro espécies de Plasmodium. Os testes disponíveis podem distinguir Plasmodium falciparum das espécies não-falciparum, mas, não distinguem entre Plasmodium vivax, Plasmodium ovale e Plasmodium malariae. Entre as apresentações comerciais está o OptiMAL® (114).

Para realizar o TR, o espécime de sangue é coletado por punção digital na quantidade de $2-50 \mu l$ (dependendo do kit) usando uma variedade de tubos microcapilares; o sangue é misturado em um tubo separado ou em uma placa com uma solução tampão que contém um composto hemolisador assim como um anticorpo específico que é marcado com um marcador visualmente detectável, como o ouro coloidal. Se o antígeno em investigação estiver presente, um complexo antígeno/anticorpo é formado. O complexo antígeno/anticorpo migra na fita do teste - geralmente de nitrocelulose/fibra de vidro - por ação capilar, em direção aos reagentes específicos que foram depositados durante a fabricação. Estes incluem: 1) uma linha de captura anticorpo-específica para o antígeno sob investigação (várias linhas são usadas se vários antígenos estão em investigação) e 2) uma linha de controle do procedimento com um anticorpo que capturará o anticorpo marcado. Uma solução tampão de lavagem é adicionada para remover a hemoglobina e permitir a visualização de qualquer linha corada na fita. Se o sangue contiver o antígeno sob investigação, o complexo antígeno-anticorpo será imobilizado na linha de captura pré-depositada e será visualmente detectável. Independente de o sangue conter antígeno ou não, a linha de controle torna-se-á visível já que o anticorpo marcado é capturado pela linha de anticorpo específico pré-depositado (168).

Os TR são mais fáceis de executar do que qualquer outra técnica de diagnóstico de malária, com alguns formatos mais simples de manipular do que outros. Profissionais de saúde com mínimas habilidades podem ser 
treinados na técnica em períodos que variam de duas horas e meia a um dia $(168,172)$.

O custo unitário do TR é mais alto quando comparado com a gota espessa $(139,168)$. Pode variar de US $\$ 0,60$ a 3,50 por teste, a depender do produto e da quantidade usada $(51,55,62,168,174)$.

No Brasil, em 2008, na Agência Nacional de Vigilância Sanitária (ANVISA) foram encontrados 12 registros de testes rápidos para diagnóstico de malária e citam-se, como exemplo, os testes das marcas OptiMAL-IT® do laboratório DIAMED-Latino América S.A. (registro 80004040139), Malar Check TM PF® do laboratório RCS - Inglaterra (registro 80009070002) e MALARIA P.F. CASSETE PARA TESTE RAPIDO (SANGUE TOTAL) AconBiotech - China (registro 80160400003) (3).

Os TR apresentam as seguintes vantagens $(51,168)$ : são de elevada reprodutibilidade; fornecem resultados instantâneos e podem ser usados em áreas remotas, como as áreas rurais; podem representar economia em termos de transporte e de tratamento presuntivo em áreas distantes de centros de diagnóstico microscópico, além de economia para os pacientes em relação ao tempo de espera, deslocamentos e redução do tempo de doença; como os testes detectam antígenos circulantes, podem detectar a infecção por Plasmodium falciparum mesmo quando os parasitos não são detectáveis pelo exame microscópico de sangue periférico, apesar da redução da sensibilidade nestas situações; em mulheres com malária placentária (demonstrado por esfregaços de malária), os testes detectaram os antígenos circulantes (HRP - 2) mesmo quando o exame de sangue periférico foi negativo devido ao seqüestro de Plasmodium falciparum na placenta.

As principais desvantagens dos TR são $(139,168)$ : os testes disponíveis para antígenos HRP-2 podem detectar somente Plasmodium 
falciparum, assim estes kits detectarão somente uma porção dos casos em áreas onde outras espécies de Plasmodium são simpátricas e não são úteis para diagnosticar casos de malária importados de áreas onde Plasmodium falciparum não é necessariamente a espécie prevalente; TR para antígenos HRP-2 de Plasmodium falciparum podem dar resultados positivos até duas semanas após a quimioterapia e negativação da parasitemia, o que pode gerar resultados confusos em relação à avaliação do tratamento ou de resistência da droga; não são quantitativos, portanto são falhos para prover informação relacionada a prognóstico e não são úteis para investigações detalhadas quanto a eficácia terapêutica de drogas antimaláricas; apresentam sensibilidade sub-ótima quando a densidade parasitária é baixa; TR para antígenos pLDH são inábeis para identificar de forma acurada a espécie dos parasitos, não diferenciando as espécies Plasmodium vivax, Plasmodium ovale e Plasmodium malariae, assim como os estádios sexuados e assexuados dos parasitos. Os TR que detectam antígenos produzidos por gametócitos, como pLDH, podem fornecer resultados positivos onde somente estão presentes os gametócitos. Estes resultados podem levar à interpretação errônea (falsos positivos) e ao tratamento desnecessário. Esta última desvantagem apontada pode, em algumas situações, constituir uma vantagem dos TR que utilizam a pLDH, como por exemplo em inquéritos populacionais para triagem de indivíduos que serão submetidos à microscopia posterior, pois permitirão identificar a carga de potencial transmissão na comunidade.

Outra desvantagem possível é o tempo curto de validade do teste, sendo recomendado aos fabricantes manter no mínimo 18 meses de validade (170), pois o prazo menor pode ser um problema quando o tempo de compra pelo serviço público é demorado e não há o cuidado com este aspecto no insumo a ser recebido.

Para garantir o seu adequado uso, os TR devem possuir as seguintes características (168): instruções claras e ilustradas, adaptadas às condições 
locais; componentes de fácil manipulação; número mínimo de etapas; e resultados facilmente interpretáveis. Os testes, idealmente, deveriam ser capazes de suportar temperaturas de 40 a $50^{\circ} \mathrm{C}$ que são comuns em países tropicais e não requerer refrigeração, porém os fabricantes usualmente recomendam de $4^{\circ}$ a $30^{\circ}$ como temperatura ótima (167).

$\mathrm{Na}$ tabela 3 são descritos algumas características e requerimentos dos TR e da microscopia tradicional como métodos diagnósticos de malária.

Tabela 3 - Diagnóstico da malária - Testes Rápidos e Microscopia - segundo algumas características e requerimentos.

\begin{tabular}{|c|c|c|}
\hline $\begin{array}{l}\text { CARACTERÍSTICAS E } \\
\text { REQUERIMENTOS }\end{array}$ & MICROSCOPIA & TESTES RÁPIDOS \\
\hline Equipamentos & Microscópio & Nenhum \\
\hline Experiência do profissional & Elevada & $\begin{array}{l}\text { Mínima - pouco } \\
\text { treinamento }\end{array}$ \\
\hline Duração do teste & Pode chegar a 60 minutos & $15-20$ minutos \\
\hline Subjetividade do observador & Alta & Baixa \\
\hline Custo por teste & US $\$ 0.12-0.40$ & US\$ $0.60-2.50$ \\
\hline Quantificação de parasitos & Sim & Não \\
\hline $\begin{array}{l}\text { Diferenciação entre as } 4 \\
\text { espécies }\end{array}$ & Sim & $\begin{array}{l}\text { Não - somente diferencia } \\
\text { P. falciparum das demais }\end{array}$ \\
\hline $\begin{array}{l}\text { Diferenciação entre estádios } \\
\text { sexuados e assexuados }\end{array}$ & Sim & Não \\
\hline $\begin{array}{l}\text { Detecção de persistência } \\
\text { antigênica na ausência de } \\
\text { formas parasitárias visualizáveis }\end{array}$ & Não & Sim \\
\hline $\begin{array}{l}\text { Detecção de parasitos } \\
\text { seqüestrados }\end{array}$ & Não & Sim \\
\hline
\end{tabular}

Fontes: Adaptado a partir de referência da World Health Organization (WHO), 2000; e lqbal e cols., 2003.

Em áreas de baixa a moderada transmissão - como na Ásia, Américas e partes da África - a maioria das infecções maláricas é sintomática e a multidrogarresistência ocorre em algumas regiões. A microscopia, geralmente, não está disponível em áreas mais remotas, onde 
os TR realizados por profissionais de saúde ou voluntários podem ser usados, facilitando o tratamento imediato, resultando em redução da morbidade e mortalidade. Indicação importante dos TR é a prevenção e manejo da malária grave em áreas de baixa a moderada transmissão; nessas áreas, devido à baixa imunidade, os pacientes apresentam maior risco de desenvolver formas graves, sendo imperativo o diagnóstico rápido e precoce. Além disso, são úteis no diagnóstico diferencial das formas graves com outras doenças como encefalite viral, dengue e febre tifóide. Em algumas circunstâncias os TR para malária têm um papel crítico, como nas seguintes situações indicadas pela OMS (168):

- Emergências, como aquelas causadas por conflitos ou catástrofes ambientais que criam condições facilitadoras para a introdução e disseminação da malária, como, por exemplo: o deslocamento de populações não-imunes para áreas endêmicas, mudanças ambientais que alteram os hábitos do mosquito vetor, problemas concorrentes como a má-nutrição e a indisponibilidade, pelo menos inicialmente, de alimentos, saneamento e atenção básica à saúde. Nestas situações, a malária pode representar $40-50 \%$ de todas as doenças presentes.

- Epidemias de malária, que podem ocorrer como resultado de mudanças ambientais ou migração. Em áreas onde o serviço de microscopia não está disponível, o uso dos TR para confirmar a epidemia em fase inicial é especialmente útil.

- Viajantes que retornam para áreas não-endêmicas os quais exigem um rápido e acurado diagnóstico pelo risco de desenvolverem formas graves.

É importante destacar que na África, devido à introdução de antimaláricos mais caros como os derivados da artemisinina, em substituição à quinino e amodiaquina, os testes rápidos têm sido empregados na rotina de diagnóstico, devido à dificuldade da manutenção de microscopia nas áreas endêmicas (15). Naquela realidade, alguns aspectos devem ser 
observados quando da implantação do teste, de modo a que a estratégia seja realmente efetiva, como: manter a acurácia do TR elevada; fazer contínuo treinamento de profissionais para o seu adequado uso; manter supervisão contínua da prática; educar a população, assim como os profissionais de saúde, para aumentar a confiança no teste, especialmente quando os resultados dos testes forem negativos para malária; e prover melhor manejo da febre não causada por malária, um efeito secundário relevante para os serviços africanos, que advém do acurado diagnóstico inicial para malária (15).

Vários TR já foram testados em condições controladas e de campo, sendo avaliados, extensivamente, em diversas situações clínicas tanto em países endêmicos como indenes, em populações imunes e suscetíveis (168).

Os TR têm demonstrado eficiência comparável à gota espessa. A eficiência de um teste diagnóstico é definida como a proporção de resultados corretamente classificados e é dada pela fórmula: 1 - [(falsos-positivos + falsos-negativos)/total da amostra] x 100 (39).

A eficiência dos TR foi mais estudada para Plasmodium falciparum, já que testes para esta espécie são mais antigos. Resultados falsos positivos foram relatados em sangue de pacientes com fator reumatóide, especialmente na versão inicial de um kit HRP-2 (114). Os testes HRP-2 podem permanecer positivos por 7-14 dias após a quimioterapia em uma substancial proporção de indivíduos, mesmo naqueles que já não tem sintomas ou que negativaram a parasitemia; esta persistência da positividade aparentemente não é encontrada em testes que têm como alvo outros antígenos $(114,168)$. Características da transmissão como intensidade, endemicidade de múltiplas espécies de Plasmodium, resistência adquirida na população exposta e tratamento prévio podem afetar individual e coletivamente os resultados dos TR (39). 
Os estudos de validação dos TR utilizam como padrão-ouro a microscopia - gota espessa ou esfregaço - e algumas vezes complementam com a PCR. A sensibilidade e especificidade dos testes é bastante variável nos diversos estudos, dependendo do perfil epidemiológico e clínico das populações e das cargas parasitárias individuais. Inúmeros estudos de validação de vários TR têm sido publicados nos últimos 10 anos.

A eficiência dos TR decresce à medida que diminui a densidade parasitária. Em estudo com OptiMAL® em população proveniente de áreas endêmicas, a sensibilidade para detectar infecção malárica (diagnóstico global) foi $97 \%$ em parasitemias acima de 100 parasitos $/ \mu l$ de sangue mas, caiu para 59\% quando havia menos de 100 parasitos/ $\mu$ e para 39\% com menos de 50 parasitos/ $\mu$ l (56). Estudos com o OptiMAL® e o ICT Pf/Pv® em população não imune, demonstraram que em densidade parasitária abaixo de 100 parasitos/ $\mu$ l de sangue, a sensibilidade para Plasmodium falciparum variou de $0 \%$ com o OptiMAL® a 50\% com o ICT Pf/Pv®, e para P.vivax foi de $0 \%$ com ICT Pf/Pv® e de 33\% com o OptiMAL® (139). Estudo com 0 Binax NOW ICT®, demonstrou que para densidade parasitária de menos de 100 parasitos/ $/ \mathrm{l}$ a sensibilidade para Plasmodium falciparum foi de $75 \%$ e para P.vivax de $50 \%$ (36). O OptiMAL® e o ICT Pf/Pv® foram testados como possíveis estratégias diagnósticas para vigilância ativa de casos assintomáticos na Tailândia, demonstrando resultados insatisfatórios em virtude da baixa densidade parasitária que apresentava a população investigada $(28,29)$. Estudo de meta-análise de testes rápidos em populações de áreas não endêmicas demonstrou mais alta sensibilidade e menores razões de verossimilhança negativas em testes que usaram HRP-2 (19 estudos) em comparação aos que usaram pLDH (seis estudos) mas, os dados não podem ser generalizados para áreas endêmicas porque os indivíduos não-imunes podem ter a doença sintomática com menor carga parasitária o que diminui a sensibilidade do teste (84). Na tabela 4 são apresentados resultados de estudos selecionados de validação TR. 
Tabela 4 - Resultados de estudos de validação de testes rápidos, segundo tipo de teste, características da população e espécie de plasmodium.

\begin{tabular}{|c|c|c|c|c|c|}
\hline $\begin{array}{l}\text { Local e espécie } \\
\text { do parasito }\end{array}$ & Tipo de Teste & $\begin{array}{c}\text { Sensibilidade } \\
\%\end{array}$ & $\begin{array}{c}\text { Especificidade } \\
\%\end{array}$ & $\begin{array}{l}\text { Padrão- } \\
\text { ouro }\end{array}$ & $\begin{array}{c}\text { Autor } \\
\text { Principal e } \\
\text { Ano }\end{array}$ \\
\hline \multicolumn{6}{|l|}{ Áreas endêmicas } \\
\hline \multicolumn{6}{|l|}{ P. falciparum } \\
\hline & OptiMAL & 90,6 & 96,5 & $\begin{array}{c}\text { Microscopia } \\
\text { ou PCR }\end{array}$ & Ferro, 2002 \\
\hline & & 85,0 & 99,0 & Microscopia & lqbal, 2003 \\
\hline & & 88,0 & 99,0 & Microscopia & Palmer, 1998 \\
\hline & & 87,0 & 99,0 & Microscopia & lqbal, 2002 \\
\hline & & 79,3 & 99,7 & Microscopia & $\begin{array}{l}\text { Kolaczinski, } \\
2004\end{array}$ \\
\hline & ICT Pf/Pv & 81,0 & 99,0 & Microscopia & lqbal, 2002 \\
\hline & Malar-Check & 97,4 & 88,5 & Microscopia & Avila, 2002 \\
\hline & Now ICT & 95,5 & $98,7^{(1)}$ & PCR & Farcas, 2003 \\
\hline \multirow[t]{8}{*}{$\begin{array}{l}\text { Não } P \text {. } \\
\text { falciparum }\end{array}$} & OptiMAL & & & & \\
\hline & & 98,6 & 97,6 & $\begin{array}{c}\text { Microscopia } \\
\text { ou PCR }\end{array}$ & Ferro, 2002 \\
\hline & & 92,3 & 100,0 & $\begin{array}{l}\text { Microscopia } \\
\text { ou PCR }\end{array}$ & Soto, 2004 \\
\hline & & 76,0 & 99,0 & Microscopia & lqbal, 2003 \\
\hline & & 94,0 & 100,0 & Microscopia & Palmer, 1998 \\
\hline & & 79,0 & 97,0 & Microscopia & lqbal, 2002 \\
\hline & & 86,1 & 98,7 & Microscopia & $\begin{array}{l}\text { Kolaczinski, } \\
2004\end{array}$ \\
\hline & ICT Pf/Pv & 58,0 & 98,0 & Microscopia & lqbal, 2002 \\
\hline \multicolumn{6}{|c|}{ Áreas não-endêmicas } \\
\hline Plasmodium & OptiMAL & 98,0 & 100,0 & $\begin{array}{l}\text { Microscopia } \\
\text { ou PCR }\end{array}$ & Palmer, 2003 \\
\hline \multirow{2}{*}{ P. falciparum } & ICT Pf/PV & 97,0 & 90,4 & $\begin{array}{c}\text { Microscopia } \\
\text { ou PCR }\end{array}$ & Playford, 2002 \\
\hline & OptiMAL & 84,8 & 96,0 & $\begin{array}{c}\text { Microscopia } \\
\text { ou PCR }\end{array}$ & Playford, 2002 \\
\hline \multirow[t]{2}{*}{$\begin{array}{l}\text { Não } P \text {. } \\
\text { falciparum }\end{array}$} & ICT Pf/PV & 44,0 & 100 & $\begin{array}{c}\text { Microscopia } \\
\text { ou PCR }\end{array}$ & Playford, 2002 \\
\hline & OptiMAL & 80,0 & 97,2 & $\begin{array}{c}\text { Microscopia } \\
\text { ou PCR }\end{array}$ & Playford, 2002 \\
\hline
\end{tabular}

Nota: (1) Especificidade global 


\subsubsection{OptiMAL®}

No Brasil, o OptiMAL® é uma das marcas registradas no pais e que se encontra em uso na rede do Sistema Único de Saúde (SUS).

Especificações técnicas do TR OptiMal ${ }^{\circledR}$ indicam que o teste "utiliza fitas de papel de nitrocelulose impregnadas com anticorpos monoclonal e policlonal contra a HRP-2 do Plasmodium falciparum e contra a enzima desidrogenase lática de todas as quatro espécies de plasmódio causadoras de malária. Amostras de sangue de pacientes com malária causada por Plasmodium falciparum reagirão com os anticorpos dirigidos contra a HRP-2 e contra a pDHL do Plasmodium falciparum e a reação é revelada pelo surgimento de duas bandas de imunoprecipitação de complexos imunes na fita de papel de nitrocelulose. As amostras de sangue infectadas com as outras espécies de plasmódio reagirão apenas com o seu respectivo anticorpo dirigido contra a $\mathrm{pDHL}$, sendo a reação revelada pelo surgimento de uma única banda de imunoprecipitação na fita" (trecho do relatório técnico da OPAS, elaborado por Fontes) (126).

Os anticorpos empregados no teste OptiMal $^{\circledR}$ foram largamente testados e não apresentaram evidência de reação cruzada com outros protozoários, como Leishmania, Babesia, bactérias patogênicas e fungos (114).

Segundo Fontes, "uma limitação do teste OptiMa ${ }^{\Theta}$, assim como de outras testes similares, é a incapacidade de identificar infecções mistas por plasmódio, uma vez que a reação simultânea de anticorpos contra as proteínas HRP-2 e pDHL é interpretada apenas como infecção por $P$. falciparum, podendo ocorrer também em situações de co-existência desta espécie com qualquer uma das outras que causam malária humana" (126). 
O OptiMal® foi validado no Brasil no ano de 2002, como parte das atividades da "Rede Amazônica de Vigilância da Resistência às Drogas Antimaláricas no Brasil (RAVREDA), que é uma iniciativa conduzida pelo Ministério da Saúde e pela OPAS. Os seguintes centros de referência em malária participaram do estudo: Fundação de Medicina Tropical do Amazonas (Manaus - AM); Instituto Evandro Chagas (Belém - PA); Centro de Pesquisas em Medicina Tropical de Rondônia (Porto Velho - RO); Núcleo de Estudos de Doenças Tropicais de Mato Grosso (Cuiabá - MT) e Centro de Referência de Doenças Tropicais do Amapá (Macapá - AM). O estudo de validação foi feito em condições controladas de laboratório, sendo os kits armazenados em condições ótimas de refrigeração e umidade em geladeiras com temperatura entre $4^{\circ} \mathrm{C}$ a $8^{\circ} \mathrm{C}$. O padrão-ouro foi a gota espessa. Para a determinação do tamanho amostral foram considerados os seguintes parâmetros: $80 \%$ dos pacientes com malária com teste positivo, amplitude do intervalo de confiança de 0,08 e significância de 5\%. Participaram do estudo 539 pacientes com suspeita de malária causada por Plasmodium falciparum ou Plasmodium vivax com diferentes níveis de parasitemia. Noventa e um pacientes (17\%) foram positivos para Plasmodium falciparum e 113 (21\%) para Plasmodium vivax no exame da gota espessa. A gota espessa foi negativa em 335 (62\%) pacientes. Os resultados da validação do TR investigado estão descritos abaixo (126):

- Sensibilidade global para o diagnóstico de malária: 93,6\%;

- Especificidade global para o diagnóstico de malária: 99,4\%

- Valor Preditivo negativo: 96,2\%

- Plasmodium falciparum

- Sensibilidade $-95,6 \%$

- Especificidade - $99,5 \%$

- Valor Preditivo Positivo - $97,8 \%$ 
- Plasmodium vivax

- Sensibilidade $-92,0 \%$

- Especificidade $-100,0 \%$

- Valor Preditivo Positivo $-100 \%$

Diversos estudos demonstram que a sensibilidade e a especificidade do OptiMAL $\circledast$ são comparáveis com as da microscopia em densidade parasitária acima de 100 parasitos $/ \mu l$ de sangue e o teste pode ser usado por pessoas relativamente inexperientes para diagnosticar malária em áreas rurais onde as facilidades de microsocopia não estão disponíveis $(55,126$, 130).

No Brasil, o PNCM indica o uso de TR "em áreas de baixa endemicidade ou difícil acesso" (102) e têm sido comprados para uso na área extra-amazônica e na área amazônica para as localidades de difícil acesso. A compra de 50.000 testes da marca OptiMAL® realizada pelo PNCM no ano de 2005 (34) teve um custo de $R \$ 9,28$ reais por teste ou US\$ 3,82 [pela cotação média do dólar para o ano de 2005 , de $\mathrm{R} \$ 2,43$ por dólar] (13) e no Estado do Pará, a compra também de 50.000 testes no mesmo ano teve o custo por teste de $R \$ 10,69$ (Processo $n^{0 .} 118630 / 05-$ informação interna da Secretaria de Estado de Saúde do Pará - dados não publicados) ou US $\$ 4,40$ (pela mesma cotação acima citada). Proposta do laboratório produtor para o Governo do Estado do Amazonas no ano de 2007 orçou o teste em $R \$ 7,79$ reais por kit individual (proposta de venda do laboratório DiaMed - dados não publicados).

Os custos são percebidos como o maior obstáculo para a disseminação do uso dos TR; no entanto, isto é contrabalançado pelos custos de organização, supervisão, controle de qualidade e treinamento de pessoal que devem ser mais baixos para os TR em comparação à microscopia; por outro lado, parece improvável que a introdução dos TR resulte em economia em áreas de alta transmissão onde se utilizam drogas 
relativamente baratas. A maior economia deve ocorrer em áreas de baixa a moderada transmissão onde a microscopia não é disponível ou é de baixa qualidade e onde a resistência a drogas leva ao uso de terapêutica mais cara. $O$ custo dos TR inclui não somente o custo da fabricação, mas também os custos de distribuição, taxas de importação e taxas locais. Estas taxas podem ser reduzidas por meio de intervenções estatais. Outra abordagem na redução de custos é a transferência de tecnologia e a produção local (168).

A tomada de decisão nas abordagens diagnósticas deve ser baseada em dados quantitativos como o custo-efetividade das diferentes alternativas e em diferentes cenários. Os TR e a microscopia oferecem vantagens complementares e a identificação de circunstâncias que permitam a melhor sinergia entre os dois tipos de testes fornecerá a ótima utilização em termos de custos assim como de benefícios à saúde. Outro ponto importante a ser discutido é o efeito potencial do uso dos TR no sistema de vigilância. A adoção dos TR como diagnóstico em uma determinada área, ou em um país, pode modificar a notificação de casos com conseqüências para o sistema de vigilância; portanto, o adequado planejamento desta transição de um sistema a outro é indicado, para evitar interrupções ou outros efeitos na notificação de casos (168).

\subsubsection{Outros métodos diagnósticos para malária}

Outros métodos diagnósticos estão disponíveis para o diagnóstico da malária, mas não são úteis para aplicação ampla no campo e também não são úteis para o manejo de rotina da doença; incluem: 
- Microscopia usando fluorocromos como a laranja acridina - que pode ser realizada em esfregaços sanguíneos ou em sangue centrifugado (técnica QBC - quantitative buffy coat); é cara e requer equipamentos e suprimentos especiais (168).

- PCR - prova mais sensível e específica do que todas as outras técnicas; entretanto, é um processo complexo que requer equipamentos e reagentes especializados assim como condições de laboratório que geralmente não são disponíveis no campo. A maior vantagem no uso da PCR é a habilidade para detectar parasitos em pacientes com baixos níveis de parasitemia e identificá-los no nível de espécie (114).

Vários fatores determinam a escolha do método diagnóstico a ser usado em determinada área geográfica. Estes incluem o nível de endemicidade, prevalência, tipo de resistência a drogas, acessibilidade geográfica, características socioeconômicas, infra-estrutura de saúde e instrumentos diagnósticos disponíveis (168). 


\subsection{AVALIAÇÃO ECONÔMICA EM SAÚDE}

A avaliação econômica em saúde tem por objetivo analisar de forma sistemática os benefícios e os custos de ações e de tecnologias, de modo a que a implementação das intervenções seja a mais eficiente possível. $O$ avanço tecnológico, a oferta cada vez maior de alternativas terapêuticas, preventivas e diagnósticas e a conseqüente demanda imposta aos serviços de saúde para a incorporação de novas tecnologias em um cenário de recursos financeiros finitos levou a que os serviços de saúde buscassem respostas quanto ao uso eficiente desses recursos $(140,164)$.

A avaliação econômica em saúde utiliza métodos analíticos para identificar, medir, valorar e comparar, de forma sistemática, os custos e conseqüências de estratégias de prevenção ou de terapêuticas alternativas. Os métodos analíticos usados são: 1) análise de custo da doença; 2) análise de custo do programa; 3) análise de custo-efetividade; 4) análise de custoutilidade (ou custo-preferência); 4) análise de custo-minimização; e 5) análise de custo-benefício.

Os estudos econômicos não devem ser a única base para tomada de decisão, mas os métodos têm sido difundidos, nas últimas décadas, entre os gestores de saúde, que enfrentam freqüentes desafios para os quais devem responder a algumas questões-chave para tomar a decisão por uma ação ou outra, principalmente quando nesta decisão está envolvida a questão de "custos" ou quando se deseja avaliar o máximo impacto causado pela introdução de uma nova tecnologia $(50,140)$.

A avaliação de tecnologias em saúde (ATS), porém, não necessariamente incorpora estudo econômico. Produtos que comprovadamente são mais efetivos em relação à alternativa e apresentam um custo global menor são, por definição, mais eficientes e devem ser implantados; o conceito de eficiência, neste contexto, incorpora a efetividade 
e os recursos envolvidos com a intervenção (140). A maioria das novas tecnologias, no entanto, vem associada a um custo maior e se tiverem efetividade similar em relação às alternativas existentes é indispensável o cálculo da diferença de custos entre as estratégias por meio de estudos de custo-minimização (140). Muitas vezes, além dos custos adicionais, as novas tecnologias trazem efeitos adicionais, tornando-as mais caras e mais efetivas em relação à tecnologia padrão usada, exigindo então que estas diferenças sejam analisadas por meio de outros métodos de avaliação econômica (140), como os estudos de custo-efetividade, muito utilizados na área da saúde e que têm sido discutidos e aperfeiçoados desde a década de 1970 (164). A valorização da avaliação econômica na gestão pública, porém, é, no mundo todo, um fenômeno mais recente na saúde.

A Austrália foi o primeiro país a incorporar estudos econômicos para as áreas de regulação e ATS, especialmente para a adoção de novas práticas (140, 155). Em 1993, o Pharmaceutical Benefits Advisory Commitee australiano passou a exigir estudos econômicos para a decisão de incorporação de novos medicamentos destinados à distribuição à população sendo a relação de custo-efetividade o mais importante critério para a decisão $(140,155)$.

Modelos similares de gestão de regulação e de ATS foram adotados consecutivamente em outros países dos continentes americano e europeu. O Canadá, em 1994, e os Estados Unidos, em 1998, embora não de forma tão determinante como na Austrália, passaram a orientar por meio de suas agências a necessidade de inclusão de estudos econômicos quando da submissão de processos para incorporação de novas tecnologias. $\mathrm{Na}$ Europa, o rigor também não é o mesmo encontrado no modelo australiano, mas a Inglaterra é o país com maior vulto em termos de política de uso de estudos econômicos para a tomada de decisão de incorporação de tecnologias. Outros países europeus que também introduziram a avaliação 
econômica como um dos requerimentos solicitados pelas agências foram Bélgica, Finlândia, Noruega, Portugal, Suécia e Hungria (155).

No Brasil a valorização da avaliação econômica como parte da tomada de decisão é um processo recente e ainda incipiente. Fatos de destaque na história brasileira que fortaleceram o uso de estudos econômicos em saúde, paralelamente a outras metodologias, foram: 1) criação da área de ATS na Secretaria de Ciência e Tecnologia e Insumos Estratégicos (SCTIE) em 2003, com os seguintes propósitos: promover estudos de ATS para subsidiar a tomada de decisão no SUS, em relação à incorporação, alocação e utilização de tecnologias, com base em critérios de segurança, eficácia, efetividade, impacto econômico e social, requisitos éticos e equidade; monitorar a utilização de tecnologias já incorporadas no SUS; capacitar os gestores e profissionais de saúde; e disseminar resultados de ATS para gestores; 2) criação da Comissão para Incorporação de Tecnologias do Ministério da Saúde, em 2006, responsável por gerenciar o processo de incorporação de tecnologias para o SUS; 3) construção da Política Nacional de Gestão de Tecnologias em Saúde, em fase de finalização no ano de 2008; e 4) estruturação da Rede Brasileira de Avaliação de Tecnologias em Saúde, que agrega profissionais de gestão, pesquisa e ensino, com o objetivo de produzir avaliações para qualificar as decisões no âmbito da gestão pública $(97,98)$.

A SVS, por seu turno, iniciou a partir de 2004 uma linha de financiamento de estudos de custo-efetividade de novas vacinas para subsidiar a decisão de incorporação no Programa Nacional de Imunização, constituindo-se a primeira experiência formal dessa secretaria com estudos econômicos em apoio à tomada de decisão pelos gestores (122). 


\subsubsection{A Análise de Custo-Efetividade}

A análise de custo-efetividade (ACE), bastante estudada desde a década de 1970 (164) é, atualmente, o método de avaliação econômica mais comumente empregado. Compara, sistematicamente, os custos e conseqüências de intervenções de saúde para prevenção, diagnóstico ou tratamento, dentre as opções que possuem um efeito comum; a sua medidasumário é a razão de custo-efetividade. Os resultados são apresentados como "razão de custo por unidade de desfecho de saúde", como por exemplo, o "custo por casos prevenidos da doença" ou "custo por mortes evitadas" ou o "custo por anos de vida salvos" (48).

Geralmente os dados de efetividade e impacto estão mais prontamente disponíveis e também são mais facilmente compreensíveis pelos usuários das informações. A ACE é especialmente útil e indicada quando o objetivo é identificar a estratégia mais custo-efetiva dentre um conjunto de alternativas que produzem o mesmo efeito e que competem entre si $(48,140)$. O uso de ACE é limitado, porém, quando se deseja comparar intervenções que resultam em impactos de saúde distintos ou quando se avaliam resultados de diferentes estudos de ACE que consideram diferentes medidas de impacto, não sendo possível, nessas situações, comparar as razões de custo-efetividade resultantes (140).

A evidência sobre o custo-efetividade de intervenções é geralmente usada para instruir decisões quanto à alocação de fundos do setor público, ajudando a identificar as intervenções que representam o melhor uso para os recursos (50). Devido aos benefícios em ACE serem medidos em termos de desfechos de saúde não é possível comparar os benefícios de investimentos em saúde com outros tipos de investimentos, como, por exemplo, em educação ou infra-estrutura. Assim, a ACE não pode ser usada como argumento para advogar aumento de orçamento público entre setores (51). 
Para a análise da efetividade e para se estimar os estados de saúde que ocorrem durante ou após uma intervenção, deve-se conhecer a cascata de eventos, considerando-se todos aqueles que tenham impacto na saúde do paciente ou que gerem custos. Existem diversos modelos que simulam esta seqüência de eventos e a metodologia mais utilizada nos estudos de ACE é a "análise de decisão", que é o uso de métodos analíticos para instruir decisões complexas sob condições de incerteza, nos quais as "probabilidades" dos eventos e suas conseqüências são explicitamente declaradas. Após a determinação do tipo de desfecho a ser avaliado e da seqüência de eventos, realiza-se a estimativa numérica dos efeitos das intervenções consideradas na análise $(26,48,140)$.

O método de análise de decisão é composto das seguintes etapas: 1) identificação e estruturação do problema considerando as estratégias alternativas disponíveis; 2) estruturação do problema e da decisão descrevendo todos os eventos que se seguem ou são conseqüência de cada uma das estratégias avaliadas; deste modo, são identificadas as alternativas de decisão e os possíveis eventos dentro de cada alternativa, utilizando, por exemplo, a árvore de decisão; 3) identificação das estimativas de probabilidade de cada um dos ramos da árvore, devendo as somas das probabilidades ser igual a 1 (100\%); 4) identificação e mensuração dos valores de custos correspondentes; e 5) determinação do desfecho final para cada um dos ramos da árvore para quantificá-los, identificar e mensurar os possíveis impactos $(26,140)$.

Etapas essenciais na ACE, além das já citadas acima, são: levantamento detalhado dos itens de custos; a aplicação de taxa de desconto aos custos e impactos - quando estes se estendem por vários anos - para trazê-los ao valor presente; o cálculo das razões de custo/desfecho de saúde; a análise de sensibilidade dos resultados; e a discussão das limitações do estudo, considerando as imprecisões do método (48). 
O levantamento de custos é uma etapa crucial da ACE e deve ser feito a partir da perspectiva que o estudo assumirá, a qual poder ser, por exemplo, a dos serviços públicos, dos serviços privados, da sociedade etc. Uma análise pode, outrossim, ser desenvolvida sob mais de uma perspectiva (22).

O nível de detalhe a ser assumido em um levantamento de custos varia com os objetivos do estudo. Existem dois métodos complementares usados em estudos de ACE: 1) Gross-costing; e 2)Micro-costing. O primeiro método tem a vantagem de ser mais rápido e com maior possibilidade de generalização, porém é menos preciso, sendo apropriado quando o objetivo do estudo é fornecer um impressão global dos custos totais. O micro-costing é um método mais laborioso que fornece um inventário detalhado dos itens de custos e melhor visão do relacionamento entre as características das atividades e seus custos; é mais preciso e menos generalizável. A escolha do método a ser usado em estudos de ACE dependerá do nível de precisão requerido, do escopo desejado de generalização e da factibilidade para sua execução por parte do pesquisador. Muitas vezes, os estudos usam uma combinação dos dois métodos na composição dos custos finais (22).

A razão de custo-efetividade, dada pelo "custo líquido por desfecho natural de saúde", é calculada por meio da divisão entre o custo total e os benefícios medidos em unidades de saúde. A estratégia mais custo-efetiva, dentre as consideradas, é a que apresentar a mais baixa razão (50). É uma medida de cunho subjetivo e relativo, não significando custo-poupado. Tendo acesso às razões de custo-efetividade os tomadores de decisão farão julgamento de valor como, por exemplo: "Dados os custos quantificados e os benefícios, o custo final vale a pena?"(26).

A razão média de custo - efetividade é a razão entre os custos e desfechos (efetividade) para uma única intervenção (estratégia A). É utilizada para intervenções independentes e para alocar recursos. A maioria 
dos estudos de ACE relata e compara as razões médias de custo-efetividade para cada uma das estratégias avaliadas. É dada por:

\section{$\mathrm{R}$ média $\mathrm{CE}=$ (custo da estratégia $\mathrm{A}) /($ desfecho da estratégia $\mathrm{A})$}

A razão de custo - efetividade adicional (RCEA) é a razão de custos adicionais para desfechos obtidos (efetividade) quando uma intervenção é comparada com a intervenção efetiva mais próxima. É utilizada para intervenções mutuamente excludentes e competitivas e para alocar recursos. Considera a diferença entre as duas estratégias sendo a medida de maior aplicabilidade para a tomada de decisão e deve ser usada para orientar incorporação de tecnologias, como a tecnologia diagnóstica. É dada por:

$R$ adicional CE = [(custo da estratégia $B)-($ custo da estratégia $A) /$ (desfecho da estratégia B) - (desfecho da estratégia A)]

Considera-se para países de baixo desenvolvimento sócio-econômico (Produto Interno Bruto - PIB - per capita abaixo de US\$315) que estratégias "altamente atrativas" em relação ao uso dos recursos, são aquelas em que a razão de custo-efetividade adicional (RCEA), representada por "custo por AVAI evitado" situa-se abaixo de US $\$ 25$ e "atrativas" se situadas abaixo de US\$ $150(50,148)$.

A OMS sugere os seguintes limiares para interpretação da RCEA: as intervenções com RCEA abaixo do PIB per capita são consideradas muito custo-efetivas; aquelas com RCEA até 3 vezes o valor do PIB são consideradas custo-efetivas; e aquelas com mais de três vezes o valor do PIB, não são consideradas custo-efetivas (173).

É importande destacar que os estudos de ACE subsidiam a decisão por parte dos gestores, mas não são os únicos critérios para determinar uma 
decisão. Outros valores subjetivos como a ética e as noções de igualdade e equidade devem ser considerados paralelamente ao custo-efetividade, assim como a disponibilidade e o acesso à tecnologia considerada.

\subsubsection{Custo-Efetividade de Estratégias de Diagnóstico, Prevenção e Tratamento da Malária}

Estudos de custo-efetividade de diversos aspectos relacionados à malária já foram realizados, tais como uso de drogas, avaliação de testes diagnósticos, estratégias de combate ao vetor, ou estratégias de controle em diferentes populações $(31,46)$.

Na Tailândia foi desenvolvido um modelo interativo epidemiológico e bioeconômico para subsidiar a tomada de decisão em relação ao esquema de tratamento da malária, considerando a resistência às drogas antimaláricas. No modelo, a razão de custo-efetividade é estimada considerando diversos esquemas terapêuticos. O modelo incorpora informações das drogas, dos parasitos, da imunidade do hospedeiro e de fatores econômicos; e por meio de variação nos seus parâmetros, os custos e a efetividade em termos de casos e de custos evitados são comparados (179).

Estudo de revisão de 14 análises de ACE realizadas na África Subsaariana, considerando diversas estratégias, entre as quais, mosquiteiros impregnados com inseticidas para a prevenção e controle, quimioprofilaxia no pré-natal, quimioprofilaxia na infância, novas drogas para tratamento de primeira linha na infância e vacinação hipotética, discute as lacunas existentes nas informações de custos e efeitos das diversas estratégias naquela realidade e indica a necessidade de que estudos de intervenção incluam avaliação econômica e que sejam aperfeiçoados os métodos para coleta tanto de custos como de efetividade, uma vez que 
estas lacunas nos dados limitam bastante a aplicação dos métodos de avaliação econômica (46). Na África também está em debate que o uso de dados de ACE de diversas intervenções para controle de epidemias de malária é uma grande necessidade, para apoiar a tomada de decisão em situações de emergência (178). Outro estudo, também conduzido na África Subsaariana, analisou sete intervenções para controle da malária e demonstrou que a alta cobertura da combinação de tratamento baseado em derivados da artemisinina foi a estratégia mais custo-efetiva para o controle da doença naquele contexto quando comparada a mosquiteiros impregnados com inseticidas; dedetização intra-domiciliar residual; manejo dos casos com cloroquina; manejo dos casos com sulfadoxina e pirimetamina; manejo dos casos com a cloroquina, sulfadoxina e pirimetamina associadas; e tratamento presuntivo e intermitente com sulfadoxina e pirimetamina durante a gravidez (115). As análises das intervenções na África, em países de condições socioeconômicas muito baixas, evidenciaram estratégias bastante atrativas de menos de 25 dólares por AVAl evitado, como por exemplo: a impregnação de mosquiteiros estimada em 4-10 dólares por AVAl evitado para uma aplicação anual quando não é necessária a distribuição dos mosquiteiros; borrifação de efeito residual em 16-29 dólares por AVAl evitado; e o tratamento intermitente de mulheres gestantes por meio de serviços de pré-natal em 429 dólares por AVAl evitado, corroborando a prática dessas intervenções para o controle da doença $(45,50)$.

No Brasil foi realizada ACE para avaliar projeto implementado no período de 1989 a 1996 por meio de recursos de empréstimo do Banco Mundial, o qual tinha como principal objetivo o controle da malária na Região Amazônica. O projeto previa ações de diagnóstico e tratamento e de controle vetorial. Comparando o projeto implementado com a "ausência do programa", estimou-se que 1,83 milhões de casos, 231.000 mortes e 8,97 milhões de AVAl foram evitados no período. A RCEA do projeto foi de 64-69 dólares por AVAI evitado (6). 
A avaliação econômica de testes diagnósticos para malária é menos difundida na literatura científica e foram encontrados apenas cinco relatos de estudos que realizaram análise de custo-eftividade $(24,37,77,146,148)$, um de custo-benefício (78) e um de custo-minimização (133); todos os estudos analisaram TR, utilizando a microscopia como a estratégia de comparação. A razão de custo-benefício e a de custo-efetividade dos TR variaram dependendo da acurácia dos testes em análise, do cenário epidemiológico, dos custos do tratamento, dos objetivos da intervenção e do custo do próprio TR $(50,170)$.

\subsection{TESTE RÁPIDO PARA O DIAGNÓSTICO DA MALÁRIA NO BRASIL E AVALIAÇÃO ECONÔMICA}

O PNCM indica o uso de TR em "áreas de baixa endemicidade ou difícil acesso" (102), onde se torna operacionalmente complicada e muitas vezes inviável, a manutenção de diagnóstico por microscopia de forma permanente. O Programa comprou, no ano de 2006, TR da marca OptiMAL® para uso em áreas fora da Região Amazônica e para áreas endêmicas distantes de laboratórios especializados no diagnóstico $(34,102)$.

Tanto a indicação como a compra do TR foram feitas sem avaliação econômica prévia e baseadas nas facilidades operacionais relativas ao uso de TR em áreas remotas.

Uma das grandes dificuldades no diagnóstico da malária é o fato de o diagnóstico laboratorial basear-se quase exclusivamente na microscopia uma técnica de grande valor somente quando corretamente executada. As dificuldades ou a ausência do diagnóstico laboratorial podem levar a situações que causam impactos negativos sobre o controle da doença, como o atraso na instalação da quimioterapia - com conseqüente aumento das formas graves e da mortalidade - e a possível emergência de 
multidrogarresistência por tratamentos auto-administrados ou inadequados. Uma melhor utilização da microscopia e o desenvolvimento de técnicas diagnósticas alternativas acarretariam substancial reforço no controle da malária. A microscopia e os testes rápidos, usados corretamente, podem contribuir para o melhor e mais custo-efetivo manejo da malária e para reduzir o uso de drogas antimaláricas quando não indicadas. Questiona-se, ainda, se os TR seriam os substitutos da microscopia, face às vantagens que apresenta.

A análise de custo-efetividade (ACE) está indicada no diagnóstico da malária porque as alternativas diferem significantemente entre si e os recursos em questão são expressivos. Neste contexto, estudos de ACE são oportunos para a tomada de decisão e foram indicados pela Organização Pan Americana da Saúde para subsidiar a implantação dos testes rápidos nas Américas (128). A partir da definição dos cenários epidemiológicos prioritários, a ACE para os testes diagnósticos será um importante subsídio para avaliação da estratégia. Os tomadores de decisão poderão, por exemplo, utilizar os resultados para discutir que estratégias serão utilizadas e em que áreas geográficas.

Neste trabalho foi realizada ACE tendo como referência o TR da marca OptiMAL ${ }^{\circledR}$, com base na hipótese de substituição de uma tecnologia pela outra. A escolha desta marca comercial decorre do fato de ser um teste que diagnostica Plasmodium falciparum e outras espécies não falciparum; ter sido validado em áreas endêmicas do Brasil (126); ter sido implantado em áreas distantes da Amazônia, como em municípios do Estado do Pará; ter registro para uso no país (3); ser fabricado por laboratório com filial no Brasil e, principalmente, por ser um teste extensivamente validado no mundo todo, com ampla literatura disponível em diferentes situações epidemiológicas e com demonstração de sensibilidade e especificidade satisfatórias, de acordo com as exigências da OMS (168). 
A avaliação econômica de alternativas para o diagnóstico da malária é um tema prioritário para o controle da endemia no Brasil. O presente estudo objetiva contribuir para a melhor tomada de decisão em relação ao uso de TR para diagnóstico da malária no país. 


\section{OBJETIVOS}

\subsection{GERAL}

Realizar análise de custo-efetividade do uso do teste rápido OptiMAL ${ }^{\circledR}$ (Diamed), para o diagnóstico de casos novos de malária, comparado com a estratégia convencional de diagnóstico por meio da gota espessa, em um período hipotético de intervenção, no ano de 2006, em 12 municípios endêmicos para malária do Estado do Pará.

\section{2 - ESPECÍFICOS}

- Construir um modelo de análise de custo-efetividade para duas abordagens de diagnóstico da malária - teste rápido e microscopia convencional pelo método da gota espessa considerando os casos novos diagnosticados em 2006 nos 12 municípios do Estado do Pará selecionados para o estudo, como referência para as estimativas de prevalência (probabilidade préteste), proporções de infecções por espécie parasitária e faixas etárias.

- Determinar os custos associados com o diagnóstico de casos novos de malária na área de estudo.

- Determinar os custos da introdução do teste rápido para o diagnóstico de casos novos de malária na área de estudo.

- Determinar a razão de custo-efetividade adicional em reais por cada caso de malária diagnosticado pelo OptiMAL® comparado com a gota espessa.

- Discutir a incorporação do teste rápido no Programa Nacional de Controle da Malária a partir dos resultados de custo-efetividade, identificando cenários prioritários para a incorporação do teste rápido. 


\section{MÉTODOS}

\subsection{TIPO DE ESTUDO E MODELO DE ANÁLISE DE CUSTO- EFETIVIDADE}

Foi realizada análise de custo-efetividade, usando o modelo de decisão analítico. Árvores de decisão foram construídas (figuras 3 e 4) e as probabilidades dos eventos foram considerados para uma dada coorte populacional, em uma perspectiva temporal linear.

A árvore de decisão desenvolvida começa com paciente ambulatorial apresentando síndrome febril ou outros sinais/sintomas que chega aos postos de saúde ou aos laboratórios de diagnóstico parasitológico do SUS. Os parâmetros epidemiológicos consideraram 12 municípios endêmicos para malária no Estado do Pará.

\subsection{ESTRATÉGIAS AVALIADAS}

Foi avaliado o teste rápido da marca OptiMAL® para o diagnóstico de casos novos de malária por Plasmodium falciparum e Plasmodium vivax, em comparação à estratégia convencional de diagnóstico - microscopia, pelo método da gota espessa.

\subsection{PERSPECTIVA DA ANÁLISE}

Os custos considerados e mensurados na análise foram aqueles assumidos pelo sistema público de saúde brasileiro; a análise foi realizada sob essa perspectiva, uma vez que o SUS é o provedor e financiador do diagnóstico e tratamento dos casos de malária nos serviços de saúde. 


\subsection{PERÍODO DE INTERVENÇÃO}

O período de intervenção foi de um ano, sendo considerados para tal, os dados epidemiológicos do ano de 2006. Os casos novos diagnosticados em 2006, nos 12 municípios endêmicos para malária no Estado do Pará, foram a referência para a prevalência de malária na população sintomática ou que procura diagnóstico (corresponde à probabilidade pré-teste), número de casos de malária por Plasmodium falciparum e Plasmodium vivax e a distribuição dos casos de malária por faixas etárias.

\subsection{DESFECHOS DE INTERESSE}

A análise foi realizada para os seguintes desfechos de interesse: casos de malária diagnosticados adequadamente e casos de malária conduzidos adequadamente em termos de manuseio terapêutico. $O$ segundo desfecho é uma conseqüência direta da acurácia do diagnóstico. A estrutura da árvore de decisão para os dois desfechos de interesse está apresentada nas figuras 3 e 4 .

\subsection{HORIZONTE ANALÍTICO}

Foram considerados dois horizontes analíticos de acordo com os desfechos. O primeiro, a partir da suspeita de malária até o diagnóstico concluído e o segundo a partir da investigação diagnóstica até a adequada condução terapêutica e a cura ou não cura nos casos de malária, com até 6 meses de observação. Os desfechos relacionados ao diagnóstico e à indicação do esquema de tratamento da malária são conseqüentes às estimativas de prevalência (probabilidade pré-teste) e das sensibilidade e especificidade de ambas as estratégias. 


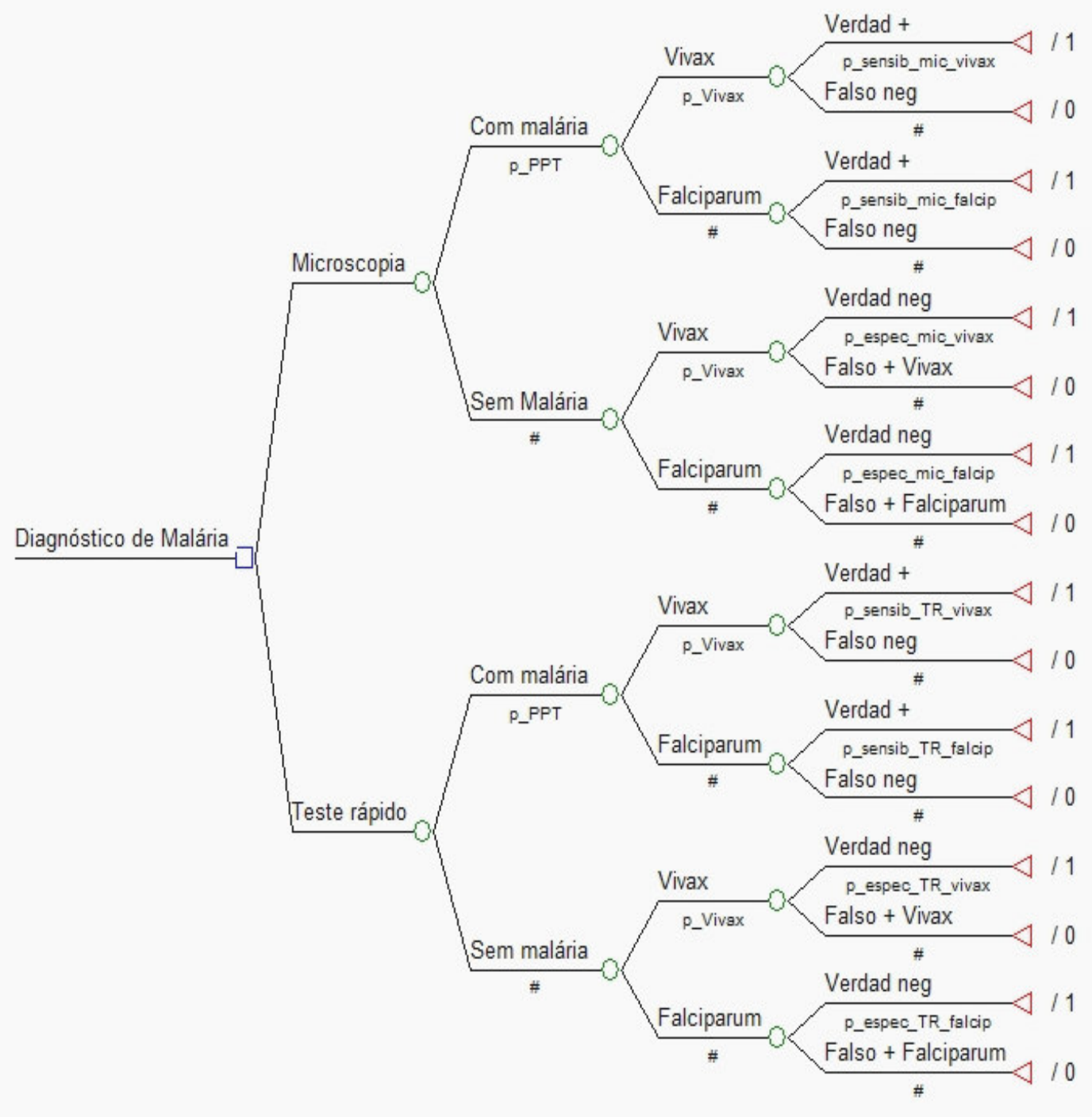

Figura 3 - Estrutura da árvore de decisão para o desfecho "casos diagnosticados adequadamente". 


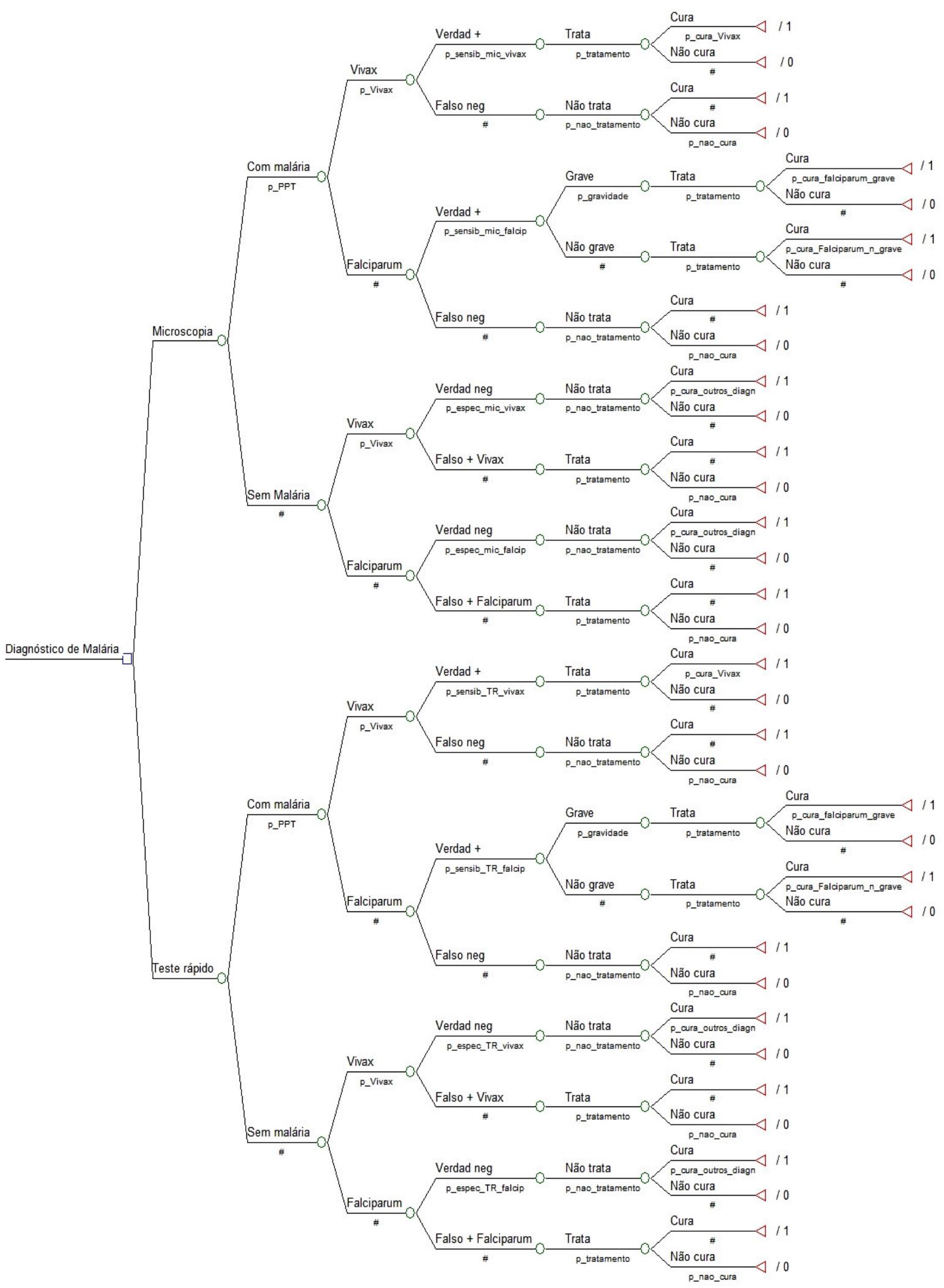

Figura 4 - estrutura da árvore de decisão para o desfecho "casos conduzidos adequadamente" 


\subsection{DESCRIÇÃO DA ÁREA DE ESTUDO}

\subsubsection{Descrição Geral dos Municípios}

A área de estudo corresponde a 12 municípios endêmicos para malária, do Estado do Pará, onde foi implementado no período de 2004 a 2006 pela Secretaria de Estado da Saúde o diagnóstico com o teste rápido OptiMal®. Os municípios são: Santana do Araguaia e São Félix do Xingu, da 12ª . Regional de Saúde; Marabá, Goianésia do Pará, São Geraldo do Araguaia, Novo Repartimento, Jacundá, Nova Ipixuna e Baião, da 11a․ Regional de Saúde; e Itaituba, Novo Progresso e Jacareacanga, da 9a Regional de Saúde. Os municípios estão indicados na Figura 5. Em conjunto correspondem a uma área geográfica não-contínua de $297.457 \mathrm{~km}^{2}$ com uma população total estimada para o ano de 2006 de 650.351 hab. $(108,109)$. O Estado do Pará definiu o uso do teste rápido para áreas de alto risco e para as localidades isoladas ou de difícil acesso, como parte da estratégia de busca ativa de casos.

As características de cada município quanto ao número de habitantes, área territorial, PIB, PIB per capita, Índice de Desenvolvimento Humano Municipal (IDH-M), situação do domicílio, distribuição da população por sexo, faixas etárias, rendimento médio mensal domiciliar e escolaridade estão apresentadas nos anexos 1 a 6 . $(108,109,111)$.

O PIB per capita dos 12 municípios para o ano de 2006 variou de $\mathrm{R} \$$ 1.203,00 para o município de Jacareacanga - um dos mais baixos do país a $\mathrm{R} \$ 11.182,00$, para o Município de São Félix do Xingu. Como pontos de comparação, o PIB per capita para o Brasil no ano de 2006 foi de $R \$$ $12.437,00$ e para o Estado do Pará de $\mathrm{R} \$ 4.991,00(107,108)$. Quanto ao IDH-M medido para o ano 2000, variou na área de estudo de 0,626 para o Novo Repartimento a 0,714 para Marabá (141). 


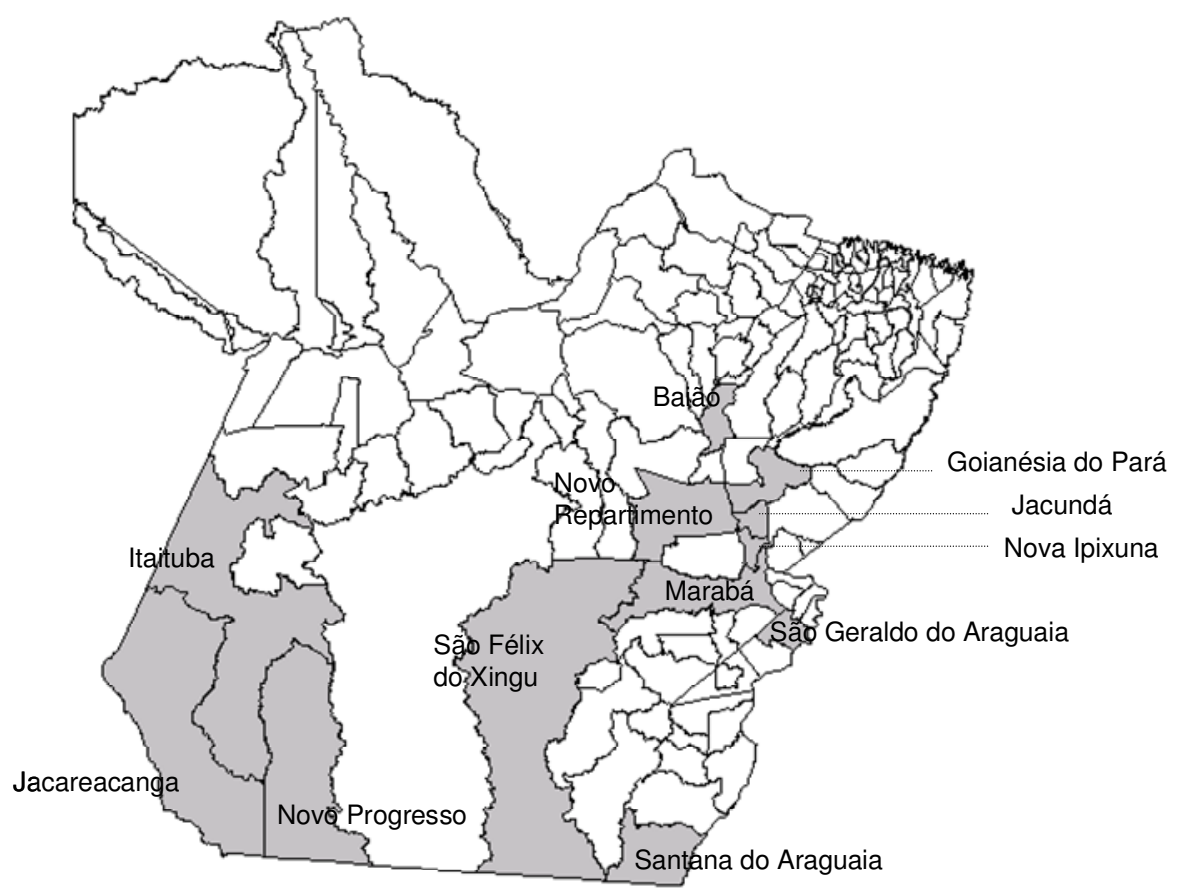

Fonte: IBGE- Ministério do Planejamento, Orçamento e Gestão.

Figura 5 - Mapa do Estado do Pará com a localização geográfica dos 12 municípios do estudo. Pará, 2006 


\subsubsection{Características da Organização dos Serviços de Atenção Básica e de Diagnóstico de Malária dos 12 Municípios}

Em relação aos serviços de diagnóstico da malária no ano de 2006, todos os 12 municípios possuíam laboratórios que realizavam a microscopia. Abaixo, na tabela 5, está demonstrado o número de laboratórios ativos para o diagnóstico da malária em cada município, naquele ano, que corresponde no total, a $27,3 \%$ do número de laboratórios do Estado do Pará (91). As localidades dos 12 municípios onde se utilizou o teste rápido são consideradas, em geral, de difícil acesso.

Tabela 5 - Distribuição dos 12 municípios do Estado do Pará de acordo com o número de laboratórios ativos para diagnóstico de malária*. Pará, 2006.

\begin{tabular}{l|c}
\hline Estado do Pará e Municípios de interesse & $\begin{array}{l}\text { Número de laboratórios ativos para } \\
\text { diagnóstico de malária }\end{array}$ \\
\hline Estado do Pará & $\mathbf{6 7 0}$ \\
& 12 \\
Baião & 6 \\
Goianésia do Pará & 26 \\
Itaituba & 25 \\
Jacareacanga & 3 \\
Jacundá & 34 \\
Marabá & 3 \\
Nova Ipixuna & 15 \\
Novo Progresso & 29 \\
Novo Repartimento & 9 \\
Santana do Araguaia & 14 \\
São Félix do Xingu & 7 \\
São Geraldo do Araguaia & $\mathbf{1 8 3}$ \\
\hline Total para os 12 municípios &
\end{tabular}

Quanto à cobertura de serviços da atenção básica no ano de 2006, os 12 municípios contavam com agentes comunitários de saúde (ACS), sendo a cobertura populacional no meio do ano de 2006 de 33,47\% em Novo Progresso, 46,86\% em Jacareacanga, 50,05\% em Marabá, 58,39\% no Novo Repartimento e de $100 \%$ nos demais municípios (95). Os ACS têm um papel 
relevante no controle da malária, pois nas áreas rurais são responsáveis pela aplicação de testes imunocromatográficos ou coleta de sangue para confecção de lâmina para diagnóstico com o seu posterior envio para o local de exame microscópico; também, nas localidades rurais, executam as coletas de sangue para os exames de Lâminas de Verificação de Cura (LVC) (94).

Na Secretaria Municipal de Saúde (SMS) do Município de Novo Repartimento foi possível coletar informações in loco quanto às características da organização do serviço de saúde local de atenção a malária, que auxiliaram a elaboração das estimativas de custos, a saber:

- Na área urbana e nos laboratórios presentes na área rural, o paciente com suspeita de malária aguarda, geralmente, no máximo por 1 hora, para o resultado da microscopia - exame de gota espessa - não necessitando retornar para uma segunda consulta para conhecer 0 resultado.

- Nas áreas rurais que não têm laboratórios instalados, o diagnóstico é feito por meio de agentes de saúde que se deslocam por motocicletas, carros ou barcos para a coleta de sangue; trazem o material coletado para processamento nos laboratórios e retornam com o resultado. O diagnóstico microscópico, então, exige a logística de duas viagens dos agentes e mais o trabalho dos microscopistas.

- Quando em uso de OptiMal®, os agentes que se deslocam até as localidades aplicam o teste rápido e fornecem o resultado de imediato, assim como os medicamentos. Coletam sangue para a realização de gota espessa, entretanto, para fins de confirmação.

- O teste OptiMal® é realizado por agentes epidemiológicos do município, por agentes comunitários de saúde e também por voluntários treinados pelos agentes.

- A proporção de exames realizados, inicialmente, pelo Teste Rápido e que corresponde às localidades remotas, foi de 30\% no ano de 2006 . 
O teste rápido favoreceu o início do tratamento de forma imediata nos casos positivos, que correspondem aos casos detectados por busca ativa nas áreas afastadas dos laboratórios de microscopia. Esta informação foi básica para definição de cenários de estudo, assumindo-se a mesma proporção de exames realizados em áreas isoladas para os demais municípios.

\subsubsection{População sob Risco}

A população total estimada para o ano de 2006, para o conjunto dos 12 municípios de referência foi de 650.351 habitantes $(108,111)$.

\subsection{PARÂMETROS EPIDEMIOLÓGICOS DO MODELO}

Os parâmetros epidemiológicos do modelo para o desfecho "casos diagnosticados adequadamente" foram: 1) prevalência de malária entre pacientes que procuram diagnóstico (probabilidade pré-teste); 2) proporção de casos de malária por Plasmodium vivax; 3) proporção de casos de malária por Plasmodium falciparum; 4) sensibilidade da microscopia para Plasmodium vivax; 5) especificidade da microscopia para Plasmodium vivax; 6) sensibilidade da microscopia para Plasmodium falciparum; 7) especificidade da microscopia para Plasmodium falciparum; 8) sensibilidade do OptiMAL® para Plasmodium vivax; 9) especificidade do OptiMAL® para Plasmodium vivax; 10) sensibilidade do OptiMAL $\circledast$ para Plasmodium falciparum; e 11) especificidade do OptiMAL® para Plasmodium falciparum.

Para o desfecho "casos conduzidos adequadamente" foram utilizados todos os parâmetros acima descritos e mais os seguintes: 1) freqüência da forma grave de malária falciparum; 2) proporção de pacientes com malária vivax curados com o tratamento antimalárico; 3) proporção de pacientes com malária falciparum grave curados com o tratamento antimalárico; 4) 
proporção de pacientes com malária falciparum não-grave curados com o tratamento antimalárico e 5) probabilidade de evolução favorável para outros diagnósticos nos casos verdadeiros negativos.

As fontes dos parâmetros epidemiológicos foram: o Sistema de Informação de Vigilância Epidemiológica da Malaria - SIVEP/Malária da SVS/MS (91), literatura científica e relatório da OPAS (126). As fontes de busca para literatura científica foram: Medline, acessada pelo Pubmed, Cochrane library, SciELO, Lilacs, Centre for Reviews and dissemination e Banco de Teses da Coordenação de Aperfeiçoamento de Pessoal de Nível Superior (CAPES) do Ministério da Educação. Na tabela 6 estão apresentados os parâmetros epidemiológicos, fontes e os valores usados no modelo. 
Tabela 6 - Parâmetros epidemiológicos do modelo de custo-efetividade segundo valores do caso-base, variação e fontes de informação

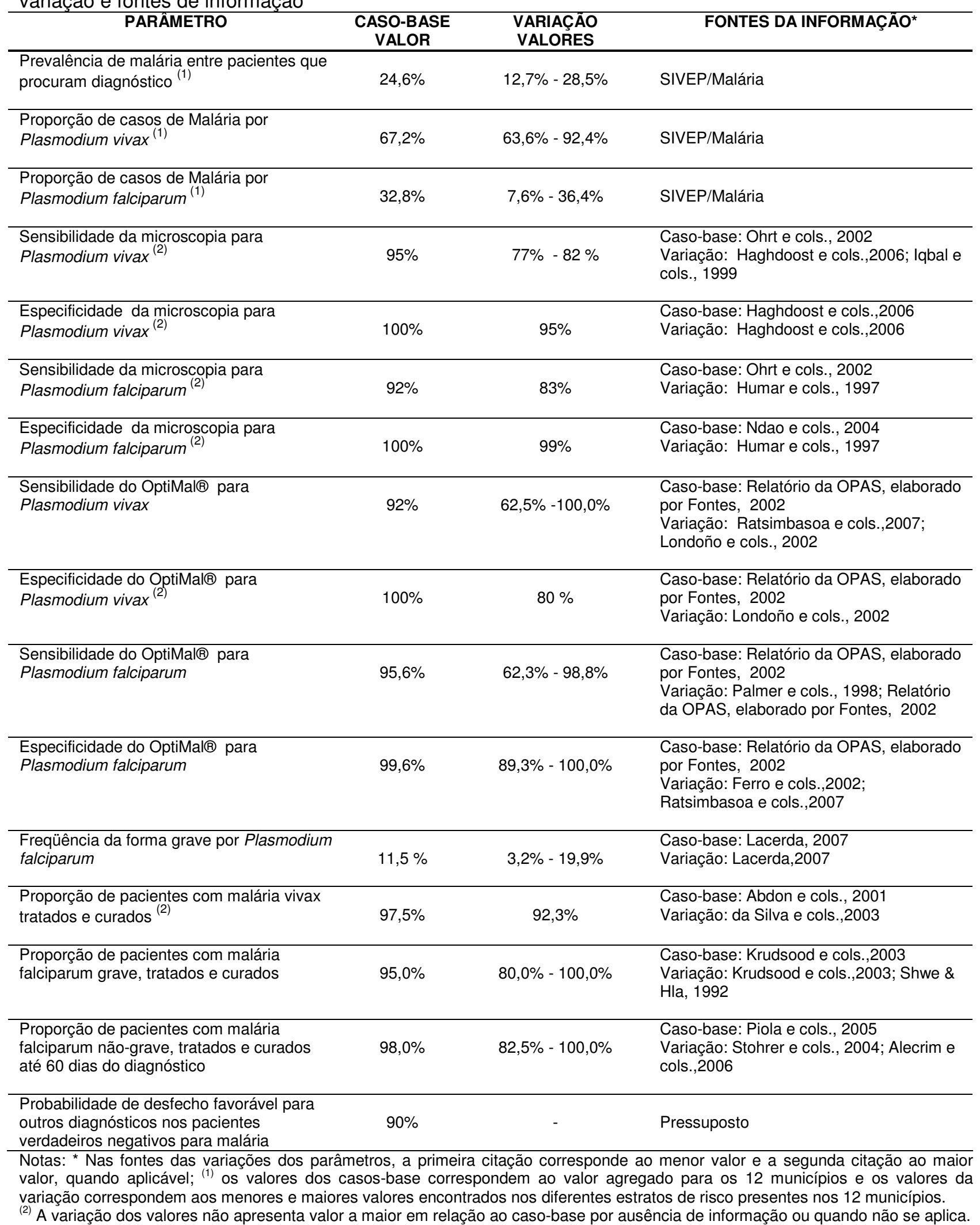




\subsection{FONTE DOS DADOS EPIDEMIOLÓGICOS DE MALÁRIA DOS 12 MUNICÍPIOS}

Por meio do SIVEP/malária (91) foram extraídos dados para estimar os seguintes parâmetros do modelo: 1) Prevalência de malária entre pacientes que procuram diagnóstico (probabilidade pré-teste - PPT); 2) Números absoluto e proporcional de casos de malária por Plasmodium vivax; 3) Números absoluto e proporcional de casos de malária por Plasmodium vivax segundo faixas etárias; 4) Números absoluto e proporcional de malária por Plasmodium falciparum; 5) Números absoluto e proporcional de malária por Plasmodium falciparum segundo faixas etárias; 6) Números absoluto e proporcioanl de mulheres gestantes com malária; e 7) Números absoluto e proporcional de casos de malária vivax e de malária falciparum nas pacientes grávidas. Os dados foram coletados do SIVEP/malária após procedimentos pertinentes de limpeza e organização do banco de dados, de acordo com os tipos de análises necessárias, conforme etapas descritas a seguir.

O ano de análise foi 2006. Os dados de 2006 foram recebidos até 30 de junho de 2007, conforme prática dos sistemas gerenciados pelo Ministério da Saúde. Os dados foram analisados no mês de agosto de 2007, a partir de um banco de dados em meio eletrônico (CD-Rom) em formato *.dbf, do Estado do Pará para o ano de 2006, obtido por meio do PNCM.

\subsection{DEFINIÇÃO DE CASOS DE MALÁRIA UTILIZADOS NA ANÁLISE E RELAÇÃO COM OS CUSTOS}

No banco de dados, na variável "resultados do exame", são registradas informações nos seguintes campos: 1)negativo; 2) falciparum; 3) falciparum mais falciparum gametócitos; 4) vivax; 5) falciparum mais vivax; 
6) vivax mais falciparum gametócitos; 7) falciparum gametócitos; 8) malariae;

9) falciparum mais malariae; e 10) ovale.

Para a identificação dos casos de malária vivax e a estimativa da sua freqüência (números absolutos e proporcionais), foram considerados os registros notificados como "vivax" e "vivax + falciparum gametócitos", de modo a se garantir que não houvesse perda de estimativas de casos de malária vivax para o parâmetro epidemiológico e para os custos de tratamento.

Para a identificação dos casos de malária falciparum e a estimativa da sua freqüência (números absolutos e proporcionais), foram considerados os registros notificados como: "falciparum" e "falciparum + falciparum gametócitos" e "falciparum + vivax" e "falciparum + malariae", captando assim todos os casos de malária falciparum para a estimativa dos casos.

Não houve registros de Plasmodium ovale no ano de 2006 e houve notificação de apenas 23 casos $(0,0 \%)$ de Plasmodium malariae de forma isolada. Devido à baixa freqüência desta espécie do parasito de forma isolada, decidiu-se pela exclusão destes casos. Os casos registrados como "falciparum gametócitos" de forma isolada também foram excluídos da definição de caso, devido a que indivíduos que apresentam essa condição não apresentam síndrome febril nem quadro clínico de malária e ainda, para o ano de 2006, para o conjunto dos 12 municípios, a presença isolada de "falciparum gametócitos", correspondeu a $0,1 \%$ dos casos.

A inclusão dos casos mistos classificados como "falciparum + vivax" e de "falciparum + malariae" na soma dos casos de malária falciparum, está justificada pelo esquema terapêutico indicado nestes casos que é o Coartem $\AA^{8}$ (88). Para os casos mistos de doença por Plasmodium falciparum e Plasmodium vivax, além do Coartem ${ }^{\circledR}$ emprega-se a primaquina do $4^{\circ}$ ao $10^{\circ}$ dias, para evitar recaídas. A definição de caso 
atende ao parâmetro epidemiológico e é básica para a estimativa de custos de medicamentos. Ao se somar todos os casos mistos para compor a "frequência de malária falciparum", já se está contabilizando os custos do Coartem ${ }^{\circledR}$ dos casos mistos. Já os custos da primaquina (indicada em malária vivax para evitar recaídas e em malária falciparum como gametocitocida) foram contabilizados da seguinte forma: custo final da primaquina $=$ custo primaquina $\mathrm{x} \%$ vivax + custo da primaquina $\times \%$ malária mista (falciparum mais vivax) + custo da primaquina $x \%$ de malária falciparum (como gametocitocida para a proporção de casos que não tem indicação de Coartem ${ }^{\circledR}$ ). Assim não se perderam estimativas de custos com o tratamento dos casos mistos e com o tratamento dos pacientes com malária falciparum que têm indicação de primaquina em dose única no $5^{\circ}$. dia de tratamento, quando em uso de esquizonticidas diferentes ao Coartem ${ }^{\circledR}$. O tratamento com Coartem ${ }^{\circledR}$ é a única situação da malária falciparum em que não há indicação absoluta para uso de primaquina, como gametocitocida.

\subsection{ANÁLISE DO BANCO DE DADOS DE MALÁRIA - SIVEP/MALÁRIA E DO BANCO DE MORBIDADE HOSPITALAR - DATASUS}

4.11.1. Preparação do Banco de Dados do SIVEP/malária com os Casos de Malária Vivax e Malária Falciparum para a Estratificação das Idades para Estimar o Custo dos Medicamentos.

O banco de dados do SIVEP/malária com os dados de notificação de casos do Estado do Pará correspondente ao ano de 2006 contém um total de 605.505 registros. $O$ arquivo, no formato *.dbf, foi importado para o software SPSS 11.0 por meio do software StatTransfer 8, convertendo-o ao formato *.sav. 
As seguintes etapas foram realizadas para o preparo e limpeza do banco de dados para estimar as faixas etárias. O número proporcional de casos em cada faixa etária foi utilizado para ponderar os custos relativos às doses dos medicamentos empregados:

- Seleção dos registros correspondentes aos 12 municípios de interesse do estudo, perfazendo 135.675 registros;

- Seleção das variáveis relevantes para o estudo: data da notificação; município da notificação; data do exame; data do nascimento; idade do paciente; sexo; gestante; tipo de lâmina; resultado do exame e esquema terapêutico;

- Exclusão de 51.825 registros que não continham a idade do paciente. Primeiro, foi feita a tentativa de resgate da idade do paciente nos registros onde ela estava ausente mas não foi possível resgatar nenhum registro por meio de procedimentos que calculassem a idade a partir da subtração da "data de nascimento" da "data de realização do exame", ou da "data de notificação", devido a que os registros que não continham a variável "idade" preenchida também não preencheram a "data de nascimento"; assim, todos os 51.825 registros foram excluídos;

- Exclusão de três registros que continham a idade registrada muito acima de 100 anos e com erros no registro da data de nascimento (ex: ano de 1658) ou com a data de nascimento ausente;

- Exclusão de 14.927 registros correspondentes aos resultados das Lâminas de Verificação de Cura (LVC);

- Exclusão de 41.254 registros de lâminas negativas;

- Exclusão de 180 registros que não atendiam à definição de caso, a saber: lâminas com presença exclusiva de gametócitos de Plasmodium falciparum ou presença exclusiva de Plasmodium malariae;

- Após os procedimentos descritos, o banco ficou definitivamente composto por 27.486 registros (Figura 6). 
O banco final com 27.486 registros foi utilizado para a estratificação por faixa etária para ambas as formas de malária, para fins de estimativas dos custos dos medicamentos de forma ponderada pela proporção de casos em cada faixa etária.

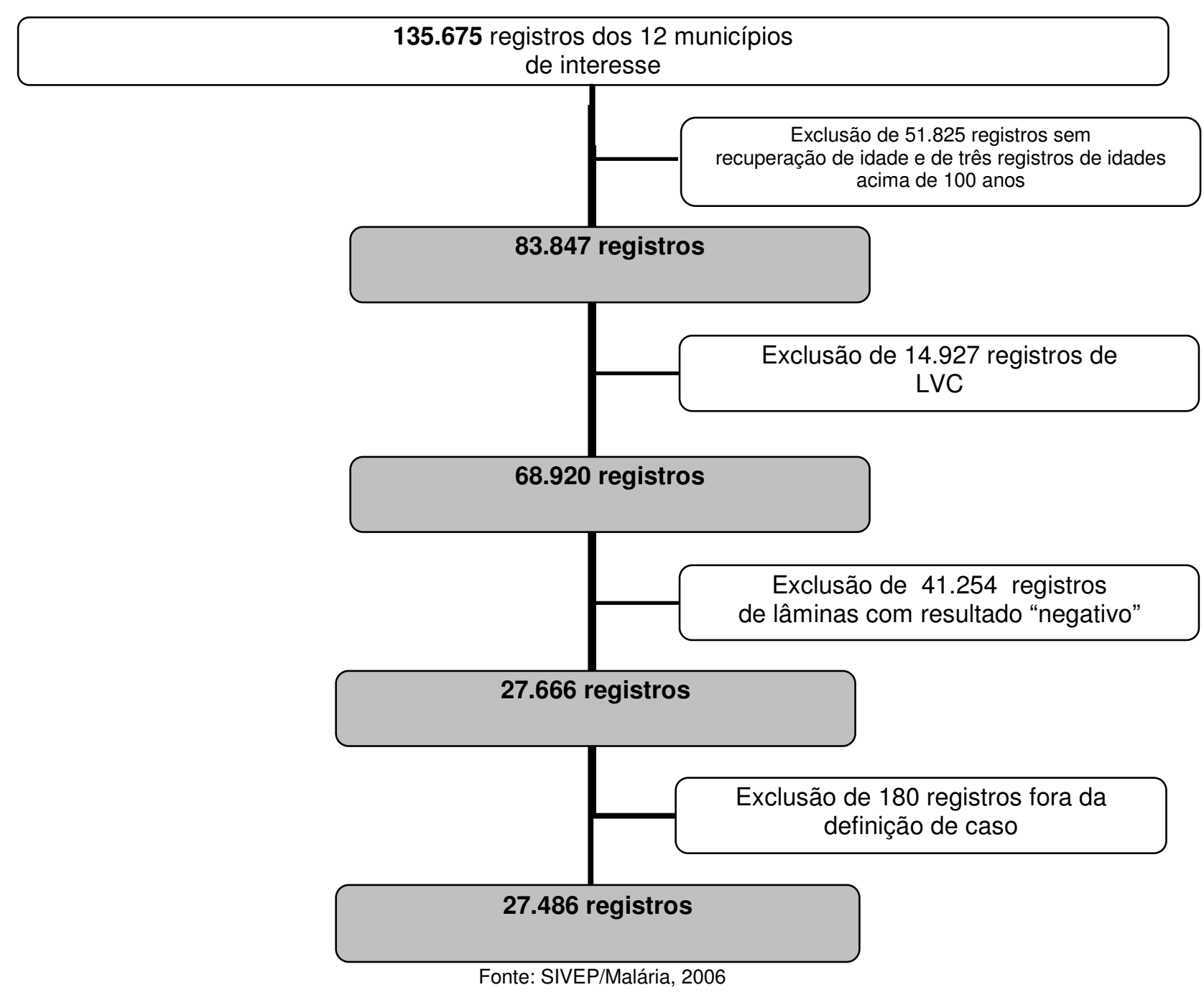

Figura 6 - Fluxograma de descrição do preparo do banco de dados de malária, para a análise dos esquemas de tratamento estratificados pelas faixas etárias de interesse - Estado do Pará, Brasil, 2006 
4.11.2. Estratificação dos Casos de acordo com as Faixas Etárias Relevantes para o Tratamento da Malária Vivax e Malária Falciparum Grave e Não-grave.

Após a limpeza e organização do banco de dados, conforme a descrição acima, foi calculada a proporção de casos nas faixas etárias indicadas para as doses dos esquemas terapêuticos por meio do cruzamento das variáveis "idade do paciente" e "idade em dias, meses e anos", variável que informa o formato em que a idade está especificada no banco de dados. Para estimar os custos de medicamentos para a malária grave, trabalhou-se, especificamente, com o número de casos registrados como "malária grave e complicada", na variável "esquema de tratamento" e seguiu-se o mesmo processo anterior de cruzamento de variáveis. Os casos classificados como "malária grave e complicada" foram excluídos da estimativa dos casos não-graves. A proporção de casos por faixas etárias foi o parâmetro para a estimativa de custos de medicamentos de forma ponderada.

4.11.3. Organização do Banco para o Cálculo da Prevalência da Malária (Probabilidade pré-teste) e a Probabilidade de Resultados Positivos para Plasmodium falciparum e Plasmodium vivax.

A prevalência da malária (probabilidade pré-teste) por meio do SIVEP/Malária foi estimada pela proporção de lâminas positivas entre todas as lâminas examinadas no período. No cálculo, foram incluídos os registros que continham informações incompletas de idade e excluídas 23.858 lâminas de verificação de cura (este valor diferente do valor acima descrito para LVC deve-se ao fato de o banco estar completo, sem exclusão dos registros com ausência de preenchimento da variável "idade") e também excluídos os 180 registros que não atendiam à definição de caso. 
Assim, o número de registros considerado foi 111.637 (111.637= 135.675 menos 23.858 menos 180); optou-se por trabalhar com este total e não com o banco reduzido, porque a exclusão dos registros que tinham informação incompleta em relação à idade causaria um importante viés na prevalência, devido a que a maior parte destes registros incompletos é de lâminas negativas. Como exemplo, tem-se o caso do Município Goianésia do Pará, que ao se analisar a prevalência utilizando-se o banco do qual foram excluídos mais de 51 mil registros sem idade, foi encontrado o valor de $66,2 \%$ de probabilidade de ter malária; enquanto que ao se usar o banco sem a exlusão dos casos com dados incompletos, encontrou-se a probabilidade de $23,9 \%$. Isto decorre do fato de que as informações de indivíduos com lâminas negativas são bastante neglicenciadas na notificação, ao contrário do que ocorre com os casos positivos.

Como o resultado das lâminas é uma informação que se encontra em todas as notificações, julgou-se que o dado mais fidedigno para a estimativa da prevalência e da proporção de casos de malária faciparum e malária vivax, seria extraído por meio da análise do banco que incluísse todas as notificações, mesmo aquelas com a idade não registrada.

\subsubsection{Estratificação dos Municípios segundo o Risco} Epidemiológico.

Após a organização do banco de dados, conforme descrito, foi feita a estratificação dos municípios segundo risco epidemiológico, sendo considerados os seguintes critérios: 1) Incidência Parasitária Anual (IPA) calculada como o número de casos confirmados dividido pela população em risco e multiplicado por 1.000. São consideradas áreas de "alto risco", as que apresentam IPA > 49,9/1.000 hab., de "médio risco" aquelas com IPA entre 10 a 49,9/1.000 hab. e de "baixo risco" com o IPA até 9,9/1.000 hab. (101); e 2) proporção de casos de malária por Plasmodium falciparum. A proporção 
de malária falciparum (IFA) igual ou superior a $20 \%$ do total de casos é um critério adotado pelo PNCM para a definição de áreas prioritárias (70).

O número de casos positivos para malária nos 12 municípios no ano de 2006 foi 27.488 casos. Foram calculadas a IPA, a IFA e a prevalência (ou probabilidade pré-teste/PPT) para cada um dos 12 municípios. Após o cálculo, para fins de análises que consideram diferentes cenários de risco, foram definidos os seguintes estratos, conforme apresentado na tabela 7 .

- Estrato 1 - constituído por 4 municípios que são de ALTO RISCO, segundo o IPA e que têm IFA acima de $20 \%$

- Estrato 2 - constituído por 3 municípios que são de MÉDIO RISCO, segundo o IPA e que têm IFA acima de $20 \%$

- Estrato 3 - constituído por 4 municípios que são de MÉDIO RISCO e que têm IFA abaixo de $20 \%$

- Estrato 4 - constituído por 1 município de BAIXO RISCO, segundo o IPA e IFA abaixo de $20 \%$ 
Tabela 7 - Distribuição dos 12 municípios segundo Índice Parasitário Anual (IPA), proporção de malária falciparum (IFA) e Probabilidade Pré-Teste (PPT) e divisão por estratos de risco. Pará, Brasil, 2006.

\begin{tabular}{l|ccccc}
\hline $\begin{array}{c}\text { Municípios e estratos } \\
\text { de risco }\end{array}$ & $\begin{array}{c}\text { População } \\
\text { IBGE - } \\
\mathbf{2 0 0 6}\end{array}$ & $\begin{array}{c}\text { Número de } \\
\text { casos } \\
\text { positivos }- \\
\mathbf{2 0 0 6}\end{array}$ & $\begin{array}{c}\text { IPA por 1.000 } \\
\text { hab. }\end{array}$ & $\begin{array}{c}\text { PPT } \\
\%\end{array}$ & $\begin{array}{c}\text { IFA } \\
\%\end{array}$ \\
\hline ESTRATO 1 & $\mathbf{2 2 2 . 0 7 0}$ & $\mathbf{2 0 . 3 3 7}$ & $\mathbf{9 1 , 5 8}$ & $\mathbf{2 8 , 5 0}$ & $\mathbf{3 6 , 4 0}$ \\
Jacareacanga & 34.683 & 6.391 & 184,27 & 28,25 & 33,75 \\
Novo Repartimento & 51.627 & 4.381 & 84,86 & 24,67 & 20,22 \\
Itaituba & 96.515 & 7.450 & 77,19 & 35,25 & 44,54 \\
Novo Progresso & 39.245 & 2.115 & 53,90 & 21,26 & 48,65 \\
\hline ESTRATO 2 & $\mathbf{2 7 3 . 9 0 7}$ & $\mathbf{4 . 6 5 2}$ & $\mathbf{1 6 , 9 8}$ & $\mathbf{2 2 , 0 0}$ & $\mathbf{2 7 , 4 0}$ \\
Goianésia do Pará & 31.293 & 1.369 & 43,75 & 23,93 & 38,79 \\
São Felix do Xingu & 41.813 & 606 & 14,50 & 15,67 & 24,26 \\
Marabá & 200.801 & 2.677 & 13,33 & 23,19 & 22,30 \\
\hline ESTRATO 3 & $\mathbf{1 2 7 . 1 3 2}$ & $\mathbf{2 . 3 2 8}$ & $\mathbf{1 8 , 3 1}$ & $\mathbf{1 2 , 7 0}$ & $\mathbf{1 4 , 5 0}$ \\
Nova Ipixuna & 14.348 & 597 & 41,61 & 21,84 & 5,19 \\
Baião & 21.893 & 593 & 27,10 & 26,31 & 19,56 \\
Santana do Araguaia & 42.523 & 597 & 14,04 & 5,62 & 18,93 \\
Jacundá & 48.368 & 541 & 11,18 & 19,77 & 14,60 \\
\hline ESTRATO 4 & $\mathbf{2 7 . 2 4 2}$ & $\mathbf{1 7 1}$ & $\mathbf{6 , 2 8}$ & $\mathbf{2 4 , 4 0}$ & $\mathbf{7 , 6 0}$ \\
São Geraldo do & 27.242 & 171 & 6,28 & 24,40 & 7,60 \\
Araguaia & $\mathbf{6 5 0 . 3 5 1}$ & $\mathbf{2 7 . 4 8 8}$ & & & \\
\hline TOTAL & & & & & \\
\hline Fonte: SIVEP/Man & & & & \\
\hline
\end{tabular}

Fonte: SIVEP/Malária, 2006

\subsubsection{Morbidade Hospitalar}

Os 12 municípios de estudo registraram, no ano de 2006, 734 internações por malária, o que corresponde a $40 \%$ do total de internações naquele ano (734/1.834 internações nos 12 municípios). As internações corrrespondem a $2,67 \%$ dos casos de malária notificados (734/27.488 casos positivos) mas, é provável que pacientes dos municípios tenham sido internados em outras áreas geográficas, especialmente em caso de gravidade, ou que nestes municípios tenham sido internados pacientes provindos de cidades vizinhas. Assim, a estimativa de $2,67 \%$ pode não ser 
acurada. Quanto ao número de óbitos, todo o Estado do Pará registrou oito óbitos entre os pacientes internados em 2006, sendo três (37,5\%) nos 12 municípios de estudo (90).

\subsection{AVALIAÇÃO DOS ESTUdOS DE ACURÁCIA DA GOTA ESPESSA E DO TESTE RÁPIDO}

A sensibilidade e a especificidade dos testes rápidos e da microscopia são os principais parâmetros epidemiológicos do modelo. São escassos, porém, os estudos de validação da microscopia, já que é uma técnica tradicional e consagrada no diagnóstico da malária.

Os estudos de validação da microscopia foram selecionados a partir da base bibliográfica Medline acessada pelo serviço de busca PubMed, por meio dos seguintes descritores: "microscopy" and "diagnosis" and "malaria" and "accuracy" (primeira busca) e "accuracy" and "microscopy" and "PCR" and "malaria" (segunda busca); e por meio dos descritores: "sensitivity" and "specificity" and "microscopy" and "malaria", utilizando-se a ferramenta de busca MeSH-PubMed. Além dos artigos identificados nas buscas, foram ainda identificados outros por meio de referências citadas nas revisões e nos artigos lidos. Foram feitas buscas nas bases SciElo e Lilacs, porém sem o encontro de citações a mais em relação ao que foi encontrado no Medline.

Como critério para a seleção dos estudos de validação da microscopia, foi definido que seriam incluídos na tabela de parâmetros apenas os artigos que fizessem a validação da microscopia tendo como padrão-ouro a PCR e foram excluídos os que utilizaram a própria microscopia realizada em laboratório de referência como padrão-ouro para a microscopia realizada em laboratórios de campo, de modo a padronizar os estudos. A PCR é considerada um padrão-ouro eficiente, por detectar a infecção malária mesmo nos casos de baixa parasitemia, quando não é detectável pela microscopia (66). Nas três buscas foram identificados, pelo 
resumo, apenas nove artigos e após a leitura completa, permaneceram cinco artigos para extração dos parâmetros do modelo $(49,54,56,121,123)$.

Em relação ao OptiMal® são inúmeros os estudos publicados na literatura, encontrando-se validações em populações de áreas endêmicas e indenes, viajantes, populações sintomáticas e assintomáticas e para espectros clínicos diferentes da malária por Plasmodium falciparum (ex: doentes graves). Assim, foi necessário que se estabelecessem critérios rigorosos para a seleção das evidências em relação à acurácia do OptiMal®, pela diversidade encontrada na literatura.

Os estudos de acurácia que avaliaram o uso do OptiMal® foram selecionados a partir da base bibliográfica Medline acessada pelo serviço de busca PubMed, por meio dos seguintes descritores: "evaluation" and "malaria" and "rapid tests" and "diagnosis" (primeira busca) e "OptiMal®" and "malaria" and "diagnosis" (segunda busca). Além disto, foi analisado o relatório técnico da OPAS elaborado por Fontes (2002) (126) que descreve a estudo de validação do OptiMal® conduzido no Brasil. Foram feitas buscas nas bases SciElo e Lilacs, porém sem o encontro de citações a mais em relação ao que foi encontrado na Medline.

As duas buscas recuperaram um total de 254 citações, sendo 11 duplicadas. Foram lidos todos os resumos e selecionados para leitura completa os artigos que tivessem realizado a validação do OptiMal $\AA^{\circledR}$ em comparação à microscopia como padrão-ouro. Por meio deste critério foram selecionados 30 artigos para leitura completa mas, foram lidos 29, pois para um dos resumos não se conseguiu recuperar o artigo completo, nem mesmo por meio de processos de comutação entre a Biblioteca Regional de Medicina (BIREME) e outras bibliotecas.

A leitura dos 29 artigos foi feita com critérios pré-definidos, com 0 objetivo de que a população dos estudos de validação a serem usados nos 
parâmetros epidemiológicos "sensibilidade" e "especificidade" fosse a mais próxima possível da população hipotética da análise de custo-efetividade, ou seja: pacientes com quadro clínico de malária, de área endêmica, de quaisquer faixas etárias. Assim, os critérios iniciais de seleção adotados para os artigos foram: 1) estudos feitos em população geral, incluindo quaisquer idades, sem focalizar em populações específicas como: gestantes, crianças ou pacientes graves; 2) estudos feitos com sujeitos sintomáticos; e 3) estudos feitos em áreas endêmicas.

Por meio dos critérios acima citados, no conjunto das duas buscas foram identificados 13 estudos $(10,32,39,44,55,62,73,130,134,144$, 150, 151, 161). Acrescentou-se a estes 13 estudos, o relatório da OPAS (126) completando 14 publicações para análise mais detalhada, visando à escolha dos parâmetros do modelo.

Os artigos selecionados e o relatório da OPAS foram lidos e analisados segundo o instrumento QUADAS - Quality assessment of Diagnostic Accuracy Studies. O QUADAS é um instrumento produzido por um grupo comissionado pelo NHS R\&D Health Technology Assessment Programme (HTA), do Reino Unido (165).

O QUADAS foi desenvolvido de modo sistemático, teve como base a revisão de evidências existentes e foi o primeiro instrumento para avaliar qualidade de estudos de acurácia desenvolvido com esta metodologia. Nove painelistas, por meio do método DELPHI, participaram de quatro etapas de discussão, a partir de uma lista inicial de 28 possíveis itens para inclusão no instrumento de avaliação. Ao final, houve a concordância em relação a 14 itens que deveriam ser incluídos. Assim, o instrumento final, consiste em 14 itens apresentados na tabela 8. Cada item deve ser respondido por SIM, NÃO, ou POUCO CLARO (unclear, no original); esta última resposta deve ser marcada em caso de haver insuficiente informação para fazer um julgamento adequado. (165). 
Para a análise dos artigos de validação do OptiMal® selecionados, todos os itens foram considerados relevantes e mantidos no instrumento. Além destes 14 itens, acrescentaram-se três outros para completar o processo de seleção: 1) descrição do processo amostral; 2) resultados de sensibilidade e especificidade apresentados com seus respectivos intervalos de confiança (IC); e 3) descrição das características demográficas dos pacientes. Para estes três itens, a resposta foi dicotômica: sim ou não.

A decisão final foi feita em duas etapas: 1) foram separados todos os artigos que continham resultados de sensibilidade e especificidade com os seus respectivos IC. Este critério foi usado como o critério inicial para a seleção, pois foi considerado um indicador da qualidade dos estudos, por fornecerem uma estimativa quanto à precisão dos dados, devido à incerteza inerente à estimativa pontual. Foi o único dos três critérios adicionais usado como eliminatório. A descrição dos IC foi encontrada em sete artigos e no relatório da OPAS $(39,44,73,126,130,134,144,161)$; 2) A partir da seleção inicial dos oito estudos, foram selecionados, entre eles, os que tiveram até $50 \%$ de respostas "SIM" no instrumento QUADAS - ou seja, sete respostas positivas. Permaneceram seis artigos publicados mais o relatório da OPAS $(39,44,73,126,130,144,161)$. Foi escolhido como parâmetrobase para o modelo de análise de custo-efetividade o relatório da OPAS, elaborado por Fontes (126), por ser um estudo feito em áreas endêmicas do Brasil, ter descrito o processo amostral, as estimativas por meio de intervalos de confiança e apresentado nove respostas positivas ("SIM") no conjunto dos critérios avaliados. Os demais seis estudos foram usados como intervalos de referência para a análise de sensibilidade. 
Tabela 8 - Instrumento de avaliação de qualidade de artigos de acurácia - QUADAS

\section{ITEM $^{*}$}

1) O espectro de pacientes foi representativo dos pacientes que receberão 0 teste na rotina?

2) Os critérios de seleção foram claramente descritos?

3) O padrão-ouro classifica corretamente a doença?

4) O período entre a aplicação do padrão-ouro e o teste em avaliação foi curto o suficiente para que se tenha segurança que não houve mudanças no estado de saúde do indivíduo testado?

5) A amostra total ou uma sub-amostra randomizada realizou o diagnóstico pelo padrão-ouro?

6) Os pacientes receberam o mesmo teste como padrão-ouro, independente do resultado obtido pelo teste em avaliação?

7) O padrão-ouro é independente do teste em avaliação (ou seja, o teste em avaliação não faz parte do teste padrão-ouro)?

8) A execução do teste em avaliação foi descrita com suficientes detalhes, permitindo a sua replicação?

9) A execução do teste padrão-ouro foi descrita com suficientes detalhes, permitindo a sua replicação?

10) Os resultados do teste em avaliação foram interpretados sem $o$ conhecimento dos resultados do teste padrão-ouro?

11) Os resultados do teste padrão-ouro foram interpretados sem 0 conhecimento dos resultados do teste em avaliação?

12) Os dados clínicos disponíveis para o laboratório foram os mesmos que são usados na prática rotineira?

13) Os resultados indefinidos ou intermediários dos testes foram relatados?

14) As perdas do estudo foram explicadas?

Fonte: Traduzido e adaptado a partir de Whiting e cols, 2004.

Nota: * Cada item deve ser respondido com: SIM ou NÃO ou POUCO CLARO 
As tabelas 9 e 10 apresentam os resultados da avaliação dos artigos segundo os critérios utilizados. A descrição detalhada de cada artigo segundo todos os critérios utilizados encontra-se no anexo 7 .

Tabela 9 - Distribuição dos 13 artigos publicados e do relatório da OPAS, segundo os critérios do QUADAS, 2007

\begin{tabular}{l|c|c|c}
\multicolumn{1}{c|}{ Critérios } & \multicolumn{2}{c}{$\begin{array}{l}\text { Número de artigos em } \\
\text { cada categoria }\end{array}$} \\
\hline & Sim & Não & $\begin{array}{c}\text { Pouco } \\
\text { claro }\end{array}$ \\
\hline $\begin{array}{l}\text { O espectro de pacientes foi representativo dos pacientes que } \\
\text { receberão o teste na rotina? }\end{array}$ & 14 & - & - \\
\hline Os critérios de seleção foram claramente descritos? & 6 & 5 & 3 \\
\hline O padrão-ouro classifica corretamente a doença? & 14 & - & - \\
\hline $\begin{array}{l}\text { O período entre a aplicação do padrão-ouro e o teste em } \\
\text { avaliação foi curto o suficiente para que se tenha segurança que } \\
\text { não houve mudanças no estado de saúde do indivíduo testado? }\end{array}$ & 7 & - & 7 \\
\hline $\begin{array}{l}\text { A amostra total ou uma sub-amostra randomizada realizou o } \\
\text { diagnóstico pelo padrão-ouro? }\end{array}$ & 14 & - & - \\
\hline $\begin{array}{l}\text { Os pacientes receberam o mesmo teste como padrão-ouro, } \\
\text { independente do resultado obtido pelo teste em avaliação? }\end{array}$ & 14 & - & - \\
\hline $\begin{array}{l}\text { O padrão-ouro é independente do teste em avaliação (ou seja, o } \\
\text { teste em avaliação não faz parte do teste padrão-ouro)? }\end{array}$ & 14 & - & - \\
\hline $\begin{array}{l}\text { A execução do teste em avaliação foi descrita com suficientes } \\
\text { detalhes, permitindo a sua replicação? }\end{array}$ & 5 & 9 & - \\
\hline $\begin{array}{l}\text { A execução do teste padrão-ouro foi descrita com suficientes } \\
\text { detalhes, permitindo a sua replicação? }\end{array}$ & 2 & 12 & - \\
\hline $\begin{array}{l}\text { Os resultados do teste em avaliação foram interpretados sem o } \\
\text { conhecimento dos resultados do teste padrão-ouro? }\end{array}$ & 9 & - & 5 \\
\hline $\begin{array}{l}\text { Os resultados do teste padrão-ouro foram interpretados sem o } \\
\text { conhecimento dos resultados do teste em avaliação? }\end{array}$ & 9 & - & 5 \\
\hline $\begin{array}{l}\text { Os dados clínicos disponíveis para o laboratório foram os } \\
\text { mesmos que são usados na prática rotineira? }\end{array}$ & - & - & 14 \\
\hline $\begin{array}{l}\text { Os resultados indefinidos ou intermediários dos testes foram } \\
\text { relatados? }\end{array}$ & 4 & 10 & - \\
\hline As perdas do estudo foram explicadas ? ${ }^{(1)}$ & & & \\
\hline
\end{tabular}

Nota: ${ }^{(1)}$ Não houve perdas em 13 estudos, não sendo aplicável a pergunta. 
Tabela 10 - Distribuição dos 13 artigos publicados e do relatório da OPAS, segundo critérios definidos para a avaliação pela autora. 2007

\begin{tabular}{l|c|c}
\hline \multicolumn{1}{c|}{ Critérios } & \multicolumn{2}{c}{$\begin{array}{c}\text { Número de artigos } \\
\text { em cada categoria }\end{array}$} \\
\hline Descrição do processo de amostragem & Sim & Não \\
\hline $\begin{array}{l}\text { Apresentação dos intervalos de confiança para os } \\
\text { parâmetros de sensibilidade e especificidade }\end{array}$ & 8 & 11 \\
\hline Descrição das características demográficas dos pacientes & 3 & 11 \\
\hline
\end{tabular}

\subsection{BUSCA E SELEÇÃO DOS ARTIGOS PARA ESTIMAR OS PARÂMETROS DE RESULTADOS DO TRATAMENTO ANTIMALÁRICO}

4.13.1. Estimativa do Parâmetro Proporção de Cura com Coartem®, para Malária Falciparum Não-grave:

Foram usados os seguintes descritores e palavras-chave: Coartem®; Brazil; Artemether-Iumefantrine; clinical trials; efficacy, para busca na base Medline, por meio do PubMed. Foram, ainda, identificadas outras referências por meio de revisões e da leitura dos artigos.

A seleção dos parâmetros para o modelo começou pela leitura da revisão sistemática "Artemether-lumefantrine (six-dose regimen) for treating uncomplicated falciparum malaria", publicado pela Biblioteca Cochrane (124). O artigo de Omari e cols., avaliou e classificou nove ensaios clínicos com Coartem $\AA$, dos quais oito foram recuperados. Na revisão sistemática, os artigos melhor classificados foram os de Piola e cols., e de Mutabingwa e cols., $(118,137)$ - este último só em crianças - seguidos imediatamente por Mayxay e cols., e Stohrer e cols., $(85,152)$. Os demais cinco artigos analisados na revisão tiveram classificação pior. Todos os artigos analisados tiveram tempo de seguimento de no mínimo 28 dias para a estimativa de 
proporção de cura com o Coartem $\AA$ e utilizaram exame de PCR para diagnóstico do genótipo do Plasmodium falciparum antes e após o tratamento, de modo a distinguir entre recrudescência (reaparecimento de sintomas clínicos devido à sobrevivência de formas parasitárias nos eritrócitos) e reinfecção (nova infecção). Assim, com base na classificação de qualidade feita na revisão sistemática, dois estudos foram selecionados: Piola e cols., - para o caso-base - e Stohrer e cols. $(137,152)$. O artigo de Mutabingwa (118) não foi selecionado para o modelo devido ser exclusivamente com crianças. $O$ artigo de Mayxay (85) teve resultado muito próximo ao de Piola ( $97 \%$ e $98 \%$ de proporção de cura, respectivamente), preferindo-se o de Stohrer, que obteve a mesma classificação, mas que trouxe resultado mais divergente $(93,6 \%)$, o que é mais adequado para a análise de sensibilidade. $\mathrm{Na}$ análise de sensibilidade também foi utilizado o resultado do estudo de Alecrim e cols. (8), por ter sido o único estudo nacional encontrado nas buscas, apesar de tempo muito curto de seguimento dos pacientes.

4.13.2. Estimativa do Parâmetro Proporção de Cura com Artesunato ou Artemeter para Malária Falciparum grave

Foram usados os seguintes descritores e palavras-chave em várias combinações: severe malaria; effectiveness; treatment; clinical trials; outcome; artesunate; artemether; mefloquine; efficacy; Brazil, para busca na base Medline, por meio do PubMed. Foram, ainda, identificadas outras referências por meio da leitura dos artigos.

Para se estimar este parâmetro, decidiu-se pelo uso de estudos com artesunato ou artemeter, uma vez que pela revisão da literatura foi concluído que ambos são igualmente eficazes. A grande dificuldade para a estimativa do parâmetro foi não haver replicação exatamente do mesmo esquema adotado no Brasil - artesunato ou artemeter seguido por mefloquina. 
Quando os artigos relatavam o mesmo esquema seqüencial não eram coincidentes as doses preconizadas ou a forma de apresentação do medicamento (ex: uso de supositórios). Mesmo com estas diferenças, foram analisados 11 artigos $(7,12,25,52,53,63,74,75,149,156,166)$ que relatavam resultados de ensaios clínicos. Foi selecionado para o caso-base o artigo de Krudssod e cols. com os resultados do artesunato (63), por ter usado um esquema semelhante ao brasileiro e ter medido o desfecho recrudescência. Para a análise de sensibilidade foi selecionado o artigo de Shwe \& Hla (149), que avaliou o artemeter, e novamente o de Krudssod e cols (63), com os resultados do artemeter. Ambos os estudos usados na variação avaliaram o desfecho recrudescência. A estimativa variou de $80 \%$ a 100\% de eficácia (tabela 6)

4.13.3. Estimativa do Parâmetro Proporção de Cura com Cloroquina e Primaquina para Malária Vivax

Foram usados os seguintes descritores e palavras-chave em várias combinações: chloroquine; primaquine; malaria vivax; Brazil; effectiveness; treatment; clinical trials; efficacy, para busca na base Medline, por meio do PubMed. Foram, ainda, identificadas outras referências por meio da leitura dos artigos.

Este parâmetro apresentou a mesma limitação do parâmetro anterior a ausência de artigos que reproduzissem exatamente o esquema brasileiro: cloroquina por três dias (4,3,3 comprimidos - para adultos) e primaquina dois comprimidos por sete dias (para adultos). Foi feita a opção de utilizar dois artigos nacionais, de Abdon e cols e Silva e cols, que seguiram os pacientes por seis meses e utilizaram o esquema preconizado em relação à dose da primaquina, embora com a cloroquina em dose única $(1,33)$. Uma vez que não se encontraram artigos que reproduzissem exatamente 0 mesmo esquema nacional, foram valorizados os que utilizaram a primaquina 
na dose recomendada, já que é a droga responsável pela cura radical (ausência de recaída em seis meses de acompanhamento). $O$ apoio a esta decisão foi o artigo de Silva e cols, que demonstrou a mesma eficácia quando utilizada a primaquina na dose de dois comprimidos por sete dias, independentemente do esquizonticida utilizado (33).

\subsection{LEVANTAMENTO DE CUSTOS}

Foram estimados os custos diretos médicos e não-médicos do diagnóstico da malária e dos cuidados com a doença.

Devido à singularidade dos municípios, os quais apresentam áreas cobertas por laboratórios de diagnóstico de malária e áreas isoladas, o levantamento de custos foi feito considerando três cenários: 1) Cenário 1 área global dos 12 municípios que corresponde a 100\% dos exames realizados no ano de 2006; 2) Cenário 2 - áreas com laboratórios de diagnóstico de malária dos 12 municípios que correspondem a $70 \%$ dos exames; e 3) Cenário 3 - áreas isoladas dos 12 municípios, que correspondem a $30 \%$ dos exames. Os custos utilizados no modelo para o cenário 1 estão apresentados nas tabelas 11 e 12. Os custos do cenário 1 foram recalculados para a realidade dos cenários 2 e 3, a partir do número de exames de cada cenário - ou seja, $70 \%$ e $30 \%$ dos exames do cenário 1 , respectivamente - e necessidades específicas. Os custos dos cenários 2 e 3 estão nos anexos 8, 9,10 e 11. O processo de composição dos diversos itens está descrito nas seções seguintes. 
Tabela 11 - Parâmetros de custos diretos do diagnóstico da malária para o modelo de custo- efetividade da área global dos 12 municípios, segundo valores básicos, variação dos valores e fontes consultadas *

\begin{tabular}{|c|c|c|c|c|}
\hline Item de custo & $\begin{array}{l}\text { Valores de } \\
\text { referência } \\
\text { para o caso- } \\
\text { base } \\
\text { R\$ }\end{array}$ & $\begin{array}{l}\text { Valores de } \\
\text { referência para a } \\
\text { variação } \\
\mathbf{R} \$\end{array}$ & $\begin{array}{c}\text { Custo para o total } \\
\text { de municípios/ } \\
\text { exames/casos } \\
\text { clínicos - caso- } \\
\text { base }\end{array}$ & Fontes da informação \\
\hline $\begin{array}{l}\text { Exames e suprimentos } \\
\text { Gota espessa }^{(2)}-\text { um exame }\end{array}$ & 1,99 & $0,41-3,04$ & $222.157,63$ & $\begin{array}{l}\text { Caso-base: Macauley, } 2005 \\
\text { Variação: IEC/SVS/MS } \\
\text { Macauley,2005 }\end{array}$ \\
\hline $\begin{array}{l}\text { OptiMal® - um teste } \\
\text { Luvas de Látex }^{(4)}\end{array}$ & $\begin{array}{l}9,28 \\
0,05\end{array}$ & $\begin{array}{c}7,79-10,69 \\
0,10\end{array}$ & $\begin{array}{c}1.035 .991,36 \\
5.581,85\end{array}$ & $\begin{array}{l}\text { Caso-base: Diário Oficial da } \\
\text { União, } 2006 \\
\text { Variação: DiaMed; SES do } \\
\text { Pará } \\
\text { Caso-base e variação: Banco } \\
\text { de Preços do MS }\end{array}$ \\
\hline $\begin{array}{l}\text { Equipamentos } \\
\text { Microscópio - uma unidade - } \\
\text { valor anualizado }^{(5)}\end{array}$ & $1.053,85^{(6)}$ & $711,62^{(7)}$ & $22.130,85$ & $\begin{array}{l}\text { Caso - base e variação: } \\
\text { PNCM/SVS/MS }\end{array}$ \\
\hline $\begin{array}{l}\text { Manutenção de microscópio - } \\
\text { uma manutenção anual }\end{array}$ & 80,00 & $\ldots$ & $1.680,00$ & $\begin{array}{l}\text { Caso - base: Laboratório de } \\
\text { Malária do Instituto Evandro } \\
\text { Chagas da SVS/MS }\end{array}$ \\
\hline $\begin{array}{l}\text { Transporte } \\
\text { Realização do teste rápido - } \\
\text { custo mensal médio }\end{array}$ & $3.147,00$ & $1.856,00-35.649,07$ & $19.826,10$ & $\begin{array}{l}\text { Caso-base e variação: SMS } \\
\text { do Novo Repartimento }\end{array}$ \\
\hline $\begin{array}{l}\text { Treinamento } \\
\text { Microscopia - um curso por } \\
\text { ano e total para } 12 \text { municípios }\end{array}$ & $24.169,00$ & $12.877,30$ & $290.028,00$ & $\begin{array}{l}\text { Caso-base e variação: } \\
\text { PNCM/SVS e SES de } \\
\text { Roraima }\end{array}$ \\
\hline $\begin{array}{l}\text { Teste Rápido - um curso por } \\
\text { ano e total para } 12 \text { municípios }\end{array}$ & 251,76 & 134,14 & $3.021,12$ & $\begin{array}{l}\text { Caso-base e variação: } \\
\text { PNCM/SVS, SES de Roraima } \\
\text { e OMS }\end{array}$ \\
\hline
\end{tabular}

Notas: * Total de exames no cenário 1: 111.637. A memória de cálculo para o custo unitário por exame ou caso clínico utilizado no modelo de custo-efetividade está apresentada nos anexos 12 a 21.

(1) Para os custos da variação, a primeira fonte corresponde ao menor valor e a segunda fonte ao maior, quando aplicáveis.

(2) Corresponde ao custo individual de um exame considerando os seguintes insumos: lâmina de vidro, Giemsa e demais corantes (todos os componentes das colorações), óleo de imersão, lanceta, algodão, álcool e luvas.

(3) O Laboratório de Malária do Instituto Evandro Chagas (IEC), da SVS/MS forneceu os custos individuais de cada insumo para realização da coloração e leitura da lâmina e os custos foram calculados para um exame produzido.

${ }^{(4)}$ Luvas de látex - compõem o custo do OptiMal®

(5) Itens que foram ponderados, para obtenção do custo total e do unitário por exame ou caso clínico e entrada no modelo de custo-

efetividade, pela carga de trabalho envolvida na malária - ver anexos 14 a 21.

(6) Custo do microscópio anualizado para 15 anos (ver memória de cálculo no anexo 18)

(7) Custo do microscópio anualizado para 30 anos (ver memória de cálculo no anexo 18).

(8) A SMS de Novo Repartimento informou os custos mensais com gasolina e óleo diesel e os custos de transporte foram calculados (ver memória de cálculo nos anexos 19 e 20). 
Tabela 12 - Parâmetros de custos diretos de cuidados com a doença para o modelo de custo-efetividade da área global dos 12 municípios, segundo valores básicos, variação dos valores e fontes consultadas *

\begin{tabular}{cccc} 
Item de custo & $\begin{array}{c}\text { Valores de } \\
\text { referência para } \\
\text { o caso-base }\end{array}$ & $\begin{array}{c}\text { Valores de referência } \\
\text { para a variação }\end{array}$ & $\begin{array}{c}\text { Custo para o total } \\
\text { de exames/casos } \\
\text { clínicos - caso- } \\
\text { base }\end{array}$ \\
\hline
\end{tabular}

\section{Custo hospitalar - casos graves}

Diária de internação hospitalar média ${ }^{(2)}$
$106,80-167,89$

$$
137,34^{(3)}
$$

Exames de pré-internação custo do conjunto de exames para um paciente

$$
41,26
$$

Caso-base e variação: Sistema de Informações Hospitalares do SUS; Tabela de Procedimentos do SUS

Caso-base: Tabela de Procedimentos do SUS

\section{Procedimentos do SUS}

\section{Custo ambulatorial}

Consulta no SUS - uma

7,55

$42.786,62^{(5)}$ consulta

\begin{tabular}{l}
\hline Transporte \\
\hline Medicamentos antimaláricos \\
para Belém/PA, por ano $^{(7)}$
\end{tabular}

Transporte
Medicamentos antimaláricos
para Belém/PA, por ano $^{(7)}$

\section{Medicamentos}

Tratamento específico da malária vivax - custo de um tratamento

$9.605,44^{(9)}$

Tratamento específico da malária falciparum não-grave custo de um tratamento ${ }^{(10)}$

Tratamento específico da malária falciparum grave custo de um tratamento ${ }^{(12)}$

Acetaminofen - um tratamento $9.590,81$ $\ldots$

$9.590,81$

Fonte: CENADI/SVS/MS e

Caso-base: Tabela de Procedimentos do SUS Gabinete/SVS/MS

Caso-base: sistema de informações de insumos estratégicos da SVS/MS

Caso-base: sistema de informações de insumos estratégicos da SVS/MS

Caso-base: sistema de informações de insumos estratégicos da SVS/MS

Caso-base e variação: banco de preços do MS

Notas: * A memória de cálculo para o custo unitário por exame ou caso clínico utilizado no modelo de custo-

efetividade está apresentada nos anexos 12 a 21.

(1) O caso-base e as variações tiveram as mesmas fontes de dados.

(2) Corresponde a um custo médio de diária considerando os custos da diária de enfermaria e de UTI.

(3) Corresponde a $50 \%$ da diária de UTI mais $50 \%$ da diária de enfermaria.

(4) Corresponde ao custo da internação por 10 dias para a estimativa de pacientes com malária falciparum grave:

1.037 pacientes (11,5\%). Cálculo: 137,34 x 10 dias x 1.037 .

(5) Exames considerados: hemograma, coagulograma, sódio, potássio, uréia, creatinina, bilirrubinas total e frações,

TGO,TGP, Gama-GT, fosfatase alcalina, DHL, glicemia, Raios X de tórax. Corresponde à estimativa de custos para pacientes graves: 1.037 pacientes.

(6) Na hipótese teórica de que todos os casos febris façam consulta; o modelo de custo-efetividade adotou critérios

para esta estimativa, explicadas no texto.

(7) Foi coletado o custo global de transporte no ano de 2006 do Rio de Janeiro para o Estado do Pará e ponderado pela proporção de casos positivos nos 12 municípios de interesse.

(8) O custo do tratamento das diversas formas de malária considera o conjunto dos medicamentos indicados por faixas etárias e por populações específicas como: menores de seis meses e grávidas, assumindo para a população geral adulta os medicamentos de primeira linha (ver memória de cálculo no anexo 13).

(9) Para estimados 18.472 casos de malária vivax, segundo o modelo.

(10) Considera na composição de custos a proporção estimada de pacientes com malária mista que utiliza cloroquina (crianças abaixo de seis meses) ou primaquina para cura radical da malária vivax (ver memória de cálculo no anexo 13).

(11) Para estimados 7.979 casos de malária falciparum não-grave, segundo o modelo.

(12) Considera custos de artemeter e artesunato e de quinino e clindamicina em grávidas; no cálculo do artesunato está

incluído o custo da solução de glicose para diluição (ver memória de cálculo no anexo 13).

(13) Para estimados 1.037 casos de malária falciparum grave, segundo o modelo.

(14) Considerado tratamento antitérmico por até 3 dias, ponderando pela estimativa da proporção de crianças e adultos. 


\subsubsection{Custos Diretos do Diagnóstico da Malária}

Os itens que compuseram estes custos foram: exame de gota espessa, composto por lâminas de vidro, corante de Giemsa, lancetas, algodão, álcool, óleo de imersão, corantes e luvas; compra do teste rápido OptiMal®; salário do microscopista; salário do técnico para realizar o teste rápido; compra e manutenção de microscópio; treinamento de equipes para realizar microscopia e testes rápidos; transporte das secretarias de saúde para coleta e entrega de resultados de microscopia e para a realização do teste rápido.

\subsubsection{Custo da Estratégia Microscopia}

No custo final da estratégia "microscopia" estão considerados: exame de gota espessa, salário do microscopista, compra e manutenção de microscópio, treinamento para microscopistas e transporte das secretarias de saúde para coleta e entrega dos resultados.

O custo do exame de gota espessa não é expresso diretamente na tabela de procedimentos do SUS, pois é um dos custos incorporados no PAB (96) que é repassado aos municípios, não havendo individualização do seu valor.

As fontes para a estimativa do custo da microscopia foram a Organização Mundial da Saúde que fez estudos de estimativas de custo de microscopia para países endêmicos (168), o artigo de Pang \& PiovesanAlves (133) que apresenta um estudo de custo-minimização realizado no Brasil, no Estado do Mato Grosso, relativo à implantação de teste rápido para diagnóstico da malária e o artigo de Macauley (80), que detalha os custos do diagnóstico microscópico em área Yanomami no Brasil no ano de 
2001, para duas estratégias diferentes: busca ativa, por meio de inquérito universal na população exposta e detecção passiva.

O custo máximo estimado pela OMS e publicado em 2000, foi de US\$ 0,40. No artigo de Pang e Piovesan-Alves, publicado em 2001 - que se baseou nas estimativas da OMS - foi de US\$ 0,33 e no artigo de Macauley para o inquérito de busca ativa, foi de US\$ 0,30 e na detecção passiva de US\$ $0,56(80,133,168)$.

Inicialmente os custos foram convertidos para reais, aplicando-se a taxa média de conversão do dólar (13) para os anos 2000 e 2001 que foram os anos de publicação do documento da OMS e do estudo de Pang \& Piovesan-Alves; já o artigo de Macauley foi publicado em 2005 mas, refere custos do ano de 2001. Após a conversão, foi aplicada a taxa oficial da inflação acumulada até 2005, de modo a obter-se o custo estimado para 2006, por meio do Índice Nacional de Preços ao Consumidor Amplo (IPCA). O IPCA é o índice oficial do Governo Federal para medição das metas inflacionárias desde julho de 1999 e é medido pelo IBGE (110). Na tabela 13 estão apresentados os cálculos feitos com o IPCA (64). A partir da OMS e do trabalho de Pang \& Piovesan-Alves, estimou-se, ao final, em $R \$ 1,16$ o custo por lâmina. A partir do trabalho de Macauley, obteve-se o custo final de $R \$ 3,04$ por lâmina, quando considerada a soma das duas estratégias (inquérito universal para busca ativa mais detecção passiva), de $R \$ 1,05$ quando considerado somente o inquérito de busca ativa e de $R \$ R \$ 1,99$ quando considerada somente a detecção passiva (tabela 13). 
Tabela 13 - Ajuste do custo da microscopia a partir de referências da WHO (2000), Pang \& Piovesan-Alves (2001) e Macauley (2005) por meio da conversão para reais pela taxa média de conversão do dólar para os anos 2000 e 2001, e pela aplicação do Índice Nacional de Preços ao Consumidor Amplo - IPCA até 2005.

\begin{tabular}{|c|c|c|c|c|c|}
\hline Anos & $\begin{array}{c}\text { Custo } \\
\text { inicial em } \\
\text { US\$ }\end{array}$ & $\begin{array}{c}\text { Custos em R\$ * } \\
\text { (1) }\end{array}$ & $\begin{array}{l}\text { IPCA } \\
(2)\end{array}$ & $\begin{array}{l}\text { Cálculo } \\
\text { (1) x (2) }\end{array}$ & $\begin{array}{l}\text { Custo final } \\
{[(1) \times(2)]+(1)}\end{array}$ \\
\hline \multicolumn{6}{|c|}{ WHO (2000) } \\
\hline 2000 & 0,4 & 0,73 & 0,0597 & 0,043581 & 0,773581 \\
\hline 2001 & & 0,773581 & 0,0767 & 0,059334 & 0,832914663 \\
\hline 2002 & & 0,832915 & 0,1253 & 0,104364 & 0,93727887 \\
\hline 2003 & & 0,937279 & 0,093 & 0,087167 & 1,024445805 \\
\hline 2004 & & 1,024446 & 0,076 & 0,077858 & 1,102303686 \\
\hline 2005 & & 1,102304 & 0,0569 & 0,062721 & 1,165024766 \\
\hline \multicolumn{6}{|c|}{ Pang (2001) } \\
\hline 2001 & 0,33 & 0,77 & 0,0767 & 0,059059 & 0,829059 \\
\hline 2002 & & 0,829059 & 0,1253 & 0,103881 & 0,932940093 \\
\hline 2003 & & 0,93294 & 0,093 & 0,086763 & 1,019703521 \\
\hline 2004 & & 1,019704 & 0,076 & 0,077497 & 1,097200989 \\
\hline 2005 & & 1,097201 & 0,0569 & 0,062431 & 1,159631725 \\
\hline \multicolumn{6}{|c|}{ Macauley (2001) - soma dos custos da busca ativa (inquérito) com a detecção passiva } \\
\hline 2001 & 0,86 & 2,02 & 0,0767 & 0,154934 & 2,174934 \\
\hline 2002 & & 2,174934 & 0,1253 & 0,272519 & 2,44745323 \\
\hline 2003 & & 2,447453 & 0,093 & 0,227613 & 2,675066381 \\
\hline 2004 & & 2,675066 & 0,076 & 0,203305 & 2,878371426 \\
\hline 2005 & & 2,878371 & 0,0569 & 0,163779 & 3,04215076 \\
\hline \multicolumn{6}{|c|}{ Macauley (2001) - Busca ativa (inquérito) } \\
\hline 2001 & 0,3 & 0,7 & 0,0767 & 0,05369 & 0,75369 \\
\hline 2002 & & 0,75369 & 0,1253 & 0,094437 & 0,848127357 \\
\hline 2003 & & 0,848127 & 0,093 & 0,078876 & 0,927003201 \\
\hline 2004 & & 0,927003 & 0,076 & 0,070452 & 0,997455444 \\
\hline 2005 & & 0,997455 & 0,0569 & 0,056755 & 1,054210659 \\
\hline \multicolumn{6}{|c|}{ Macauley (2001) - Detecção passiva } \\
\hline 2001 & 0,56 & 1,32 & 0,0767 & 0,101244 & 1,421244 \\
\hline 2002 & & 1,421244 & 0,1253 & 0,178082 & 1,599325873 \\
\hline 2003 & & 1,599326 & 0,093 & 0,148737 & 1,748063179 \\
\hline 2004 & & 1,748063 & 0,076 & 0,132853 & 1,880915981 \\
\hline 2005 & & 1,880916 & 0,0569 & 0,107024 & 1,9879401 \\
\hline
\end{tabular}

Fontes: WHO, 2000; Pang \& Piovesan-Alves, 2001; Macauley, 2005; Banco Central do Brasil, 2008; IBGE- Ministério do Planejamento, orçamento e gestão,2008.

Nota: * Aplicação da taxa média de conversão do dólar para o ano 2000: 1,83 e para o ano 2001: 2,35 
Além da busca nas fontes citadas, também foi estimado o custo do exame de gota espessa, por meio dos insumos usados na coleta do sangue, na coloração da lâmina e na sua leitura, usando os custos individuais dos vários elementos como: lâminas de vidro, lancetas, corantes (e insumos para produção dos corantes), óleo de imersão, álcool, algodão e luvas. Os custos de cada componente foram obtidos nos registros do Laboratório de Malária do Instituto Evandro Chagas, da Secretaria de Vigilância em Saúde (Comunicação pessoal de Dra. Marinete Póvoa, expert em malária e chefe do laboratório - dados não publicados) e no Banco de Preços do Ministério da Saúde $(89,99,99)$. Os detalhes das técnicas de confecção e de coloração da lâmina foram consultados no Manual de Diagnóstico Laboratorial da Malária, da SVS (101).

O custo final obtido por esta técnica de micro-costing para o exame de gota espessa, foi de $R \$ 0,41$ reais por lâmina. Cálculo detalhado no anexo 12.

Não foram considerados os custos de uma segunda lâmina para verificação de cura, em regime ambulatorial, por não ser recomendado o monitoramento do tratamento na Região Amazônica, na rotina dos serviços de saúde (106).

O custo do caso-base foi o custo relatado por Macauley na detecção passiva (80) e na variação utilizou-se o custo resultante da técnica de microcosting e o o custo relatado por Macauley na estratégia global de diagnóstico (80) (tabela 13 e anexo 12).

Os custos relativos aos salários dos agentes de saúde que realizam a gota espessa e teste rápido - microscopistas e agentes comunitários de saúde, respectivamente - assim como o gasto médio mensal com combustíveis - gasolina e diesel - em operações de busca ativa de malária foram estimados a partir de dados do Município de Novo Repartimento 
(dados não publicados). Os valores dos salários foram extrapolados para os 12 municípios, devido à uniformidade entre os salários de agentes de saúde na Região Norte.

A estimativa de custos de salários de microscopistas, microscópios, manutenção de microscópios, transporte de equipes para realizar exames, assim como o salário de agentes de saúde que realizam o teste rápido foi feita com base em documento da OMS (177), que considera a carga de trabalho dos profissionais a partir da prevalência de lâminas positivas. A partir da referência da carga de trabalho horária estimada para as diferentes prevalências dos estratos de risco que compõem o risco global dos 12 municípios, chegou-se a uma estimativa de profissionais necessários em cada estrato e, a partir daí, a um custo médio para cada um dos custos acima listados.

Para o cálculo dos salários dos microscopistas, a partir da ponderação de acordo com os quatro estratos de risco e estimativas de lâminas examinadas por cada profissional em diferentes prevalências (177) estimou-se a necessidade de 12 profissionais no estrato 1, quatro profissionais nos estratos 2 e 3 e um profissional no estrato 4. 0 custo final relativo aos salários corresponde a um valor médio que considerou estas diferenças (memória de cálculo nos anexos 14 a 17).

O custo final de salário envolvido em um exame de gota espessa para a área global dos municípios, no entanto, foi a soma dos salários dos microscopistas com o salário dos agentes comunitários de saúde (ACS), este último ponderado por $30 \%$, que é a proporção estimada de exames feitos em áreas isoladas (dados não publicados do Município do Novo Repartimento). Nas áreas isoladas, o ACS desloca-se para colher a lâmina, que é lida no laboratório pelos microscopistas. Os salários foram ainda ponderados para os cenários de estudo, ocorrendo um custo anual diferente para cada cenário (memória de cálculo nos anexos 14 a 17). 
O custo de microscópio foi estimado a partir de compra feita pelo PNCM (documento interno da Secretaria de Vigilância em Saúde - dados não publicados) no ano de 2006. Foram comprados naquele ano 380 microscópios com custo unitário de $\mathrm{R} \$ 10.939,00$. Este custo foi anualizado para obtenção do seu valor equivalente por ano e estimar a sua distribuição pelo tempo de duração do equipamento $(48,135)$. O tempo de uso foi estimado em 15 anos, baseado em artigo de Fernando e cols. (37). A taxa de desconto utilizada foi de $5 \%(162,163)$. A Tabela de Anualização (135) indica para uma vida útil de 15 anos do bem de capital e para uma taxa de desconto de $5 \%$ o fator de anualização de 10,380. Assim, o custo final do microscópio foi estimado em $\mathrm{R} \$ 1.053,85 /$ ano $(\mathrm{R} \$ 10.939 / 10,380)$. Para análise de sensibilidade foi feita a variação do custo do microscópio, tomando como base uma vida útil de 30 anos, com base na opinião e experiência de expert (Dra. Marinete Póvoa - Laboratório de malária do Instituto Evandro Chagas, SVS/MS). A Tabela de Anualização (135) indica para uma vida útil de 30 anos do bem de capital e para uma taxa de desconto de $5 \%$ o fator de anualização de 15,372. Assim, o custo final do microscópio foi estimado, para fins de variação no seu custo, em $\mathrm{R} \$$ $711,62 /$ ano ( $R \$ 10.939 / 15,372)$. O custo final do microscópio considerou a estratificação pelas áreas de risco, assumindo um microscópio para cada microscopista, replicando as quantidades de profissionais utilizadas para calcular os salários em cada estrato. O custo final relativo ao microscópio corresponde a um valor médio que considerou as diferenças de risco (memória de cálculo no anexo 18).

O custo de manutenção de microscópios foi obtido por meio de registros do Laboratório de Malária do Instituto Evandro Chagas (dados nãopublicados). O custo final foi estimado do mesmo modo citado para os microscópios, por meio da estratificação de risco e assumindo uma manutenção por ano para cada microscópio. O custo final de manutenção corresponde a um valor médio que considerou as diferenças de risco (memória de cálculo no anexo 18). 
O custo médio de treinamento para formar microscopistas foi obtido no PNCM, em tabelas de monitoramento de capacitações realizadas pela Secretaria de Estado da Saúde (SES) de Roraima, por meio de recursos repassados pelo PNCM e que refletem os custos praticados em geral pelos demais Estados (documentos internos da Secretaria de Vigilância em Saúde - dados não publicados). $O$ treinamento para microscopistas é de 240 horas e pode ocorrer uma vez por ano em cada município endêmico para turmas de 10 técnicos, tendo periodicidade maior nos municípios que têm equipes estáveis. O custo final do treinamento incluiu os itens de passagens e diárias para o monitor e alunos. Os custos podem variar dependendo dos custos de deslocamentos, principalmente. Decidiu-se pela estimativa de um treinamento por ano em cada município, com o total de 12 treinamentos em 2006. Os custos de treinamento variaram de acordo com os cenários de análise.

O método de estimativa de custo do transporte para realizar microscopia em áreas isoladas está detalhado no item de transporte relativo ao teste rápido (a seguir). O custo de transporte para a intervenção "microscopia" é o dobro do custo da intervenção "teste rápido", já que ela envolve dois deslocamentos: um para a coleta do sangue e outro para a entrega dos resultados. $\mathrm{O}$ custo final também considerou os quatro estratos de risco.

\subsubsection{Custo da Estratégia Teste Rápido}

No custo final da estratégia "teste rápido" estão considerados os seguintes custos: compra do kit diagnóstico, luvas, salário de agente comunitário de saúde que realiza o teste, treinamento na técnica de execução do teste e transporte das secretarias de saúde para a realização do teste rápido. 
O custo do OptiMal® foi obtido da Portaria de compra pelo PNCM no ano 2005 (34) e de documento interno da Secretaria de Estado da Saúde do Pará (Processo no 118630/05 - dados não publicados). O OptiMal® comprado pelas duas instituições no ano 2005 foi do tipo IT (individual test), apresentado em kits com 24 testes individuais. Cada IT contém: um dispositivo com tira-teste, poço de conjugado e poço de lavagem, uma tampa para os poços, uma ampola conta-gotas para os poços, uma lanceta estéril, um lenço umedecido desinfetante, uma pipeta capilar e um procedimento esquemático com as instruções de uso. Os testes comprados foram usados na rede do SUS durante $o$ ano seguinte. Ainda se considerou para efeito de variação, o orçamento estimado pela DiaMed, produtora do teste, para o ano de 2007 em resposta à solicitação da Secretaria de Estado da Saúde do Amazonas (proposta de orçamento - dados não publicados e fornecidos pelo PNCM/SVS/MS).

Para a estimativa do custo do salário do agente comunitário de saúde que realiza o teste rápido, utilizou-se a mesma referência usada para a microscopia, devido a que a OMS estima 13 minutos para a coleta, confecção e leitura de uma lâmina com baixa parasitemia e 15 minutos para a realização de um teste rápido $(168,177)$, então o número máximo de testes realizados foi considerado o mesmo de lâminas examinadas, em cada estrato, assim como o número de ACS necessários. O custo final relativo aos salários corresponde a um valor médio que considerou estas diferenças. Os salários foram ainda ponderados para os cenários de estudo, ocorrendo um custo anual diferente para cada cenário (memória de cálculo nos anexos 15 e 16).

Não há registros no PNCM de custos de treinamento para uso do OptiMal®, uma vez que o treinamento das equipes para a realização do teste foi proporcionado pelo laboratório produtor para os Laboratórios Centrais de Saúde Pública (LACEN) dos noves estados da Amazônia Legal; Os estados realizaram a sua multiplicação para os municípios (informação 
do PNCM - dados não publicados). No Estado do Pará, a Secretaria de Estado da Saúde multiplicou o treinamento para os municípios mas, não foram encontrados registros dos custos incorridos.

Para a estimativa do custo do treinamento para realização do OptiMal®, tomou-se como base, então, o custo do treinamento de 240 horas para formar microscopistas, reduzindo-o a um custo equivalente a duas horas e meia (custo dividido por 240 e multiplicado por 2,5) e assumindo-se que os itens de custos incorridos são os mesmos: passagens e diárias para o monitor e alunos. A duração do treinamento de duas horas e meia foi baseada em manual de treinamento da Organização Mundial da Saúde que explica o processo em etapas, as quais somam 150 minutos (172). A literatura científica afirma que o uso de testes rápidos exige pouco tempo de treinamento mas, é falha em quantificar a carga horária exata necessária $(14,27,87,168)$. Estudo realizado no Laos (85), por sua vez, demonstrou que apenas uma hora de treinamento ministrado a voluntários foi suficiente para garantir a qualidade do exame. Como o manual da OMS detalha precisamente os passos do treinamento, decidiu-se pelo uso de 150 minutos para a estimativa dos custos (172), com um treinamento por ano em cada município. $\mathrm{O}$ custo de treinamento variou de acordo com os cenários de análise.

O custo de transporte para deslocamento de equipes de saúde para realizar a busca ativa e o diagnóstico foi estimado a partir de gastos com os combustíveis. No Município do Novo Repartimento foram consumidos 500 litros de óleo diesel por mês e 800 litros de gasolina por mês durante o período de implantação do OptiMa|®. O gasto com os combustíveis corresponde aos deslocamentos feitos pelos agentes comunitários de saúde para as áreas distantes de laboratórios de diagnóstico microscópico. Para o diagnóstico com o OptiMal® foi feito um deslocamento para realização de cada busca ativa de pacientes febris; neste caso, o diagnóstico e os respectivos medicamentos são fornecidos de imediato aos pacientes com 
resultados positivos. Para o diagnóstico com a gota espessa são feitos dois deslocamentos, o primeiro para a coleta do sangue dos pacientes febris e $o$ segundo com o retorno do resultado e os medicamentos. Assim, a quantidade de combustíveis estimada no modelo foi duplicada para a intervenção "microscopia": 1.000 litros de óleo diesel por mês e 1.600 litros de gasolina por mês.

Os custos da gasolina e do óleo diesel foram coletados na Agência Nacional de Petróleo, Gás Natural e Biocombustíveis (ANP), por meio de relatórios de levantamento de custos de revenda. Os dados da ANP são apresentados por Macrorregiões, então foram selecionados os custos da Região Norte. O preço médio de revenda de gasolina na Região Norte em 2006 foi de $R \$ 2,69 /$ litro e o preço médio do óleo diesel foi de $R \$ 1,99 /$ itro $(4,5)$.

Para a estratégia "teste rápido", o custo de gasolina por mês foi estimado em $\mathrm{R} \$ 2.152,00(800 \times 2,69)$ e do óleo diesel por mês em $\mathrm{R} \$$ $995,00(500 \times 1,99)$, com um total de $R \$ 3.147,00$ de gastos com combustíveis por mês. Para a estratégia "microscopia" em $R \$ 4.304,00$ $(1.600 \times 2,69)$ e $R \$ 1.990,00(1.000 \times 1,99)$, respectivamente, com um total de $R \$ 6.294,00$ de gastos com combustíveis por mês. Estes custos foram considerados para o caso-base.

Para estimar os custos com combustíveis para os demais municípios de modo a obter-se bases para variações de custos, foi estabelecida, inicialmente, a relação de unidade laboratorial por $\mathrm{Km}^{2}$, a partir da área territorial dividida pelo número de laboratórios ativos em 2006, o que estima a cobertura espacial de laboratório por $\mathrm{Km}^{2}$. A relação estimada para o Município do Novo Repartimento foi usada, então, como referência (um laboratório para cada $531 \mathrm{~km}^{2}$ ), por ter sido a fonte da coleta do dado. Todas as relações dos 11 outros municípios foram divididas por 531, obtendo-se assim um fator de correção por município para a estimativa de área a ser 
coberta por transporte, assumindo-se que quanto maior o fator de correção maior seria a possibilidade de dispersão territorial e, consequentemente, de necessidade de transporte. Os custos relativos ao Município do Novo Repartimento foram usados como caso-base e os custos estimados pelo fator de correção, foram usados como intervalos para variação. Os cálculos e valores usados para o caso-base e para os intervalos estão expressos na tabela 14.

Para o custo final do transporte foi ainda considerada a carga da malária nos quatro estratos de risco, tomando como base a relação existente entre lâminas e quantidade de profissionais em cada estrato, como já mencionado (12 para o estrato 1, quatro para os estratos 2 e 3 e um para 0 estrato 4). Os números de profissionais para cada estrato foi usado como proxy para a magnitude do transporte que seria necessário em cada estrato. Foi considerado que no estrato 1 o custo do transporte seria o custo total obtido conforme os cálculos da tabela 14, multiplicado por 12 meses (para o ano de 2006), o que resulta em $\mathrm{R} \$ 37.764,00$ por ano no estrato 1. A partir deste estrato foi estabelecido um fator de correção. $O$ fator de correção teve o objetivo de estimar a carga de transporte a partir do número de profissionais, tendo com como base o número de profissionais do estrato 1 (12 profissionais). Para o estrato 1 o fator de correção foi igual a um (12/12); para os estratos 2 e 3 o fator de correção foi igual a três (12/4) e para o estrato 4 o fator de correção foi igual a 12 (12/1) (cálculos detalhados para o caso-base nos anexos 19 e 20). O custo de transporte para a carga da malária de cada estrato foi o resultado da divisão do custo do estrato 1 (valor integral multiplicado por 12 meses) pelo fator de correção. A soma dos custos de cada estrato corresponde a 111.637 testes/ano (considerando o cenário 1), e foi ponderada por 0,3 , que corresponde a $30 \%$ de áreas isoladas, onde se utiliza o transporte. $O$ mesmo método foi adotado para teste rápido e para gota espessa (memórias de cálculo no anexos 19 e 20). 
Tabela 14 - Custos estimados de combustíveis usados no controle de malária no ano de 2006 por município, a partir da área territorial e número de laboratórios, tomando como referência o Município do Novo Repartimento. 12 Municípios do Estado do Pará, 2006.

\begin{tabular}{|c|c|c|c|c|c|c|}
\hline Municípios & $\begin{array}{c}\text { Extensão } \\
\text { territorial } \\
\text { (área em } \\
\text { km2) }\end{array}$ & $\begin{array}{l}\text { Número de } \\
\text { Laboratórios } \\
\text { ativos para } \\
\text { diagnóstico de } \\
\text { malária em } \\
2006 \\
\\
\text { (2) }\end{array}$ & $\begin{array}{l}\text { Relação } \\
\text { "unidade } \\
\text { laboratorial } \\
\text { por área" (em } \\
\text { km2) }- \\
\text { cobertura } \\
\text { laboratorial } \\
\text { por km² } \\
\\
(1) /(2)\end{array}$ & $\begin{array}{l}\text { Fator de } \\
\text { correção de } \\
\text { custo de } \\
\text { combustíveis } \\
\text { em relação à } \\
\text { referência - } \\
\text { Município } \\
\text { Novo } \\
\text { Repartimento } \\
\text { [(1)/(2)]/531 } \\
\end{array}$ & $\begin{array}{c}\text { Custo do } \\
\text { transporte para } \\
\text { realização de teste } \\
\text { répido em áreas } \\
\text { remotas (por mês), } \\
\text { a partir da } \\
\text { multiplicação do } \\
\text { custo de referência } \\
-\mathrm{R} \$ 3.147 \text { - pelo } \\
\text { fator de correção } \\
(\mathrm{R} \$)\end{array}$ & $\begin{array}{c}\text { Custo do transporte } \\
\text { para realização de } \\
\text { gota espessa em } \\
\text { areas remotas (por } \\
\text { mês), a partiri da } \\
\text { multiplicação do } \\
\text { custo de referência - - } \\
\mathbf{R} \$ 6.294,00 \text { - pelo } \\
\text { fator de correção } \\
(\mathbf{R} \$)\end{array}$ \\
\hline Baião & 3.758 & 12 & 313,17 & 0,589767734 & $1.856,00^{(1)}$ & $3.712,00^{(1)}$ \\
\hline $\begin{array}{l}\text { Goianésia do } \\
\text { Pará }\end{array}$ & 7.021 & 6 & $1.170,17$ & 2,203703704 & $6.935,06$ & $13.870,11$ \\
\hline Itaituba & 62.041 & 26 & $2.386,19$ & 4,493770824 & $14.141,90$ & $28.283,79$ \\
\hline Jacareacanga & 53.303 & 25 & $2.132,12$ & 4,015291902 & $12.636,12$ & $25.272,25$ \\
\hline Jacundá & 2.008 & 3 & 669,33 & 1,260514752 & $3.966,84$ & $7.933,68$ \\
\hline Marabá & 15.092 & 34 & 443,88 & 0,835936635 & $2.630,69$ & $5.261,39$ \\
\hline Nova Ipixuna & 1.600 & 3 & 533,33 & 1,004394225 & $3.160,83$ & $6.321,66$ \\
\hline $\begin{array}{l}\text { Novo } \\
\text { Progresso }\end{array}$ & 38.162 & 15 & $2.544,13$ & 4,791211551 & $15.077,94$ & $30.155,89$ \\
\hline $\begin{array}{l}\text { Novo } \\
\text { Repartimento }\end{array}$ & 15.399 & 29 & 531,00 & 1 & $3.147,00$ & $6.294,00$ \\
\hline $\begin{array}{l}\text { Santana do } \\
\text { Araguaia }\end{array}$ & 11.591 & 9 & $1.287,89$ & 2,425402804 & $7.632,74$ & $15.265,49$ \\
\hline $\begin{array}{l}\text { São Félix do } \\
\text { Xingu }\end{array}$ & 84.212 & 14 & $6.015,14$ & 11,32795265 & $35.649,07^{(1)}$ & $71.298,13^{(1)}$ \\
\hline $\begin{array}{l}\text { São Geraldo } \\
\text { do Araguaia }\end{array}$ & 3.270 & 7 & 467,14 & 0,879741727 & $2.768,55$ & $5.537,09$ \\
\hline $\begin{array}{l}\text { Total dos } \\
\text { municípios }\end{array}$ & 297.457 & 183 & $1.625,45$ & & & \\
\hline
\end{tabular}

Fontes: IBGE- Ministério do Planejamento, Orçamento e Gestão; Município do Novo Repartimento-PA. Nota: ${ }^{(1)}$ Valores usados para intervalos de custos em cada intervenção.

Os cálculos para o custo de transporte de equipes tiveram o objetivo de refletir, teoricamente, no custo final de transporte, as diferentes extensões territoriais, os diferentes estratos de risco e a proporção de exames em áreas isoladas. Custos de transporte não foram considerados para o cenário 2 - áreas com laboratórios. 


\subsubsection{Custos Diretos do Cuidado da Doença}

Os itens componentes destes custos foram: consultas, internação, exames gerais realizados em ambulatório, medicamentos antimaláricos, medicamento antitérmico e transporte de medicamentos. As fontes consultadas foram: Tabela de procedimentos do SUS; Sistema de Informações hospitalares do SUS (SIH-SUS); Sistema de Informação de Insumos Estratégicos (SIES); Banco de Preços do Ministério da Saúde; e tabelas de custos relativos a contrato de empresa de transporte aéreo da SVS. $(89,96)(92)$

O custo de consulta foi estimado assumindo que todos os pacientes com malária grave realizaram uma consulta ambulatorial para a realização de exames de pré-internação. $O$ custo de consulta também foi contabilizado em todas as possibilidades de não encerramento do diagnóstico (verdadeiros negativos, falsos positivos e falsos negativos) e ainda nas possibilidades de desfechos não favoráveis durante o tratamento (recidivas ou recrudescências). Nas situações citadas, o custo da consulta foi um estimador mínimo de reuso do sistema de saúde para continuidade da investigação clínica ou de retratamento.

Foi assumida a prescrição de medicamento antitérmico para uso por três dias $(1,8,68)$ para todos os pacientes febris. $O$ antitérmico selecionado como padrão para uso foi o acetaminofen, devido ao seu uso disseminado e sem contra-indicações absolutas (169). O custo do acetaminofen foi coletado no Banco de Preços do Ministério da Saúde $(89,99)$.

Os custos de internação foram estimados assumindo que todos os pacientes internados receberam antimaláricos, apresentavam diagnóstico de malária falciparum grave (de acordo com a previsão do modelo), na préinternação realizaram um conjunto de testes diagnósticos que são preditivos de malária grave, como: hemograma; coagulograma; glicemia; dosagens 
sanguíneas de sódio, potássio, uréia, creatinina, bilirrubinas totais e frações, Transaminase Glutâmico-Oxalacética (TGO), Transaminase GlutâmicoPirúvica (TGP), Gama-GT, Desidrogenase Lática (DHL), fosfatase alcalina; e Telerradiografia do Tórax. Foi assumido, ainda, que durante a internação foi realizado um exame de gota espessa por dia para monitoramento, mesmo quando o diagnóstico inicial fora com o teste rápido (68).

Os custos da consulta e dos exames ambulatoriais foram coletados da Tabela de Procedimentos do SUS (96).

Os custos da hospitalização foram estimados a partir de valores de diárias de internação e de CTI pagos no ano de 2006, pelo SUS, na área de estudo (90). O custo de diária de Unidade de Terapia Intensiva (UTI) foi coletado na Tabela de Procedimentos do SUS (96). Para a estimativa do tempo de permanência em regime de internação, tomou-se como base a média do tempo de permanência por malária por Plasmodium falciparum no Estado do Pará em 2006, por município. A média para o Estado do Pará foi 3,8 dias e na distribuição por municípios a menor média foi 2 dias e a maior 18,5 dias. A Fundação de Medicina Tropical do Amazonas, em suas normas, define que "o paciente deverá permanecer, quando internado, por um período mínimo de 07 dias (malária falciparum)" (68). Com base nas duas fontes, decidiu-se, então, trabalhar com a média de 10 dias de internação, com variação de sete a 18 dias. Foi arbitrado ainda $50 \%$ do período de internação em regime de UTI e 50\% em regime de enfermaria comum, com variação de 30 a $70 \%$ em regime de UTI. O custo do caso-base e os custos das variações representam a média dos cálculos feitos em todos os cenários possíveis (memória de cálculo no anexo 21). Decidiu-se por esta estimativa e não pelo uso do valor médio pago pelo SUS nas internações por malária por Plasmodium falciparum, devido a que a média dos gastos das internações é, usualmente, enviesada pela inclusão de gastos com internação de pacientes não-graves, o que é evidenciado pelo curto tempo médio de internação, o que diminui o valor médio de gastos por internação. 
A média simples que se pode extrair dos valores pagos nas internações não reflete, fielmente, o tempo de internação praticado nos casos graves e os seus custos decorrentes.

Os custos do tratamento específico foram estimados prevendo-se que todos os pacientes com exame positivo para malária receberam medicação antimalárica. Também foi coletado o custo do transporte para o Estado do Pará, pois os medicamentos comprados pela SVS são entregues e armazenados no Centro Nacional de Armazenamento e Distribuição de Imunobiológicos (CENADI), unidade da SVS na cidade do Rio de Janeiro. Não foi possível obter os custos de transporte de medicamentos de Belém para os municípios selecionados.

Os custos dos medicamentos antimaláricos foram coletados por meio do Sistema de Informação de Insumos Estratégicos (SIES), da SVS (92), que contém todos os custos e movimentação de insumos como medicamentos, vacinas e inseticidas. Foram coletados os dados relativos às compras de 2005 e 2006. Os custos de 2005 foram usados para os medicamentos que foram comprados naquele ano, para seu uso em 2006. Os custos incluídos no SIES são do tipo CIF (costs, insurance and freight), ou seja, que incluem, no caso de medicamentos importados por meio da OPAS (artesunato, artemeter, Coartem ${ }^{\circledR}$ e dicloridrato de quinina) os custos de seguro e de frete, além da taxa de administração da cooperação com a OPAS; no caso dos demais medicamentos, o custo expresso no SIES contempla os custos repassados pelos laboratórios produtores nacionais e pagos por meio de nota fiscal pelo Ministério da Saúde. O Ministério da Saúde está isento das taxas de importação que incidiria sobre os medicamentos importados.

Devido ao artesunato ter seu uso indicado na forma de diluição em solução de glicose a $5 \%$, foi levantado o custo da glicose no Banco de Preços do Ministério da Saúde $(89,99)$, para a composição do custo. 
Após a obtenção dos custos individuais dos medicamentos antimaláricos, os custos finais foram organizados para três situações: 1) malária vivax; 2) malária falciparum não-grave; e 3) malária falciparum grave, de acordo com os medicamentos e respectivas doses indicadas nas diversas faixas etárias e na gestação. Os esquemas utilizados como padrão foram os de primeira linha preconizados pelo Ministério da Saúde segundo as doses demonstradas na tabela $2(88,102,125)$. Para cada uma das três formas de malária citadas, os custos finais representam a soma ponderada dos custos básicos de cada esquema de tratamento pela proporção de casos de malária nas faixas etárias consideradas e pela freqüência de gravidez. As estimativas do número de casos por faixas etárias e gravidez foram coletadas no SIVEP malária, pelos dados de notificação de 2006 (91) e a estimativa de malária grave na gravidez em dados publicados na literatura científica (83). Cálculos detalhados dos custos dos medicamentos antimaláricos no anexo 13.

O custo do transporte dos medicamentos foi coletado nas planilhas de pagamentos do Ministério da Saúde, relativas ao contrato de empresa aérea licitada para este fim (documentos internos da SVS - dados não publicados). Obteve-se a planilha com todos os pagamentos feitos pela SVS com o transporte de medicamentos antimaláricos no ano de 2006, para o Estado do Pará. Para estimar o custo relativo aos 12 municípios de estudo, o custo total para o Estado do Pará foi ponderado pela proporção de casos positivos que correspondem aos 12 municípios: $27,2 \%$ dos casos positivos do Estado do Pará em 2006. No custo do transporte incorrem o "peso taxado ou cubado" da mercadoria (o peso cubado é calculado da seguinte forma: largura $\mathrm{x}$ altura $\mathrm{x}$ comprimento/6.000 $\mathrm{x}$ quantidade de volumes; 0 denominador 6.000 é uma convenção usada pelo transporte aéreo de cargas), o valor do frete, os valores de coleta e de entrega e o seguro (corresponde a $0,33 \%$ sobre o valor dos medicamentos). 


\subsection{PRESSUPOSTOS DO MODELO}

O modelo de análise foi estruturado para estimar o custo-efetividade do diagnóstico para os casos novos de malária. Os casos novos de malária notificados no ano de 2006 nos 12 municípios de estudo foram a base para estimativas de alguns parâmetros epidemiológicos. Este pressuposto foi contemplado por meio do número total de lâminas positivas, excluindo-se LVC. Assim, cada lâmina positiva não classificada como LVC representou um caso novo, que pode ser um caso de reinfecção também. Para contemplar este pressuposto, obedeceu-se à normatização relativa à LVC e de casos novos do PNCM, que preconiza para a área amazônica que lâminas de pacientes que realizaram tratamento para Plamodium vivax dentro dos últimos 60 dias e para Plasmodium falciparum dentro dos últimos 40 dias do diagnóstico atual, devam ser consideradas como LVC e em qualquer situação em que não preencham estes critérios devam ser classificadas como "caso novo" (106). Para o banco completo de 135.675 registros do ano de 2006, as LVC representam 17,6\% (23.858) de todas as lâminas examinadas. Entre as lâminas de LVC 70,5\% (16.829) foram negativas. As lâminas positivas de LVC, que são 2.454 lâminas de Plasmodium falciparum (10,3\%) e 4.365 lâminas de Plasmodium vivax (18,3\%), representam no conjunto das lâminas de 2006 apenas 5\% dos casos (Plasmodium falciparum-1,8\% e Plasmodium vivax-3,2\%), nos 12 municípios estudados. Estas lâminas positivas de LVC poderiam ser casos de recidiva, recrudescência ou reinfecções. Além da pequena magnitude da ocorrência dos possíveis casos de recrudescência ou recidiva, estes dois eventos não representam estados contínuos na evolução da malária e nem se relacionam com graus de gravidade da doença, o que limita o uso de outros modelos de análise de decisão, como o modelo de Markov, indicados para doenças com quadros clínicos recorrentes (65). Assim, assumiu-se como pressuposto considerar no modelo apenas os casos novos e fez-se a opção pela árvore de decisão. 
Os casos de malária mista foram considerados no modelo conforme descrito na definição de caso e não como um dos braços dos resultados de diagnóstico da árvore de decisão, já que o OptiMal®, assim como os demais testes rápidos existentes, não discrimina a malária mista (114). Os casos mistos de malária falciparum e malária vivax corresponderam a apenas $0,8 \%$ (846 casos) das lâminas examinadas em 2006, nos 12 municípios estudados, dentre todas as lâminas de casos novos examinadas no período e que correspondiam à definição de caso. Este número de casos foi contabilizado nos custos conforme descrito na definição de caso.

Os eventos adversos às drogas foram considerados como "0". Os antimaláricos, em geral, são muito bem tolerados, $(1,8,35,136,138)$ não havendo custos adicionais significativos devido às conseqüências do tratamento.

A probabilidade de desenvolvimento da forma grave de malária por Plasmodium vivax, foi considerada como "0" no modelo, com base em estudo de Lacerda (2007), que estimou esta freqüência em 1,4\% dos casos com IC 95\%: 0,0 - 4,6\%. (66).

A probabilidade de cura espontânea para as duas formas de malária (vivax e falciparum), também foi considerada como "0", no modelo.

No modelo de decisão, para o grupo "sem malária" - onde se estima a especificidade das duas intervenções - foram utilizadas as mesmas freqüências esperadas de Plasmodium falciparum e Plasmodium vivax do grupo "com malária", já que os dados do SIVEP não identificam os falsos positivos, que são tratados como malária invariavelmente. Com esta dicotomia inicial no grupo "sem malária", foi possível seguir o modelo para a estimativa das probabilidades de resultados falsos positivos de Plasmodium falciparum e de Plasmodium vivax, em cada uma das intervenções. 
Em ambas as intervenções, para os braços de decisão relativos aos "verdadeiros negativos", foi considerado que o resultado negativo acurado aumenta a probabilidade de uma condução clínica adequada da síndrome febril, por descartar a malária como diagnóstico. Foi arbitrada em $90 \%$ a probabilidade de um desfecho adequado para os diagnósticos diferenciais da malária, que muitas vezes, na Amazônia, são quadros clínicos virais ou bacterianos auto-limitados ou com tratamento eficaz $(102,125)$.

Para os cenários 2 e 3 foram assumidas as mesmas probabilidades do cenário $1 \mathrm{em}$ relação às proporções de casos de malária vivax e falciparum e de probabilidade de malária falciparum grave.

Foi assumida a ausência de casos de malária associados com qualquer outra doença.

Foram considerados como esquemas terapêuticos aqueles indicados como de primeira linha pelo $\operatorname{PNCM}(88,102,125)$ e foi assumido que todos os pacientes recebem o tratamento antimalárico e aderem totalmente aos esquemas preconizados.

Em um modelo de decisão para testes diagnósticos as principais diferenças recaem sobre os custos relativos aos testes e diferenças na sua acurácia, assim foi assumido que os pacientes, após o diagnóstico inicial, têm a mesma probabilidade de desfechos de saúde e apresentam os mesmos itens de custos para cada tipo de infecção, independentemente do método diagnóstico utilizado (148).

Foi assumido que o TR encontrava-se com o tempo de validade útil para o período de intervenção de 12 meses.

Não foram considerados custos relativos à infra-estrutura, como a construção e manutenção de laboratórios e custos de cadeia de frio. 
Não foram considerados os custos relativos ao controle de qualidade de ambos os métodos diagnósticos.

Não foi considerada a perspectiva da sociedade e não foram considerados os custos intangíveis.

\subsection{RAZÕES DE CUSTO-EFETIVIDADE}

Foram estimadas as seguintes razões de custo-efetividade: 1) razão média de custo-efetividade para cada uma das estratégias estudadas, por paciente; e 2) razão de custo-efetividade adicional (RCEA).

\subsection{ANÁLISE DE SENSIBILIDADE}

Foi realizada análise de sensibilidade univariada. Cada parâmetro relevante do modelo foi variado individualmente, mantendo-se os demais inalterados, para testar o impacto da variação dos parâmetros nos resultados. A análise de sensibilidade fornece respostas em relação a possíveis modificações de impacto quando algum valor de estimativas incertas utilizadas na análise for modificado.

\subsection{ANÁLISE DOS DADOS DE CUSTO-EFETIVIDADE}

Para a construção do modelo de decisão, análise dos resultados de custo-efetividade e análise de sensibilidade foi utilizado o software TreeAge Pro® (159). 


\subsection{CONSIDERAÇÕES ÉTICAS}

O estudo não acarretou quaisquer riscos individuais ou coletivos para a população e os seus resultados subsidiarão a avaliação das ações do Ministério da Saúde em relação ao uso de testes rápidos na rotina do controle da malária, o que resultará em benefícios diretos à população sob risco. O protocolo de pesquisa foi submetido ao Comitê de Ética em Pesquisa (CEP) da Faculdade de Saúde Pública da Universidade de São Paulo em fevereiro de 2006, sob o número 1440. O CEP emitiu despacho informando que por se tratar de pesquisa que não envolve seres humanos, não houve necessidade de parecer por parte do comitê (ofício COEP 07/06 de 02 de fevereiro de 2006). 


\section{RESULTADOS}

\subsection{CENÁRIOS DA ANÁLISE DE CUSTO-EFETIVIDADE}

A análise de custo-efetividade foi realizada para três cenários hipotéticos diferentes: 1) cenário 1 - corresponde à área global do conjunto dos 12 municípios, considerando espaços que têm laboratórios instalados e mais as áreas isoladas e $100 \%$ das lâminas examinadas no ano de 2006 . O termo "áreas isoladas" significa o conjunto de áreas dos 12 municípios que não contam com infra-estrutura de laboratórios de malária e são, geralmente, localizadas em zonas rurais; 2) cenário 2 - corresponde à análise relativa às áreas dos 12 municípios cobertas por laboratórios de diagnóstico de malária e que respondem por cerca de $70 \%$ das lâminas examinadas em 2006; e 3) cenário 3 - áreas isoladas, cenário que corresponde somente às áreas dos 12 municípios sem cobertura de laboratórios para diagnóstico e que respondem por cerca de $30 \%$ das lâminas examinadas em 2006.

Para cada cenário foram feitas duas análises de custo-efetividade: a primeira para o desfecho "caso diagnosticado adequadamente" e a segunda para o desfecho "caso conduzido adequadamente".

\subsection{ANÁLISE DE CUSTO-EFETIVIDADE}

Os custos das estratégias "microscopia" e "teste rápido", resultantes da ACE, distribuídos por cenários e desfechos, estão apresentados nas tabelas 15 e 16.

O teste rápido é a estratégia diagnóstica mais cara nos cenários 1 e 2 . O custo do teste rápido para o desfecho 1 - "caso diagnosticado adequadamente" - é de $R \$ 11,09$ no cenário 1 e $R \$ 10,51$ no cenário 2, que 
correspondem a custos $40 \%$ mais elevados em relação à microscopia. Para o desfecho 2 - "caso conduzido adequadamente" - o custo do teste rápido é de $R \$ 30,97$ no cenário 1 e de $R \$ 30,42$ no cenário 2 , cerca de $13 \%$ mais elevados em comparação à microscopia (tabelas 15 e 16).

Nos dois desfechos do cenário 3 , a relação é inversa, sendo a microscopia mais cara, com custo de $R \$ 14,73$ para o desfecho 1 e de $R \$$ 34,27 para o desfecho 2 (tabelas 15 e 16).

Os efeitos das estratégias "microscopia" e "teste rápido" distribuídos por cenários e desfechos, estão também apresentados nas tabelas 15 e 16. O teste rápido foi menos efetivo nos três cenários e nos dois desfechos de cada cenário, deixando de diagnosticar e de conduzir adequadamente 300 casos em 100.000 lâminas em qualquer uma das situações, comparativamente à microscopia.

Os resultados da ACE para os três cenários e os dois desfechos estão apresentados nas tabelas 15 e 16. A estratégia "teste rápido" foi dominada pela estratégia "microscopia" nos cenários 1 (análise global) e 2 (análise de áreas com laboratório), devido a maior custo e menor efetividade e para ambos os desfechos. No cenário 3 a estratégia "teste rápido" foi a de menor custo e a menos efetiva e a "microscopia" apresentou custos mais altos e foi mais efetiva, permanecendo, ainda, como a estratégia mais custo-efetiva.

Para o primeiro desfecho (diagnóstico adequado) e em todos os cenários, o teste rápido deixaria de diagnosticar adequadamente 300 casos em 100.000 lâminas, quando comparado à microscopia. No cenário 3 a estratégia microscopia é mais cara e para cada caso a mais diagnosticado nesta intervenção seria incorrido um custo de $R \$ 1.193,33$ em comparação ao teste rápido (tabela 15), o que corresponde a $R \$$ 
$357.999,00$ para 300 casos a mais diagnosticados adequadamente em 100.000 lâminas examinadas.

Para o segundo desfecho (caso conduzido adequadamente) e em todos os cenários, o teste rápido deixaria de conduzir adequadamente 300 casos em 100.000 lâminas, quando comparado à microscopia. No cenário 3 a estratégia microscopia é mais cara e mais efetiva e para cada caso a mais conduzido de forma adequada seria incorrido um custo de $\mathrm{R} \$ 1.016,67$ em comparação ao teste rápido (tabela 16), o que corresponde a $R \$ 305.001,00$ para 300 casos a mais conduzidos adequadamente em 100.000 lâminas examinadas.

Tabela 15 - Custos, custos adicionais, efeitos, efeitos adicionais, razão média de custo-efetividade e razão de custo-efetividade adicional das estratégias "microscopia" e "teste rápido", segundo o desfecho "caso diagnosticado adequadamente" e para os três cenários de análise. 12 municípios do Estado do Pará, 2006.

\begin{tabular}{|c|c|c|c|c|c|c|}
\hline Estratégia * $^{*}$ & Custo (R\$) & $\begin{array}{l}\text { Custo adicional } \\
\text { (R\$) }\end{array}$ & Efeito & $\begin{array}{c}\text { Efeito adicional } \\
\text { (caso } \\
\text { diagnosticado } \\
\text { adequadamente) }\end{array}$ & $\begin{array}{l}\text { Razão de Custo- } \\
\text { Efetividade } \\
\text { média (R\$ por } \\
\text { caso } \\
\text { diagnosticado } \\
\text { adequadamente) }\end{array}$ & $\begin{array}{l}\text { Razão de } \\
\text { Custo- } \\
\text { Efetividade } \\
\text { adicional } \\
\text { (RCEA) }\end{array}$ \\
\hline \multicolumn{7}{|c|}{ Cenário 1 - Análise Global - áreas com laboratório e áreas isoladas - 12 municípios } \\
\hline $\begin{array}{l}\text { Microscopia } \\
\text { Teste Rápido }\end{array}$ & $\begin{array}{c}7,87 \\
11,09\end{array}$ & 3,22 & $\begin{array}{l}0,985 \\
0,982\end{array}$ & $-0,003$ & $\begin{array}{c}7,99 \\
11,29\end{array}$ & (Dominada) \\
\hline \multicolumn{7}{|c|}{ Cenário 2 - Áreas com laboratório - 12 municípios } \\
\hline $\begin{array}{l}\text { Microscopia } \\
\text { Teste Rápido }\end{array}$ & $\begin{array}{c}7,46 \\
10,51\end{array}$ & 3,05 & $\begin{array}{l}0,985 \\
0,982\end{array}$ & $-0,003$ & $\begin{array}{c}7,57 \\
10,70\end{array}$ & (Dominada) \\
\hline \multicolumn{7}{|c|}{ Cenário 3 - Áreas isoladas - 12 municípios } \\
\hline $\begin{array}{l}\text { Teste Rápido } \\
\text { Microscopia }\end{array}$ & $\begin{array}{l}11,15 \\
14,73\end{array}$ & 3,58 & $\begin{array}{l}0,982 \\
0,985\end{array}$ & 0,003 & $\begin{array}{l}11,35 \\
14,95\end{array}$ & $1.193,33$ \\
\hline
\end{tabular}

Nota: * microscopia: comparador-base 
Tabela 16 - Custos, custos adicionais, efeitos, efeitos adicionais, razão média de custo-efetividade e razão de custo-efetividade adicional das estratégias "microscopia" e "teste rápido", segundo o desfecho "caso conduzido adequadamente" e para os três cenários de análise. 12 municípios do Estado do Pará, 2006.

\begin{tabular}{|c|c|c|c|c|c|c|}
\hline Estratégia * & $\begin{array}{c}\text { Custo } \\
\text { (R\$) }\end{array}$ & $\begin{array}{c}\text { Custo adicional } \\
\text { (R\$) }\end{array}$ & Efeito & $\begin{array}{l}\text { Efeito adicional } \\
\text { (caso conduzido } \\
\text { adequadamente) }\end{array}$ & $\begin{array}{l}\text { Razão de Custo- } \\
\text { Efetividade } \\
\text { média (R\$ por } \\
\text { caso conduzido } \\
\text { adequadamente) }\end{array}$ & $\begin{array}{l}\text { Razão de } \\
\text { Custo- } \\
\text { Efetividade } \\
\text { adicional } \\
\text { (RCEI) }\end{array}$ \\
\hline \multicolumn{7}{|c|}{ Cenário 1 - Análise Global - áreas com laboratório e áreas isoladas - 12 municípios } \\
\hline Microscopia & 27,22 & & 0,904 & & 30,11 & \\
\hline Teste Rápido & 30,97 & 3,75 & 0,901 & $-0,003$ & 34,37 & (Dominada) \\
\hline \multicolumn{7}{|c|}{ Cenário 2 - Áreas com laboratório - 12 municípios } \\
\hline Microscopia & 26,85 & & 0,904 & & 29,70 & \\
\hline Teste Rápido & 30,42 & 3,57 & 0,901 & $-0,003$ & 33,76 & (Dominada) \\
\hline \multicolumn{7}{|c|}{ Cenário 3 - Áreas isoladas - 12 municípios } \\
\hline Teste $\mathrm{F}$ & 31,22 & & 0,901 & & 34,65 & \\
\hline Microscopia & 34,27 & 3,05 & 0,904 & 0,003 & 37,91 & $1.016,67$ \\
\hline
\end{tabular}

Nota: * microscopia: comparador-base

\subsection{ANÁLISE DE SENSIBILIDADE}

Foi conduzida análise de sensibilidade do tipo univariada, ou seja, foi feita a variação de cada parâmetro epidemiológico ou de custo individualmente, mantendo-se todos os demais inalterados. A análise de sensibilidade utilizou, exclusivamente, os valores encontrados nas fontes utilizadas para o levantamento de parâmetros epidemiológicos e de custos: sistemas de informação de dados epidemiológicos e de custos; documentos oficiais da SVS, do Estado do Pará e Município do Novo Repartimento; e dados de literatura científica, conforme apresentado nas tabelas de parâmetros do estudo (tabelas 6, 11 e 12).

$\mathrm{Na}$ análise de sensibilidade foram variados todos os parâmetros epidemiológicos apresentados na tabela 6 e quanto aos custos foram variados, de acordo com cada um dos desfechos do estudo, os valores de: lâmina de gota espessa; lâmina de gota espessa em regime hospitalar; teste rápido; microscópio; transporte de equipes de saúde para realização da 
microscopia e do teste rápido em áreas isoladas; treinamentos para formar microscopistas e para a técnica do teste rápido; e diária de internação hospitalar para os casos graves.

A decisão para os parâmetros a serem incluídos na análise de sensibilidade baseou-se em estudos publicados de ACE de testes rápidos para malária $(24,37,77,146,148)$. As estimativas de sensibilidade e de especificidade da microscopia e do teste rápido são os parâmetros fundamentais da análise e foram considerados os itens mais importantes para a variação. Quanto aos custos, foram valorizados para a análise de sensibilidade, os parâmetros de custos que apresentaram grande dispersão dos valores quando da sua composição.

A análise de sensibilidade foi realizada para os três cenários e para os dois desfechos em cada cenário. As tabelas 17 a 22 apresentam os resultados da análise de sensibilidade por cenário e por desfecho, em um total de seis análises. São apresentados nas tabelas apenas os resultados dos parâmetros cujas variações alteraram o resultado da ACE em relação ao caso-base. 
Tabela 17 - Resultados da análise de sensibilidade para o desfecho "caso diagnosticado adequadamente" no cenário 1: áreas com laboratórios mais áreas isoladas. 12 municípios do Estado do Pará, 2006.

\begin{tabular}{|c|c|c|c|c|c|c|c|c|}
\hline Parâmetro & $\begin{array}{c}\text { Valor do } \\
\text { Parâmetro } \\
\text { usado na análise } \\
\text { de sensibilidade }\end{array}$ & Estratégias & Custo $(\mathrm{R} \$)$ & $\begin{array}{l}\text { Custo adicional } \\
\text { (R\$) }\end{array}$ & Efeito & $\begin{array}{l}\text { Efeito adicional - } \\
\text { caso diagnosticado } \\
\text { adequadamente }\end{array}$ & $\begin{array}{l}\text { Razão de custo - } \\
\text { efetividade média - } \\
\text { R } \$ \text { por caso } \\
\text { diagnosticado } \\
\text { adequadamente }\end{array}$ & $\begin{array}{l}\text { Razão de custo- } \\
\text { efetividade adicional } \\
\text { (RCEA) - R\$ por } \\
\text { caso a mais } \\
\text { diagnosticado } \\
\text { adequadamente }\end{array}$ \\
\hline \multirow{2}{*}{$\begin{array}{l}\text { Sensibilidade } \\
\text { da microscopia } \\
\text { - Plasmodium } \\
\text { vivax }\end{array}$} & 0,770 & $\begin{array}{l}\text { Microscopia } \\
\text { Teste Rápido }\end{array}$ & $\begin{array}{c}7,87 \\
11,09\end{array}$ & 3,22 & $\begin{array}{l}0,956 \\
\mathbf{0 , 9 8 2}\end{array}$ & 0,026 & $\begin{array}{c}8,23 \\
11,29\end{array}$ & 123,85 \\
\hline & 0,905 & $\begin{array}{l}\text { Microscopia } \\
\text { Teste Rápido }\end{array}$ & $\begin{array}{c}7,87 \\
11,09\end{array}$ & 3,22 & $\begin{array}{l}0,978 \\
0,982\end{array}$ & 0,004 & $\begin{array}{c}8,05 \\
11,29\end{array}$ & 805,00 \\
\hline \multirow{2}{*}{$\begin{array}{l}\text { Especificidade } \\
\text { da microscopia } \\
\text { - Plasmodium } \\
\text { vivax }\end{array}$} & 0,950 & $\begin{array}{l}\text { Microscopia } \\
\text { Teste Rápido }\end{array}$ & $\begin{array}{c}7,87 \\
11,09 \\
\end{array}$ & 3,22 & $\begin{array}{l}0,960 \\
0,982 \\
\end{array}$ & 0,022 & $\begin{array}{c}8,20 \\
11,29 \\
\end{array}$ & 146,36 \\
\hline & 0,988 & $\begin{array}{l}\text { Microscopia } \\
\text { Teste Rápido }\end{array}$ & $\begin{array}{r}7,87 \\
11,09 \\
\end{array}$ & 3,22 & $\begin{array}{l}0,979 \\
\mathbf{0}, 982 \\
\end{array}$ & 0,003 & $\begin{array}{c}8,04 \\
11,29 \\
\end{array}$ & $1.073,33$ \\
\hline \multirow{2}{*}{$\begin{array}{l}\text { Sensibilidade } \\
\text { da microscopia } \\
\text { - Plasmodium } \\
\text { falciparum }\end{array}$} & 0,830 & $\begin{array}{l}\text { Microscopia } \\
\text { Teste Rápido }\end{array}$ & $\begin{array}{c}7,87 \\
11,09\end{array}$ & 3,22 & $\begin{array}{l}0,978 \\
0,982\end{array}$ & 0,004 & $\begin{array}{c}8,05 \\
11,29\end{array}$ & 805,00 \\
\hline & 0,875 & $\begin{array}{l}\text { Microscopia } \\
\text { Teste Rápido }\end{array}$ & $\begin{array}{r}7,87 \\
11,09 \\
\end{array}$ & 3,22 & $\begin{array}{l}0,981 \\
0,982 \\
\end{array}$ & 0,001 & $\begin{array}{c}8,02 \\
11,29 \\
\end{array}$ & \multirow[t]{2}{*}{$3.220,00$} \\
\hline \multirow{2}{*}{$\begin{array}{l}\text { Sensibilidade } \\
\text { do teste rápido } \\
\text { - Plasmodium } \\
\text { vivax }\end{array}$} & \multirow[b]{2}{*}{1,00} & Microscopia & 7,87 & & 0,985 & & 7,99 & \\
\hline & & Teste Rápido & 11,09 & 3,22 & 0,995 & 0,010 & 11,14 & 322,00 \\
\hline \multirow{4}{*}{$\begin{array}{l}\text { Custo do } \\
\text { transporte de } \\
\text { equipes para } \\
\text { realizar a } \\
\text { microscopia }\end{array}$} & \multirow[t]{2}{*}{7,05} & Teste Rápido & 11,09 & & 0,982 & & 11,29 & \multirow{3}{*}{883,33} \\
\hline & & Microscopia & 13,74 & 2,65 & 0,985 & 0,003 & 13,95 & \\
\hline & \multirow[t]{2}{*}{13,41} & Teste Rápido & 11,09 & & 0,982 & & 11,29 & \\
\hline & & Microscopia & 20,10 & 9,01 & 0,985 & 0,003 & 20,40 & $3.003,33$ \\
\hline
\end{tabular}


Tabela 18 - Resultados da análise de sensibilidade para o desfecho "caso conduzido adequadamente" no cenário 1: áreas com laboratórios mais áreas isoladas. 12 municípios do Estado do Pará, 2006.

\begin{tabular}{|c|c|c|c|c|c|c|c|c|}
\hline Parâmetro & $\begin{array}{c}\text { Valor do } \\
\text { Parâmetro } \\
\text { usado na análise } \\
\text { de sensibilidade }\end{array}$ & Estratégias & Custo $(\mathrm{R} \$)$ & $\begin{array}{l}\text { Custo adicional } \\
\text { (R\$) }\end{array}$ & Efeito & $\begin{array}{l}\text { Efeito adicional - } \\
\text { caso diagnosticado } \\
\text { adequadamente }\end{array}$ & $\begin{array}{l}\text { Razão de custo - } \\
\text { efetividade média - } \\
\text { R\$ por caso } \\
\text { diagnosticado } \\
\text { adequadamente }\end{array}$ & $\begin{array}{l}\text { Razão de custo- } \\
\text { efetividade adicional } \\
\text { (RCEA) - R\$ por } \\
\text { caso a mais } \\
\text { diagnosticado } \\
\text { adequadamente }\end{array}$ \\
\hline \multirow{2}{*}{$\begin{array}{l}\text { Sensibilidade } \\
\text { da microscopia } \\
\text { - Plasmodium } \\
\text { vivax }\end{array}$} & 0,770 & $\begin{array}{l}\text { Microscopia } \\
\text { Teste Rápido }\end{array}$ & $\begin{array}{l}27,42 \\
30,97\end{array}$ & 3,55 & $\begin{array}{l}0,875 \\
\mathbf{0}, 901\end{array}$ & 0,026 & $\begin{array}{l}31,33 \\
34,37 \\
\end{array}$ & 136,54 \\
\hline & \multirow{2}{*}{$\begin{array}{l}0,905 \\
0,950\end{array}$} & $\begin{array}{l}\text { Microscopia } \\
\text { Teste Rápido }\end{array}$ & $\begin{array}{l}27,27 \\
30,97\end{array}$ & 3,70 & $\begin{array}{l}0,897 \\
0,901\end{array}$ & 0,004 & $\begin{array}{l}30,40 \\
34,37\end{array}$ & 925,00 \\
\hline \multirow{2}{*}{$\begin{array}{l}\text { Especificidade } \\
\text { da microscopia } \\
\text { - Plasmodium } \\
\text { vivax }\end{array}$} & & $\begin{array}{l}\text { Microscopia } \\
\text { Teste Rápido }\end{array}$ & $\begin{array}{l}27,25 \\
30,97\end{array}$ & 3,72 & $\begin{array}{l}0,881 \\
0,901\end{array}$ & 0,020 & $\begin{array}{l}30,93 \\
34,37\end{array}$ & 186,00 \\
\hline & 0,988 & $\begin{array}{l}\text { Microscopia } \\
\text { Teste Rápido }\end{array}$ & $\begin{array}{l}27,33 \\
30,97 \\
\end{array}$ & 3,74 & $\begin{array}{l}0,899 \\
0,901\end{array}$ & 0,003 & $\begin{array}{l}30,40 \\
34,37 \\
\end{array}$ & $1.246,67$ \\
\hline \multirow{2}{*}{$\begin{array}{l}\text { Sensibilidade } \\
\text { da microscopia } \\
\text { - Plasmodium } \\
\text { falciparum }\end{array}$} & 0,830 & $\begin{array}{l}\text { Microscopia } \\
\text { Teste Rápido }\end{array}$ & $\begin{array}{l}26,01 \\
30,97\end{array}$ & 4,96 & $\begin{array}{l}0,897 \\
\mathbf{0 , 9 0 1}\end{array}$ & 0,004 & $\begin{array}{l}28,99 \\
34,37\end{array}$ & $1.180,02$ \\
\hline & 0,875 & $\begin{array}{l}\text { Microscopia } \\
\text { Teste Rápido }\end{array}$ & $\begin{array}{l}26,62 \\
30,97 \\
\end{array}$ & 4,35 & $\begin{array}{l}0,901 \\
0,901\end{array}$ & 0,001 & $\begin{array}{l}29,54 \\
34,37 \\
\end{array}$ & $4.350,00$ \\
\hline \multirow{2}{*}{$\begin{array}{l}\text { Sensibilidade } \\
\text { do teste rápido } \\
\text { - Plasmodium } \\
\text { vivax }\end{array}$} & \multirow[b]{2}{*}{1,00} & Microscopia & 27,22 & & 0,904 & & 30,11 & \\
\hline & & Teste Rápido & 30,88 & 3,65 & 0,914 & 0,010 & 33,78 & 365,00 \\
\hline \multirow{2}{*}{$\begin{array}{l}\text { Sensibilidade } \\
\text { do teste rápido } \\
\text { - Plasmodium } \\
\text { falciparum }\end{array}$} & \multirow[t]{2}{*}{0,623} & Teste Rápido & 26,46 & & 0,875 & & 30,24 & \\
\hline & & Microscopia & 27,22 & 0,76 & 0,904 & 0,029 & 30,11 & 26,21 \\
\hline \multirow{4}{*}{$\begin{array}{l}\text { Custo do } \\
\text { transporte de } \\
\text { equipes para } \\
\text { realizar a } \\
\text { microscopia }\end{array}$} & \multirow[t]{2}{*}{7,05} & Teste Rápido & 30,97 & & 0,901 & & 34,37 & \\
\hline & & Microscopia & 33,10 & 2,13 & 0,904 & 0,003 & 36,61 & 710,00 \\
\hline & \multirow[t]{2}{*}{13,41} & Teste Rápido & 30,97 & & 0,901 & & 34,37 & \\
\hline & & Microscopia & 39,45 & 8,49 & 0,904 & 0,003 & 43,63 & $2.830,00$ \\
\hline
\end{tabular}


Tabela 19 - Resultados da análise de sensibilidade para o desfecho "caso diagnosticado adequadamente" no cenário 2: áreas com laboratórios. 12 municípios do Estado do Pará, 2006.

\begin{tabular}{|c|c|c|c|c|c|c|c|c|}
\hline Parâmetro & $\begin{array}{c}\text { Valor do } \\
\text { Parâmetro } \\
\text { usado na análise } \\
\text { de sensibilidade }\end{array}$ & Estratégias & Custo (R\$) & $\begin{array}{l}\text { Custo adicional } \\
\text { (R\$) }\end{array}$ & Efeito & $\begin{array}{c}\text { Efeito adicional - } \\
\text { caso diagnosticado } \\
\text { adequadamente }\end{array}$ & $\begin{array}{l}\text { Razão de custo - } \\
\text { efetividade média - } \\
\mathbf{R} \text { por caso } \\
\text { diagnosticado } \\
\text { adequadamente }\end{array}$ & $\begin{array}{c}\text { Razão de custo- } \\
\text { efetividade adicional } \\
\text { (RCEA) - R\$por } \\
\text { caso a mais } \\
\text { diagnosticado } \\
\text { adequadamente }\end{array}$ \\
\hline \multirow{2}{*}{$\begin{array}{l}\text { Sensibilidade } \\
\text { da microscopia } \\
\text { - Plasmodium } \\
\text { vivax }\end{array}$} & 0,770 & $\begin{array}{l}\text { Microscopia } \\
\text { Teste Rápido }\end{array}$ & $\begin{array}{c}7,46 \\
10,51\end{array}$ & 3,05 & $\begin{array}{l}0,956 \\
\mathbf{0 , 9 8 2}\end{array}$ & 0,026 & $\begin{array}{c}7,81 \\
10,70\end{array}$ & 117,31 \\
\hline & \multirow{2}{*}{$\begin{array}{l}0,905 \\
0,950\end{array}$} & $\begin{array}{l}\text { Microscopia } \\
\text { Teste Rápido }\end{array}$ & $\begin{array}{c}7,46 \\
10,51\end{array}$ & 3,05 & $\begin{array}{l}0,978 \\
\mathbf{0 , 9 8 2}\end{array}$ & 0,004 & $\begin{array}{c}7,63 \\
10,70\end{array}$ & 762.50 \\
\hline \multirow{2}{*}{$\begin{array}{l}\text { Especificidade } \\
\text { da microscopia } \\
\text { - Plasmodium } \\
\text { vivax } \\
\end{array}$} & & $\begin{array}{l}\text { Microscopia } \\
\text { Teste Rápido }\end{array}$ & $\begin{array}{c}7,46 \\
\mathbf{1 0 , 5 1} \\
\end{array}$ & 3,05 & $\begin{array}{l}0,960 \\
\mathbf{0 , 9 8 2} \\
\end{array}$ & 0,022 & $\begin{array}{c}7,77 \\
10,70 \\
\end{array}$ & 138,64 \\
\hline & 0,988 & $\begin{array}{l}\text { Microscopia } \\
\text { Teste Rápido }\end{array}$ & $\begin{array}{c}7,46 \\
10,51\end{array}$ & 3,05 & $\begin{array}{l}0,979 \\
\mathbf{0 , 9 8 2} \\
\end{array}$ & 0,003 & $\begin{array}{c}7,62 \\
10,70 \\
\end{array}$ & $1.016,67$ \\
\hline \multirow{2}{*}{$\begin{array}{l}\text { Sensibilidade } \\
\text { da microscopia } \\
\text { - Plasmodium } \\
\text { falciparum } \\
\end{array}$} & 0,830 & $\begin{array}{l}\text { Microscopia } \\
\text { Teste Rápido }\end{array}$ & $\begin{array}{c}7,46 \\
10,51 \\
\end{array}$ & 3,05 & $\begin{array}{l}0,978 \\
\mathbf{0 , 9 8 2} \\
\end{array}$ & 0,004 & $\begin{array}{c}7,63 \\
10,70 \\
\end{array}$ & 762,50 \\
\hline & 0,875 & $\begin{array}{l}\text { Microscopia } \\
\text { Teste Rápido }\end{array}$ & $\begin{array}{r}7,46 \\
10,51 \\
\end{array}$ & 3,05 & $\begin{array}{l}0,981 \\
\mathbf{0 , 9 8 2} \\
\end{array}$ & 0,001 & $\begin{array}{r}7,60 \\
10,70 \\
\end{array}$ & $3.050,00$ \\
\hline \multirow{2}{*}{$\begin{array}{l}\text { Sensibilidade } \\
\text { do teste rápido } \\
\text { - Plasmodium } \\
\text { vivax }\end{array}$} & \multirow[b]{2}{*}{1,00} & Microscopia & 7,46 & & 0,985 & & 7,57 & \\
\hline & & Teste Rápido & 10,51 & 3,05 & 0,995 & 0,010 & 10,55 & 305,00 \\
\hline
\end{tabular}


Tabela 20 - Resultados da análise de sensibilidade para o desfecho "caso conduzido adequadamente" no cenário 2: áreas com laboratórios.

12 municípios do Estado do Pará, 2006.

\begin{tabular}{|c|c|c|c|c|c|c|c|c|}
\hline Parâmetro & $\begin{array}{c}\text { Valor do } \\
\text { Parâmetro } \\
\text { usado na análise } \\
\text { de sensibilidade }\end{array}$ & Estratégias & Custo (R\$) & $\begin{array}{c}\text { Custo adicional } \\
\text { (R\$) }\end{array}$ & Efeito & $\begin{array}{l}\text { Efeito adicional - } \\
\text { caso diagnosticado } \\
\text { adequadamente }\end{array}$ & $\begin{array}{l}\text { Razão de custo - } \\
\text { efetividade média - } \\
\mathbf{R} \$ \text { por caso } \\
\text { diagnosticado } \\
\text { adequadamente }\end{array}$ & $\begin{array}{l}\text { Razão de custo- } \\
\text { efetividade adicional } \\
\text { (RCEA) - R\$ por } \\
\text { caso a mais } \\
\text { diagnosticado } \\
\text { adequadamente }\end{array}$ \\
\hline \multirow{2}{*}{$\begin{array}{l}\text { Sensibilidade } \\
\text { da microscopia } \\
\text { - Plasmodium } \\
\text { vivax }\end{array}$} & 0,770 & $\begin{array}{l}\text { Microscopia } \\
\text { Teste Rápido }\end{array}$ & $\begin{array}{l}27,04 \\
30,42\end{array}$ & 3,38 & $\begin{array}{l}0,875 \\
\mathbf{0 , 9 0 1}\end{array}$ & 0,026 & $\begin{array}{l}30,89 \\
33,75\end{array}$ & 130,00 \\
\hline & 0,905 & $\begin{array}{l}\text { Microscopia } \\
\text { Teste Rápido }\end{array}$ & $\begin{array}{l}26,89 \\
30,42\end{array}$ & 3,52 & $\begin{array}{l}0,897 \\
\mathbf{0 , 9 0 1}\end{array}$ & 0,004 & $\begin{array}{l}29,98 \\
33,75\end{array}$ & 880,00 \\
\hline \multirow{2}{*}{$\begin{array}{l}\text { Especificidade } \\
\text { da microscopia } \\
\text { - Plasmodium } \\
\text { vivax }\end{array}$} & 0,950 & $\begin{array}{l}\text { Microscopia } \\
\text { Teste Rápido }\end{array}$ & $\begin{array}{l}26,87 \\
30,42 \\
\end{array}$ & 3,55 & $\begin{array}{l}0,881 \\
\mathbf{0 , 9 0 1}\end{array}$ & 0,020 & $\begin{array}{l}30,49 \\
33,75\end{array}$ & 177,50 \\
\hline & 0,988 & $\begin{array}{l}\text { Microscopia } \\
\text { Teste Rápido }\end{array}$ & $\begin{array}{l}26,85 \\
30,42\end{array}$ & 3,57 & $\begin{array}{l}0,899 \\
\mathbf{0 , 9 0 1}\end{array}$ & 0,003 & $\begin{array}{l}29,89 \\
33,75\end{array}$ & $1.190,00$ \\
\hline \multirow{2}{*}{$\begin{array}{l}\text { Sensibilidade } \\
\text { da microscopia } \\
\text { - Plasmodium } \\
\text { falciparum }\end{array}$} & 0,830 & $\begin{array}{l}\text { Microscopia } \\
\text { Teste Rápido }\end{array}$ & $\begin{array}{l}25,63 \\
30,42\end{array}$ & 4,79 & $\begin{array}{l}0,897 \\
\mathbf{0 , 9 0 1}\end{array}$ & 0,004 & $\begin{array}{l}28,57 \\
33,75\end{array}$ & $1.197,50$ \\
\hline & 0,875 & $\begin{array}{l}\text { Microscopia } \\
\text { Teste Rápido }\end{array}$ & $\begin{array}{l}26,24 \\
30,42\end{array}$ & 4,18 & $\begin{array}{l}0,900 \\
\mathbf{0 , 9 0 1}\end{array}$ & 0,001 & $\begin{array}{l}29,13 \\
33,75\end{array}$ & $4.180,00$ \\
\hline \multirow{2}{*}{$\begin{array}{l}\text { Sensibilidade } \\
\text { do teste rápido } \\
\text { - Plasmodium } \\
\text { vivax }\end{array}$} & \multirow{2}{*}{1,00} & Microscopia & 26,85 & & 0,904 & & 29,69 & \multirow[b]{2}{*}{349,00} \\
\hline & & Teste Rápido & 30,34 & 3,49 & 0,914 & 0,010 & 33,18 & \\
\hline \multirow{2}{*}{$\begin{array}{l}\text { Sensibilidade } \\
\text { do teste rápido } \\
\text { - Plasmodium } \\
\text { falciparum }\end{array}$} & \multirow{2}{*}{0,623} & Teste Rápido & 25,91 & & 0,875 & & 29,61 & \multirow[b]{2}{*}{32,41} \\
\hline & & Microscopia & 26,85 & 0,94 & 0,904 & 0,029 & 29,69 & \\
\hline
\end{tabular}


Tabela 21 - Resultados da análise de sensibilidade para o desfecho "caso diagnosticado adequadamente" no cenário 3: áreas isoladas.

12 municípios do Estado do Pará, 2006.

\begin{tabular}{|c|c|c|c|c|c|c|c|c|}
\hline Parâmetro & $\begin{array}{c}\text { Valor do } \\
\text { Parâmetro } \\
\text { usado na análise } \\
\text { de sensibilidade }\end{array}$ & Estratégias & Custo (R\$) & $\begin{array}{l}\text { Custo adicional } \\
\text { (R\$) }\end{array}$ & Efeito & $\begin{array}{l}\text { Efeito adicional - } \\
\text { caso diagnosticado } \\
\text { adequadamente }\end{array}$ & $\begin{array}{l}\text { Razão de custo - } \\
\text { efetividade média - } \\
\mathbf{R} \$ \text { por caso } \\
\text { diagnosticado } \\
\text { adequadamente }\end{array}$ & $\begin{array}{l}\text { Razão de custo- } \\
\text { efetividade adicional } \\
\text { (RCEA) - R\$por } \\
\text { caso a mais } \\
\text { diagnosticado } \\
\text { adequadamente }\end{array}$ \\
\hline \multirow{2}{*}{$\begin{array}{l}\text { PPT - } \\
\text { prevalência de } \\
\text { malária }\end{array}$} & 0,127 & $\begin{array}{l}\text { Teste Rápido } \\
\text { Microscopia }\end{array}$ & $\begin{array}{l}11,15 \\
\mathbf{1 4 , 7 3}\end{array}$ & 3,58 & $\begin{array}{l}0,990 \\
\mathbf{0 , 9 9 2}\end{array}$ & 0,002 & $\begin{array}{l}11,26 \\
14.84\end{array}$ & $1.790,00$ \\
\hline & 0,167 & $\begin{array}{l}\text { Teste Rápido } \\
\text { Microscopia }\end{array}$ & $\begin{array}{l}11,15 \\
\mathbf{1 4 , 7 3} \\
\end{array}$ & 3,58 & $\begin{array}{l}0,988 \\
\mathbf{0 , 9 9 0} \\
\end{array}$ & 0,002 & $\begin{array}{l}11,29 \\
14,88 \\
\end{array}$ & $1.790,00$ \\
\hline \multirow{2}{*}{$\begin{array}{l}\text { Proporção de } \\
\text { casos de } \\
\text { Malária Vivax }\end{array}$} & 0,708 & $\begin{array}{l}\text { Teste Rápido } \\
\text { Microscopia }\end{array}$ & $\begin{array}{l}11,15 \\
\mathbf{1 4 , 7 3} \\
\end{array}$ & 3,58 & $\begin{array}{l}0,982 \\
\mathbf{0 , 9 8 6} \\
\end{array}$ & 0,004 & $\begin{array}{l}11,35 \\
14,94 \\
\end{array}$ & 895,00 \\
\hline & 0,924 & $\begin{array}{l}\text { Teste Rápido } \\
\text { Microscopia }\end{array}$ & $\begin{array}{l}11,15 \\
\mathbf{1 4 , 7 3}\end{array}$ & 3,58 & $\begin{array}{l}0,981 \\
\mathbf{0 , 9 8 7}\end{array}$ & 0,006 & $\begin{array}{l}11,37 \\
14,92 \\
\end{array}$ & 596,67 \\
\hline \multirow{2}{*}{$\begin{array}{l}\text { Sensibilidade } \\
\text { da microscopia } \\
\text { - Plasmodium } \\
\text { vivax }\end{array}$} & 0,770 & $\begin{array}{l}\text { Teste Rápido } \\
\text { Microscopia }\end{array}$ & $\begin{array}{l}11,15 \\
\mathbf{1 4 , 7 3}\end{array}$ & & $\begin{array}{l}0,982 \\
0,956\end{array}$ & & $\begin{array}{l}11,35 \\
15,41\end{array}$ & $\begin{array}{c}\text { Microscopia } \\
\text { dominada }\end{array}$ \\
\hline & 0,905 & $\begin{array}{l}\text { Teste Rápido } \\
\text { Microscopia }\end{array}$ & $\begin{array}{l}11,15 \\
\mathbf{1 4 , 7 3}\end{array}$ & & $\begin{array}{l}0,982 \\
0,978\end{array}$ & & $\begin{array}{l}11,35 \\
15,06\end{array}$ & $\begin{array}{l}\text { Microscopia } \\
\text { dominada }\end{array}$ \\
\hline \multirow{2}{*}{$\begin{array}{l}\text { Especificidade } \\
\text { da microscopia } \\
\text { - Plasmodium } \\
\text { vivax }\end{array}$} & 0,950 & $\begin{array}{l}\text { Teste Rápido } \\
\text { Microscopia }\end{array}$ & $\begin{array}{l}11,15 \\
14,73\end{array}$ & & $\begin{array}{l}\mathbf{0 , 9 8 2} \\
0,960\end{array}$ & & $\begin{array}{l}11,35 \\
15,34\end{array}$ & $\begin{array}{c}\text { Microscopia } \\
\text { dominada }\end{array}$ \\
\hline & 0,988 & $\begin{array}{l}\text { Teste Rápido } \\
\text { Microscopia }\end{array}$ & $\begin{array}{l}11,15 \\
\mathbf{1 4 , 7 3}\end{array}$ & & $\begin{array}{l}\mathbf{0 , 9 8 2} \\
0,979\end{array}$ & & $\begin{array}{l}11,35 \\
15,05\end{array}$ & $\begin{array}{c}\text { Microscopia } \\
\text { dominada }\end{array}$ \\
\hline \multirow{2}{*}{$\begin{array}{l}\text { Sensibilidade } \\
\text { da microscopia } \\
\text { - Plasmodium } \\
\text { falciparum }\end{array}$} & 0,830 & $\begin{array}{l}\text { Teste Rápido } \\
\text { Microscopia }\end{array}$ & $\begin{array}{l}11,15 \\
\mathbf{1 4 , 7 3}\end{array}$ & & $\begin{array}{l}0,982 \\
0,978\end{array}$ & & $\begin{array}{l}11,35 \\
15,06\end{array}$ & $\begin{array}{l}\text { Microscopia } \\
\text { dominada }\end{array}$ \\
\hline & 0,898 & $\begin{array}{l}\text { Teste Rápido } \\
\text { Microscopia }\end{array}$ & $\begin{array}{l}11,15 \\
\mathbf{1 4 , 7 3}\end{array}$ & & $\begin{array}{l}0,982 \\
\mathbf{0 , 9 8 3}\end{array}$ & & $\begin{array}{l}11,35 \\
14,98\end{array}$ & $3.580,00$ \\
\hline
\end{tabular}


Tabela 21 - Resultados da análise de sensibilidade para o desfecho "caso diagnosticado adequadamente" no cenário 3: áreas isoladas.

12 municípios do Estado do Pará, 2006.

\begin{tabular}{|c|c|c|c|c|c|c|c|c|}
\hline & & & & & & & & \\
\hline Parâmetro & $\begin{array}{c}\text { Valor do } \\
\text { Parâmetro } \\
\text { usado na análise } \\
\text { de sensibilidade }\end{array}$ & Estratégias & Custo (R\$) & $\begin{array}{l}\text { Custo adicional } \\
\text { (R\$) }\end{array}$ & Efeito & $\begin{array}{l}\text { Efeito adicional - } \\
\text { caso diagnosticado } \\
\text { adequadamente }\end{array}$ & $\begin{array}{l}\text { Razão de custo - } \\
\text { efetividade média - } \\
\mathbf{R} \$ \text { por caso } \\
\text { diagnosticado } \\
\text { adequadamente }\end{array}$ & $\begin{array}{l}\text { Razão de custo- } \\
\text { efetividade adicional } \\
\text { (RCEA) - R\$ por } \\
\text { caso a mais } \\
\text { diagnosticado } \\
\text { adequadamente }\end{array}$ \\
\hline \multirow{4}{*}{$\begin{array}{l}\text { Especificidade } \\
\text { da microscopia } \\
\text { - Plasmodium } \\
\text { falciparum }\end{array}$} & \multirow[t]{2}{*}{0,990} & Teste Rápido & 11,15 & & 0,982 & & 11,35 & \multirow[b]{2}{*}{$3.580,00$} \\
\hline & & Microscopia & 14,73 & 3,58 & 0,983 & 0,001 & 14,99 & \\
\hline & \multirow[t]{2}{*}{0,995} & Teste Rápido & 11,15 & & 0.982 & & 11,35 & \multirow[b]{2}{*}{$1.790,00$} \\
\hline & & Microscopia & 14,73 & 3,58 & 0,984 & 0,002 & 14,97 & \\
\hline \multirow{4}{*}{$\begin{array}{l}\text { Sensibilidade } \\
\text { do teste rápido } \\
\text { - Plasmodium } \\
\text { vivax }\end{array}$} & \multirow[t]{2}{*}{0,625} & Teste Rápido & 11,15 & & 0,933 & & 11,94 & \multirow[b]{2}{*}{68,85} \\
\hline & & Microscopia & 14,73 & 3,58 & 0,985 & 0,052 & 14,95 & \\
\hline & \multirow[b]{2}{*}{1,00} & Teste Rápido & 11,15 & & 0,995 & & 11,20 & \multirow[b]{2}{*}{$\begin{array}{l}\text { Microscopia } \\
\text { dominada }\end{array}$} \\
\hline & & Microscopia & 14,73 & & 0,985 & & 14,95 & \\
\hline \multirow{4}{*}{$\begin{array}{l}\text { Especificidade } \\
\text { do teste rápido } \\
\text { - Plasmodium } \\
\text { vivax }\end{array}$} & \multirow[t]{2}{*}{0,80} & Teste Rápido & 11,15 & & 0,881 & & 12,66 & \multirow[b]{2}{*}{34,42} \\
\hline & & Microscopia & 14,73 & 3,58 & 0,985 & 0,104 & 14,95 & \\
\hline & \multirow[t]{2}{*}{0,950} & Teste Rápido & 11,15 & & 0,957 & & 11,65 & \multirow[b]{2}{*}{127,86} \\
\hline & & Microscopia & 14,73 & 3,58 & 0,985 & 0,028 & 14,95 & \\
\hline \multirow{4}{*}{$\begin{array}{l}\text { Sensibilidade } \\
\text { do teste rápido } \\
\text { - Plasmodium } \\
\text { falciparum }\end{array}$} & \multirow[t]{2}{*}{0,623} & Teste Rápido & 11,15 & & 0,955 & & 11,67 & \multirow[b]{2}{*}{119,33} \\
\hline & & Microscopia & 14,73 & 3,58 & 0,985 & 0,030 & 14,95 & \\
\hline & \multirow[t]{2}{*}{0,988} & Teste Rápido & 11,15 & & 0,985 & & 11,32 & \multirow[b]{2}{*}{$3.580,00$} \\
\hline & & Microscopia & 14,73 & 3,58 & 0,986 & 0,001 & 14,95 & \\
\hline \multirow{4}{*}{$\begin{array}{l}\text { Especificidade } \\
\text { do teste rápido } \\
\text { - Plasmodium } \\
\text { falciparum }\end{array}$} & \multirow[t]{2}{*}{0,893} & Teste Rápido & 11,15 & & 0,957 & & 11,65 & \multirow[b]{2}{*}{127,86} \\
\hline & & Microscopia & 14,73 & 3,58 & 0,985 & 0,028 & 14,95 & \\
\hline & \multirow[t]{2}{*}{1,00} & Teste Rápido & 11,15 & & 0,983 & & 11,34 & \multirow[b]{2}{*}{$1.790,00$} \\
\hline & & Microscopia & 14,73 & 3,58 & 0,985 & 0,002 & 14,95 & \\
\hline \multirow{4}{*}{$\begin{array}{l}\text { Custo do } \\
\text { exame de gota } \\
\text { espessa - } \\
\text { lâmina (reais) }\end{array}$} & \multirow[t]{2}{*}{0,41} & Teste Rápido & 11,15 & & 0,982 & & 11,35 & \multirow[b]{2}{*}{666,67} \\
\hline & & Microscopia & 13,15 & 2,00 & 0,985 & 0,003 & 13,34 & \\
\hline & \multirow[t]{2}{*}{3,04} & Teste Rápido & 11,15 & & 0,982 & & 11,35 & \multirow[b]{2}{*}{$1.543,33$} \\
\hline & & Microscopia & 15,78 & 4,63 & 0,985 & 0,003 & 16,01 & \\
\hline
\end{tabular}


Tabela 21 - Resultados da análise de sensibilidade para o desfecho "caso diagnosticado adequadamente" no cenário 3: áreas isoladas.

12 municípios do Estado do Pará, 2006.

\begin{tabular}{|c|c|c|c|c|c|c|c|c|}
\hline Parâmetro & $\begin{array}{c}\text { Valor do } \\
\text { Parâmetro } \\
\text { usado na análise } \\
\text { de sensibilidade }\end{array}$ & Estratégias & Custo $(\mathbf{R} \$)$ & $\begin{array}{l}\text { Custo adicional } \\
\text { (R\$) }\end{array}$ & Efeito & $\begin{array}{l}\text { Efeito adicional - } \\
\text { caso diagnosticado } \\
\text { adequadamente }\end{array}$ & $\begin{array}{l}\text { Razão de custo - } \\
\text { efetividade média - } \\
\mathbf{R} \$ \text { por caso } \\
\text { diagnosticado } \\
\text { adequadamente }\end{array}$ & $\begin{array}{l}\text { Razão de custo- } \\
\text { efetividade adicional } \\
\text { (RCEA) - R\$por } \\
\text { caso a mais } \\
\text { diagnosticado } \\
\text { adequadamente }\end{array}$ \\
\hline \multirow{4}{*}{$\begin{array}{l}\text { Custo do Teste } \\
\text { Rápido }\end{array}$} & \multirow[t]{2}{*}{7,79} & Teste Rápido & 9,66 & & 0,982 & & 9,83 & \\
\hline & & Microscopia & 14,73 & 5,07 & 0,985 & 0,003 & 14,95 & $1.690,00$ \\
\hline & \multirow[t]{2}{*}{10,69} & Teste Rápido & 12,56 & & 0,982 & & 12,79 & \\
\hline & & Microscopia & 14,73 & 2,17 & 0,985 & 0,003 & 14,95 & 723,33 \\
\hline \multirow{4}{*}{$\begin{array}{l}\text { Custo do } \\
\text { microscópio }\end{array}$} & \multirow[t]{2}{*}{0,134} & Teste Rápido & 11,15 & & 0,982 & & 11,35 & \\
\hline & & Microscopia & 14,66 & 3,51 & 0,985 & 0,003 & 14,88 & $1.170,00$ \\
\hline & \multirow[t]{2}{*}{0,182} & Teste Rápido & 11,15 & & 0,982 & & 11,35 & \\
\hline & & Microscopia & 14,71 & 3,56 & 0,985 & 0,003 & 14,93 & $1.186,67$ \\
\hline \multirow{4}{*}{$\begin{array}{l}\text { Custo de } \\
\text { transporte de } \\
\text { equipes para } \\
\text { realizar o teste } \\
\text { rápido }\end{array}$} & \multirow[t]{2}{*}{0,349} & Teste Rápido & 10,91 & & 0,982 & & 11,10 & \\
\hline & & Microscopia & 14,73 & 3,82 & 0,985 & 0,003 & 14,95 & $1.273,33$ \\
\hline & \multirow[t]{2}{*}{6,706} & Microscopia & 14,73 & & 0,985 & & 14,95 & \\
\hline & & Teste Rápido & 17,26 & & 0,982 & & 17,58 & $\begin{array}{l}\text { Teste Rápido } \\
\text { dominado }\end{array}$ \\
\hline \multirow{4}{*}{$\begin{array}{l}\text { Custo de } \\
\text { transporte de } \\
\text { equipes para } \\
\text { realizar a } \\
\text { microscopia }\end{array}$} & \multirow[t]{2}{*}{0,698} & Teste Rápido & 11,15 & & 0,982 & & 11,35 & \\
\hline & & Microscopia & 14,24 & 3,09 & 0,985 & 0,003 & 14,46 & $1.030,00$ \\
\hline & \multirow[t]{2}{*}{13,412} & Teste Rápido & 11,15 & & 0,982 & & 11,35 & \\
\hline & & Microscopia & 26,96 & 15,81 & 0,985 & 0,003 & 27,36 & $5.270,00$ \\
\hline
\end{tabular}


Tabela 21 - Resultados da análise de sensibilidade para o desfecho "caso diagnosticado adequadamente" no cenário 3: áreas isoladas.

12 municípios do Estado do Pará, 2006.

Parâmetro

$$
\begin{aligned}
& \text { Valor do } \\
& \text { Parâmetro } \\
& \text { usado na análise }
\end{aligned}
$$

Estratégias

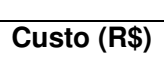

de sensibilidade

Custo (R\$) Custo adicional

(R\$)

Efeito

) Efeito adicional -
caso diagnosticado
adequadamente

(conclusão)

Razão de custo -
efetividade média -

$\mathbf{R} \$$ por caso

diagnosticado

Razão de custo-

adequadamente fetividade adiciona

(RCEA) - R\$ por

caso a mais

adequadamente

\begin{tabular}{l|clc}
\hline $\begin{array}{l}\text { Custo do } \\
\text { treinamento } \\
\text { para }\end{array}$ & 4,614 & Microscopia & 10,68 \\
microscopistas & & Teste Rápido & $\mathbf{1 1 , 1 5}$ \\
\cline { 2 - 4 } & 7,648 & $\begin{array}{l}\text { Teste Rápido } \\
\text { Microscopia }\end{array}$ & 11,15 \\
\hline Custo do & & $\mathbf{1 3 , 7 2}$ \\
treinamento & 0,048 & Teste Rápido & 11,11 \\
para realizar & & Microscopia & $\mathbf{1 4 , 7 3}$ \\
teste rápido & 0,080 & Teste Rápido & 11,14 \\
& & Microscopia & $\mathbf{1 4 , 7 3}$ \\
\hline
\end{tabular}

10,68

0,985

10,84

11,35

Teste Rápido dominado

3,72

0,982

0,985

2,57

4,73

3,62

0,982

0,985

$11,14 \quad 0,982$

$\begin{array}{lll}\mathbf{1 4 , 7 3} & 3,59 & \mathbf{0 , 9 8 5}\end{array}$

$0,985 \quad 0,003$

11,35

13,92

856,67

14,95

$1.206,67$

11,34

14,95

$1.196,67$ 


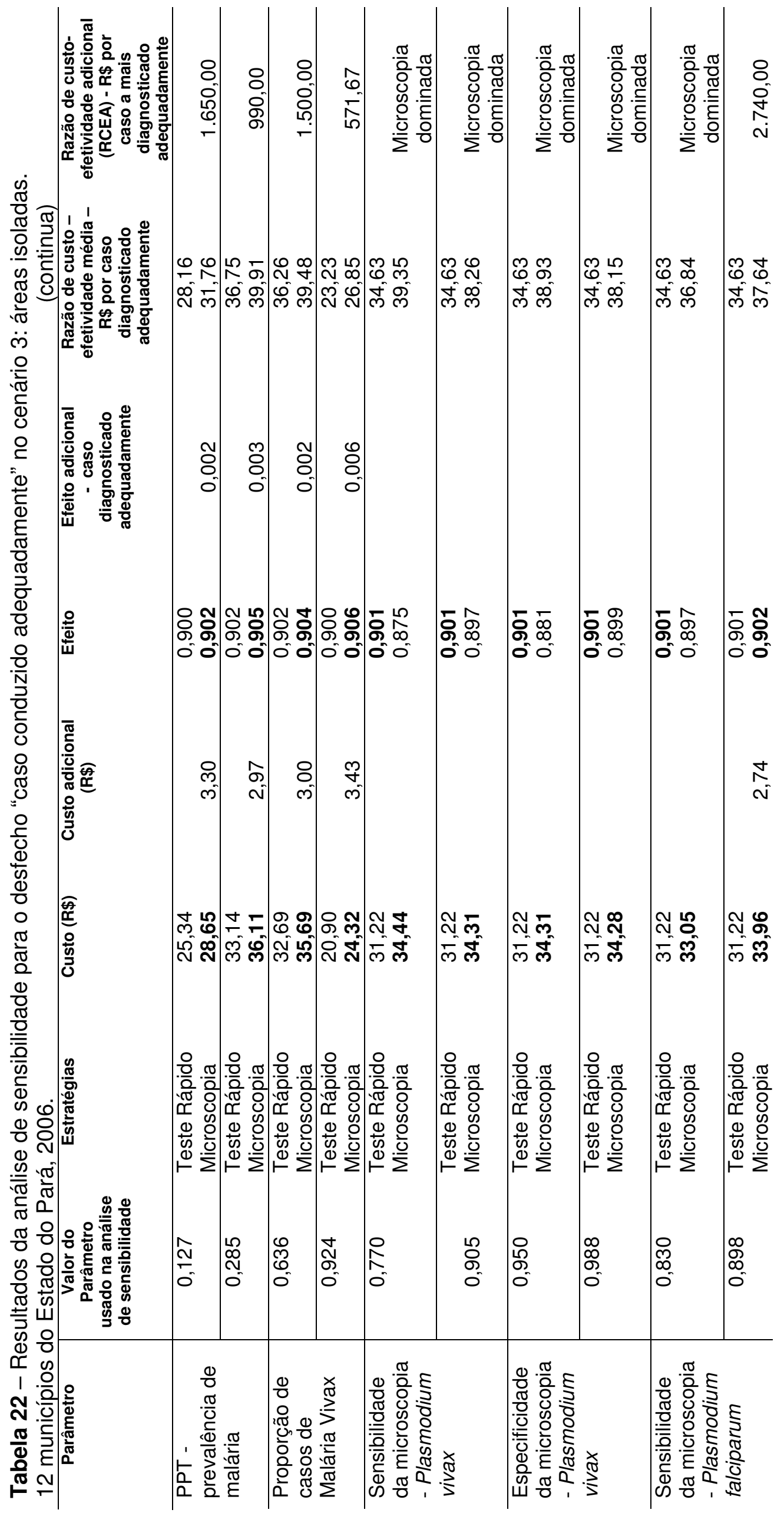


Tabela 22 - Resultados da análise de sensibilidade para o desfecho "caso conduzido adequadamente" no cenário 3: áreas isoladas.

12 municípios do Estado do Pará, 2006.

\begin{tabular}{|c|c|c|c|c|c|c|c|c|}
\hline Parâmetro & $\begin{array}{c}\text { Valor do } \\
\text { Parâmetro } \\
\text { usado na análise } \\
\text { de sensibilidade }\end{array}$ & Estratégias & Custo (R\$) & $\begin{array}{c}\text { Custo adicional } \\
\text { (R\$) }\end{array}$ & Efeito & $\begin{array}{l}\text { Efeito adicional } \\
\text { - caso } \\
\text { diagnosticado } \\
\text { adequadamente }\end{array}$ & $\begin{array}{l}\text { Razão de custo - } \\
\text { efetividade média - } \\
\mathbf{R} \$ \text { por caso } \\
\text { diagnosticado } \\
\text { adequadamente }\end{array}$ & $\begin{array}{l}\text { Razão de custo- } \\
\text { efetividade adicional } \\
\text { (RCEA) - R\$ por } \\
\text { caso a mais } \\
\text { diagnosticado } \\
\text { adequadamente }\end{array}$ \\
\hline \multirow{4}{*}{$\begin{array}{l}\text { Especificidade } \\
\text { da microscopia } \\
\text { - Plasmodium } \\
\text { falciparum }\end{array}$} & \multirow[t]{2}{*}{0,990} & Teste Rápido & 31,22 & & 0,901 & & 34,63 & \multirow[b]{2}{*}{$3.070,00$} \\
\hline & & Microscopia & 34,29 & 3,07 & 0,902 & 0,001 & 38,01 & \\
\hline & \multirow[t]{2}{*}{0,995} & Teste Rápido & 31,22 & & 0,901 & & 34,63 & \multirow[b]{2}{*}{$1.530,00$} \\
\hline & & Microscopia & 34,28 & 3,06 & 0,903 & 0,002 & 37,96 & \\
\hline \multirow{4}{*}{$\begin{array}{l}\text { Sensibilidade } \\
\text { do teste rápido } \\
\text { - Plasmodium } \\
\text { vivax }\end{array}$} & \multirow[t]{2}{*}{0,625} & Teste Rápido & 31,49 & & 0,854 & & 36,89 & \multirow[b]{2}{*}{55,60} \\
\hline & & Microscopia & 34,27 & 2,78 & 0,904 & 0,050 & 37,90 & \\
\hline & \multirow[b]{2}{*}{1,00} & Teste Rápido & 31,14 & & 0,914 & & 34,06 & \multirow[b]{2}{*}{$\begin{array}{l}\text { Microscopia } \\
\text { dominada }\end{array}$} \\
\hline & & Microscopia & 34,27 & & 0,904 & & 37,90 & \\
\hline \multirow{4}{*}{$\begin{array}{l}\text { Especificidade } \\
\text { do teste rápido } \\
\text { - Plasmodium } \\
\text { vivax }\end{array}$} & \multirow[t]{2}{*}{0,800} & Teste Rápido & 31,39 & & 0,810 & & 38,74 & \multirow[b]{2}{*}{30,64} \\
\hline & & Microscopia & 34,27 & 2,88 & 0,904 & 0,094 & 37,90 & \\
\hline & \multirow[t]{2}{*}{0,950} & Teste Rápido & 31,26 & & 0,879 & & 35,58 & \multirow[b]{2}{*}{120,40} \\
\hline & & Microscopia & 34,27 & 3,01 & 0,904 & 0,025 & 37,90 & \\
\hline \multirow{4}{*}{$\begin{array}{l}\text { Sensibilidade } \\
\text { do teste rápido } \\
\text { - Plasmodium } \\
\text { falciparum }\end{array}$} & \multirow[t]{2}{*}{0,623} & Teste Rápido & 26,69 & & 0,875 & & 30,50 & \multirow[b]{2}{*}{261,38} \\
\hline & & Microscopia & 34,27 & 7,58 & 0,904 & 0,029 & 37,90 & \\
\hline & \multirow[t]{2}{*}{0,988} & Teste Rápido & 31,65 & & 0,903 & & 35,02 & \multirow[b]{2}{*}{$2.620,00$} \\
\hline & & Microscopia & 34,27 & 2,62 & 0,904 & 0,001 & 37,90 & \\
\hline \multirow{4}{*}{$\begin{array}{l}\text { Especificidade } \\
\text { do teste rápido } \\
\text { - Plasmodium } \\
\text { falciparum }\end{array}$} & \multirow[t]{2}{*}{0,893} & Teste Rápido & 31,36 & & 0,878 & & 35,70 & \multirow[b]{2}{*}{111,92} \\
\hline & & Microscopia & 34,27 & 2,91 & 0,904 & 0,026 & 37,90 & \\
\hline & \multirow[t]{2}{*}{1,00} & Teste Rápido & 31,21 & & 0,902 & & 34,59 & \multirow[b]{2}{*}{$1.530,00$} \\
\hline & & Microscopia & 34,27 & 3,06 & 0,904 & 0,002 & 37,90 & \\
\hline \multirow{4}{*}{$\begin{array}{l}\text { Freqüência de } \\
\text { malária } \\
\text { falciparum } \\
\text { grave }\end{array}$} & \multirow[t]{2}{*}{0,032} & Teste Rápido & 21,74 & & 0,902 & & 24,11 & \multirow[b]{2}{*}{$1.705,00$} \\
\hline & & Microscopia & 25,15 & 3,41 & 0,904 & 0,002 & 27,81 & \\
\hline & \multirow[t]{2}{*}{0,199} & Teste Rápido & 40,81 & & 0,901 & & 45,28 & \multirow[b]{2}{*}{896,67} \\
\hline & & Microscopia & 43,50 & 2,69 & 0,904 & 0,003 & 48,12 & \\
\hline
\end{tabular}


Tabela 22 - Resultados da análise de sensibilidade para o desfecho "caso conduzido adequadamente" no cenário 3: áreas isoladas.

12 municípios do Estado do Pará, 2006.

\begin{tabular}{|c|c|c|c|c|c|c|c|c|}
\hline Parâmetro & $\begin{array}{c}\text { Valor do } \\
\text { Parâmetro } \\
\text { usado na análise } \\
\text { de sensibilidade }\end{array}$ & Estratégias & Custo $(\mathbf{R} \$)$ & $\begin{array}{c}\text { Custo adicional } \\
\text { (R\$) }\end{array}$ & Efeito & $\begin{array}{l}\text { Efeito adicional } \\
\text { - caso } \\
\text { diagnosticado } \\
\text { adequadamente }\end{array}$ & $\begin{array}{l}\text { Razão de custo - } \\
\text { efetividade média - } \\
\mathbf{R} \text { por caso } \\
\text { diagnosticado } \\
\text { adequadamente }\end{array}$ & $\begin{array}{l}\text { Razão de custo- } \\
\text { efetividade adicional } \\
\text { (RCEA) - R\$ por } \\
\text { caso a mais } \\
\text { diagnosticado } \\
\text { adequadamente }\end{array}$ \\
\hline \multirow{3}{*}{$\begin{array}{l}\text { Custo do } \\
\text { exame de gota } \\
\text { espessa - } \\
\text { lâmina (reais) }\end{array}$} & 0,41 & $\begin{array}{l}\text { Teste Rápido } \\
\text { Microscopia }\end{array}$ & $\begin{array}{l}31,22 \\
32,69\end{array}$ & 1,47 & $\begin{array}{l}0,901 \\
\mathbf{0 , 9 0 4}\end{array}$ & 0,003 & $\begin{array}{l}34,63 \\
36,15\end{array}$ & 490,00 \\
\hline & \multirow[t]{2}{*}{3,04} & Teste Rápido & 31,22 & & 0,901 & & 34,63 & \\
\hline & & Microscopia & 35,32 & 4,10 & 0,904 & 0,003 & 39,06 & $1.366,67$ \\
\hline \multirow{4}{*}{$\begin{array}{l}\text { Custo do Teste } \\
\text { Rápido }\end{array}$} & \multirow[t]{2}{*}{7,79} & Teste Rápido & 29,73 & & 0,901 & & 32,98 & \\
\hline & & Microscopia & 34,27 & 4,54 & 0,904 & 0,003 & 37,90 & $1.513,33$ \\
\hline & \multirow[t]{2}{*}{10,69} & Teste Rápido & 32,63 & & 0,901 & & 36,20 & \\
\hline & & Microscopia & 34,27 & 1,64 & 0,904 & 0,003 & 37,90 & 546,67 \\
\hline \multirow{4}{*}{$\begin{array}{l}\text { Custo do } \\
\text { microscópio }\end{array}$} & \multirow[t]{2}{*}{0,134} & Teste Rápido & 31,22 & & 0,901 & & 34,63 & \\
\hline & & Microscopia & 34,21 & 2,99 & 0,904 & 0,003 & 37,83 & 996,67 \\
\hline & \multirow[t]{2}{*}{0,182} & Teste Rápido & 31,22 & & 0,901 & & 34,63 & \\
\hline & & Microscopia & 34,25 & 3,03 & 0,904 & 0,003 & 37,88 & $1.010,00$ \\
\hline \multirow{4}{*}{$\begin{array}{l}\text { Custo de } \\
\text { transporte de } \\
\text { equipes para } \\
\text { realizar o teste } \\
\text { rápido }\end{array}$} & \multirow{2}{*}{0,349} & Teste Rápido & 30,97 & & 0,901 & & 34,36 & \\
\hline & & Microscopia & 34,27 & 3,30 & 0,904 & 0,003 & 37,90 & $1.100,00$ \\
\hline & \multirow[t]{2}{*}{6,706} & Microscopia & 34,27 & & 0,904 & & 37,90 & \\
\hline & & Teste Rápido & 37,33 & & 0,901 & & 39,65 & $\begin{array}{l}\text { Teste Rápido } \\
\text { dominado }\end{array}$ \\
\hline \multirow{4}{*}{$\begin{array}{l}\text { Custo de } \\
\text { transporte de } \\
\text { equipes para } \\
\text { realizar a } \\
\text { microscopia }\end{array}$} & \multirow[t]{2}{*}{0,698} & Teste Rápido & 31,22 & & 0,901 & & 34,63 & \\
\hline & & Microscopia & 33,79 & 2,57 & 0.904 & 0,003 & 37,36 & 856,67 \\
\hline & \multirow[t]{2}{*}{13,412} & Teste Rápido & 31,22 & & 0,901 & & 34,63 & \\
\hline & & Microscopia & 46,50 & 15,28 & 0,904 & 0,003 & 51,42 & $5.093,33$ \\
\hline
\end{tabular}


Tabela 22 - Resultados da análise de sensibilidade para o desfecho "caso conduzido adequadamente" no cenário 3: áreas isoladas.

12 municípios do Estado do Pará, 2006.

\begin{tabular}{|c|c|c|c|c|c|c|c|c|}
\hline Parâmetro & $\begin{array}{c}\text { Valor do } \\
\text { Parâmetro } \\
\text { usado na análise } \\
\text { de sensibilidade }\end{array}$ & Estratégias & Custo (R\$) & $\begin{array}{c}\text { Custo adicional } \\
\qquad(\mathbf{R} \$)\end{array}$ & Efeito & $\begin{array}{c}\text { Efeito adicional } \\
\text { - caso } \\
\text { diagnosticado } \\
\text { adequadamente }\end{array}$ & $\begin{array}{l}\text { Razão de custo - } \\
\text { efetividade média - } \\
\text { R\$ por caso } \\
\text { diagnosticado } \\
\text { adequadamente }\end{array}$ & $\begin{array}{l}\text { Razão de custo- } \\
\text { efetividade adicional } \\
\text { (RCEA) - R } \$ \text { por } \\
\text { caso a mais } \\
\text { diagnosticado } \\
\text { adequadamente }\end{array}$ \\
\hline \multirow{4}{*}{$\begin{array}{l}\text { Custo do } \\
\text { treinamento } \\
\text { para } \\
\text { microscopistas }\end{array}$} & \multirow[t]{2}{*}{4,614} & Microscopia & 30,23 & & 0,904 & & 33,43 & \\
\hline & & Teste Rápido & 31,22 & & 0,901 & & 34,63 & $\begin{array}{l}\text { Teste Rápido } \\
\text { dominado }\end{array}$ \\
\hline & \multirow[t]{2}{*}{7,648} & Teste Rápido & 31,22 & & 0,901 & & 34,63 & \\
\hline & & Microscopia & 33,26 & 2,04 & 0,904 & 0,003 & 36,78 & 680,00 \\
\hline \multirow{4}{*}{$\begin{array}{l}\text { Custo do } \\
\text { treinamento } \\
\text { para realizar } \\
\text { teste rápido }\end{array}$} & \multirow[t]{2}{*}{0,048} & Teste Rápido & 31,17 & & 0,901 & & 34,59 & \\
\hline & & Microscopia & 34,27 & 3,10 & 0,904 & 0,003 & 37,90 & $1.033,33$ \\
\hline & \multirow[t]{2}{*}{0,080} & Teste Rápido & 31,21 & & 0,901 & & 34,62 & \\
\hline & & Microscopia & 34,27 & 3,06 & 0,904 & 0,003 & 37,90 & $1.020,00$ \\
\hline \multirow{4}{*}{$\begin{array}{l}\text { Custo da } \\
\text { hospitalização } \\
\text { de casos } \\
\text { graves }\end{array}$} & \multirow[t]{2}{*}{747,593} & Teste Rápido & 25,66 & & 0,901 & & 28,47 & \\
\hline & & Microscopia & 28,93 & 3,27 & 0,904 & 0,003 & 31,99 & $1.090,00$ \\
\hline & \multirow[t]{2}{*}{$3.022,038$} & Teste Rápido & 45,84 & & 0,901 & & 50,86 & \\
\hline & & Microscopia & 48,34 & 2,50 & 0,904 & 0,003 & 53,47 & 833,33 \\
\hline
\end{tabular}


As tabelas 17 a 20 demonstram que para os cenários 1 e 2 e para ambos os desfechos nestes dois cenários, houve variações no modelo com poucos parâmetros. Para todos os demais parâmetros não apresentados nas tabelas dos cenários 1 e 2, o resultado da análise de sensibilidade manteve-se o mesmo, ou seja, com o teste rápido dominado pela microscopia.

No cenário 1 e para o desfecho 1, quando os valores da acurácia da microscopia são alterados para menos em relação ao caso-base (parâmetros: sensibilidade para Plasmodium vivax, especificidade para Plasmodium vivax e sensibilidade para Plasmodium falciparum), o teste rápido torna-se mais efetivo e pode ser a estratégia mais interessante em algumas situações. Tome-se como exemplo: com a especificidade da microscopia para Plasmodium vivax em torno de 95\%, o teste rápido, mantidas as demais condições do modelo, diagnosticaria a mais do que microscopia 2.200 casos e com uma RCEA de apenas $R \$ 146,36$ por cada caso a mais diagnosticado, extremamente custo-efetivo. Mudança na mesma direção ocorre quando se varia a sensibilidade do teste rápido para Plasmodium vivax para $100 \%$. Quanto aos custos, o único item que provocou mudanças na análise foi o custo do transporte de equipes para realização da microscopia. Se este custo ultrapassar $R \$ 7,00$ por lâmina, a microscopia torna-se a estratégia mais cara, porém ainda custo-efetiva (tabela 17).

No cenário 1 e para o desfecho 2, valem as mesmas considerações feitas para o desfecho 1, como se observa na tabela 18. Para o desfecho 2 , houve, porém, uma mudança não observada no desfecho 1 que foi o pequeno aumento no custo da microscopia em relação ao teste rápido, com a sensibilidade do teste rápido para Plasmodium falciparum em torno de $62,3 \%$. Como esta estimativa de sensibilidade não é aceitável para testes diagnósticos de malária (168), embora seja relatada na literatura (130), esta 
mudança no modelo não é relevante do ponto de vista da prática dos serviços de saúde.

No cenário 2 para os desfechos 1 e 2 , as variações seguem a mesma tendência dos resultados do cenário 1 (tabelas 19 e 20). A diferença é que não houve parâmetros de custos que modificassem a decisão neste cenário. De todos, o cenário 2 foi o mais estável à análise de sensibilidade.

No cenário 3, no entanto, para ambos os desfechos, houve várias mudanças nos resultados na análise de sensibilidade (tabelas 21 e 22). É um cenário onde o teste rápido não foi dominado e a microscopia comportase como a estratégia mais cara e mais efetiva. As mudanças mais importantes na análise de sensibilidade foram aquelas provocadas pela variação dos valores de acurácia da microscopia. As variações com valores menores em relação ao caso-base na estimativa da sensibilidade da microscopia para Plasmodium vivax e Plasmodium falciparum e da especificidade para Plasmodium vivax invertem a análise, tornando a estratégia "teste rápido" mais custo-efetiva neste cenário e para os dois desfechos. Também foi interessante que a elevação na proporção de casos de malária vivax (com conseqüente redução na proporção de casos de malária falciparum), reduz à metade a RCEA da estratégia "microscopia" para ambos os desfechos. A microscopia foi a estratégia dominada pelo teste rápido, nos dois desfechos, com o valor de sensibilidade do teste rápido para Plasmodium vivax de $100 \%$, estimativa pouco realista. Quanto mais baixos os custos do exame da gota espessa (lâmina) ou mais elevados - custo do teste rápido, mais custo-efetiva torna-se a estratégia "microscopia". Outros custos que causam impacto são os custos de transporte de equipes e de treinamentos que podem ser determinantes para o custo-efetividade do diagnóstico microscópico. Custo mais alto do transporte de equipes para realizar o teste rápido, em relação ao caso-base, tornou o teste rápido dominado pela microscopia neste cenário e para os dois desfechos; o mesmo foi observado quando o custo de treinamento para 
microscopia foi mais barato em relação ao caso-base. Assim, no cenário 3 e para os dois desfechos, a variação destes dois custos, mantendo-se os demais parâmetros inalterados, tornaram a microscopia mais custo-efetiva ainda pela dominância em relação ao teste rápido, como ocorreu nos cenários 1 e 2.

\subsection{ANÁLISE DE BREAK-EVEN}

Devido ao alto custo do preço unitário do teste rápido, foi realizada uma análise de break-even, para determinar que preço unitário do teste tornaria o custo da estratégia "teste rápido" mais baixo do que da estratégia "microscopia" nos cenários 1 e 2 , onde o teste rápido foi dominado. Os resultados está apresentados na tabela 23.

Tabela 23 - Análise de break-even para os cenários 1 e 2 e os desfechos: "casos diagnosticados adequadamente" e "casos conduzidos adequadamente". 12 municípios do Estado do Pará, 2006

\begin{tabular}{c|c|cc}
\hline Cenários e desfechos & $\begin{array}{c}\text { Custo da } \\
\text { estratégia } \\
\text { "Teste Rápido" } \\
\text { - ACE com o } \\
\text { caso-base (R\$) }\end{array}$ & $\begin{array}{c}\text { Preço do break- } \\
\text { even para custo } \\
\text { unitário do } \\
\text { OptiMal@ (R\$) }\end{array}$ & $\begin{array}{c}\text { Custo da } \\
\text { estratégia "Teste } \\
\text { Rápido" (R\$) * } \\
\text { ACE com preços } \\
\text { do break-even }\end{array}$ \\
\hline $\begin{array}{c}\text { Cenário 1 - área global - } \\
\text { com desfecho: "caso } \\
\text { diagnosticado } \\
\text { adequadamente" }\end{array}$ & 11,09 & 6,00 & 7,81 \\
$\begin{array}{c}\text { Cenário 1 - área global - } \\
\text { com desfecho: "caso } \\
\text { conduzido adequadamente" }\end{array}$ & 30,97 & 5,50 & 27,19 \\
$\begin{array}{c}\text { Cenário 2 - áreas com } \\
\text { laboratório - com desfecho: } \\
\text { "caso diagnosticado } \\
\text { adequadamente" }\end{array}$ & 10,51 & 6,00 & 7,23 \\
$\begin{array}{c}\text { Cenário 2 - áreas com } \\
\text { laboratório - com desfecho: } \\
\text { "caso conduzido } \\
\text { adequadamente" }\end{array}$ & 30,42 & 5,50 & 26,64 \\
\hline
\end{tabular}

Nota: * custos da estratégia "teste rápido" em cada cenário e desfechos, que se tornariam mais baixos do que os custos da estratégia "microscopia" com a aplicação do preço de break-even em cada cenário. 


\section{DISCUSSÃO}

Os testes rápidos para a malária têm sido uma alternativa efetiva para o diagnóstico da doença em todo o mundo nas últimas décadas, principalmente por sua fácil implantação nos serviços e por alcançarem acurácia similar à da microscopia em diversos cenários (168). Algumas das suas desvantagens são limitantes para o seu uso e um dos maiores impedimentos para adoção em larga escala é o custo individual dos testes. No Brasil, como demonstrado pelo levantamento dos custos, o teste rápido é a opção mais cara em comparação a um exame de gota espessa, quando se comparam, isoladamente, apenas os custos unitários dos dois exames, sem considerar o contexto para a realização do diagnóstico da malária, como os custos associados a todo o processo de estruturação dos serviços para o diagnóstico e para a condução dos casos clínicos, o acesso das populações ao diagnóstico e as singularidades das áreas endêmicas e indenes para malária. Impõe-se, portanto, a avaliação econômica das estratégias de diagnóstico, com o objetivo de fornecer maiores subsídios aos tomadores de decisão. A análise de custo-efetividade, que permite comparar os custos e desfechos de saúde entre duas ou mais intervenções, constitui o método mais indicado para a avaliação e o modelo de decisão usado permitiu estimar a razão de custo-efetividade a partir dos custos e conseqüências extraídos de fontes de dados provenientes do mundo real.

A área de estudo hipotética, como referência para os parâmetros epidemiológicos relativos à notificação de malária, foi composta por 12 municípios endêmicos para malária no Estado do Pará com diferentes estratos de risco. Os resultados do estudo são válidos para essas áreas somente, não sendo generalizáveis para outros cenários epidemiológicos, como áreas não-endêmicas, que devem possuir parâmetros epidemiológicos e de custos diversos ao modelo apresentado. 
O Estado do Pará foi selecionado porque foi um estado que implantou o diagnóstico com OptiMal $\AA^{\circledR}$ no ano de 2006, o que favoreceu a coleta de dados de custos e administrativos relativos ao uso do teste. Os 12 municípios selecionados foram alvo da implantação do diagnóstico com o TR, o qual foi utilizado nas áreas municipais isoladas. A prevalência considerada no caso-base foi a prevalência para o conjunto dos municípios 24,6\% - que representa o número de lâminas positivas para malária entre pacientes que procuram diagnóstico nos 12 municípios. A prevalência nessa população representa, ao mesmo tempo, a estimativa da probabilidade préteste (PPT) - ou seja, a probabilidade, prévia ao diagnóstico, de resultados positivos aos exames. A PPT é mais adequada para uso em modelos de custo-efetividade de testes diagnósticos para doença clinicamente manifesta quando o modelo inicia com paciente sintomático que procura os serviços de saúde, como foi o caso neste estudo.

A construção do modelo de decisão adotou como parâmetros principais as estimativas de sensibilidade e de especificidade dos dois diagnósticos. A avaliação de testes diagnósticos leva em consideração as medidas de acurácia e de confiabilidade. A acurácia é avaliada pelas estimativas de sensibilidade, especificidade e valores preditivos positivo e negativo e a confiabilidade pelas medidas de concordância. Os testes que têm interesse para seguimento de estudos em Saúde Pública são os que têm alta concordância. Uma vez definido que os testes são confiáveis, o interesse para o seu uso em Saúde Pública recairá sobre as medidas de acurácia, que são as medidas que melhor definem o rendimento de um teste diagnóstico. Além de serem os principais estimadores da acurácia de testes, a sensibilidade e a especificidade também são apropriadas para estudos de custo-efetividade por não serem afetadas pela prevalência do evento. Isto é evidenciado pelos estudos de custo-efetividade de TR para malária publicados na literatura que utilizaram como principal parâmetro epidemiológico as medidas de acurácia $(24,37,77,146,148)$. 
A adoção de dois desfechos no modelo teve como objetivo a estimativa do custo-efetividade em dois importantes processos que envolvem a atenção ao paciente com malária: o diagnóstico propriamente dito e a condução clínica do caso, que além de serem os eixos principais da atenção individual ao paciente são atividades de controle em saúde pública, já que o homem doente é a única fonte de transmissão e de perpetuação do ciclo "mosquito-homem-mosquito-homem".

A observação dos dados coletados e, principalmente, o conhecimento da experiência em um dos municípios de referência, permitiu identificar que no mesmo território coexistem duas situações diferenciadas em termos de logística do diagnóstico, pois há áreas cobertas e descobertas por laboratórios para diagnóstico de malária nos municípios. O diagnóstico envolve custos diferenciados, pois nas áreas isoladas é feito por meio de busca ativa realizada por agentes comunitários de saúde, comprometendo recursos não somente de salários de profissionais para este fim, como de transporte para deslocamento das equipes. Estes custos foram considerados de forma ponderada na composição dos custos quando se considerou a "área global dos 12 municípios", porém o interesse pelo estudo também voltou-se para a realização de análises individualizadas por áreas, de modo a se estimar as possíveis diferenças de custo-efetividade entre áreas diferentes dentro do mesmo território. Outro ponto considerado na decisão foi a orientação do PNCM quanto ao uso do TR em áreas isoladas (102), sendo relevante a análise especificamente neste cenário de isolamento em relação à estrutura de diagnóstico (104), de modo a avaliar se o TR seria a alternativa que substituiria a microscopia em áreas isoladas.

As considerações acima determinaram a realização de seis análises, que permitiram obter diversas visões do processo, podendo servir de modelo para futuras análises em contextos outros, pela simples variação dos dados, caso haja este interesse pelos serviços de saúde. 
$\mathrm{Na}$ valoração final dos desfechos, foi adotado o mesmo valor "1" para os resultados verdadeiros positivos e verdadeiros negativos e, consequentemente, o valor "0", para os resultados falsos negativos e falsos positivos, valorizando igualmente todos os diagnósticos corretos. O TR, que apresenta elevadas sensibilidade e especificidade, foi comparado à microscopia (gota espessa), diagnóstico também com elevadas estimativas de acurácia, não justificando a necessidade de destacar-se no modelo algum resultado em especial e sim, conhecer, globalmente, o efeito dos dois testes no modelo de decisão. Este desenho diferiu do modelo adotado por Rolland e cols (146), que por comparar o teste rápido à estratégia "tratamento presuntivo", a qual apresenta baixíssima especificidade, decidiu pela apresentação dos resultados em termos de "resultados falsos positivos evitados" (ou seja, verdadeiros negativos diagnosticados).

O estudo assumiu como pressuposto que todos os pacientes diagnosticados como malária foram tratados. É importante considerar que no mundo real existem questões ligadas à adesão dos pacientes aos esquemas, por condicionantes vários (culturais, sociais, de saúde etc), ou dificuldades para o acesso aos medicamentos, o que poderá determinar que o tratamento não seja feito em $100 \%$ dos casos como no modelo teórico apresentado. A adesão de $100 \%$ foi assumida para ambas as estratégias de diagnóstico, mas o tipo de exame utilizado nos serviços poderia ser também, teoricamente, mais um fator com impacto na adesão, por exemplo, para aquelas áreas onde o retorno do diagnóstico microscópico é demorado ou exige mais de um deslocamento para cumprir as etapas de realização do exame e de medicação.

Uma das limitações para a construção de modelos de decisão relativos a diagnóstico da malária e que usam desfechos de evolução clínica é a estimativa de resultados para a evolução dos casos de "não malária". A decisão tomada neste estudo foi a de considerar que casos verdadeiros negativos tiveram uma probabilidade de $90 \%$ para evolução favorável, 
considerando que um diagnóstico negativo acurado é a base para a recondução do paciente ao serviço de saúde para a continuidade do diagnóstico e que muitos dos diagnósticos diferenciais da malária são autolimitados ou de abordagem não-complexa (102). Esta limitação, porém, impede que seja definido como desfecho da análise "casos curados", decidindo-se pelo uso de "caso conduzido adequadamente" como desfecho relativo à evolução clínica (desfecho 2). Mesma decisão é encontrada em estudo de Lubell e cols, na Tanzânia (77) que, apesar de ter incluído a opção de uso de antibióticos para os casos negativos, afirma que a lacuna das informações quanto aos benefícios de testagem de pacientes sem malária, conduz à avaliação de custo-efetividade de testes em termos de "pacientes corretamente tratados" e que se faz necessário aperfeiçoar a base de evidências científicas para os diagnósticos diferenciais, de modo a ser possível realizar análises de custo-efetividade sem estas limitações. $\mathrm{Na}$ África, Shillcutt e cols (148) adotaram para o braço dos verdadeiros negativos o diagnóstico presuntivo de infecção respiratória aguda, com tratamento com amoxicilina e a adoção da proporção de cura com o antibiótico como probabilidade para o modelo. O pressuposto do estudo foi justificado, pelos autores, pelo diagnóstico de saúde conhecido na região estudada. Na ausência de um diagnóstico similar para a área de estudo, sendo a realidade brasileira diferente da realidade africana, compreendendose que a definição de introdução de antibiótico seria uma decisão sem bases científicas e com base nos argumentos de Lubell e cols (148) foi julgado mais adequado organizar o modelo conforme explicado, sem considerar "cura" ou "não-cura" como desfechos finais do modelo.

A segunda limitação do estudo que advém da decisão acima é a subestimação dos custos dos casos verdadeiros negativos e também dos falsos negativos, por não serem incluídos os tratamentos ministrados a estes casos, à exceção do acetaminofen. A subestimação ocorreu para ambas as intervenções e qualquer acréscimo nos custos seria incorrido nas duas opções de diagnóstico. As diferenças poderiam, no entanto, ser evidentes, 
quando da ponderação dos custos pelos verdadeiros negativos e falsos negativos de cada teste. Outra subestimação de custos foi ocasionada pela ausência do custo de transporte de medicamentos no Estado do Pará para distribuição nos municípios, por impossibilidade de coleta deste dado no local.

Vários itens de custo utilizados no modelo não estão publicados na literatura e nem divulgados oficialmente em documentos dos serviços de saúde (portarias), ou não são de acesso público por meio de bancos de dados. Várias fontes usadas foram os documentos internos da Secretaria de Vigilância em Saúde, da Secretaria de Estado da Saúde do Pará e da Secretaria Municipal de Saúde do Novo Repartimento, por meio de buscas com os profissionais de saúde. Exemplos desta dificuldade foram os custos dos medicamentos antimaláricos, transporte de medicamentos, salários dos profissionais, gastos com óleo diesel e gasolina, treinamentos de microscopistas e da compra de microscópios. É uma limitação que não é específica do programa de malária e sim, constitui uma característica da gestão dos serviços de saúde que não possuem, geralmente, sistemas de registros de preços para consulta pública. Exceções a esta prática foram: o Banco de Preços do Ministério da Saúde, de acesso livre, que foi a fonte de dados para alguns itens mais genéricos, como luvas, glicose e acetaminofen e as tabelas do SIH-SUS e de procedimentos do SUS $(89,96)$.

Tanto os casos negativos para malária (verdadeiros ou falsos) como os casos que recebem resultados falsos positivos têm necessidade de reusar o sistema para a continuidade do diagnóstico. No modelo foi incluído o custo de uma consulta ambulatorial em cada um destes braços, como proxy dos custos de reuso do sistema, o que também foi subestimado, se considerarmos todos os desdobramentos possíveis para esclarecimento diagnóstico nestas situações. 
A estimativa de custos de salários de microscopistas, microscópios, manutenção de microscópios, transporte de equipes para realizar exames, assim como o salário de agentes de saúde que realizam o TR foi feita com base em documento da OMS (177), que considera a carga de trabalho dos profissionais a partir da prevalência de lâminas positivas. Como citado nos métodos, a partir da carga de trabalho horária estimada para as diferentes prevalências dos estratos de risco que compõem o risco global dos 12 municípios, chegou-se a uma estimativa de profissionais necessários em cada estrato e, a partir daí, a um custo médio para cada um dos itens de custos acima listados.

A opção pelo uso da referência da OMS (177) e, consequentemente, pelo custo médio estratificado pelos riscos, foi feita por considerar que os salários, equipamentos e sua manutenção, e o transporte das equipes, não são variáveis de custos exclusivas para a malária, diferentemente de outros itens (antimaláricos, gota espessa, teste rápido), já que na estrutura dos serviços do SUS tanto os profissionais como os equipamentos (microscópios e carros) devem ser usados para outras estratégias de atenção à população no mesmo território onde ocorrem casos de malária. Assim, o custo médio usado, que considerou as diversas cargas da malária em cada estrato, representa o custo que, teoricamente, pode ser imputado ao trabalho com a malária, para o diagnóstico de casos novos (pois não foram consideradas as laminas de LVC), desde que se aceitem as estimativas da OMS.

As estimativas usadas podem, entretanto, subestimar o número de lâminas examinadas por dia, ao se comparar com a prática dos profissionais no país, que chegam a examinar mais do que o dobro do estimado pela OMS (dados não publicados - PNCM - comunicação pessoal). Se a estimativa de custo daqueles itens fosse realizada a partir desta prática, dobrando-se o número de lâminas examinadas por dia por cada profissional e, consequentemente, os demais custos decorrentes também, resultaria um custo individual por lâmina para salários, microscópios e manutenção de 
microscópios mais reduzido em relação à estimativa adotada, porque seriam necessários menos profissionais, mantendo-se portanto, a dominação da microscopia sobre o TR nos cenários 1 e 2, não afetando a conclusão final. Já no cenário 3 , em que a microscopia apresentou-se como a intervenção mais cara e mais efetiva, os resultados da análise de custo-efetividade considerando o dobro de lâminas examinadas por cada profissional (dados não apresentados), resultaria em uma RCEI menor: $R \$ 910,10$ para o desfecho 1 e $R \$ 777,64$ no desfecho 2, ou seja, com mais economia para o SUS, do que se fosse obedecida a estimativa da OMS. A decisão pelo uso da estimativa da OMS foi tomada, no entanto, pelo fato de ser uma referência publicada e legitimada por instituição internacional, já que qualquer outra estimativa seria empírica ou presumida, por ausência de dados teóricos ou baseados em levantamentos nos serviços que estimassem com maior precisão o número de lâminas examinadas pelos profissionais brasileiros.

O conjunto dos 12 municípios tinha 183 laboratórios ativos para a malária no ano de 2006. A estimativa dos custos das variáveis citadas sem considerar a carga de trabalho da OMS e a estratificação dos riscos, resulta em valores muito mais altos para cada uma delas (cerca de 7 a 8,7 vezes maior - dados não apresentados), se considerarmos cada laboratório com a presença de um profissional e um microscópio e a mesma quantidade de agentes de saúde para realização do TR. Os custos calculados dessa forma invertem os custos nos cenários 1 e 2 (dados não-apresentados), devido ao grande peso que representa a compra de microscópios e a sua manutenção. Ou seja, uma análise que optasse por calcular este custo bruto para os 183 laboratórios teria como resultado um maior custo para a estratégia "microscopia", similar ao que ocorreu com o cenário 3 - áreas isoladas neste estudo. Na gestão dos serviços, porém, está plenamente justificada a existência desta quantidade grande de laboratórios nos municípios devido à necessidade de facilitar o acesso da população ao diagnóstico em uma região que, por condições climáticas e geográficas, apresenta imensas 
dificuldades para o deslocamento de pessoas. O que os números estimados a partir da OMS trazem ao modelo deste estudo é uma estimativa do "isolamento" da carga do trabalho exclusivo para o diagnóstico de casos novos de malária nas áreas e não a oposição à necessidade de expansão do diagnóstico nos territórios. É importante ressaltar que existe ociosidade nos serviços de diagnóstico da malária (104) em áreas de baixa transmissão, e que a estratégia adotada neste estudo não considera o tempo ocioso de profissionais e equipamentos e sim, o tempo e custos realmente envolvidos com a doença com base nas prevalências estimadas. Assim, os dados de custos do estudo não significam avaliação do investimento total feito pelos serviços de saúde para implantação de diagnóstico, o que exigiria outro método e outra abordagem e foge ao escopo desta análise.

O estudo não considerou os custos fixos de infra-estrutura de laboratórios de diagnóstico (construção e manutenção de prédios), assim como o uso de cadeias de frio para o transporte e uso do TR - estratégia não adotada no Brasil nas áreas onde o teste foi utilizado. No mundo real, a expansão do diagnóstico microscópico envolve investimentos do setor público para obras e manutenção de laboratórios, o que eleva o custo de implantação da estratégia "microscopia".

Algumas outras limitações ou dificuldades para a elaboração do modelo estão relacionadas com as fontes dos dados epidemiológicos. Os parâmetros que tiveram como fonte o SIVEP/Malária podem ter sofrido as conseqüências da sub-notificação dos casos ou de irregularidades no preenchimento da notificação, embora seja esperado que todo caso positivo seja notificado já que a distribuição do medicamento antimalárico é feita exclusivamente no SUS. Quando da análise e limpeza do banco de dados de 2006 ficou óbvio que existe melhor preenchimento e completitude dos dados para os casos positivos, o que alerta para possíveis problemas na 
atividade de notificação, a merecer ajustes e redirecionamento por parte das coordenações local e nacional do programa.

Quanto aos parâmetros epidemiológicos que tiveram como fonte a literatura científica, foi percebida a carência de estudos publicados com dados nacionais, especialmente para estudos de validação de testes, ensaios terapêuticos e de evolução clínica.

O maior estudo nacional de validação do OptiMal® (126), utilizado no caso-base do modelo e que se destaca pelo rigor metodológico na amostragem, na amostra examinada e na estimativa da acurácia, foi acessado por meio do serviço de saúde. Durante o período de coleta dos dados, nos anos de 2006 e 2007 não foram encontrados estudos nacionais de acurácia da microscopia, raros estudos nacionais publicados de ensaios clínicos de drogas antimaláricas $(1,7,8,33)$ e apenas uma tese acadêmica que estimou a frequência de formas graves de malária (66) em centro de referência brasileiro.

A limitação na busca de artigos de ensaios clínicos nacionais foi corroborada por artigo de revisão de literatura que utilizou como fontes o PubMed e a Base SciELO, realizado por Freitas e cols, publicado em 2007 (41). O estudo revisou artigos nacionais de estudos terapêuticos para malária vivax e malária falciparum não-complicada publicados de 1980 a 2005 e concluiu que "há, comparativamente a outras enfermidades, reduzido número de artigos brasileiros sobre malária, na literatura, se forem consideradas especificamente questões relativas ao tratamento" (41). Destaca-se que todos os artigos de tratamento para malária vivax citados pelo autor na sua revisão foram considerados neste estudo, seja na categoria de "excluídos" por não atenderem, minimamente, ao atual esquema preconizado, seja como parâmetros finais do modelo, o que demonstra que os artigos selecionados foram os melhores, face à escassez de ensaios. 
Procurou-se então confrontar a literatura internacional com a experiência brasileira, definindo-se para o modelo informações científicas que não produzissem grandes distorções em relação ao Brasil, como por exemplo, os dados de eficácia do Coartem $\AA$ que foram confrontados com tabelas de monitoramento da RAVREDA.

Artigo de Myint e cols, de 2004, que realizou revisão sistemática de ensaios clínicos de drogas antimaláricas publicados no mundo todo no período de 1966 a 2002 (fontes: PubMed, OLDMEDLINE, Medscape e Cochrane) captou 435 ensaios, sendo apenas 17 (4\%) provenientes da América do Sul (119), demonstrando que a carência existe também para demais países sul-americanos.

Quanto à validação da microscopia, ressalta-se que mesmo na literatura internacional, foram os poucos os trabalhos encontrados, o que gerou menos precisão para os dados utilizados no modelo. Decidiu-se por dados de acurácia da gota espessa que tivessem como padrão-ouro a PCR, o que limitou mais a busca pelos estudos.

É importante destacar que por ser um modelo teórico foram utilizados como parâmetros da resposta terapêutica os relacionados com as drogas de primeira linha preconizadas atualmente pelo PNCM, mesmo que não fossem utilizadas amplamente em 2006 na área de estudo. É o caso, por exemplo, do Coartem ${ }^{\circledR}$, que começou a ser comprado pelo Brasil em 2006 mas, foi indicado como droga de escolha para tratamento da malária falciparum nãograve, posteriormente. Esta opção foi mais razoável, pois adotar as demais drogas como base do modelo poderia ocasionar vieses tanto em relação à resposta terapêutica como em relação aos custos dos esquemas, para uma tomada de decisão a ser extrapolada para o presente. Ressalta-se porém, que na composição de custos dos esquemas foram consideradas outras drogas para situações especiais como para o tratamento de menores de seis meses e de gestantes, ponderadas pelas respectivas proporções de número 
de casos notificados. A adoção das drogas de primeira linha como parâmetro básico do modelo não distorce os resultados, pois o tratamento das situações especiais é feito com drogas igualmente eficazes e o número de casos do banco de dados é pequeno. $O$ fato foi comprovado na análise de sensibilidade, que será discutida mais adiante.

Estudos internacionais, no entanto, não reproduzem, na íntegra, os esquemas nacionais em termos de posologia ou forma de administração, como ocorreu com os esquemas para tratamento de malária falciparum grave, em que foram utilizados os ensaios que utilizaram os esquemas mais próximos aos esquemas nacionais, ou seja, artesunato ou artemeter seguido por mefloquina, mesmo que as doses usadas não fossem exatamente as mesmas dos esquemas nacionais; do contrário, não seria viável a obtenção do parâmetro. Como a eficácia do artesunato e do artemeter é praticamente a mesma, para se estimar a proporção de cura no caso-base e variação, utilizaram-se, indistintamente, estudos de uma ou outra droga. A decisão foi corroborada por artigo de revisão publicado pela Cochrane no ano de 2000. O estudo, por meio de metaanálise de 23 ensaios clínicos de derivados de artemisinina em malária grave usados na Ásia e África, chegou às seguintes conclusões: 1) "não foram encontradas diferenças significativas em relação à mortalidade quando se comparam artemisina, artesunato e artemeter e nem quando se comparam as vias intramuscular e intravenosa para o mesmo medicamento"; 2) "não foram encontradas diferenças significativas em relação ao tempo transcorrido para a recuperação da consciência quando se comparam artemisina, artesunato e artemeter"; e 3) "não foram encontradas diferenças significativas em relação ao tempo transcorrido para a resolução da febre ou da parasitemia quando se comparam artemisina, artesunato e artemeter". O artigo discute, porém, que a falta de padronização entre os estudos quanto a critérios de inclusão, definição de malária grave grave e processos de monitoramente dos ensaios dificultam a comparação entre eles (86). 
Para a malária vivax, mesmo utilizando-se somente estudos nacionais - uma vez que não foram encontrados estudos internacionais com esquema de primaquina por 07 dias como usado no Brasil - não foram encontrados ensaios que reproduzissem fielmente a dose de cloroquina preconizada no esquema nacional, sendo a opção feita pelos estudos que estimaram, embora com as limitações citadas pelos autores, a cura radical aos 6 meses, que é um efeito da combinação de cloroquina e primaquina, esta por 07 dias.

As limitações dos parâmetros de resposta terapêutica não comprometeram o modelo, devido não causarem variações nos resultados na análise de sensibilidade.

O Brasil não definiu até o momento os limiares (threshold) a partir dos quais se consideraria uma intervenção custo-efetiva. É consenso, no entanto, que uma intervenção em saúde é considerada custo-efetiva quando domina a intervenção com a qual é comparada, ou seja, é mais barata e mais efetiva. Segundo a OMS, para países de mais baixas condições sócio econômicas, consideram-se também custo-efetivas as estratégias que apresentam RCEA abaixo de US\$150 por AVAI evitado (148) ou, ainda, tomando-se em consideração o PIB per capita, seriam muito custo-efetivas as intervenções com RCEA abaixo do PIB per capita, custo-efetivas aquelas com RCEA até 3 vezes o valor do PIB e com mais de três vezes o valor do PIB, não seriam custo-efetivas (173). Na ausência de uma definição nacional de quanto a sociedade estaria disposta a pagar por uma intervenção e considerando a definição da OMS a partir do PIB, a microscopia é custoefetiva em todos os cenários, pois mesmo no cenário 3 a RCEA do casobase e de todas as variações da análise de sensibilidade ficaram bem abaixo do PIB per capita, considerando os seguintes valores: PIB per capita do ano de 2006 para o Brasil: $R \$ 12.437,00$ (107) e PIB per capita para o Estado do Pará no ano de 2005: $\mathrm{R} \$ 5.617,00$ (47) e no ano de 2006: $\mathrm{R} \$$ 4.991,00 (108). É importante, no entanto, face à ausência de um critério nacional, que os tomadores de decisão debrucem-se sobre os resultados de 
análise de custo-efetividade e definam, com base em orçamento disponível para as ações de saúde, se as RCEA geradas nos estudos são aceitáveis para cada situação específica e o quanto se deseja pagar por cada intervenção. É necessário, no entanto, com o avanço do papel da avaliação econômica como suporte às decisões de incorporação de novas tecnologias no SUS, que evoluam as discussões acadêmicas e técnicas no sentido de serem gerados estes critérios, pois ter um limite aceito pela sociedade estimulará a dotação de orçamento público para novas tecnologias custoefetivas.

Assim, para todos os cenários, a microscopia foi mais custo-efetiva do que o TR. Nos cenários 1 e 2, nos quais a microscopia é dominante, esta decisão foi alterada por poucos parâmetros na análise de sensibilidade. Já para o cenário 3 , não houve dominação clara de uma estratégia sobre a outra, mas a microscopia mantém-se custo efetiva se considerarmos os limiares acima discutidos. A microscopia é mais cara nas áreas isoladas, sendo determinante para este custo mais alto o envolvimento de mais profissionais na execução do diagnóstico para as atividades de busca ativa e de diagnóstico propriamente dito, feitas, geralmente, por profissionais diferentes e o custo de transporte de equipes, com pelo menos dois deslocamentos por caso examinado. É importante esclarecer que o custo de transporte pode estar superestimado no modelo, pois, na prática, a cada deslocamento podem ser feitos vários exames.

Foi realizada análise de sensibilidade do tipo univariada, que é um dos métodos adotados para modelos determinísticos (21). Uma das limitações da análise de sensibilidade univariada é a subestimação da incerteza global do modelo, além do fato de que na vida prática dificilmente um componente usado na avaliação varia de forma isolada (20), porém é o processo mais adotado para analisar as incertezas do modelo, quando os dados provêm de múltiplas fontes. 
A análise de sensibilidade para os cenários 1 e 2 demonstra que 0 modelo é sensível a alguns dos parâmetros de acurácia da microscopia e do TR (tabelas 17 a 20), quando variados individualmente. Em relação à microscopia, esta estratégia deixaria de ser dominante, porém ainda custoefetiva, se a sua acurácia fosse menor do que a estimada no caso-base do modelo ou se a sensibilidade do TR para Plasmodium vivax fosse de $100 \%$ opção menos realista, na prática. Assim, é importante que seja bem conhecida a acurácia da microscopia feita nos laboratórios da região de estudo, pois a decisão do modelo depende da manutenção de altas sensibilidade e especifidade da gota espessa, como definidas no caso-base. O PNCM tem por estratégia o treinamento contínuo dos microscopistas e o controle de qualidade do diagnóstico (104), atividades estas extremamente importantes para manutenção da qualidade do exame. O controle da qualidade implantado pelo PNCM implica em contratar os microscopistas segundo avaliação de competência e implementar sistema de monitoramento de desempenho, com a revisão pelo supervisor, de forma cega, de um número de lâminas positivas de baixa parasitemia e de lâminas negativas (104). Como o modelo de decisão foi construído com dados internacionais para este parâmetro, devido a ausência de estudos nacionais, poderia ser interessante fazer futuros estudos para avaliar a acurácia da microscopia feita nos laboratórios de campo, uma vez que o controle de qualidade mede a concordância - útil para o objetivo a que se propõe - e não a acurácia.

No cenário 1 - área global - o único parâmetro de custo que altera a decisão é o custo do transporte de equipes para realizar a microscopia a partir de um custo de transporte por exame de $R \$ 7,05$, em que a microscopia deixa de ser dominante. Isto ocorre pelo peso do deslocamento para as áreas isoladas que fazem parte do conjunto do território. Como já comentado, porém, este é um custo que pode ser bastante racionalizado ao se aproveitar um mesmo deslocamento para a realização de múltiplos exames. 
No cenário 3 (tabelas 21 e 22), ficam mais evidentes na análise de sensibilidade o impacto das estimativas da acurácia da microscopia para o modelo de decisão. Neste cenário, a redução da acurácia da microscopia teve um impacto importante, pois ocasionou inversão total nos resultados da análise, tornando o TR a estratégia dominante e mais custo-efetiva para os dois desfechos. Este cenário diferencia-se pelo maior custo para realização da microscopia, devido aos custos mais altos de transporte e envolvimento de maior número de profissionais para realizar o exame e, portanto, a microscopia só se manteria como uma estratégia custo-efetiva se fossem mantidas elevadas sensibilidade e especificidade do exame de gota espessa. Valem aqui as mesmas considerações feitas anteriormente sobre a acurácia do exame, com o agravante de que nas áreas isoladas, a redução da acurácia significa outra tomada de decisão: a implantação do TR. Também se observa na análise de sensibilidade que alterações de estimativas para mais na sensibilidade do TR, em relação ao caso-base, podem causar a mesma inversão nos resultados, como ocorreu quando se utilizou a sensibilidade do TR para Plasmodium vivax estimada a $100 \%$, porém não é um dado de acurácia a ser valorizado nos resultados, pois é de pouca aplicação prática. Quanto aos custos, quanto mais baixo o custo do exame de gota espessa ou mais alto o custo do TR, mais custo-efetiva torna-se a microscopia neste cenário. $O$ custo de $R \$ 0,41$ para o exame de gota espessa usado na análise de sensibilidade derivou de um processo de micro-costing a partir de todos os componentes do exame, como detalhado na metodologia (anexo 12), o que pode conferir mais precisão ao custo, e a RCEA mais baixa gerada na análise seria também mais precisa. Custos que também geram impactos, isoladamente, são os de transporte de equipes e de treinamentos. A simples redução do custo no treinamento de microscopistas torna a estratégia "microscopia" dominante também neste cenário.

Os problemas mais críticos em áreas isoladas e distantes de centros de diagnóstico, como no cenário 3 , não são os relativos aos custos de 
transporte per se e sim, à dificuldade de acesso, pois muitas vezes por condições das estradas, chuvas, desabamentos e outras situações, o diagnóstico é retardado, não por questões de distância mas, por condições de acesso (informações do município do Novo Repartimento - dados não publicados). Para a tomada de decisão de qual a melhor estratégia de diagnóstico nestas áreas há que se levar em consideração vários outros aspectos que não apenas o custo-efetividade. Em áreas de difícil acesso pode ter um grande peso na decisão a facilidade do uso do TR, a possibilidade de realização de apenas uma viagem da equipe e não duas (para a coleta e depois para o entrega do resultado, no caso da gota espessa) e outros fatores como a disponibilidade de recursos financeiros para alguns gastos (diesel, gasolina) pelos serviços de saúde. Assim, mesmo considerando que a microscopia foi mais custo-efetiva também em áreas isoladas, este não deve ser o mais relevante critério para a decisão em uma região tão complexa como a Amazônia.

São poucos os estudos publicados que abordam o tema desta tese. $\mathrm{Na}$ literatura científica foram encontrados apenas cinco artigos publicados com estudos de custo-efetividade de TR de malária $(24,37,77,146,148)$, um estudo de custo-benefício e um de custo-minimização $(78,133)$. O único estudo brasileiro foi o de custo-minimização em localidade rural do Estado do Mato Grosso (133), em que foram comparados a microscopia e o TR ParaSight $-\mathrm{F} \AA$, este último em estratégia baseada na comunidade para a execução do teste. O estudo evidenciou ser a estratégia com o TR mais econômica ao longo do tempo, devido principalmente à economia com transporte.

O estudo de Bualombai e cols., na Tailândia, (24) não determinou a RCEA, restringindo-se à apresentação das razões de custo-efetividade médias das três estratégias utilizadas: microscopia, OptiMal® e outro TR, o ICT®. O estudo partiu de uma validação das três estratégias, tendo como padrão-ouro a gota espessa realizada por laboratórios de referência e 
concluiu que o OptiMal® e a gota espessa têm acurácia muito similares, sendo o OptiMal® mais custo-efetivo; a ausência de RCEA, porém, limita as suas conclusões.

O estudo de Fernando e cols., no Sri Lanka (37) comparou os custos do TR ICTß com a microscopia gerando também razão de custo-efetividade média: custo por caso detectado. O TR foi cerca de 14 vezes mais caro do que microscopia e o seu custo por caso detectado foi 20 vezes maior. 0 custo por caso detectado foi sensível às variações de prevalência da malária e da sensibilidade do TR, sendo reduzido quanto mais alta a prevalência da malária e mais elevada a sensibilidade do TR. A ausência de RCEA também limita as conclusões do estudo mas, similarmente à realidade brasileira, 0 TR apresenta alto custo se comparado ao exame de rotina e o autor discute este ponto como um grande impedimento para a expansão do diagnóstico rápido no país.

Os estudos de Lubell e cols, Shillcutt e cols, e Rolland e cols (77, 146, 148) tiveram em comum o cenário africano e discutem a baixa acurácia da microscopia nos países da África, o que determina a necessidade de uma alternativa diagnóstica. Além deste fato, o TR para os países africanos teve um custo baixo em comparação ao preço praticado no Brasil, embora possa representar ônus importante para os países africanos.

Lubell e cols., na Tanzânia, (77) analisaram o TR Paracheck Pf®, que teve um custo unitário de US\$ 0,60 por TR e a estratégia de diagnóstico completa com esta opção de US\$ 0,81, sendo a estratégia "microscopia" de US\$ 0,26 por exame. A microscopia apresentou baixa sensibilidade - 71\% e o TR foi opção mais custo-efetiva, especialmente em cenários de mais alta prevalência, sendo a RCEA de US\$25,20 por pacientes corretamente tratados em áreas de mais baixa prevalência e de US $\$ 7,0$ no cenário de mais alta prevalência. Apesar de a microscopia ter um custo mais baixo, a 
sua baixa sensibilidade foi determinante para que o TR fosse a alternativa mais custo-efetiva neste estudo.

Rolland e cols., em cenário hipotético na África Subsaariana (146) realizaram análise de custo-efetividade comparando o tratamento presuntivo para malária com o TR Paracheck $\mathrm{Pf}$. $\mathrm{O}$ tratamento presuntivo é a prática e a recomendação oficial para os países da Região, devido às dificuldades de manutenção de laboratórios de microscopia com garantia de diagnóstico acurado. O desfecho utilizado na análise foi "falsos positivos evitados", já que o tratamento presuntivo é uma estratégia de baixa especificidade. O TR teve um custo por teste de US\$ 0,64, foi mais custo-efetivo em cenários de mais baixa prevalência e os resultados foram dependentes do custo dos medicamentos, sendo mais custo-efetivo quando em uso de esquemas de tratamento com o Coartem $®$ em comparação com esquemas de artesunato e amodiaquina; mesmo em cenários de mais alta prevalência o teste seria considerado custo-efetivo se o threshold fosse de até 2 euros (US\$2,44) por cada caso falso positivo a mais evitado pelo TR.

Shillcutt e cols, também na África Subsaariana (148) compararam TR do tipo HRP-2 com o tratamento presuntivo (em cenário similar ao trabalho de Rolland e cols, no qual não há acesso fácil a diagnóstico microscópico na rotina) e também com a microscopia, assumindo sensibilidade de $82 \%$ e especificidade de $85 \%$ - que o autor refere serem os melhores rendimentos do exame nos hospitais locais -, mais baixas do que as assumidas para 0 TR: $96 \%$ e 95\%, respectivamente. O custo do TR foi de US\$ 0,60 a US\$ 1,00 e da microscopia de US\$ 0.32 a US\$ 1.27 e o desfecho foi medido em AVAl evitado. O estudo fez análise probabilística e, em comparação ao tratamento presuntivo, estima com $97 \%$ de certeza que em cenário de prevalência de malária de $40 \%$, o TR seria custo-efetivo e com prevalência acima de $70 \%$ seria dominante; e com $95 \%$ de certeza de que não seria custo-efetivo em prevalência acima de $90 \%$. O TR seria mais custo-efetivo do que a microscopia em qualquer nível de prevalência, com $85 \%$ de 
certeza. O TR foi mais atrativo do que a microscopia e a análise de sensibilidade pouco alterou esta decisão. $O$ estudo chama atenção para o fato de que os resultados dependem também de quanto os clínicos aderem aos resultados dos testes diagnósticos, prescrevendo os medicamentos de acordo com os resultados recebidos. Já foi demonstrado que os resultados de avaliação econômica podem variar bastante a depender da prescrição médica consistente com o diagnóstico (78) e os modelos que assumem $100 \%$ de adesão aos resultados tanto por parte do paciente quanto por parte dos médicos e outros profissionais de saúde constituem aproximações da realidade; este fato, porém é mais decisivo para a modelagem em países em que a baixa confiabilidade nos exames diagnósticos é uma realidade, como na África.

Tanto Rolland e cols quanto Shillcutt e cols discutem $(146,148)$ que a baixa especificidade - próxima de zero - do tratamento presuntivo foi determinante para os resultados encontrados, já que o diagnóstico com os testes rápidos evitaria o tratamento de todos os falsos positivos que recebem o tratamento presuntivo. O mesmo ocorreu quando foram assumidos para a gota espessa valores mais baixos de sensibilidade e especificidade em relação ao TR (148). Similar conclusão foi encontrada em estudo de custobenefício, em que a baixa sensibilidade da microscopia resultou em mais altos custos para esta estratégia, quando comparada com TR ou tratamento presuntivo, em diferentes cenários de prevalência e de adesão aos resultados do diagnóstico (78).

No presente estudo foi demonstrado que as estimativas de sensibilidade e especificidade foram também determinantes para os resultados de custo-efetividade e que a melhor relação de custo-efetividade da microsocopia em relação ao TR é dependente da manutenção de elevada acurácia (sensibilidade e especificidade) da gota espessa. Os estudos publicados estimam que em cenários de baixa acurácia do diagnóstico padrão, o TR seria a opção mais atrativa do ponto de vista econômico. 
Como retorno do estudo ao PNCM, é esperado que o programa possa beneficiar-se dos resultados, e que este primeiro estudo de ACE contribua para a valorização do método de avaliação econômica na gestão dos serviços. Como contribuições secundárias que vão além dos resultados mesmos do estudo, o modelo de ACE aqui desenvolvido pode ser modificado a partir, por exemplo, dos seus pressupostos, gerando novas análises; pode ser apropriado para avaliar TR - da mesma marca comercial ou de outras marcas de interesse - em outros cenários do país; ou pode ser a base para a ACE de novas técnicas diagnósticas que surjam como alternativas.

Recomenda-se, ainda, ao PNCM: 1) a realização de pesquisa para se conhecer, além da concordância, a acurácia do exame microscópio feito nos laboratórios de campo, o que seria importante como evidência científica nacional; 2) a manutenção de elevada acurácia da gota espessa, por meio das atividades que já são desenvolvidas para o controle de qualidade do exame; e 3) a realização de amplo estudo de custos do Programa, englobando todas as suas atividades e cenários de ação. Também é recomendável a redução do preço de compra do TR, talvez por meio de fundos subsidiados por organismos internacionais, pois mesmo tendo mostrado-se menos efetivo no modelo em comparação à microscopia, é uma alternativa de grande utilidade para áreas de difícil acesso ou para áreas não endêmicas, onde, nestas últimas, pode ser mais complexo manter microscopistas com capacidade de realizar exames acurados de gota espessa; além do fato de o TR poder ser a estratégia mais atrativa também do ponto de vista da efetividade, caso não se mantenham elevadas sensibilidade e especificidade da gota espessa nos laboratórios de campo ou em áreas indenes. A expansão da rede de diagnóstico microscópico, por sua vez, está justificada somente se a realidade epidemiológica justificar o investimento, já que são elevados os custos de implantação; portanto, ter acesso a uma tecnologia como TR para realidades singulares é uma necessidade e a redução do seu custo deve ser exigida pelo SUS. 


\section{CONCLUSÕES}

Do ponto de vista da relação de custo-efetividade, a estratégia "teste rápido" foi dominada pela estratégia "microscopia" nos cenários 1 e 2 , que correspondem à área global dos 12 municípios e às áreas cobertas por laboratórios de diagnóstico de malária, respectivamente.

A estratégia "microscopia" também foi mais custo-efetiva no cenário 3 - áreas isoladas dos 12 municípios - quando considerados os limiares (thresholds) aceitos internacionalmente para a definição de intervenções custo-efetivas.

O parâmetro epidemiológico que mais alterou os resultados de custoefetividade na análise de sensibilidade foi a acurácia da microscopia, estimada pelos valores de sensibilidade e especificidade.

Reduções nos valores de sensibilidade e especificidade da gota espessa inverteram a relação de custo-efetividade, em relação ao casobase, no cenário 3 - onde a microscopia é mais cara devido a custos de transporte e de salários de duas categorias de profissionais envolvidas no exame.

Custos de transportes para deslocamento de equipes de saúde e de treinamento de microscopia também tiveram impacto nos resultados de custo-efetividade. $\mathrm{Na}$ análise de sensibilidade, a redução do custo de treinamento para microscopia no cenário 3 tornou a gota espessa dominante em relação ao teste rápido também neste cenário. 


\section{REFERÊNCIAS}

1. Abdon NP et al. Assessment of the response to reduced treatment schemes for vivax malaria. Rev Soc Bras Med Trop 2001;34:343-8.

2. Adam I et al. Quinine therapy in severe Plasmodium falciparum malaria during pregnancy in Sudan. East Mediterr. Health J. 2004;10:159-66.

3. Agência Nacional de Vigilância Sanitária.Ministério da Saúde. Pesquisa de produtos para saúde registrados. [acessado em julho de 2008 para informações do mesmo ano]. Disponível em http://www7.anvisa.gov.br/datavisa/Consulta_Produto_correlato/consu Ita_correlato.asp . 2008.

4. Agência Nacional do Petróleo Gás Natural e Biocombustíveis. Relatório anual de acompanhamento de mercado - 2006 - gasolina comum. [acessado em 17 de março de 2008, para informações do ano de 2006]. Disponível em http://www.anp.gov.br/doc/petroleo/relatorios_precos/2006/Gasolina_2 006.pdf . 2008.

5. Agência Nacional do Petróleo Gás Natural e Biocombustíveis. Relatório anual de acompanhamento de mercado - 2006 - óleo diesel. [acessado em 17 de março de 2008, para informações do ano de 2006]. Disponível em http://www.anp.gov.br/doc/petroleo/relatorios_precos/2006/Diesel_200 6.pdf . 2008.

6. Akhavan D et al. Cost-effective malaria control in Brazil. Costeffectiveness of a Malaria Control Program in the Amazon Basin of Brazil, 1988-1996. Soc.Sci.Med. 1999;49:1385-99.

7. Alecrim MG et al. Treatment of children with malaria Plasmodium falciparum with derivatives artemisinin. Rev Soc Bras Med Trop 2003;36:223-6.

8. Alecrim MG et al. Successful treatment of Plasmodium falciparum malaria with a six-dose regimen of artemether-lumefantrine versus quinine-doxycycline in the Western Amazon region of Brazil. Am.J.Trop Med Hyg. 2006;74:20-5.

9. Alecrim MGC. Estudo clínico, resistência e polimorfismo parasitário na malária pelo Plasmodium vivax, em Manaus-AM [Tese de Doutorado]. Brasília (DF):Universidade de Brasília. 2000. 
10. Aslan $\mathrm{G}$ et al. Diagnostic performance characteristics of rapid dipstick test for Plasmodium vivax malaria. Mem. Inst.Oswaldo Cruz 2001;96:683-6.

11. Avila PE et al. Evaluation of a rapid dipstick test, Malar-Check, for the diagnosis of Plasmodium falciparum malaria in Brazil.

Rev.Inst.Med.Trop.São Paulo 2002;44:293-6.

12. Awad Ml et al. Descriptive study on the efficacy and safety of artesunate suppository in combination with other antimalarials in the treatment of severe malaria in Sudan. Am.J.Trop Med Hyg. 2003;68:153-8.

13. Banco Central do Brasil. Serviços ao Cidadão. Taxas de Câmbio. [acessado em fevereiro de 2008, para obter informações de 2001 e 2006]. Disponível em http://www5.bcb.gov.br/pec/taxas/port/ptaxnpesq.asp?id=taxacambio . 2008.

14. Bell $D$ et al. Diagnosis of malaria in a remote area of the Philippines: comparison of techniques and their acceptance by health workers and the community. Bull.World Health Organ 2001;79:933-41.

15. Bell D, Perkins MD. Making malaria testing relevant: beyond test purchase. Trans.R.Soc.Trop.Med.Hyg.Article in Press 2008.

16. Bircan $Z$ et al. Two cases of nephrotic syndrome and tertian malaria in south-eastern Anatolia. Pediatr.Nephrol. 1997;11:78-9.

17. Brasil.Ministério da Saúde. Portaria da Secretaria Executiva no. 950, de 23 de dezembro de 1999. Diário Oficial da União de 24 de dezembro de 1999. 1999.

18. Brasil.Ministério da Saúde. Portaria Ministerial no. 1399, de 14 de dezembro de 1999. Diário Oficial da União de 16 de dezembro de 1999. 1999.

19. Breman JG, Alilio MS, Mills A. Conquering the intolerable burden of malaria: what's new, what's needed: a summary. Am.J.Trop.Med.Hyg. 2004;71:1-15.

20. Briggs $A$. Economics notes: handling uncertainty in economic evaluation. BMJ 1999;319:120.

21. Briggs $\mathrm{AH}$. Handling uncertainty in cost-effectiveness models. Pharmacoeconomics. 2000;17:479-500. 
22. Brouwer W, Rutten F, Koopmanschap M. Costing in economic evaluation. In: Drummond M, McGuire A, eds. Economic evaluation in health care. New York: Oxford University Press Inc., 2006:68-93.

23. Bruneel $\mathrm{F}$ et al. The clinical spectrum of severe imported falciparum malaria in the intensive care unit: report of 188 cases in adults. Am.J.Respir.Crit Care Med 2003;167:684-9.

24. Bualombai $P$ et al. Determining cost-effectiveness and cost component of three malaria diagnostic models being used in remote non-microscope areas. Southeast Asian J.Trop.Med.Public Health 2003;34:322-33.

25. Cao XT et al. Comparison of artemisinin suppositories, intramuscular artesunate and intravenous quinine for the treatment of severe childhood malaria. Trans.R.Soc Trop Med Hyg. 1997;91:335-42.

26. Centers for Disease Control and Prevention. Prevention effectiveness: decision analysis and economic evaluation course; March 19-20. Atlanta: CDC, 2002.

27. Cho MN, Gatton ML. Performance appraisal of rapid on-site malaria diagnosis (ICT malaria Pf/Pv test) in relation to human resources at village level in Myanmar. Acta Trop. 2002;81:13-9.

28. Coleman RE et al. Short report: Failure of the OptiMAL rapid malaria test as a tool for the detection of asymptomatic malaria in an area of Thailand endemic for Plasmodium falciparum and P. vivax. Am.J.Trop.Med.Hyg. 2002;67:563-5.

29. Coleman RE et al. Field evaluation of the ICT Malaria Pf/Pv immunochromatographic test for the detection of asymptomatic malaria in a Plasmodium falciparum/vivax endemic area in Thailand. Am.J.Trop.Med.Hyg. 2002;66:379-83.

30. Coleman RE et al. Comparison of field and expert laboratory microscopy for active surveillance for asymptomatic Plasmodium falciparum and Plasmodium vivax in western Thailand. Am.J.Trop.Med.Hyg. 2002;67:141-4.

31. Conteh $L$ et al. The cost and cost-effectiveness of malaria vector control by residual insecticide house-spraying in southern Mozambique: a rural and urban analysis. Trop.Med.Int. Health 2004;9:125-32. 
32. Cooke AH et al. Comparison of a parasite lactate dehydrogenasebased immunochromatographic antigen detection assay (OptiMAL) with microscopy for the detection of malaria parasites in human blood samples. Am.J.Trop.Med.Hyg. 1999;60:173-6.

33. da Silva RS et al. Short course schemes for vivax malaria treatment. Rev Soc Bras Med Trop 2003;36:235-9.

34. Diário Oficial da União No.11. 16 de janeiro de 2006. Seção 3. Extrato de contrato no. 92/2005. Brasília: Imprensa Nacional, 2006.

35. Duarte EC et al. Association of subtherapeutic dosages of a standard drug regimen with failures in preventing relapses of vivax malaria. Am.J.Trop Med Hyg. 2001;65:471-6.

36. Farcas GA et al. Evaluation of the Binax NOW ICT test versus polymerase chain reaction and microscopy for the detection of malaria in returned travelers. Am.J.Trop.Med.Hyg. 2003;69:589-92.

37. Fernando SD et al. A cost analysis of the use of the rapid, wholeblood, immunochromatographic P.f/P.v assay for the diagnosis of Plasmodium vivax malaria in a rural area of Sri Lanka. Ann.Trop.Med.Parasitol. 2004;98:5-13.

38. Ferreira MU, da Silva NM, Wunderlich G. Antigenic diversity and immune evasion by malaria parasites. Clin.Diagn.Lab Immunol. 2004;11:987-95.

39. Ferro BE et al. Performance of OptiMAL(R) in the diagnosis of Plasmodium vivax and Plasmodium falciparum infections in a malaria referral center in Colombia. Mem. Inst.Oswaldo Cruz 2002;97:731-5.

40. Fievet $\mathrm{N}$ et al. Immune response to Plasmodium falciparum antigens in Cameroonian primigravidae: evolution after delivery and during second pregnancy. Clin.Exp.Immunol. 1997;107:462-7.

41. Freitas LF et al. Uncomplicated Plasmodium vivax and P. falciparum malaria in Brazil: evidence on single and combined drug treatments recommended by official guidelines. Cad.Saude Publica 2007;23:2285-94.

42. Fundação Instituto Brasileiro de Geografia e Estatística - IBGE. 1995. Anuário Estatístico do Brasil. Rio de Janeiro: IBGE, 1995.

43. Fundação Nacional de Saúde. Plano de Intensificação das Ações de Controle da Malária na Amazônia Legal: documento técnico. Brasília: Ministério da Saúde, 2000. 
44. Gonzalez-Ceron $L$ et al. [Efficacy of a rapid test to diagnose Plasmodium vivax in symptomatic patients of Chiapas, Mexico]. Salud Publica Mex. 2005;47:282-7.

45. Goodman CA, Coleman PG, Mills AJ. Cost-effectiveness of malaria control in sub-Saharan Africa. Lancet 1999;354:378-85.

46. Goodman CA, Mills AJ. The evidence base on the cost-effectiveness of malaria control measures in Africa. Health Policy Plan. 1999;14:301-12.

47. Governo do Estado do Pará.Secretaria de Estado de Planejamento OeF. Produto Interno Bruto. 2002-2005. [acessado em julho de 2008 para informações de 2005]. Disponível em http://www.sepof.pa.gov.br/estatistica/ipc_cesta_basica/pib.pdf . 2008.

48. Haddix AC et al. Prevention effectiveness - a guide to decision analysis and economic evaluation. New York: Oxford University Press, Inc., 1996.

49. Haghdoost AA, Mazhari S, Bahadini K. Comparing the results of light microscopy with the results of PCR method in the diagnosis of Plasmodium vivax. J.Vector.Borne.Dis. 2006;43:53-7.

50. Hanson $\mathrm{K}$ et al. The economics of malaria control interventions. Geneva: Global Forum for Health Research, 2004.

51. Hanson K. Public and private roles in malaria control: the contributions of economic analysis. Am.J.Trop.Med.Hyg. 2004;71:168-73.

52. Hien TT et al. Comparison of artemisinin suppositories with intravenous artesunate and intravenous quinine in the treatment of cerebral malaria. Trans.R.Soc Trop Med Hyg. 1992;86:582-3.

53. Hien TT et al. An open randomized comparison of intravenous and intramuscular artesunate in severe falciparum malaria. Trans.R.Soc.Trop.Med.Hyg. 1992;86:584-5.

54. Humar $A$ et al. Parasight $F$ test compared with the polymerase chain reaction and microscopy for the diagnosis of Plasmodium falciparum malaria in travelers. Am.J.Trop.Med.Hyg. 1997;56:44-8.

55. Iqbal $\mathrm{J}$ et al. Performance of the OptiMAL test for malaria diagnosis among suspected malaria patients at the rural health centers. Am.J.Trop.Med.Hyg. 2003;68:624-8.

56. Iqbal $\mathrm{J}$ et al. Comparison of the OptiMAL test with PCR for diagnosis of malaria in immigrants. J.Clin.Microbiol. 1999;37:3644-6. 
57. Kachur SP et al. Prevalence of malaria parasitemia and accuracy of microscopic diagnosis in Haiti, October 1995. Rev.Panam.Salud Publica 1998;3:35-9.

58. Kakar A et al. Profound thrombocytopenia in Plasmodium vivax malaria. Diagn.Microbiol.Infect.Dis. 1999;35:243-4.

59. Kazembe LN, Kleinschmidt I, Sharp BL. Patterns of malaria-related hospital admissions and mortality among Malawian children: an example of spatial modelling of hospital register data. Malar.J. 2006;5:93.

60. Kochar DK et al. Plasmodium vivax malaria. Emerg.Infect.Dis. 2005;11:132-4.

61. Koh $\mathrm{KH}$, Chew $\mathrm{PH}$, Kiyu A. A retrospective study of malaria infections in an intensive care unit of a general hospital in Malaysia. Singapore Med J. 2004;45:28-36.

62. Kolaczinski $\mathrm{J}$ et al. Comparison of the OptiMAL rapid antigen test with field microscopy for the detection of Plasmodium vivax and $P$. falciparum: considerations for the application of the rapid test in Afghanistan. Ann.Trop.Med.Parasitol. 2004;98:15-20.

63. Krudsood $\mathrm{S}$ et al. Clinical experience with intravenous quinine, intramuscular artemether and intravenous artesunate for the treatment of severe malaria in Thailand. Southeast Asian J.Trop Med Public Health 2003;34:54-61.

64. Kumaranayake $L$. The real and the nominal? Making inflationary adjustments to cost and other economic data. Health Policy Plan. 2000;15:230-4.

65. Kuntz KM, Weinstein MC. Modelling in economic evaluation. In: Drummond M, McGuire A, eds. Economic evaluation in health care. New York: Oxford University Press Inc., 2006:141-71.

66. Lacerda MV. Manifestações clínicas e patogênese da plaquetopenia na malária [Tese de Doutorado]. Brasília (DF):Universidade de Brasília. 2007.

67. Lacerda MV et al. Idiopathic thrombocytopenic purpura due to vivax malaria in the Brazilian Amazon. Acta Trop 2004;90:187-90.

68. Lacerda MV, Mourao MP, Tavares AM. Manual de Rotinas da Fundação de Medicina Tropical do Amazonas. [Acessado em janeiro de 2008]. Disponível em http://www.fmt.am.gov.br/manual/index.htm . 2008. 
69. Lacerda MVG et al. Estudo clínico de pacientes internados com malária ( $P$. falciparum) na FMT-AM. Rev Soc Bras Med Trop 2001;34:70-1.

70. Ladislau JLB, Leal MC, Tauil PL. Avaliação do plano de intensificação das ações de controle da malária na região da Amazônia Legal, Brasil, no contexto da descentralização. Epidemiol. Serv. Saúde 2006;15:9-20.

71. Loiola CC, da Silva CJ, Tauil PL. Malaria control in Brazil: 1965 to 2001. Rev.Panam.Salud Publica 2002;11:235-44.

72. Lomar AV et al. Acute respiratory distress syndrome due to vivax malaria: case report and literature review. Braz.J.Infect.Dis. 2005;9:425-30.

73. Londono B, Carmona J, Blair S. Comparison between OptiMAL and the thick smear tests for malaria diagnosis in an endemic area during a non-epidemic period. Biomedica. 2002;22:466-75.

74. Looareesuwan S et al. A comparative clinical trial of sequential treatments of severe malaria with artesunate suppository followed by mefloquine in Thailand. Am.J.Trop Med Hyg. 1997;57:348-53.

75. Looareesuwan S et al. Efficacy and tolerability of a sequential, artesunate suppository plus mefloquine, treatment of severe falciparum malaria. Ann.Trop Med Parasitol. 1995;89:469-75.

76. Lorenzetti A et al. Mixed Plasmodium falciparum infections and its clinical implications in four areas of the Brazilian Amazon region. Acta Trop. 2008;107:8-12.

77. Lubell $\mathrm{Y}$ et al. The cost-effectiveness of parasitologic diagnosis for malaria-suspected patients in an era of combination therapy. Am.J.Trop.Med.Hyg. 2007;77:128-32.

78. Lubell $Y$ et al. The impact of response to the results of diagnostic tests for malaria: cost-benefit analysis. BMJ 2008;336:202-5.

79. Luxemburger $\mathrm{C}$ et al. The epidemiology of severe malaria in an area of low transmission in Thailand. Trans. R.Soc Trop Med Hyg. 1997;91:256-62.

80. Macauley C. Aggressive active case detection: a malaria control strategy based on the Brazilian model. Soc.Sci.Med. 2005;60:563-73.

81. Marques $A C$, Cárdenas H. Combate à malária no Brasil: evolução, situação atual e perspectivas. Rev Soc Bras Med Trop 1994;27:91108. 
82. Marsh $\mathrm{K}$ et al. Indicators of life-threatening malaria in African children. N.Engl.J.Med 1995;332:1399-404.

83. Martinez-Espinosa FE. Malária na gravidez: estudo de pacientes do Instituto de Medicina Tropical do Amazonas: Brasil, 1990-1997 [Tese de Mestrado]. Rio de Janeiro (RJ): Fundação Oswaldo Cruz. 1998. Ref Type: Thesis/Dissertation

84. Marx A et al. Meta-analysis: accuracy of rapid tests for malaria in travelers returning from endemic areas. Ann.Intern.Med 2005;142:836-46.

85. Mayxay M et al. Short communication: An assessment of the use of malaria rapid tests by village health volunteers in rural Laos. Trop.Med.Int.Health 2004;9:325-9.

86. Mclntosh $\mathrm{HM}$, Olliaro P. Artemisinin derivatives for treating severe malaria. Cochrane.Database.Syst.Rev. 2000;CD000527.

87. Mharakurwa S, Manyame B, Shiff CJ. Trial of the ParaSight-F test for malaria diagnosis in the primary health care system, Zimbabwe. Trop.Med.Int.Health 1997;2:544-50.

88. Ministério da Saúde. Programa Nacional de Controle da MaláriaEsquemas recomendados para o tratamento da malária não complicada no Brasil- Folder. 2006.

89. Ministério da Saúde. Banco de Preços em Saúde. [acessado em 2008]. Disponível em http://bpreco.saude.gov.br/bprefd/owa/consulta.inicio . 2008.

90. Ministério da Saúde. Informações de saúde epidemiológicas e de morbidade. [acessado em janeiro de 2008 para obter informações do ano de 2006]. Disponível em http://w3.datasus.gov.br/datasus/datasus.php . 2008.

91. Ministério da Saúde.Datasus.Secretaria de Vigilância em Saúde. Sistema de informação de Vigilância Epidemiológica - SIVEP-Malária. [acessado em 2007 para informações de notificações do ano de 2006]. Disponível em http://portalweb04.saude.gov.br/sivep_malaria/default.asp . 2007.

92. Ministério da Saúde.Datasus.Secretaria de Vigilância em Saúde. Sistema de Informação de Insumos Estratégicos. [acessado em janeiro de 2008 para obter informações do ano de 2006]. Disponível em http://portalweb04.saude.gov.br/sies/ . 2008. 
93. Ministério da Saúde.Fundação Nacional de Saúde. Manual de Terapêutica da Malária. Brasília: Ministério da Saúde, 2001.

94. Ministério da Saúde.Secretaria de Atenção à Saúde. Malária. In: Ministério da Saúde, ed. Cadernos de Atenção Básica no. 21 Vigilância em Saúde. Brasília: 2007:105-24.

95. Ministério da Saúde.Secretaria de Atenção à Saúde. Evolução do credenciamento e implantação da estratégia Saúde da Família. [acessado em janeiro de 2008 para obter informações do ano de 2006]. Disponível em http://dtr2004.saude.gov.br/dab/localiza_cadastro.php . 2008.

96. Ministério da Saúde. Secretaria de Atenção à Saúde.Tabela de procedimentos do SIA/SIH-SUS. [acessada em janeiro de 2008]. Disponível em http://dtr2001.saude.gov.br/sas/Decas/tabelasia.sih.htm . 2008.

97. Ministério da Saúde.Secretaria de Ciência e Tecnologia e Insumos Estratégicos. Política nacional de gestão de tecnologias em saúde. Brasília: Ministério da Saúde, 2007.

98. Ministério da Saúde.Secretaria de Ciência e Tecnologia e Insumos Estratégicos. Avaliação de tecnologias em saúde. Brasília: Ministério da Saúde, 2008.

99. Ministério da Saúde.Secretaria de Gestão de Investimentos em Saúde. BPPH - Banco de Preços Praticados na Área Hospitalar. [acessado em janeiro de 2008]. Disponível em http://www.fmb.unesp.br/compras/docs/Notas_Tecnicas.pdf . 2008.

100. Ministério da Saúde.Secretaria de Vigilância em Saúde. Programa Nacional de Prevenção e Controle da Malária. Série C. Projetos, Programas e Relatórios. 2003. Brasília, Ministério da Saúde.

101. Ministério da Saúde.Secretaria de Vigilância em Saúde. Manual de Diagnóstico da Malária. Brasília: Ministério da Saúde, 2005.

102. Ministério da Saúde.Secretaria de Vigilância em Saúde. Guia de Vigilância Epidemiológica. Série A. Normas e Manuais Técnicos. Brasília: Ministério da Saúde, 2006.

103. Ministério da Saúde.Secretaria de Vigilância em Saúde. Vigilância em Saúde. Situação epidemiológica da malária no Brasil - folder. 2007. Brasília, Ministério da Saúde.

104. Ministério da Saúde.Secretaria de Vigilância em Saúde. Guia para gestão local do controle da malária - Diagnóstico e tratamento. Brasília: Ministério da Saúde, 2008. 
105. Ministério da Saúde.Secretaria de Vigilância em Saúde. Vigilância em Saúde. Situação epidemiológica da malária no Brasil - folder. 2008. Brasília, Ministério da Saúde.

106. Ministério da Saúde.Secretaria de Vigilância em Saúde - Programa Nacional de Controle da Malária. Nota Técnica número 13 Regulamentação de Lâmina de Verificação de Cura (LVC). 2004. Brasília, Brasil.

107. Ministério do Desenvolvimento leCE. Anuário estatístico 2007. [acessado em julho de 2008 para informações do ano de 2006]. Disponível em http://www2.desenvolvimento.gov.br/sitio/publicacoes/desProducao/an u_Estatistico.php . 2008.

108. Ministério do Planejamento oeg. IBGE cidades@. [acessado em 19 de junho de 2007, para informações do ano de 2006]. Disponível em http://www.ibge.gov.br/cidadesat/ . 2007.

109. Ministério do Planejamento oeg. IBGE. [acessado em 24 de junho de 2007, para informações do ano de 2000]. Disponível em ftp://ftp.ibge.gov.br/Censos/Censo_Demografico_2000/Indicadores_S ociais/UFs/ . 2007.

110. Ministério do Planejamento oeg. IBGE. Sistema Nacional de Índices de Preços ao Consumidor - SNIPC.[acessado em janeiro de 2008, para informações a partir de 2000]. Disponível em http://www.sidra.ibge.gov.br/snipc/default.asp . 2008.

111. Ministério do Planejamento oeg. IBGE. [acessado em 19 de março de 2008, para informações do ano 2006]. Disponível em http://www.ibge.gov.br/home/estatistica/populacao/estimativa2006/esti mativa.shtm . 2008.

112. Mishra SK et al. Management of severe and complicated malaria. J.Postgrad.Med 2006;52:281-7.

113. Mohanty $\mathrm{S}$ et al. Complications and mortality patterns due to Plasmodium falciparum malaria in hospitalized adults and children, Rourkela, Orissa, India. Trans.R.Soc Trop Med Hyg. 2003;97:69-70.

114. Moody A. Rapid diagnostic tests for malaria parasites. Clin.Microbiol.Rev 2002;15:66-78.

115. Morel CM, Lauer JA, Evans DB. Cost effectiveness analysis of strategies to combat malaria in developing countries. BMJ 2005;331:1299. 
116. Mourão MPG et al. Estudo clínico em crianças internadas com malária (P.falciparum) na FMT-AM. Rev Soc Bras Med Trop 2001;34:71.

117. Murphy SC, Breman JG. Gaps in the childhood malaria burden in Africa: cerebral malaria, neurological sequelae, anemia, respiratory distress, hypoglycemia, and complications of pregnancy. Am.J.Trop Med Hyg. 2001;64:57-67.

118. Mutabingwa TK et al. Amodiaquine alone, amodiaquine+sulfadoxinepyrimethamine, amodiaquine+artesunate, and artemetherlumefantrine for outpatient treatment of malaria in Tanzanian children: a four-arm randomised effectiveness trial. Lancet 2005;365:1474-80.

119. Myint $\mathrm{HY}$ et al. A systematic overview of published antimalarial drug trials. Trans.R.Soc Trop Med Hyg. 2004;98:73-81.

120. Nabarro DN, Tayler EM. The "roll back malaria" campaign. Science 1998;280:2067-8.

121. Ndao $\mathrm{M}$ et al. Comparison of blood smear, antigen detection, and nested-PCR methods for screening refugees from regions where malaria is endemic after a malaria outbreak in Quebec, Canada. J.Clin.Microbiol. 2004;42:2694-700.

122. Novaes HMD. Estudos de custo-efetividade da incorporação de novas vacinas à rotina do Programa Nacional de Imunizações: rotavírus, varicela, meningocócica $\mathrm{C}$ conjugada, hepatite $\mathrm{A}$ e pneumocócica conjugada. Relatórios de projetos de pesquisa. 2006.

123. Ohrt $\mathrm{C}$ et al. Impact of microscopy error on estimates of protective efficacy in malaria-prevention trials. J.Infect.Dis. 2002;186:540-6.

124. Omari AA, Gamble C, Garner P. Artemether-lumefantrine (six-dose regimen) for treating uncomplicated falciparum malaria. Cochrane.Database.Syst.Rev 2005;CD005564.

125. Organização Mundial da Saúde. Tratamento da malária grave e complicada - Guia de condutas práticas. Distrito Federal, Brasília, Brasil: 2000.

126. Organização Pan Americana da Saúde.Rede Amazônica de Vigilância da Resistência às Drogas Antimaláricas no Brasil - RAVREDA. Relatório sobre o resultado final da avaliação do teste de diagnóstico rápido de malária - OptiMal. Organizado por Fontes CJ. Fontes CJ. 2002.

127. Organización Panamericana de la Salud. Boletín Epidemiológico Vol 22:1; Marzo. WDC: OPS, 2001. 
128. Organización Panamericana de la Salud. Investigación operacional sobre la implementación del uso de pruebas rápidas de diagnóstico de malária. Reporte Técnico. Guayaquil: 2005.

129. Palmer CJ et al. Multicenter study to evaluate the OptiMAL test for rapid diagnosis of malaria in U.S. hospitals. J.Clin.Microbiol. 2003;41:5178-82.

130. Palmer $\mathrm{CJ}$ et al. Evaluation of the OptiMAL test for rapid diagnosis of Plasmodium vivax and Plasmodium falciparum malaria.

J.Clin.Microbiol. 1998;36:203-6.

131. Pan American Health Organization. 2006 - Malaria in the Americas: data tables.[acessado em julho de 2008 para informações do ano de 2006]. Disponível em http://www.paho.org/English/AD/DPC/CD/malamericas-2006.pdf . 2006.

132. Pan American Health Organization. Malaria in the Americas: progress report. [acessado em julho de 2008]. Disponível em http://www.paho.org/English/GOV/CSP/csp27-09-e.pdf . 2008.

133. Pang LW, Piovesan-Alves F. Economic advantage of a communitybased malaria management program in the Brazilian Amazon. Am.J.Trop.Med.Hyg. 2001;65:883-6.

134. Pattanasin $\mathrm{S}$ et al. Evaluation of a new Plasmodium lactate dehydrogenase assay (OptiMAL-IT) for the detection of malaria. Trans.R.Soc.Trop.Med.Hyg. 2003;97:672-4.

135. Phillips M, Mills A, Dye C. Directrices para el analisis del costoeficacia de la lucha antivectorial. Serie de Directrices CEOM 3. Ginebra: OMS, 1996.

136. Pinto AY et al. Clinical efficacy of four schemes for vivax malaria treatment in children. J.Pediatr.(Rio J.) 1998;74:222-7.

137. Piola $P$ et al. Supervised versus unsupervised intake of six-dose artemether-lumefantrine for treatment of acute, uncomplicated Plasmodium falciparum malaria in Mbarara, Uganda: a randomised trial. Lancet 2005;365:1467-73.

138. Pittler MH, Ernst E. Artemether for severe malaria: a meta-analysis of randomized clinical trials. Clin.Infect.Dis. 1999;28:597-601.

139. Playford EG, Walker J. Evaluation of the ICT malaria P.f/P.v and the OptiMal rapid diagnostic tests for malaria in febrile returned travellers. J.Clin.Microbiol. 2002;40:4166-71. 
140. Polanczyk CA, Toscano CM. Avaliação econômica em saúde: desafios para gestão no Sistema Único de Saúde. Brasília: Ministério da Saúde, 2007.

141. Programa das Nações Unidas para o Desenvolvimento - PNUD. Atlas de Desenvolvimento humano. [acessado em 29 de agosto de 2007]. Disponível em http://www.pnud.org.br/atlas/ranking/IDH-M . 2007.

142. Pukrittayakamee $S$ et al. Pulmonary oedema in vivax malaria. Trans.R.Soc Trop Med Hyg. 1998;92:421-2.

143. Ramos CCBSR. Malária vivax na pré-Amazônia maranhense: aspectos epidemiológicos e características clínicas [Tese de Mestrado]. Brasília (DF): Universidade de Brasília. 2006.

144. Ratsimbasoa A et al. Which malaria rapid test for Madagascar? Field and laboratory evaluation of three tests and expert microscopy of samples from suspected malaria patients in Madagascar. Am.J.Trop.Med.Hyg. 2007;76:481-5.

145. Rodriguez-Morales AJ et al. Anemia and thrombocytopenia in children with Plasmodium vivax malaria. J.Trop Pediatr. 2006;52:49-51.

146. Rolland $\mathrm{E}$ et al. Operational response to malaria epidemics: are rapid diagnostic tests cost-effective? Trop.Med.Int.Health 2006;11:398-408.

147. Satpathy SK et al. Severe falciparum malaria. Indian J.Pediatr. 2004;71:133-5.

148. Shillcutt $S$ et al. Cost-effectiveness of malaria diagnostic methods in sub-Saharan Africa in an era of combination therapy. Bull.WHO 2008;86:101-10.

149. Shwe T, Hla KK. The effect of artemether plus mefloquine on Myanmar patients with complicated falciparum malaria. Southeast Asian J.Trop Med Public Health 1992;23 Suppl 4:117-21.

150. Singh $\mathrm{N}$ et al. The hospital- and field-based performances of the OptiMAL test, for malaria diagnosis and treatment monitoring in central India. Ann.Trop.Med.Parasitol. 2003;97:5-13.

151. Soto TA et al. Evaluation of the rapid diagnostic test OptiMAL for diagnosis of malaria due to Plasmodium vivax. Braz.J.Infect.Dis. 2004;8:151-5.

152. Stohrer JM et al. Therapeutic efficacy of artemether-lumefantrine and artesunate-mefloquine for treatment of uncomplicated Plasmodium falciparum malaria in Luang Namtha Province, Lao People's Democratic Republic. Trop Med Int.Health 2004;9:1175-83. 
153. Tauil PL. Comments on the epidemiology and control of malaria in Brazil. Mem.Inst.Oswaldo Cruz 1988;81 (Suppl. II):39-41.

154. Tauil PL. Avaliação de uma nova estratégia de controle da malária na Amazônia [Tese de doutorado]. Brasília (DF): Universidade de Brasília. 2002.

155. Taylor RS et al. Inclusion of cost effectiveness in licensing requirements of new drugs: the fourth hurdle. BMJ 2004;329:972-5.

156. Tin $\mathrm{S}$ et al. The effect of mefloquine-artemether compared with quinine on patients with complicated falciparum malaria. Trans.R.Soc Trop Med Hyg. 1988;82:665-6.

157. Tobón A et al. Epidemiologia de la malaria falciparum complicada: estudio de casos y controles en Tumaco y Turbo, Colômbia, 2003. Rev. Brasil. Epidemiol. 2006;9:283-96.

158. Torres JR et al. Acute non-cardiogenic lung injury in benign tertian malaria. Lancet 1997;350:31-2.

159. Tree Age Pro [software]. Version 2005 - release 1.0. Williamstown (MA): TreeAge Software Inc, 2005.

160. Udomsanpetch $R$ et al. Rosette formation by Plasmodium vivax. Trans.R.Soc Trop Med Hyg. 1995;89:635-7.

161. Van $\mathrm{dB}, \mathrm{I}$ et al. Evaluation of three rapid tests for diagnosis of $P$. falciparum and P. vivax malaria in Colombia. Am.J.Trop.Med.Hyg. 2006;75:1209-15.

162. Walker D, Kumaranayake L. Allowing for differential timing in cost analyses: discounting and annualization. Health Policy Plan. 2002;17:112-8.

163. Weinstein MC et al. Recommendations of the Panel on Costeffectiveness in Health and Medicine. JAMA 1996;276:1253-8.

164. Weinstein MC, Stason WB. Foundations of cost-effectiveness analysis for health and medical practices. N.Engl.J.Med. 1977;296:716-21.

165. Whiting $P$ et al. Development and validation of methods for assessing the quality of diagnostic accuracy studies. Health Technol.Assess. 2004;8:1-234.

166. Win K, Than M, Thwe Y. Comparison of combinations of parenteral artemisinin derivatives plus oral mefloquine with intravenous quinine plus oral tetracycline for treating cerebral malaria. Bull.World Health Organ 1992;70:777-82. 
167. Wongsrichanalai $C$ et al. A review of malaria diagnostic tools: microscopy and rapid diagnostic test (RDT). Am.J.Trop.Med.Hyg. 2007;77:119-27.

168. World Health Organization. Malaria diagnosis - new perspectives. Geneva: WHO graphics, 2000.

169. World Health Organization. Severe falciparum malaria. Trans.R.Soc Trop Med Hyg. 2000;94:S1-S90.

170. World Health Organization. Malaria Rapid Diagnosis: Making it Work [acessado em março de 2008]. Disponível em http://www.wpro.who.int/sites/rdt/ . 2003.

171. World Health Organization. Guidelines for the treatment of malaria. WHO Press. 2006. Geneva, Switzerland, WHO Press. Available from: http://www.who.int/malaria/docs/TreatmentGuidelines2006.pdf.

172. World Health Organization. How to use a rapid diagnostic test (RDT): A guide for training at a village and clinic level.2006. [acessado em janeiro de 2008]. Disponível em http://www.wpro.who.int/sites/rdt/ . 2006.

173. World Health Organization. CHOosing Interventions that are Cost Effective (WHO-CHOICE). [acessado em julho de 2008 para informações do mesmo ano]. Disponível em http://www.who.int/choice/costs/CER_levels/en/index.html . 2008.

174. World Health Organization. Malaria - Rapid Diagnostic Tests. [acessado em março de 2008]. Disponível em http://www.wpro.who.int/sites/rdt/ . 2008.

175. World Health Organization. Malária. [acessado em abril de 2008]. Disponível em http://www.who.int/mediacentre/factsheets/fs094/en/index.html . 2008.

176. World Health Organization, UNICEF. World Malaria Report 2005. [acessado em abril de 2008). Disponível em http://rbm.who.int/wmr2005/pdf/intro_section.pdf . 2005.

177. World Health Organization - Regional office for the Western Pacific. Malaria Light Microscopy - creating a culture of quality. [acessado em março de 2008]. Disponível em http://whqlibdoc.who.int/wpro/2005/RS_2005_GE_03(MAA)_eng.pdf . 2005.

178. Worrall E, Rietveld A, Delacollette C. The burden of malaria epidemics and cost-effectiveness of interventions in epidemic situations in Africa. Am.J.Trop Med Hyg. 2004;71:136-40. 
179. Yeung $S$ et al. Antimalarial drug resistance, artemisinin-based combination therapy, and the contribution of modeling to elucidating policy choices. Am.J.Trop Med Hyg. 2004;71:179-86. 


\section{ANEXOS}

\section{Anexo 1}

Tabela A1 - Distribuição dos 12 municípios quanto à população estimada em 01 de julho de 2006, extensão territorial, Produto Interno Bruto (PIB) e Produto Interno Bruto per capita. Municípios do Estado do Pará, Brasil, 2006*

\begin{tabular}{|c|c|c|c|c|}
\hline Municípios & $\begin{array}{l}\text { População estimada } \\
\text { em } 01 \text { de julho de } \\
2006 \text { (hab.) }\end{array}$ & $\begin{array}{l}\text { Extensão territorial } \\
\left(\text { área em } \mathbf{k m}^{2}\right)\end{array}$ & PIB (reais) & PIB per capita(reais) \\
\hline Baião & 21.893 & 3.758 & $116.361,00$ & $5.368,00$ \\
\hline Goianésia do Pará & 31.293 & 7.021 & $112.847,00$ & $3.911,00$ \\
\hline Itaituba & 96.515 & 62.041 & $319.569,00$ & $3.328,00$ \\
\hline Jacareacanga & 34.683 & 53.303 & $38.095,00$ & $1.203,00$ \\
\hline Jacundá & 48.368 & 2.008 & $152.347,00$ & $3.301,00$ \\
\hline Marabá & 200.801 & 15.092 & $1.470 .758,00$ & $7.679,00$ \\
\hline Nova Ipixuna & 14.348 & 1.600 & $38.353,00$ & $2.811,00$ \\
\hline Novo Progresso & 39.245 & 38.162 & $162.894,00$ & $4.628,00$ \\
\hline Novo Repartimento & 51.627 & 15.399 & $258.507,00$ & $5.292,00$ \\
\hline Santana do Araguaia & 42.523 & 11.591 & $250.993,00$ & $6.383,00$ \\
\hline São Félix do Xingu & 41.813 & 84.212 & $444.762,00$ & $11.182,00$ \\
\hline $\begin{array}{l}\text { São Geraldo do } \\
\text { Araguaia }\end{array}$ & 27.242 & 3.270 & $158.420,00$ & $5.791,00$ \\
\hline Total dos municípios & 650.351 & 297.457 & & \\
\hline Pará & 7.110 .465 & $1.247 .689,515$ & $34.195 .676,00$ & $4.991,00$ \\
\hline
\end{tabular}

Fonte: IBGE- Ministério do Planejamento, Orçamento e Gestão.

Notas:

* O produto interno bruto (PIB) representa a soma (em valores monetários) de todos os bens e serviços finais produzidos em uma determinada região (qual seja, países, estados, cidades), durante um período determinado (mês, trimestre, ano, etc). O PIB é um dos indicadores mais utilizados na macroeconomia com o objetivo de mensurar a atividade econômica de uma região.Na contagem do PIB, consideram-se apenas bens e serviços finais, excluindo da conta todos os bens de consumo intermediário (insumos). Isso é feito com o intuito de evitar o problema da dupla contagem, quando valores gerados na cadeia de produção aparecem contados duas vezes na soma do PIB.

(1) Refere-se ao ano de 2004

(2) Em relação à população estimada em 2004 


\section{Anexo 2}

Tabela A2 - Distribuição dos 12 municípios quanto a população total e sua respectiva distribuição percentual, por sexo e situação do domicílio, e proporção de pessoas naturais dos municípios. Municípios do Estado do Pará, Brasil, 2000

\begin{tabular}{|c|c|c|c|c|c|c|}
\hline \multirow{3}{*}{ Municípios } & \multicolumn{6}{|c|}{ População } \\
\hline & \multirow{2}{*}{ Total } & \multicolumn{2}{|c|}{ Sexo (\%) } & \multicolumn{2}{|c|}{\begin{tabular}{|c|}
$\begin{array}{c}\text { Situação do domicílio } \\
(\%)\end{array}$ \\
\end{tabular}} & \multirow{2}{*}{$\begin{array}{c}\text { Proporção } \\
\text { de pessoas } \\
\text { naturais dos } \\
\text { municípios } \\
(\%)^{*}\end{array}$} \\
\hline & & Masculino & Feminino & Urbana & Rural & \\
\hline Pará & 6195965 & 50,6 & 49,4 & 66,5 & 33,5 & 64,2 \\
\hline Baião & 21119 & 52,1 & 47,9 & 51,4 & 48,6 & 82,1 \\
\hline Goianésia do Pará & 22685 & 52,5 & 47,5 & 65,6 & 34,4 & 30,1 \\
\hline Itaituba & 94750 & 51,4 & 48,6 & 68,1 & 31,9 & 54,7 \\
\hline Jacareacanga & 22078 & 56,0 & 44,0 & 25,7 & 74,3 & 85,5 \\
\hline Jacundá & 40546 & 51,4 & 48,6 & 85,1 & 14,9 & 38,5 \\
\hline Marabá & 168020 & 50,4 & 49,6 & 80,0 & 20,0 & 47,4 \\
\hline Nova Ipixuna & 11866 & 54,2 & 45,8 & 43,9 & 56,1 & 34,3 \\
\hline Novo Progresso & 24948 & 60,3 & 39,7 & 36,7 & 63,3 & 25,0 \\
\hline Novo Repartimento & 41817 & 52,9 & 47,1 & 37,1 & 62,9 & 35,1 \\
\hline Santana do Araguaia & 31218 & 53,3 & 46,7 & 55,5 & 44,5 & 36,6 \\
\hline $\begin{array}{l}\text { São Félix do Xingu } \\
\text { São Geraldo do } \\
\text { Araguaia }\end{array}$ & $\begin{array}{l}34621 \\
27646\end{array}$ & $\begin{array}{l}55,1 \\
52,0\end{array}$ & $\begin{array}{l}44,9 \\
48,0\end{array}$ & $\begin{array}{l}36,2 \\
43,2\end{array}$ & $\begin{array}{l}63,8 \\
56,8\end{array}$ & $\begin{array}{l}33,5 \\
49,3\end{array}$ \\
\hline
\end{tabular}

Fonte: IBGE- Ministério do Planejamento, Orçamento e Gestão. Censo Demográfico 2000.

Nota: * Refere-se às pessoas que sempre moraram ou nasceram no município de residência por ocasião do Censo. 


\section{Anexo 3}

Tabela A3 - Distribuição dos 12 municípios segundo percentual da população residente, por grupos de idade, Municípios do Estado do Pará, 2000

\begin{tabular}{l|c|c|c|c|c|c|c|c}
\hline \multirow{2}{*}{ Municípios } & \multicolumn{7}{|c}{ População residente por grupos de idade (\%) } \\
\cline { 2 - 9 } & $\begin{array}{c}\mathbf{0} \text { a 3 } \\
\text { anos }\end{array}$ & $\begin{array}{c}\mathbf{4} \text { a 6 } \\
\text { anos }\end{array}$ & $\begin{array}{c}\mathbf{7} \text { a 14 } \\
\text { anos }\end{array}$ & $\begin{array}{c}\mathbf{1 5} \text { a 17 } \\
\text { anos }\end{array}$ & $\begin{array}{c}\mathbf{1 8} \text { a 24 } \\
\text { anos }\end{array}$ & $\begin{array}{c}\mathbf{2 5} \text { a 59 } \\
\text { anos }\end{array}$ & $\begin{array}{c}\mathbf{6 0} \text { a 64 } \\
\text { anos }\end{array}$ & $\begin{array}{c}\mathbf{6 5} \text { anos } \\
\text { ou mais }\end{array}$ \\
\hline Pará & $\mathbf{1 0 , 0}$ & $\mathbf{7 , 6}$ & $\mathbf{1 9 , 5}$ & $\mathbf{7 , 3}$ & $\mathbf{1 4 , 6}$ & $\mathbf{3 5 , 2}$ & $\mathbf{1 , 9}$ & $\mathbf{3 , 8}$ \\
Baião & 11,7 & 8,6 & 22,0 & 8,3 & 13,2 & 30,0 & 2,3 & 3,8 \\
Goianésia do Pará & 10,7 & 8,1 & 21,6 & 7,1 & 15,3 & 33,2 & 1,9 & 2,1 \\
Itaituba & 11,1 & 7,5 & 19,9 & 7,6 & 13,5 & 36,2 & 1,4 & 2,8 \\
Jacareacanga & 9,8 & 7,9 & 19,0 & 5,8 & 12,5 & 42,3 & 1,6 & 1,0 \\
Jacundá & 10,2 & 7,6 & 20,1 & 7,6 & 15,3 & 34,1 & 1,7 & 3,4 \\
Marabá & 10,0 & 7,7 & 19,9 & 7,5 & 14,9 & 35,1 & 1,7 & 3,1 \\
Nova Ipixuna & 10,9 & 8,4 & 20,6 & 7,9 & 14,2 & 32,6 & 1,7 & 3,8 \\
Novo Progresso & 6,9 & 5,6 & 14,4 & 5,7 & 13,6 & 51,3 & 1,0 & 1,4 \\
Novo Repartimento & 11,7 & 8,7 & 22,3 & 8,0 & 13,4 & 31,6 & 2,0 & 2,3 \\
Santana do Araguaia & 9,4 & 8,0 & 19,5 & 6,5 & 14,3 & 38,6 & 1,7 & 1,9 \\
São Félix do Xingu & 11,0 & 7,8 & 21,3 & 7,0 & 13,5 & 35,3 & 1,7 & 2,4 \\
São Geraldo do Araguaia & 10,5 & 7,5 & 20,8 & 7,8 & 14,2 & 33,5 & 2,1 & 3,7 \\
\hline
\end{tabular}

Fonte: IBGE- Ministério do Planejamento, Orçamento e Gestão. Censo Demográfico 2000. 


\section{Anexo 4}

Tabela A4 - Distribuição dos 12 municípios segundo percentual dos domicílios particulares permanentes, por classes de rendimento médio mensal domiciliar per capita em salários mínimos, Municípios do Estado do Pará, 2000

\begin{tabular}{|c|c|c|c|c|c|c|c|}
\hline \multirow{3}{*}{ Municípios } & \multicolumn{7}{|c|}{ Domicílios particulares permanentes } \\
\hline & \multirow[b]{2}{*}{ Total } & \multicolumn{6}{|c|}{ Classes de salário mínimo (\%) * } \\
\hline & & $\begin{array}{l}\text { Até } \\
1 / 4\end{array}$ & $\begin{array}{c}\text { De } 1 / 4 \text { a } \\
1 / 2\end{array}$ & $\begin{array}{c}\text { De } 1 / 2 \text { a } \\
1\end{array}$ & De 1 a 2 & De 2 a 3 & $\begin{array}{c}\text { Mais de } \\
3\end{array}$ \\
\hline Pará & 1.308 .511 & 22,1 & 22,4 & 25,3 & 16,0 & 5,1 & 9,1 \\
\hline Baião & 3782 & 39,9 & 24,4 & 20,0 & 9,0 & 2,5 & 4,2 \\
\hline Goianésia do Pará & 4974 & 20,2 & 23,8 & 30,3 & 16,7 & 3,7 & 5,4 \\
\hline Itaituba & 20007 & 20,9 & 23,0 & 26,7 & 16,0 & 5,0 & 8,5 \\
\hline Jacareacanga & 3683 & 35,7 & 16,3 & 20,9 & 15,2 & 4,5 & 7,4 \\
\hline Jacundá & 9308 & 13,4 & 28,1 & 32,8 & 16,0 & 3,5 & 6,1 \\
\hline Marabá & 37919 & 17,7 & 20,8 & 27,0 & 17,9 & 6,3 & 10,3 \\
\hline Nova Ipixuna & 2657 & 21,2 & 27,2 & 26,0 & 14,9 & 4,7 & 6,0 \\
\hline Novo Progresso & 4314 & 14,2 & 13,1 & 24,5 & 25,1 & 11,8 & 11,3 \\
\hline Novo Repartimento & 8545 & 40,4 & 22,9 & 21,0 & 10,7 & 1,6 & 3,5 \\
\hline Santana do Araguaia & 7609 & 28,9 & 22,0 & 25,4 & 16,0 & 2,5 & 5,2 \\
\hline $\begin{array}{l}\text { São Félix do Xingu } \\
\text { São Geraldo do } \\
\text { Araguaia }\end{array}$ & $\begin{array}{l}7480 \\
6187\end{array}$ & $\begin{array}{l}17,1 \\
26,0\end{array}$ & $\begin{array}{l}18,7 \\
27,0\end{array}$ & $\begin{array}{l}30,3 \\
28,6\end{array}$ & $\begin{array}{c}18,5 \\
9,0\end{array}$ & $\begin{array}{l}6,1 \\
4,0\end{array}$ & $\begin{array}{l}9,4 \\
5,5\end{array}$ \\
\hline
\end{tabular}

Fonte: IBGE- Ministério do Planejamento, Orçamento e Gestão. Censo Demográfico 2000.

Nota: * Salário mínimo de julho de 2000: $\mathrm{R} \$ 151,00$. 


\section{Anexo 5}

Tabela A5 - Distribuição dos 12 municípios segundo a proporção de pessoas de 15 anos ou mais de idade com menos de 4 anos de estudo e por sexo, Municípios do Estado do Pará, 2000

\begin{tabular}{l|c|c|c}
\hline \multirow{2}{*}{$\begin{array}{c}\text { Municípios e classes de } \\
\text { tamanho da população }\end{array}$} & \multicolumn{3}{c}{$\begin{array}{c}\text { Proporção de pessoas de 15 anos ou mais de idade com } \\
\text { menos de 4 anos de estudo (\%) }\end{array}$} \\
\cline { 2 - 4 } & Total & \multicolumn{2}{c}{ Por sexo } \\
\cline { 2 - 4 } Pará & $\mathbf{3 7 , 5}$ & $\mathbf{4 0 m e m}$ & Mulher \\
Baião & 43,2 & 46,3 & $\mathbf{3 4 , 1}$ \\
Goianésia do Pará & 54,5 & 57,8 & 39,9 \\
Itaituba & 42,7 & 46,8 & 50,5 \\
Jacareacanga & 61,4 & 62,6 & 38,4 \\
Jacundá & 48,1 & 51,3 & 59,7 \\
Marabá & 34,3 & 36,6 & 44,7 \\
Nova Ipixuna & 52,1 & 55,3 & 32,0 \\
Novo Progresso & 47,6 & 50,9 & 48,2 \\
Novo Repartimento & 58,4 & 60,4 & 41,6 \\
Santana do Araguaia & 46,6 & 49,6 & 56,0 \\
São Félix do Xingu & 53,3 & 57,9 & 43,0 \\
São Geraldo do Araguaia & 54,2 & 55,8 & 47,2 \\
\hline
\end{tabular}

Fonte: IBGE- Ministério do Planejamento, Orçamento e Gestão. Censo Demográfico 2000.

Nota: * Exclusive as pessoas com anos de estudo não determinados. 


\section{Anexo 6}

Tabela A6 - Distribuição dos 12 municípios de interesse segundo Índice de desenvolvimento Humano - Municipal - IDH-M1991 e 2000

\begin{tabular}{|c|c|c|c|c|c|c|c|c|c|}
\hline Código & Município & IDHM, 1991 & IDHM, 2000 & IDHM-Renda, 1991 & IDHM-Renda, 2000 & $\begin{array}{c}\text { IDHM-Longevidade, } \\
1991\end{array}$ & $\begin{array}{l}\text { IDHM-Longevidade, } \\
2000\end{array}$ & $\begin{array}{c}\text { IDHM-Educação, } \\
1991\end{array}$ & $\begin{array}{l}\text { IDHM-Educação, } \\
2000\end{array}$ \\
\hline 150670 & $\begin{array}{l}\text { Santana do Araguaia } \\
\text { (PA) }\end{array}$ & 0,597 & 0,69 & 0,542 & 0,573 & 0,639 & 0,747 & 0,61 & 0,751 \\
\hline 150360 & Itaituba (PA) & 0,622 & 0,704 & 0,601 & 0,623 & 0,634 & 0,691 & 0,632 & 0,797 \\
\hline 150309 & Goianésia do Pará (PA) & 0,518 & 0,665 & 0,543 & 0,602 & 0,548 & 0,696 & 0,464 & 0,696 \\
\hline 150730 & $\begin{array}{l}\text { São Félix do Xingu } \\
\text { (PA) }\end{array}$ & 0,605 & 0,709 & 0,587 & 0,693 & 0,609 & 0,741 & 0,62 & 0,692 \\
\hline 150503 & Novo Progresso (PA) & 0,692 & 0,76 & 0,739 & 0,68 & 0,727 & 0,805 & 0,609 & 0,795 \\
\hline 150375 & Jacareacanga (PA) & 0,534 & 0,652 & 0,632 & 0,599 & 0,678 & 0,743 & 0,292 & 0,615 \\
\hline 150420 & Marabá (PA) & 0,639 & 0,714 & 0,588 & 0,647 & 0,613 & 0,668 & 0,717 & 0,826 \\
\hline 150745 & $\begin{array}{l}\text { São Geraldo do } \\
\text { Araguaia (PA) }\end{array}$ & 0,546 & 0,691 & 0,48 & 0,593 & 0,632 & 0,748 & 0,525 & 0,732 \\
\hline 150506 & $\begin{array}{l}\text { Novo Repartimento } \\
\text { (PA) }\end{array}$ & 0,512 & 0,626 & 0,469 & 0,527 & 0,571 & 0,669 & 0,497 & 0,682 \\
\hline 150380 & Jacundá (PA) & 0,627 & 0,691 & 0,6 & 0,635 & 0,664 & 0,714 & 0,617 & 0,723 \\
\hline 150497 & Nova Ipixuna (PA) & 0,52 & 0,664 & 0,495 & 0,582 & 0,587 & 0,718 & 0,477 & 0,692 \\
\hline 150120 & Baião (PA) & 0,589 & 0,677 & 0,452 & 0,507 & 0,638 & 0,705 & 0,677 & 0,82 \\
\hline
\end{tabular}

Fonte: PNUD 


\section{Anexo 7}

Tabela A7 - Distribuição dos 13 artigos publicados e do relatório da OPAS, segundo todos os critérios definidos para a avaliação e resultados individuais. 2007

\begin{tabular}{|c|c|c|c|c|c|c|c|c|c|c|c|c|c|c|}
\hline \multirow{3}{*}{ Critérios } & \multirow{2}{*}{\multicolumn{14}{|c|}{ Artigos por autores e ano de publicação }} \\
\hline & & & & & & & & & & & & & & \\
\hline & $\begin{array}{l}\text { Van, I e } \\
\text { cols., } \\
2006\end{array}$ & $\begin{array}{l}\text { lqbal e } \\
\text { cols., } \\
2003\end{array}$ & $\begin{array}{l}\text { Londoño } \\
\text { e cols., } \\
2002\end{array}$ & $\begin{array}{l}\text { Gonzalez } \\
\text {-Ceron e } \\
\text { cols., } \\
2005\end{array}$ & $\begin{array}{l}\text { Cooke e } \\
\text { cols., } \\
1999\end{array}$ & $\begin{array}{l}\text { Ratsimbasoa } \\
\text { e cols., } 2007\end{array}$ & $\begin{array}{l}\text { Soto e } \\
\text { cols., } \\
2004\end{array}$ & $\begin{array}{l}\text { Palmer } \\
\text { e cols., } \\
1998\end{array}$ & $\begin{array}{l}\text { Singh e } \\
\text { cols., } \\
2003\end{array}$ & $\begin{array}{l}\text { Ferro e } \\
\text { cols., } \\
2002\end{array}$ & $\begin{array}{l}\text { Relatório } \\
\text { da OPAS } \\
\text { - Fontes, } \\
2002\end{array}$ & $\begin{array}{l}\text { Aslan e } \\
\text { cols., } \\
2001\end{array}$ & $\begin{array}{l}\text { Pattanasin e } \\
\text { cols., } 2003\end{array}$ & $\begin{array}{l}\text { Kolaczinski } \\
\text { e cols., } 2004\end{array}$ \\
\hline $\begin{array}{l}\text { O espectro de } \\
\text { pacientes foi } \\
\text { representativo } \\
\text { dos pacientes } \\
\text { que receberão o } \\
\text { teste na rotina? }\end{array}$ & Sim & Sim & Sim & Sim & Sim & Sim & Sim & Sim & Sim & Sim & Sim & Sim & Sim & Sim \\
\hline $\begin{array}{l}\text { Os critérios de } \\
\text { seleção foram } \\
\text { claramente } \\
\text { descritos? }\end{array}$ & Sim & Sim & Sim & Sim & Não & Sim & Sim & $\begin{array}{l}\text { Pouco } \\
\text { claro }\end{array}$ & Não & $\begin{array}{l}\text { Pouco } \\
\text { claro }\end{array}$ & $\begin{array}{l}\text { Pouco } \\
\text { claro }\end{array}$ & Não & Não & Não \\
\hline $\begin{array}{l}\text { O padrão-ouro } \\
\text { classifica } \\
\text { corretamente a } \\
\text { doença? }\end{array}$ & Sim & Sim & Sim & Sim & Sim & Sim & Sim & Sim & Sim & Sim & Sim & Sim & Sim & Sim \\
\hline $\begin{array}{l}\text { O perí́odo entre } \\
\text { a aplicação do } \\
\text { padrão-ouro e o } \\
\text { teste em } \\
\text { avaliação foi } \\
\text { curto o } \\
\text { suficiente para } \\
\text { que se tenha } \\
\text { segurança que } \\
\text { não houve } \\
\text { mudanças no } \\
\text { estado de saúde } \\
\text { do indivíduo } \\
\text { testado? }\end{array}$ & Sim & Sim & Sim & Sim & Sim & Sim & $\begin{array}{l}\text { Pouco } \\
\text { claro }\end{array}$ & $\begin{array}{l}\text { Pouco } \\
\text { claro }\end{array}$ & Sim & $\begin{array}{l}\text { Pouco } \\
\text { claro }\end{array}$ & $\begin{array}{l}\text { Pouco } \\
\text { claro }\end{array}$ & $\begin{array}{l}\text { Pouco } \\
\text { claro }\end{array}$ & Pouco claro & Pouco claro \\
\hline
\end{tabular}


Tabela A7 - Distribuição dos 13 artigos publicados e do relatório da OPAS, segundo todos os critérios definidos e resultados individuais. 2007

(continuação)

\begin{tabular}{|c|c|c|c|c|c|c|c|c|c|c|c|c|c|c|}
\hline \multirow{2}{*}{ Critérios } & \multicolumn{14}{|c|}{ Artigos por autores e ano de publicação } \\
\hline & $\begin{array}{l}\text { Van, I e } \\
\text { cols., } \\
2006\end{array}$ & $\begin{array}{l}\text { lqbal e } \\
\text { cols., } \\
2003\end{array}$ & $\begin{array}{l}\text { Londoño e } \\
\text { cols., } \\
2002\end{array}$ & $\begin{array}{l}\text { Gonzalez- } \\
\text { Ceron e } \\
\text { cols., } \\
2005\end{array}$ & $\begin{array}{l}\text { Cooke e } \\
\text { cols., } \\
1999\end{array}$ & $\begin{array}{l}\text { Ratsimbasoa e } \\
\text { cols., } 2007\end{array}$ & $\begin{array}{l}\text { Soto e } \\
\text { cols., } \\
2004\end{array}$ & $\begin{array}{l}\text { Palmer } \\
\text { e cols., } \\
1998\end{array}$ & $\begin{array}{l}\text { Singh e } \\
\text { cols., } \\
2003\end{array}$ & $\begin{array}{l}\text { Ferro e } \\
\text { cols., } \\
2002\end{array}$ & $\begin{array}{l}\text { Relatório } \\
\text { da OPAS } \\
\text { - Fontes, } \\
2002\end{array}$ & $\begin{array}{l}\text { Aslan e } \\
\text { cols., } \\
2001\end{array}$ & $\begin{array}{l}\text { Pattanasin } \\
\text { e cols., } \\
2003\end{array}$ & $\begin{array}{l}\text { Kolaczinsk } \\
\text { i e cols., } \\
2004\end{array}$ \\
\hline $\begin{array}{l}\text { A amostra total } \\
\text { ou uma sub- } \\
\text { amostra } \\
\text { randomizada } \\
\text { realizou o teste } \\
\text { pelo padrão- } \\
\text { ouro? }\end{array}$ & Sim & Sim & Sim & Sim & Sim & Sim & Sim & Sim & Sim & Sim & Sim & Sim & Sim & Sim \\
\hline $\begin{array}{l}\text { Os pacientes } \\
\text { receberam o } \\
\text { mesmo teste } \\
\text { como padrão- } \\
\text { ouro, } \\
\text { independente } \\
\text { do resultado } \\
\text { obtido pelo } \\
\text { teste em } \\
\text { avaliação? }\end{array}$ & Sim & Sim & Sim & Sim & Sim & Sim & Sim & Sim & Sim & Sim & Sim & Sim & Sim & Sim \\
\hline $\begin{array}{l}\text { O padrão-ouro } \\
\text { é } \\
\text { independente } \\
\text { do teste em } \\
\text { avaliação (ou } \\
\text { seja, o teste } \\
\text { em avaliação } \\
\text { não faz parte } \\
\text { do teste } \\
\text { padrão-ouro)? }\end{array}$ & Sim & Sim & Sim & Sim & Sim & Sim & Sim & Sim & Sim & Sim & Sim & Sim & Sim & Sim \\
\hline
\end{tabular}


Tabela A7 - Distribuição dos 13 artigos publicados e do relatório da OPAS, segundo todos os critérios definidos e resultados individuais. 2007

(continuação)

\begin{tabular}{|c|c|c|c|c|c|c|c|c|c|c|c|c|c|c|}
\hline \multirow[t]{2}{*}{ Critérios } & \multicolumn{14}{|c|}{ Artigos por autores e ano de publicação } \\
\hline & $\begin{array}{l}\text { Van, I e } \\
\text { cols., } \\
2006\end{array}$ & $\begin{array}{l}\text { lqbal e } \\
\text { cols., } \\
2003\end{array}$ & $\begin{array}{l}\text { Londoño e } \\
\text { cols., } \\
2002\end{array}$ & $\begin{array}{l}\text { Gonzalez- } \\
\text { Ceron e } \\
\text { cols., } \\
2005 \\
\end{array}$ & $\begin{array}{l}\text { Cooke e } \\
\text { cols., } \\
1999\end{array}$ & $\begin{array}{l}\text { Ratsimbasoa e } \\
\text { cols., } 2007\end{array}$ & $\begin{array}{l}\text { Soto e } \\
\text { cols., } \\
2004\end{array}$ & $\begin{array}{l}\text { Palmer } \\
\text { e cols., } \\
1998\end{array}$ & $\begin{array}{l}\text { Singh e } \\
\text { cols., } \\
2003\end{array}$ & $\begin{array}{l}\text { Ferro e } \\
\text { cols., } \\
2002\end{array}$ & $\begin{array}{l}\text { Relatório } \\
\text { da OPAS } \\
\text { - Fontes, } \\
2002 \\
\end{array}$ & $\begin{array}{l}\text { Aslan e } \\
\text { cols., } \\
2001\end{array}$ & $\begin{array}{l}\text { Pattanasin } \\
\text { e cols., } \\
2003\end{array}$ & $\begin{array}{l}\text { Kolaczinsk } \\
\text { i e cols., } \\
2004\end{array}$ \\
\hline $\begin{array}{l}\text { A execução do } \\
\text { teste em } \\
\text { avaliação foi } \\
\text { descrita com } \\
\text { suficientes } \\
\text { detalhes, } \\
\text { permitindo a } \\
\text { sua } \\
\text { replicação? }\end{array}$ & Não & Sim & Sim & Sim & Sim & Não & Não & Sim & Não & Não & Não & Não & Não & Não \\
\hline $\begin{array}{l}\text { A execução do } \\
\text { teste padrão- } \\
\text { ouro foi } \\
\text { descrita com } \\
\text { suficientes } \\
\text { detalhes, } \\
\text { permitindo a } \\
\text { sua } \\
\text { replicação? }\end{array}$ & Sim & Não & Não & Não & Não & Não & Não & Não & Não & Sim & Não & Não & Não & Não \\
\hline $\begin{array}{l}\text { Os resultados } \\
\text { do teste em } \\
\text { avaliação } \\
\text { foram } \\
\text { interpretados } \\
\text { sem o } \\
\text { conhecimento } \\
\text { dos resultados } \\
\text { do teste } \\
\text { padrão-ouro? }\end{array}$ & Sim & Sim & Sim & $\begin{array}{l}\text { Pouco } \\
\text { claro }\end{array}$ & Sim & Sim & Sim & Sim & Sim & $\begin{array}{l}\text { Pouco } \\
\text { claro }\end{array}$ & Sim & $\begin{array}{l}\text { Pouco } \\
\text { claro }\end{array}$ & $\begin{array}{l}\text { Pouco } \\
\text { claro }\end{array}$ & $\begin{array}{l}\text { Pouco } \\
\text { claro }\end{array}$ \\
\hline
\end{tabular}


Tabela A7 - Distribuição dos 13 artigos publicados e do relatório da OPAS, segundo todos os critérios definidos e resultados individuais. 2007

(continuação)

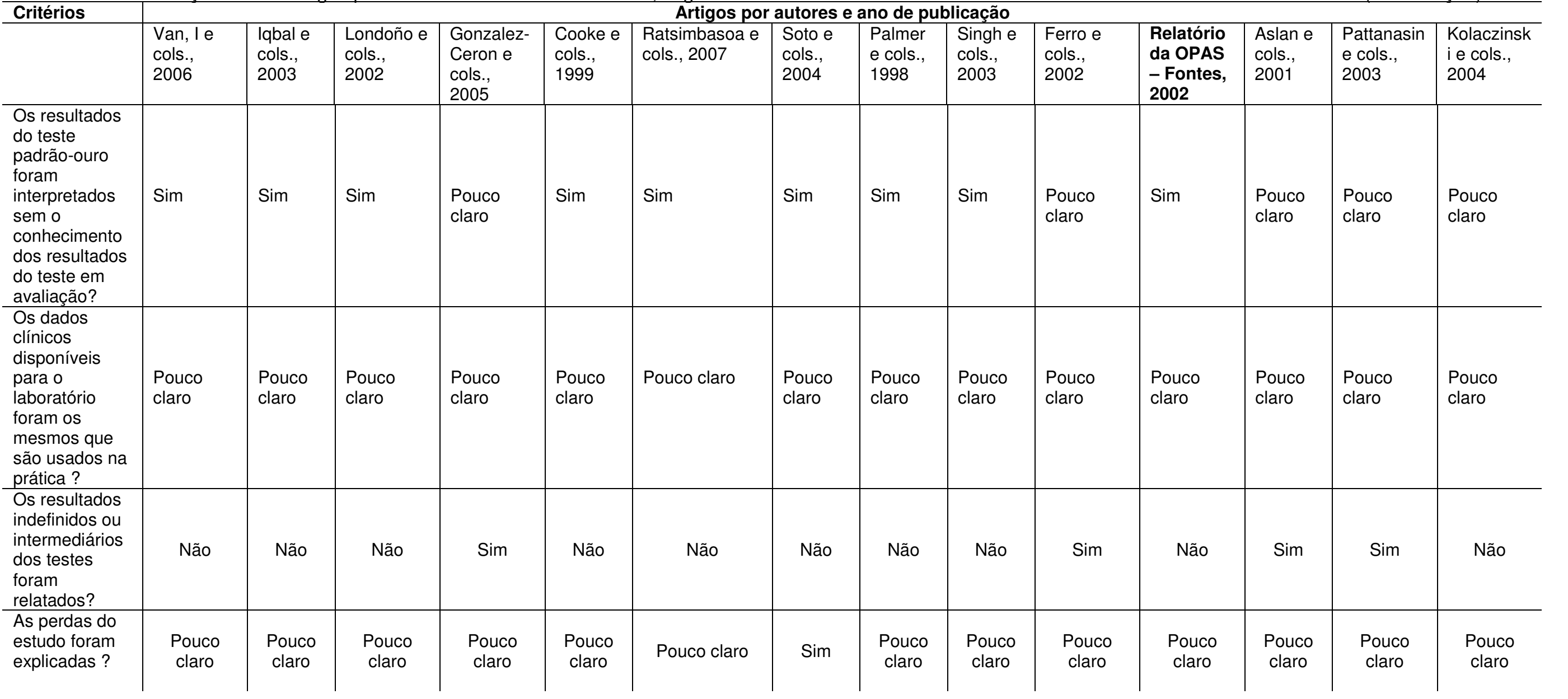


Tabela A7 - Distribuição dos 13 artigos publicados e do relatório da OPAS, segundo todos os critérios definidos e resultados individuais. 2007 (conclusão) Artigos por autores e ano de publicação

\begin{tabular}{|c|c|c|c|c|c|c|c|c|c|c|c|c|c|c|}
\hline \multirow{2}{*}{ Critérios } & \multirow[b]{2}{*}{$\begin{array}{l}\text { Van, I e } \\
\text { cols., } \\
2006\end{array}$} & \multirow[b]{2}{*}{$\begin{array}{l}\text { lqbal e } \\
\text { cols., } \\
2003\end{array}$} & \multirow[b]{2}{*}{$\begin{array}{l}\text { Londoño e } \\
\text { cols., } \\
2002\end{array}$} & \multirow[b]{2}{*}{$\begin{array}{l}\text { Gonzalez- } \\
\text { Ceron e } \\
\text { cols., } \\
2005\end{array}$} & \multirow[b]{2}{*}{$\begin{array}{l}\text { Cooke e } \\
\text { cols., } \\
1999\end{array}$} & \multirow[b]{2}{*}{$\begin{array}{l}\text { Ratsimbasoa } \\
\text { e cols., } 2007\end{array}$} & \multirow[b]{2}{*}{$\begin{array}{l}\text { Soto e } \\
\text { cols., } \\
2004\end{array}$} & \multirow[b]{2}{*}{$\begin{array}{l}\text { Palmer } \\
\text { e cols., } \\
1998\end{array}$} & \multirow[b]{2}{*}{$\begin{array}{l}\text { Singh e } \\
\text { cols., } \\
2003\end{array}$} & \multirow[b]{2}{*}{$\begin{array}{l}\text { Ferro e } \\
\text { cols., } \\
2002\end{array}$} & \multirow[b]{2}{*}{$\begin{array}{l}\text { Relatório } \\
\text { da OPAS } \\
\text { - Fontes, } \\
2002\end{array}$} & \multirow[b]{2}{*}{$\begin{array}{l}\text { Aslan e } \\
\text { cols., } \\
2001\end{array}$} & \multirow[b]{2}{*}{$\begin{array}{l}\text { Pattanasin } \\
\text { e cols., } \\
2003\end{array}$} & \multirow[b]{2}{*}{$\begin{array}{l}\text { Kolaczinsk } \\
\text { i e cols., } \\
2004\end{array}$} \\
\hline & & & & & & & & & & & & & & \\
\hline $\begin{array}{l}\text { Descrição do } \\
\text { processo de } \\
\text { amostragem }\end{array}$ & Sim & Não & Sim & Não & Não & Não & Não & Não & Não & Não & Sim & Não & Não & Não \\
\hline $\begin{array}{l}\text { Apresentação } \\
\text { dos Intervalos } \\
\text { de Confiança } \\
\text { para os } \\
\text { parâmetros de } \\
\text { sensibilidade e } \\
\text { especificidade }\end{array}$ & Sim & Não & Sim & Sim & Não & Sim & Não & Sim & Não & Sim & Sim & Não & Sim & Não \\
\hline $\begin{array}{l}\text { Descrição das } \\
\text { características } \\
\text { demográficas } \\
\text { dos pacientes }\end{array}$ & Sim & Não & Sim & Não & Não & Sim & Não & Não & Sim & Não & Não & Não & Não & Não \\
\hline
\end{tabular}




\section{Anexo 8}

Tabela A8 - Parâmetros de custos diretos do diagnóstico da malária para o modelo de custo- efetividade do cenário 2 - área cobertas por laboratórios nos 12 municípios - segundo valores básicos, variação dos valores e fontes consultadas *

\begin{tabular}{|c|c|c|c|c|}
\hline Item de custo & $\begin{array}{l}\text { Valores de } \\
\text { referência } \\
\text { para o caso- } \\
\text { base } \\
\text { R\$ }\end{array}$ & $\begin{array}{c}\text { Valores de } \\
\text { referência para a } \\
\text { variação } \\
\mathbf{R} \$\end{array}$ & $\begin{array}{c}\text { Custo para o total } \\
\text { de municípios/ } \\
\text { exames/casos } \\
\text { clínicos - caso- } \\
\text { base }\end{array}$ & Fontes da informação (1) \\
\hline $\begin{array}{l}\text { Exames e suprimentos } \\
\text { Gota espessa }_{(2)} \text { - um exame }\end{array}$ & 1,99 & $0,41-3,04$ & $155.510,54$ & $\begin{array}{l}\text { Caso-base: Macauley, } 2005 \\
\text { Variação: IEC/SVS/MS } \\
\text { Macauley,2005 }\end{array}$ \\
\hline OptiMal® - um teste & 9,28 & $7,79-10,69$ & $725.194,88$ & $\begin{array}{l}\text { Caso-base: Diário Oficial da } \\
\text { União, } 2006 \\
\text { Variação: DiaMED; SES/PA }\end{array}$ \\
\hline Luvas de Látex ${ }^{(4)}$ & 0,05 & 0,10 & $3.907,30$ & $\begin{array}{l}\text { Caso-base e variação: Banco } \\
\text { de Preços do MS }\end{array}$ \\
\hline $\begin{array}{l}\text { Agente de saúde - salário } \\
\text { mensal }\end{array}$ & 465,20 & $\cdots$ & $88.899,72$ & $\begin{array}{l}\text { Caso-base: SMS do Novo } \\
\text { Repartimento }\end{array}$ \\
\hline $\begin{array}{l}\text { Equipamentos } \\
\text { Microscópio - uma unidade - } \\
\text { valor anualizado }\end{array}$ & $1.053,85^{(6)}$ & $711,62^{(7)}$ & $15.491,60$ & $\begin{array}{l}\text { Caso - base e variação: } \\
\text { PNCM/SVS/MS }\end{array}$ \\
\hline $\begin{array}{l}\text { Manutenção de microscópio - } \\
\text { uma manutenção anual }\end{array}$ & 80,00 & $\ldots$ & $1.176,00$ & $\begin{array}{l}\text { Caso - base: Laboratório de } \\
\text { Malária do Instituto Evandro } \\
\text { Chagas da SVS/MS }\end{array}$ \\
\hline $\begin{array}{l}\text { Treinamento } \\
\text { Microscopia - um curso por } \\
\text { ano e total para } 12 \text { municípios }\end{array}$ & $24.169,00$ & $12.877,30$ & $290.028,00$ & $\begin{array}{l}\text { Caso-base e variação: } \\
\text { PNCM/SVS e SES de } \\
\text { Roraima }\end{array}$ \\
\hline $\begin{array}{l}\text { Teste Rápido - um curso por } \\
\text { ano e total para } 12 \text { municípios }\end{array}$ & 251,76 & 134,14 & $3.021,12$ & $\begin{array}{l}\text { Caso-base e variação: } \\
\text { PNCM/SVS, SES de Roraima } \\
\text { e OMS }\end{array}$ \\
\hline
\end{tabular}

Notas:

* Total de exames para o cenário 2: 78.146.

(1) Para os custos da variação, a primeira fonte corresponde ao menor valor e a segunda fonte ao maior, quando aplicáveis.

(2) Corresponde ao custo individual de um exame considerando os seguintes insumos: lâmina de vidro, Giemsa e demais corantes (todos os componentes das colorações), óleo de imersão, lanceta, algodão, álcool e luvas.

(3) O Laboratório de Malária do Instituto Evandro Chagas, da SVS/MS forneceu os custos individuais de cada insumo para realização da coloração e leitura da lâmina e os custos foram calculados para um exame produzido.

(4) Luvas de látex - compõem o custo do OptiMalß

(5) Itens que foram ponderados, para obtenção do custo total e unitário por exame ou caso clínico e entrada no modelo de custo-efetividade, pela carga de trabalho envolvida na malária (ver memória de cálculo nos anexos 14 a 18).

(6) Custo do microscópio anualizado para 15 anos (ver memória de cálculo no anexo 18).

(7) Custo do microscópio anualizado para 30 anos (ver memória de cálculo no anexo 18). 


\section{Anexo 9}

Tabela A9 - Parâmetros de custos diretos de cuidados com a doença para o modelo de custo-efetividade do cenário 2 área cobertas com laboratórios nos 12 municípios - segundo valores básicos, variação dos valores e fontes consultadas

\begin{tabular}{|c|c|c|c|c|}
\hline Item de custo & $\begin{array}{c}\text { Valores de } \\
\text { referência para } \\
\text { o caso-base } \\
\mathbf{R} \$\end{array}$ & $\begin{array}{c}\text { Valores de referência } \\
\text { para a variação } \\
\mathbf{R} \$\end{array}$ & $\begin{array}{l}\text { Custo para o total } \\
\text { de exames/casos } \\
\text { clínicos - caso-base }\end{array}$ & Fontes da informação \\
\hline \multicolumn{5}{|l|}{$\begin{array}{l}\text { Custo hospitalar - casos } \\
\text { graves }\end{array}$} \\
\hline $\begin{array}{l}\text { Diária de internação hospitalar } \\
\text { média }^{(2)}\end{array}$ & $137,34^{(3)}$ & $106,80-167,89$ & $997.088,40^{(4)}$ & $\begin{array}{l}\text { Caso-base e variação: } \\
\text { SIH-SUS e Tabela de } \\
\text { Procedimentos do SUS }\end{array}$ \\
\hline $\begin{array}{l}\text { Exames de pré-internação - } \\
\text { custo do conjunto de exames } \\
\text { para um paciente }\end{array}$ & 41,26 & $\ldots$ & $29.954,76^{(5)}$ & $\begin{array}{l}\text { Caso-base: Tabela de } \\
\text { Procedimentos do SUS }\end{array}$ \\
\hline \multicolumn{5}{|l|}{ Custo ambulatorial } \\
\hline $\begin{array}{l}\text { Consulta no SUS - uma } \\
\text { consulta }\end{array}$ & 7,55 & $\ldots$ & $590.002,30^{(6)}$ & $\begin{array}{l}\text { Caso-base: Tabela de } \\
\text { Procedimentos do SUS }\end{array}$ \\
\hline \multicolumn{5}{|l|}{ Transporte } \\
\hline $\begin{array}{l}\text { Medicamentos antimaláricos } \\
\text { para Belém/PA, por ano }{ }^{(7)}\end{array}$ & $9.590,81$ & $\cdots$ & $9.590,81$ & $\begin{array}{l}\text { Fonte: CENADI/SVS/MS } \\
\text { e Gabinete/SVS/MS }\end{array}$ \\
\hline \multicolumn{5}{|l|}{ Medicamentos $^{(8)}$} \\
\hline $\begin{array}{l}\text { Tratamento específico da } \\
\text { malária vivax - custo de um } \\
\text { tratamento }\end{array}$ & 0,52 & $\ldots$ & $6.724,12^{(9)}$ & $\begin{array}{l}\text { Caso-base: sistema de } \\
\text { informações de insumos } \\
\text { estratégicos da SVS/MS }\end{array}$ \\
\hline $\begin{array}{l}\text { Tratamento específico da } \\
\text { malária falciparum não-grave - } \\
\text { custo de um tratamento }\end{array}$ & 4,59 & $\ldots$ & $25.639,74^{(11)}$ & $\begin{array}{l}\text { Caso-base: sistema de } \\
\text { informações de insumos } \\
\text { estratégicos da SVS/MS }\end{array}$ \\
\hline $\begin{array}{l}\text { Tratamento específico da } \\
\text { malária falciparum grave - } \\
\text { custo de um tratamento }{ }^{(12)}\end{array}$ & 42,40 & $\ldots$ & $30.782,40^{(13)}$ & $\begin{array}{l}\text { Caso-base: sistema de } \\
\text { informações de insumos } \\
\text { estratégicos da SVS/MS }\end{array}$ \\
\hline$\underset{(14)}{\text { Acetaminofen - um tratamento }}$ & 0,37 & $0,35-0,66$ & $28.914,02$ & $\begin{array}{l}\text { Caso-base e variação: } \\
\text { banco de preços do MS }\end{array}$ \\
\hline
\end{tabular}

Notas: ${ }^{(1)}$ O caso-base e as variações tiveram as mesmas fontes de dados.

(2) Corresponde a um custo médio de diária considerando os custos da diária de enfermaria e de UTI (anexo 21)

(3) Corresponde a $50 \%$ da diária de UTI mais $50 \%$ da diária de enfermaria.

(4) Corresponde ao custo da internação por 10 dias para a estimativa de pacientes com malária falciparum grave:

726 pacientes (11,5\%). Cálculo: 137,34 x 10 dias x 726 .

(5) Exames considerados: hemograma, coagulograma, sódio, potássio, uréia, creatinina, bilirrubinas total e frações,

TGO,TGP, Gama-GT, fosfatase alcalina, DHL, glicemia, Raios X de tórax. Corresponde à estimativa de custos para pacientes graves: 726 pacientes.

(6) Na hipótese teórica de que todos os casos febris façam consulta; o modelo de custo-efetividade adotou critérios para esta estimativa, explicadas no texto.

(7) Foi coletado o custo global de transporte no ano de 2006 do Rio de Janeiro para o Estado do Pará e ponderado pela proporção de casos positivos nos 12 municípios de interesse.

(8) O custo do tratamento das diversas formas de malária considera o conjunto dos medicamentos indicados por faixas etárias e por populações específicas como: menores de seis meses e grávidas, assumindo para a população geral adulta os medicamentos de primeira linha (ver memória de cálculo no anexo 13).

(9) Para estimados 12.931 casos de malária vivax, segundo o modelo.

(10) Considera na composição de custos a proporção estimada de pacientes com malária mista que utiliza cloroquina

(crianças abaixo de seis meses) ou primaquina para cura radical da malária vivax (ver memória de cálculo no anexo 13).

(11) Para estimados 5.586 casos de malária falciparum não-grave, segundo o modelo.

(12) Considera custos de artemeter e artesunato e de quinino e clindamicina em grávidas; no cálculo do artesunato está incluído o custo da solução de glicose para diluição (ver memória de cálculo no anexo 13).

(13) Para estimados 726 casos de malária falciparum grave, segundo o modelo.

(14) Considerado tratamento antitérmico por até 3 dias, ponderando pela estimativa da proporção de crianças e adultos. 


\section{Anexo 10}

Tabela A10 - Parâmetros de custos diretos do diagnóstico da malária para o modelo de custo- efetividade do cenário 3 - áreas isoladas dos 12 municípios - segundo valores básicos, variação dos valores e fontes consultadas*

\section{Item de custo}

\section{Valores de \\ referência \\ para o caso- \\ base}

$\mathbf{R} \$$
Valores de

referência para

a variação

$\mathbf{R} \mathbf{}$
Custo para o total de municípios/

exames/casos

clínicos - caso-base

Fontes da informação

ção

esuprimentos

Gota espessa ${ }^{(2)}$ - um exame

1,99

$0,41-3,04$

$66.647,09$

OptiMal® - um teste

$7,79-10,69$

$310.796,48$

Luvas de Látex ${ }^{(4)}$

0,05

0,10

$1.674,55$

Caso-base: Macauley, 2005 Variação: IEC/SVS/MS ${ }^{(3)}$ Macauley,2005

Caso-base: Diário Oficial da União, 2006 Variação: DiaMED; SES/PA

Caso-base e variação: Banco de Preços do MS

\section{Salários dos profissionais}

Microscopista - salário mensal

(5)

Agente de saúde - salário mensal ${ }^{(5)}$

\section{Equipamentos}

Microscópio - uma unidade valor anualizado (5)

$1.053,85^{(6)}$

$711,62^{(7)}$

$6.639,25$

$38.099,88$

$51.704,29$

Caso-base: Secretaria Municipal de Saúde do Novo Repartimento

Caso-base: SMS do Novo Repartimento
Manutenção de microscópio uma manutenção anual ${ }^{(5)}$

80,00
504,00
Caso - base e variação: PNCM/SVS/MS

Caso - base: Laboratório de Malária do Instituto Evandro Chagas da SVS/MS

\section{Transporte}

Realização do teste rápido -

Realização do teste ráp

$3.147,00 \quad 1.856,00-$

$35.649,07$

Realização da microscopia

custo mensal médio ${ }^{(5)}$

$3.147,00$

$3.712,00$ -

$71.298,13$

Treinamento

Microscopia - um curso por

ano e total para 12

municípios

$6.294,00$

$24.169,00$

$12.877,30$

251,76
134,14
$19.826,10$

$39.652,20$

$290.028,00$

Teste Rápido - um curso por ano e total para 12 municípios

\subsection{1}

Notas: Total de exames no cenário 3: 33.491

Para os custos da variação, a primeira fonte corresponde ao menor valor e a segunda fonte ao maior, quando aplicáveis.

(2) Corresponde ao custo individual de um exame considerando os seguintes insumos: lâmina de vidro, Giemsa e demais corantes (todos os componentes das colorações), óleo de imersão, lanceta, algodão, álcool e luvas.

(3) O Laboratório de Malária do Instituto Evandro Chagas, da SVS/MS forneceu os custos individuais de cada insumo para realização da coloração e leitura da lâmina e os custos foram calculados para um exame produzido.

(4) Luvas de látex - compõem o custo do OptiMal®i.

${ }^{(5)}$ Itens que foram ponderados, para obtenção do custo total e unitário por exame ou caso clínico e entrada no modelo de custo-efetividade, pela carga de trabalho envolvida na malária (ver anexos 14 a 20).

${ }^{(6)}$ Custo do microscópio anualizado para 15 anos (ver memória de cálculo no anexo 18).

(7) Custo do microscópio anualizado para 30 anos (ver memória de cálculo no anexo 18).

${ }^{(8)}$ A SMS de Novo Repartimento informou os custos mensais com gasolina e óleo diesel e os custos de transporte foram calculados (ver memória de cálculo nos anexos 19 e 20). 


\section{Anexo 11}

Tabela A11 - Parâmetros de custos diretos de cuidados com a doença para o modelo de custo-efetividade do cenário 3 - áreas isoladas dos 12 municípios - segundo valores básicos, variação dos valores e fontes consultadas

\begin{tabular}{|c|c|c|c|c|}
\hline Item de custo & $\begin{array}{c}\text { Valores de } \\
\text { referência para } \\
\text { o caso-base } \\
\mathrm{R} \$\end{array}$ & $\begin{array}{c}\text { Valores de referência } \\
\text { para a variação } \\
\mathbf{R} \$\end{array}$ & $\begin{array}{c}\text { Custo para o total } \\
\text { de exames/casos } \\
\text { clínicos - caso-base }\end{array}$ & Fontes da informação \\
\hline \multicolumn{5}{|l|}{$\begin{array}{l}\text { Custo hospitalar - casos } \\
\text { graves }\end{array}$} \\
\hline $\begin{array}{l}\text { Diária de internação hospitalar } \\
\text { média }^{(2)}\end{array}$ & $137,34^{(3)}$ & $106,80-167,89$ & $427.127,40^{(4)}$ & $\begin{array}{l}\text { Caso-base e variação: } \\
\text { SIH-SUS e Tabela de } \\
\text { Procedimentos do SUS }\end{array}$ \\
\hline $\begin{array}{l}\text { Exames de pré-internação - } \\
\text { custo do conjunto de exames } \\
\text { para um paciente }\end{array}$ & 41,26 & $\ldots$ & $12.831,86^{(5)}$ & $\begin{array}{l}\text { Caso-base: Tabela de } \\
\text { Procedimentos do SUS }\end{array}$ \\
\hline \multicolumn{5}{|l|}{ Custo ambulatorial } \\
\hline $\begin{array}{l}\text { Consulta no SUS - uma } \\
\text { consulta }\end{array}$ & 7,55 & $\cdots$ & $252.857,05^{(6)}$ & $\begin{array}{l}\text { Caso-base: Tabela de } \\
\text { Procedimentos do SUS }\end{array}$ \\
\hline \multicolumn{5}{|l|}{ Transporte } \\
\hline $\begin{array}{l}\text { Medicamentos antimaláricos } \\
\text { para Belém/PA, por ano }{ }^{(7)}\end{array}$ & $9.590,81$ & $\cdots$ & $9.590,81$ & $\begin{array}{l}\text { Fonte: CENADI/SVS/MS e } \\
\text { Gabinete/SVS/MS }\end{array}$ \\
\hline \multicolumn{5}{|l|}{ Medicamentos $^{(8)}$} \\
\hline $\begin{array}{l}\text { Tratamento específico da } \\
\text { malária vivax - custo de um } \\
\text { tratamento }\end{array}$ & 0,52 & $\ldots$ & $2.881,32^{(9)}$ & $\begin{array}{l}\text { Caso-base: sistema de } \\
\text { informações de insumos } \\
\text { estratégicos da SVS/MS }\end{array}$ \\
\hline $\begin{array}{l}\text { Tratamento específico da } \\
\text { malária falciparum não-grave - } \\
\text { custo de um tratamento }\end{array}$ & 4,59 & $\ldots$ & $10.983,87^{(11)}$ & $\begin{array}{l}\text { Caso-base: sistema de } \\
\text { informações de insumos } \\
\text { estratégicos da SVS/MS }\end{array}$ \\
\hline $\begin{array}{l}\text { Tratamento específico da } \\
\text { malária falciparum grave - } \\
\text { custo de um tratamento }\end{array}$ & 42,40 & $\cdots$ & $13.186,40^{(13)}$ & $\begin{array}{l}\text { Caso-base: sistema de } \\
\text { informações de insumos } \\
\text { estratégicos da SVS/MS }\end{array}$ \\
\hline $\begin{array}{l}\text { Acetaminofen - } \\
\text { um tratamento }\end{array}$ & 0,37 & $0,35-0,66$ & $12.391,67$ & $\begin{array}{l}\text { Caso-base e variação: } \\
\text { banco de preços do MS }\end{array}$ \\
\hline $\begin{array}{l}\text { Notas: } \\
\text { (1) O caso-base e as variações } \\
{ }^{(2)} \text { Corresponde a um custo mé } \\
{ }^{(3)} \text { Corresponde a } 50 \% \text { da diária } \\
{ }^{(4)} \text { Corresponde ao custo da inte } \\
311 \text { pacientes (11,5\%). Cálculo } \\
\text { (5) Exames considerados: hemo } \\
\text { TGO,TGP, Gama-GT, fosfatase } \\
\text { pacientes graves: } 311 \text { paciente } \\
\text { (6) Na hipótese teórica de que to } \\
\text { para esta estimativa, explicadas } \\
\text { (7) Foi coletado o custo global d } \\
\text { proporção de casos positivos n } \\
\text { (8) O custo do tratamento das di } \\
\text { etárias e por populações espec } \\
\text { os medicamentos de primeira li } \\
\text { (9) Para estimados } 5.541 \text { casos } \\
\text { (10) Considera na composição d } \\
\text { (crianças abaixo de seis meses } \\
\text { (11) Para estimados } 2.393 \text { caso } \\
\text { (12) Considera custos de arteme } \\
\text { incluído o custo da solução de } \\
\text { (13) Para estimados } 311 \text { casos } \\
\text { (14) Considerado tratamento ant }\end{array}$ & $\begin{array}{l}\text { eram as mesmas } \\
\text { de diária consider } \\
\text { e UTI mais } 50 \% \text { da } \\
\text { ação por } 10 \text { dias p } \\
37,34 \text { x } 10 \text { dias x } 3 \\
\text { ama, coagulogram } \\
\text { lcalina, DHL, glicer } \\
\text { s os casos febris } \\
\text { o texto. } \\
\text { ransporte no ano o } \\
12 \text { municípios de i } \\
\text { rsas formas de ma } \\
\text { sas como: menores } \\
\text { a (ver memória de } \\
\text { malária vivax, seg } \\
\text { ustos a proporção } \\
\text { u primaquina para } \\
\text { le malária falciparu } \\
\text { e artesunato e de } \\
\text { cose para diluição } \\
\text { malária falciparum } \\
\text { mico por até } 3 \text { dia }\end{array}$ & $\begin{array}{l}\text { tes de dados. } \\
\text { do os custos da diária de } \\
\text { iária de enfermaria. } \\
\text { a estimativa de paciente } \\
\text { (anexo 21). } \\
\text { sódio, potássio, uréia, cre } \\
\text { a, Raios X de tórax. Corre } \\
\text { am consulta; o modelo d } \\
\text { 2006 do Rio de Janeiro } \\
\text { eresse. } \\
\text { ia considera o conjunto o } \\
\text { e seis meses e grávidas, } \\
\text { lculo no anexo 13). } \\
\text { do o modelo. } \\
\text { timada de pacientes com } \\
\text { dra radical da malária viv́ } \\
\text { não-grave, segundo o m } \\
\text { dinino e clindamicina em } \\
\text { r memória de cálculo no } \\
\text { rave, segundo o modelo. } \\
\text { ponderando pela estimati }\end{array}$ & $\begin{array}{l}\text { nfermaria e de UTI. } \\
\text { com malária falciparum } \\
\text { inina, bilirrubinas total } \\
\text { sonde à estimativa de c } \\
\text { uusto-efetividade adoto } \\
\text { ra o Estado do Pará e p } \\
\text { ssumindo para a popula } \\
\text { nalária mista que utiliza } \\
\text { (ver memória de cálcul } \\
\text { lelo. } \\
\text { ávidas; no cálculo do ar } \\
\text { exexo 13). }\end{array}$ & $\begin{array}{l}\text { grave: } \\
\text { frações, } \\
\text { stos para } \\
\text { critérios } \\
\text { nderado pela } \\
\text { s por faixas } \\
\text { ão geral adulta } \\
\text { loroquina } \\
\text { no anexo 13). } \\
\text { sunato está }\end{array}$ \\
\hline
\end{tabular}




\section{Anexo 12}

Tabela A12 - Memória de cálculo para o custo final de um exame de gota espessa, a partir dos custos de insumos para a técnica de coloração de lâmina, para a técnica de leitura e para a coleta do sangue.

\begin{tabular}{|c|c|}
\hline Custo em Reais & Especificação \\
\hline & Preparo do corante de azul de metileno \\
\hline $1,2(a)$ & $1 \mathrm{~g}$ de azul de metileno \\
\hline $0,4(b)$ & 1g de potássio monobásico \\
\hline $1,2(\mathrm{c})$ & 3g de sódio anidro \\
\hline $2,8(d)$ & $5 \mathrm{~g}$ do composto de azul de metileno mais os sais $(\mathrm{d})=(\mathrm{a})+(\mathrm{b})+(\mathrm{c})$ \\
\hline $0,56(\mathrm{e})$ & $1 \mathrm{~g}$ do composto de azul de metileno mais os sais $(e)=(d) / 5$ \\
\hline $0,62(\mathrm{f})$ & $250 \mathrm{ml}$ de água destilada \\
\hline \multirow[t]{2}{*}{$1,18(\mathrm{~g})$} & $\begin{array}{l}250 \mathrm{ml} \text { da solução de azul de metileno (composto mais água destilada) } \\
(\mathrm{g})=(\mathrm{e})+(\mathrm{f})\end{array}$ \\
\hline & Preparo da água tamponada \\
\hline $1,6(h)$ & $4 \mathrm{~g}$ de potássio monobásico $(\mathrm{h})=(\mathrm{b}) \times 4$ \\
\hline 2,4 (i) & $6 \mathrm{~g}$ de sódio anidro $(\mathrm{i})=(\mathrm{c}) \times 2$ \\
\hline $4,0(\mathrm{j})$ & $10 \mathrm{~g}$ do composto de sais para a água tamponada $(\mathrm{j})=(\mathrm{h})+(\mathrm{i})$ \\
\hline $0,4(k)$ & $1 \mathrm{~g}$ do composto de sais para a água tamponada $(\mathrm{k})=(\mathrm{j}) / 10$ \\
\hline $1,27(\mathrm{I})$ & 1 litro de água destilada * \\
\hline \multirow[t]{2}{*}{$1,67(\mathrm{~m})$} & 1 litro de água tamponada $(\mathrm{m})=(\mathrm{k})+(\mathrm{l})$ \\
\hline & Coloração - 1a. etapa \\
\hline $0,0236(n)$ & $5 \mathrm{ml}$ de azul de metileno $(\mathrm{n})=[(\mathrm{g}) \times 5] / 250(\mathrm{ml})$ \\
\hline $0,00835(0)$ & $5 \mathrm{ml}$ de água tamponada $(0)=[(\mathrm{m}) \times 5] / 1000(\mathrm{ml})$ \\
\hline \multirow[t]{2}{*}{$0,03195(p)$} & Custo da 1a. etapa da coloração \\
\hline & Coloração - 2a. etapa \\
\hline $0,065(q)$ & $1 \mathrm{ml}$ de corante de Giemsa \\
\hline $0,0325(r)$ & 10 gotas de Giemsa $(r)=(q) / 20$ (gotas) $\times 10$ \\
\hline $0,00835(0)$ & $5 \mathrm{ml}$ de água tamponada $(\mathrm{o})=[(\mathrm{m}) \times 5] / 1000(\mathrm{ml})$ \\
\hline $0,02505(\mathrm{~s})$ & $15 \mathrm{ml}$ de água tamponada para lavagem $(\mathrm{s})=(\mathrm{o}) \times 3$ \\
\hline $0,0659(t)$ & Custo da 2a. etapa da coloração $(t)=(r)+(0)+(s)$ \\
\hline \multirow[t]{2}{*}{$0,09785(\mathrm{u})$} & Custo total da coloração $(u)=(p)+(t)$ \\
\hline & Coleta e leitura da lâmina - insumos \\
\hline $0,28(v)$ & 10 gotas de óleo de imersão \\
\hline $0,056(x)$ & 2 gotas de óleo de imersão $(x)=[(v) \times 2] / 10$ \\
\hline $0,011(w)$ & 5ml de álcool (desinfecção) \\
\hline $0,01432(\mathrm{y})$ & 2g de algodão (desinfecção) \\
\hline $0,14(z)$ & Lâminas de vidro \\
\hline $0,04(\mathrm{a} 1)$ & Lancetas \\
\hline 0,05 (b1) & Luvas \\
\hline $0,31132(c 1)$ & $\begin{array}{l}\text { Custo da coleta e leitura da lâmina - insumos }(c 1)=(x)+(w)+(y)+ \\
(z)+(a 1)+(b 1)\end{array}$ \\
\hline 0,40917 (d1) & $\begin{array}{l}\text { Custo final de uma lâmina corada para gota espessa mais insumos } \\
\text { para a coleta e leitura }\end{array}$ \\
\hline
\end{tabular}

Fontes: Banco de Preços do MS; Laboratório de Malária - Instituto Evandro Chagas/SVS/MS 


\section{Anexo 13}

Tabela A13 - Memória de cálculo do custo de tratamento específico para malária vivax, segundo ponderações pelas proporções de casos nas faixas etárias e gravidez a partir das notificações de casos de 2006 e esquemas preconizados pelo PNCM/SVS/MS

\begin{tabular}{|c|c|c|c|c|c|c|c|}
\hline $\begin{array}{l}\text { Faixas etárias } \\
\text { consideradas no } \\
\text { esquema de tratamento } \\
\text { preconizado }\end{array}$ & $\begin{array}{l}\text { Proporção de } \\
\text { casos por faixa } \\
\text { etária - } \\
\text { notificações de } \\
2006\end{array}$ & $\begin{array}{l}\text { Drogas e doses } \\
\text { indicadas por faixa etária } \\
\text { e gravidez }\end{array}$ & $\begin{array}{l}\text { Quantidade por } \\
\text { pessoa tratada }\end{array}$ & $\begin{array}{l}\text { Custo unitáriol do } \\
\text { medicamento } \\
\mathbf{R} \boldsymbol{\$}^{(1)}\end{array}$ & $\begin{array}{c}\text { Custo por } \\
\text { medicamento e por } \\
\text { doses de cada } \\
\text { esquema de acordo } \\
\text { com idades }\end{array}$ & $\begin{array}{l}\text { Custo bruto } \\
\text { por } \\
\text { esquemas de } \\
\text { tratamento }\end{array}$ & $\begin{array}{c}\text { Custos finais } \\
\text { ponderados pela } \\
\text { frequência de } \\
\text { ocorrência nas } \\
\text { faixas etárias e } \\
\text { gravidez }\end{array}$ \\
\hline \multirow{2}{*}{ Menor de 6 meses } & \multirow{2}{*}{0,0056} & Cloroquina - comp & 1 & 0,03 & 0,03 & \multirow{2}{*}{0,12} & \multirow{2}{*}{0,0007} \\
\hline & & Cloroquina semanal & 3 & 0,03 & 0,09 & & \\
\hline \multirow{2}{*}{6 a 11 meses } & \multirow{2}{*}{0,0095} & Cloroquina & 2 & 0,03 & 0,06 & \multirow{2}{*}{0,13} & \multirow{2}{*}{0,0012} \\
\hline & & Primaquina $5 \mathrm{mg}$ & 7 & 0,01 & 0,07 & & \\
\hline \multirow{2}{*}{1 a 2 anos } & \multirow{2}{*}{0,0449} & Cloroquina & 2 & 0,03 & 0,06 & \multirow{2}{*}{0,13} & \multirow{2}{*}{0,0058} \\
\hline & & Primaquina $5 \mathrm{mg}$ & 7 & 0,01 & 0,07 & & \\
\hline \multirow{2}{*}{3 a 6 anos } & \multirow{2}{*}{0,0973} & Cloroquina & 3 & 0,03 & 0,09 & \multirow{2}{*}{0,23} & \multirow{2}{*}{0,0224} \\
\hline & & Primaquina $5 \mathrm{mg}$ & 14 & 0,01 & 0,14 & & \\
\hline \multirow{3}{*}{7 a 11 anos } & \multirow{3}{*}{0,1077} & Cloroquina & 5 & 0,03 & 0,15 & \multirow{3}{*}{0,36} & \multirow{3}{*}{0,0388} \\
\hline & & Primaquina $5 \mathrm{mg}$ & 7 & 0,01 & 0,07 & & \\
\hline & & Primaquina $15 \mathrm{mg}$ & 7 & 0,02 & 0,14 & & \\
\hline \multirow{2}{*}{12 a 14 anos } & \multirow{2}{*}{0,0624} & Cloroquina & 7 & 0,03 & 0,21 & \multirow{2}{*}{0,43} & \multirow{2}{*}{0,0268} \\
\hline & & Primaquina $15 \mathrm{mg}$ & 11 & 0,02 & 0,22 & & \\
\hline \multirow{2}{*}{15 anos ou mais } & \multirow{2}{*}{0,6704} & Cloroquina & 10 & 0,03 & 0,3 & \multirow{2}{*}{0,58} & \multirow{2}{*}{0,3888} \\
\hline & & Primaquina $15 \mathrm{mg}$ & 14 & 0,02 & 0,28 & & \\
\hline $\begin{array}{l}\text { Custo total do tratament } \\
\text { na população geral }\end{array}$ & o de malária vivax & & & & & 1,98 & 0,4846 \\
\hline \multirow{2}{*}{$\begin{array}{l}\text { Malária vivax na } \\
\text { gravidez }\end{array}$} & \multirow{2}{*}{0,013} & Cloroquina & 10 & 0,03 & 0,3 & \multirow{2}{*}{2,7} & \multirow{2}{*}{0,0351} \\
\hline & & Cloroquina semanal & 80 & 0,03 & 2,4 & & \\
\hline \multicolumn{2}{|c|}{$\begin{array}{l}\text { Custo total do tratamento de malária vivax } \\
\text { na população geral e grávidas }\end{array}$} & & & & & & 0,5197 \\
\hline
\end{tabular}

Fontes: PNCM/SVS/MS; SIVEP/Malária/SVS/MS; Martinez-Espinosa, 1998. Nota: ${ }^{(1)}$ Por comprimidos, ampolas, cápsulas ou blíster a depender da droga 


\section{Anexo 13}

Tabela A14 - Memória de cálculo do custo de tratamento específico para malária falciparum não-grave, segundo ponderações pelas proporções de casos nas faixas etárias e gravidez a partir das notificações de casos de 2006 e esquemas preconizados pelo PNCM/SVS/MS

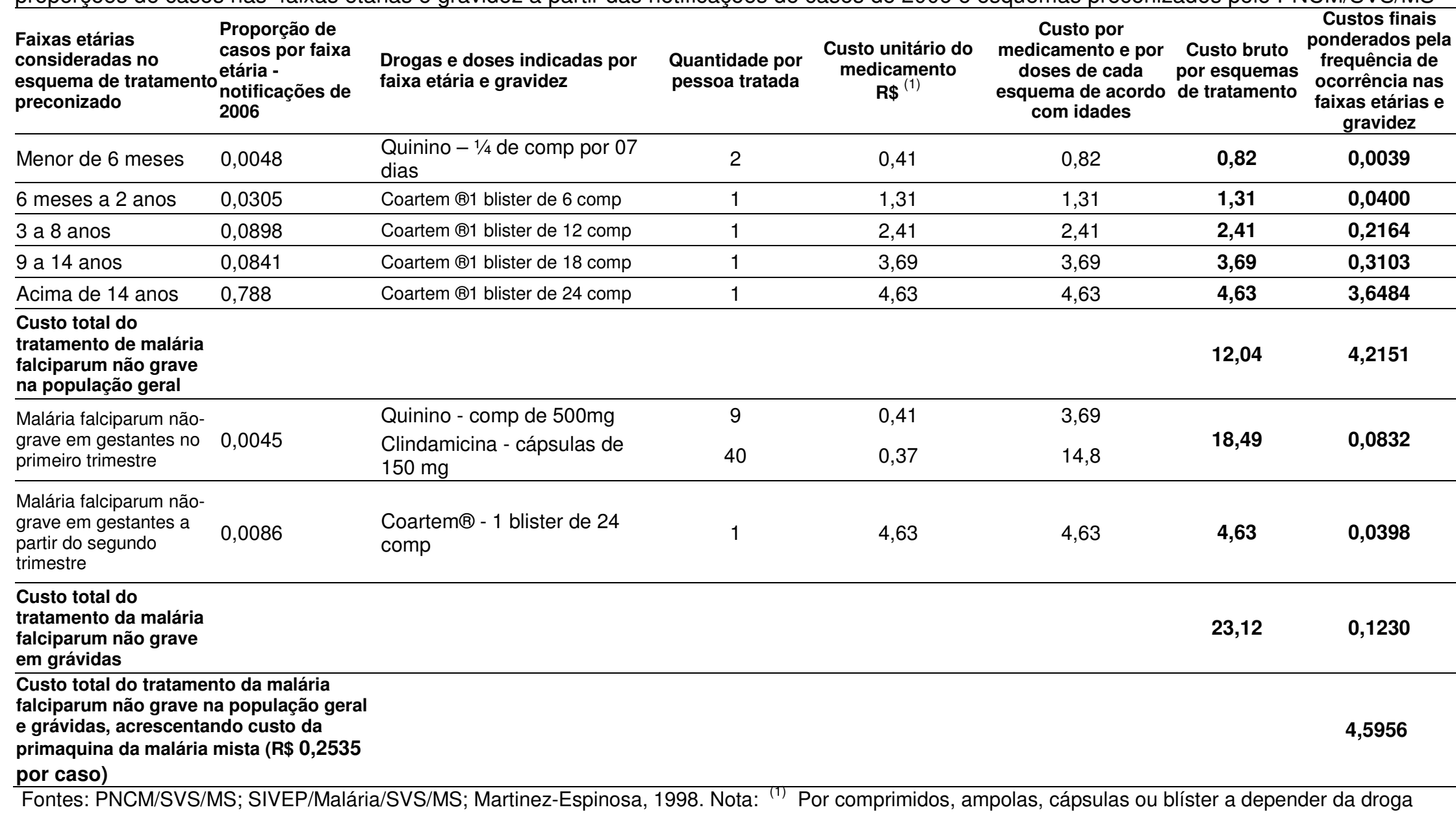




\section{Anexo 13}

Tabela A15 - Memória de cálculo do custo de tratamento específico para malária falciparum grave, segundo ponderações pelas proporções de casos nas faixas etárias e gravidez a partir das notificações de casos de 2006 e esquemas preconizados pelo PNCM/SVS/MS

\begin{tabular}{|c|c|c|c|c|c|c|c|}
\hline $\begin{array}{l}\text { Faixas etárias } \\
\text { consideradas no } \\
\text { esquema de } \\
\text { tratamento } \\
\text { preconizado }\end{array}$ & $\begin{array}{l}\text { Proporção de casos } \\
\text { por faixa etária - } \\
\text { notificações de } 2006\end{array}$ & $\begin{array}{l}\text { Drogas e doses } \\
\text { indicadas por faixa } \\
\text { etária e gravidez }\end{array}$ & $\begin{array}{l}\text { Quantidade por } \\
\text { pessoa tratada }\end{array}$ & $\begin{array}{l}\text { Custo unitário do } \\
\text { medicamento } \\
\mathbf{R}^{(1)}\end{array}$ & $\begin{array}{c}\text { Custo por } \\
\text { medicamento e por } \\
\text { doses de cada } \\
\text { esquema de acordo } \\
\text { com idades }\end{array}$ & $\begin{array}{c}\text { Custo bruto } \\
\text { por esquemas } \\
\text { de tratamento }\end{array}$ & $\begin{array}{c}\text { Custos finais } \\
\text { ponderados pela } \\
\text { frequência de } \\
\text { ocorrência nas } \\
\text { faixas etárias e } \\
\text { gravidez }\end{array}$ \\
\hline \multirow{3}{*}{10 a $14 \mathrm{~kg}$ ou } & \multirow{4}{*}{0,0278} & Artesunato & 9 & 4,05 & 36,45 & \multirow{4}{*}{46,97} & \multirow{4}{*}{1,3058} \\
\hline & & SG $5 \%$ & 9 & 0,96 & 8,64 & & \\
\hline & & Mefloquina & 1 & 1,86 & 1,86 & & \\
\hline 1 a 2 anos & & Primaquina - $15 \mathrm{mg}$ & 1 & 0,02 & 0,02 & & \\
\hline \multirow{2}{*}{15 a $19 \mathrm{~kg}$ ou } & \multirow{4}{*}{0,0278} & Artesunato & 9 & 4,05 & 36,45 & \multirow{4}{*}{46,97} & \multirow{4}{*}{1,3058} \\
\hline & & SG 5\% & 9 & 0,96 & 8,64 & & \\
\hline \multirow{2}{*}{3 a 5 anos } & & Mefloquina & 1 & 1,86 & 1,86 & & \\
\hline & & Primaquina -15 mg & 1 & 0,02 & 0,02 & & \\
\hline \multirow[b]{2}{*}{20 a 29 kg ou } & \multirow{4}{*}{0,0417} & Artesunato & 9 & 4,05 & 36,45 & \multirow{4}{*}{48,85} & \multirow{4}{*}{2,0370} \\
\hline & & SG $5 \%$ & 9 & 0,96 & 8,64 & & \\
\hline \multirow{2}{*}{6 a 9 anos } & & Mefloquina & 2 & 1,86 & 3,72 & & \\
\hline & & Primaquina - $15 \mathrm{mg}$ & 2 & 0,02 & 0,04 & & \\
\hline \multirow{4}{*}{$\begin{array}{l}30 \text { a } 60 \mathrm{~kg} \text { ( } 14 \text { anos e } \\
\text { mais) ou acima de } 12 \\
\text { anos }\end{array}$} & \multirow{4}{*}{0,8871} & Artesunato & 10 & 4,05 & 40,5 & \multirow{4}{*}{57,6} & \multirow{4}{*}{51,0970} \\
\hline & & SG $5 \%$ & 10 & 0,96 & 9,6 & & \\
\hline & & Mefloquina & 4 & 1,86 & 7,44 & & \\
\hline & & Primaquina - $15 \mathrm{mg}$ & 3 & 0,02 & 0,06 & & \\
\hline
\end{tabular}


Anexo 13

Tabela A15 - Memória de cálculo do custo de tratamento específico para malária falciparum grave, segundo ponderações pelas proporções de casos nas faixas etárias e gravidez a partir das notificações de casos de 2006 e esquemas preconizados pelo PNCM/SVS/MS

\begin{tabular}{|c|c|c|c|c|c|c|c|}
\hline $\begin{array}{l}\text { Faixas etárias } \\
\text { consideradas no } \\
\text { esquema de } \\
\text { tratamento } \\
\text { preconizado }\end{array}$ & $\begin{array}{l}\text { Proporção de casos } \\
\text { por faixa etária - } \\
\text { notificações de } 2006\end{array}$ & $\begin{array}{l}\text { Drogas e doses } \\
\text { indicadas por faixa etária } \\
\text { e gravidez }\end{array}$ & $\begin{array}{l}\text { Quantidade por } \\
\text { pessoa tratada }\end{array}$ & $\begin{array}{l}\text { Custo unitário do } \\
\text { medicamento } \\
\mathbf{R} \$^{(1)}\end{array}$ & $\begin{array}{l}\text { Custo por } \\
\text { medicamento e por } \\
\text { doses de cada } \\
\text { esquema de acordo } \\
\text { com idades }\end{array}$ & $\begin{array}{l}\text { Custo bruto } \\
\text { por esquemas } \\
\text { de tratamento }\end{array}$ & $\begin{array}{c}\text { Custos finais } \\
\text { ponderados pela } \\
\text { frequência de } \\
\text { ocorrência nas } \\
\text { faixas etárias e } \\
\text { gravidez }\end{array}$ \\
\hline 10 a $14 \mathrm{~kg}$ ou & \multirow{3}{*}{0,0278} & Artemeter & 7 & 1,90 & 13,3 & \multirow{3}{*}{15,18} & \multirow{3}{*}{0,4220} \\
\hline \multirow{2}{*}{1 a 2 anos } & & Mefloquina & 1 & 1,86 & 1,86 & & \\
\hline & & Primaquina - $15 \mathrm{mg}$ & 1 & 0,02 & 0,02 & & \\
\hline 15 a $19 \mathrm{~kg}$ ou & \multirow{3}{*}{0,0278} & Artemeter & 7 & 1,90 & 13,3 & \multirow{3}{*}{15,18} & \multirow{3}{*}{0,4220} \\
\hline \multirow{2}{*}{3 a 5 anos } & & Mefloquina & 1 & 1,86 & 1,86 & & \\
\hline & & Primaquina $-15 \mathrm{mg}$ & 1 & 0,02 & 0,02 & & \\
\hline 20 a 29 kg ou & \multirow{3}{*}{0,0417} & Artemeter & 7 & 1,90 & 13,3 & \multirow{3}{*}{17,06} & \multirow{3}{*}{0,7114} \\
\hline \multirow{2}{*}{6 a 9 anos } & & Mefloquina & 2 & 1,86 & 3,72 & & \\
\hline & & Primaquina - $15 \mathrm{mg}$ & 2 & 0,02 & 0,04 & & \\
\hline \multirow{3}{*}{$\begin{array}{l}30 \text { a } 60 \mathrm{~kg}(14 \text { anos e } \\
\text { mais) ou acima de } 12 \\
\text { anos }\end{array}$} & \multirow{3}{*}{0,8871} & Artemeter & 8 & 1,90 & 15,2 & \multirow{3}{*}{22,7} & \multirow{3}{*}{20,1372} \\
\hline & & Mefloquina & 4 & 1,86 & 7,44 & & \\
\hline & & Primaquina - $15 \mathrm{mg}$ & 3 & 0,02 & 0,06 & & \\
\hline \multicolumn{2}{|c|}{$\begin{array}{l}\text { Custo do tratamento de malária falciparum } \\
\text { grave na população geral, considerando } 50 \% \\
\text { de uso de Artemeter }{ }^{(2)}\end{array}$} & & & & & 35,06 & 10,8463 \\
\hline \multirow{2}{*}{$\begin{array}{l}\text { Malária falciparum grave } \\
\text { em gestantes em } \\
\text { qualquer trimestre da } \\
\text { gestação }\end{array}$} & \multirow{2}{*}{0,1389} & Quinino - 500mg & 9 & 1,11 & 9,99 & \multirow[b]{2}{*}{26,49} & \multirow[b]{2}{*}{3,6795} \\
\hline & & Clindamicina - 600 mg & 10 & 1,65 & 16,5 & & \\
\hline \multicolumn{4}{|c|}{ Custo do tratamento de malária falciparum grave em gestantes } & & & 26,49 & 3,6795 \\
\hline \multicolumn{4}{|c|}{$\begin{array}{l}\text { Custo total do tratamento de malária falciparum grave na população } \\
\text { geral e gestantes }\end{array}$} & & & & 42,3986 \\
\hline
\end{tabular}




\section{Anexo 13}

Tabela A16 - Memória de cálculo do custo de tratamento específico para malária mista (falciparum e vivax) para prevenção de recaída da malária vivax, segundo ponderações pelas proporções de casos nas faixas etárias a partir das notificações de casos de 2006 e esquemas preconizados pelo PNCM/SVS/MS *

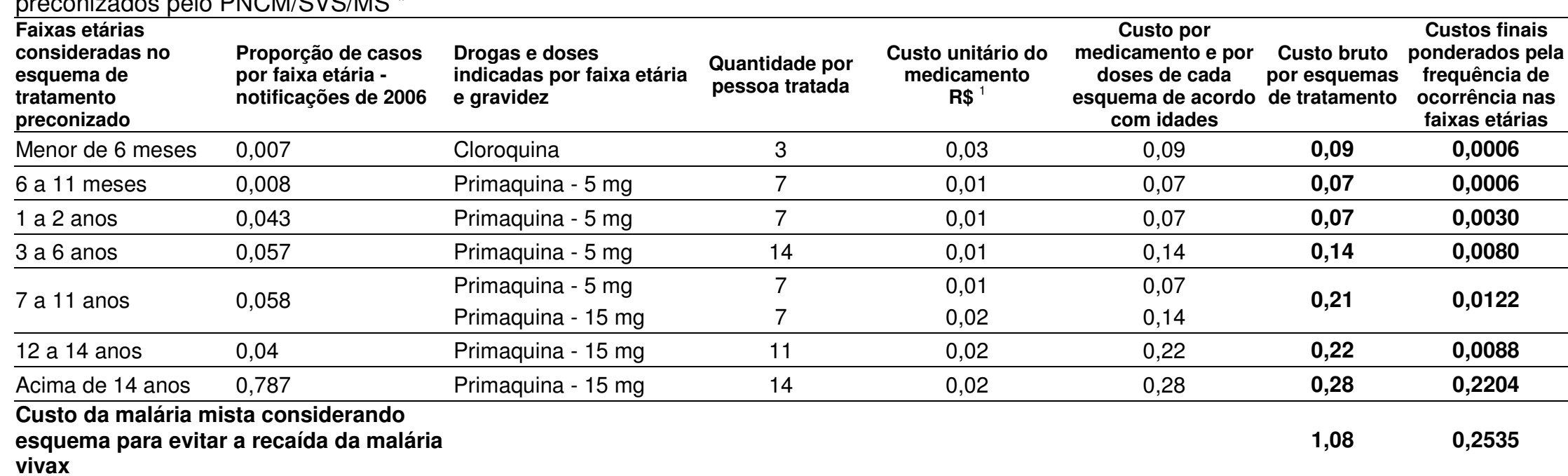

\section{vivax}

Fontes: PNCM/SVS/MS; SIVEP/Malária/SVS/MS

Notas: * Custo usado para compor o custo de malária falciparum, segundo a definição de caso usada.

(1) Por comprimidos. 


\section{Anexo 14}

Tabela A17 - Memória de cálculo para a estimativa de custo do salário do microscopista de acordo com o número de lâminas examinadas em cada estrato e com o número de profissionais necessários no cenário 1 - área global dos municípios

\begin{tabular}{|c|c|c|c|c|c|c|c|}
\hline $\begin{array}{l}\text { Estratos de } \\
\text { risco }\end{array}$ & $\begin{array}{l}\text { Número de } \\
\text { lâminas/hora } \\
\text { fonte: WHO, } \\
2005 \text { (1) }\end{array}$ & $\begin{array}{c}\text { Número de } \\
\text { lâminas/dia } \\
\text { fonte: } \\
\text { WHO,2005 } \\
\text { (2) }\end{array}$ & $\begin{array}{l}\text { Número de } \\
\text { lâminas/mês } \\
\text { (3) } x(2) \times 21 \text { dias } \\
\text { de trabalho }\end{array}$ & $\begin{array}{l}\text { Número de } \\
\text { lâminas por } \\
\text { ano } \\
\begin{array}{l}(4)=(3) \times 12 \\
\text { meses }\end{array}\end{array}$ & $\begin{array}{c}\text { Número de } \\
\text { profissionais } \\
\text { necessários para } \\
\text { o total de } \\
\text { lâminas/ano em } \\
\text { cada estrato } \\
\text { (5) = (número de } \\
\text { lâminas no } \\
\text { estrato)/(4) }\end{array}$ & $\begin{array}{c}\text { Salário anual por } \\
\text { estrato = salário } \\
\text { mensal }{ }^{(1)} \times 13 \\
\text { meses } \times \\
\text { número de } \\
\text { profissionais por } \\
\text { estrato } \\
(6) \\
(\mathrm{R} \$)\end{array}$ & $\begin{array}{c}\text { Salário do } \\
\text { microscopista por } \\
\text { lâmina - custo médio } \\
=(6) / 111.637 \\
\text { lâminas }^{(2)} \\
(\mathrm{R} \$)\end{array}$ \\
\hline $\mathbf{1}^{(3)}$ & 4 & 23 & 483 & 5.796 & 12 & $98.484,3600$ & \\
\hline $2^{(4)}$ & 4 & 21 & 441 & 5.292 & 4 & $32.828,1200$ & \\
\hline $3^{(5)}$ & 3 & 20 & 420 & 5.040 & 4 & $32.828,1200$ & \\
\hline $4^{(6)}$ & 4 & 21 & 441 & 5.292 & 1 & $8.207,0300$ & \\
\hline $\begin{array}{l}\text { SALÁRIO } \\
\text { ANUAL } \\
\text { TOTAL }\end{array}$ & & & & & & $172.347,6300$ & 1,5438 \\
\hline
\end{tabular}

Notas: ${ }^{(1)}$ Salário mensal de 2006: R \$ 631,31 (SMS de Novo Repartimento)

(2) Total de lâminas examinadas nos 12 municípios

(3) Estrato 1: Prevalência igual a 28,5\%; total de lâminas examinadas: 71.461

(4) Estrato 2: Prevalência igual a 22,0\%; total de lâminas examinadas: 21.130

(5) Estrato 3: Prevalência igual a 12,7\%; total de lâminas examinadas: 18.345

${ }^{(6)}$ Estrato 4: Prevalência igual a 24,4\%; total de lâminas examinadas: 701 


\section{Anexo 15}

Tabela A18 - Memória de cálculo para a estimativa de custo do salário do agente comunitário de saúde que realiza o teste rápido de acordo com o número de testes realizados em cada estrato e com o número de profissionais necessários no cenário 1 - área global dos municípios

\begin{tabular}{|c|c|c|c|c|c|c|c|}
\hline $\begin{array}{l}\text { Estratos de } \\
\text { risco }\end{array}$ & $\begin{array}{c}\text { Número de } \\
\text { testes/hora } \\
\text { fonte: WHO, } \\
2005 \text { (1) }\end{array}$ & $\begin{array}{l}\text { Número de } \\
\text { testes/dia } \\
\text { fonte: } \\
\text { WHO,2005 } \\
\text { (2) }\end{array}$ & $\begin{array}{l}\text { Número de } \\
\text { testes/mês } \\
\text { (3) } \times(2) \times 21 \text { dias } \\
\text { de trabalho }\end{array}$ & $\begin{array}{c}\text { Número de } \\
\text { testes por ano } \\
\begin{array}{c}(4)=(3) \times 12 \\
\text { meses }\end{array}\end{array}$ & $\begin{array}{c}\text { Número de } \\
\text { profissionais } \\
\text { necessários para } \\
\text { o total de } \\
\text { testes/ano em } \\
\text { cada estrato } \\
\text { (5) = (número de } \\
\text { testes no } \\
\text { estrato)/(4) }\end{array}$ & $\begin{array}{c}\text { Salário anual por } \\
\text { estrato = salário } \\
\text { mensal }{ }^{(1)} \times 13 \\
\text { meses } \times \\
\text { número de } \\
\text { profissionais por } \\
\text { estrato } \\
(6) \\
(\mathrm{R} \$)\end{array}$ & $\begin{array}{l}\text { Salário do agente de } \\
\text { saúde por tese - } \\
\text { custo médio } \\
=(6) / 111.637 \\
\text { testes } \\
\\
\\
(2) \\
(R \$)\end{array}$ \\
\hline $\mathbf{1}^{(3)}$ & 4 & 23 & 483 & 5.796 & 12 & $72.571,2000$ & \\
\hline $2^{(4)}$ & 4 & 21 & 441 & 5.292 & 4 & $24.190,4000$ & \\
\hline $3^{(5)}$ & 3 & 20 & 420 & 5.040 & 4 & $24.190,4000$ & \\
\hline $4^{(6)}$ & 4 & 21 & 441 & 5.292 & 1 & $6.047,6000$ & \\
\hline $\begin{array}{l}\text { SALÁRIO } \\
\text { ANUAL } \\
\text { TOTAL }\end{array}$ & & & & & & $126.999,6000$ & 1,1376 \\
\hline
\end{tabular}

Notas: ${ }^{(1)}$ Salário mensal de 2006: $\mathrm{R} \$ 465,20$ (SMS de Novo Repartimento); ${ }^{(2)}$ Total de testes realizados nos 12 municípios

${ }^{(3)}$ Estrato 1: Prevalência igual a $28,5 \%$; total de testes realizados: 71.461

(4) Estrato 2: Prevalência igual a 22,0\%; total de testes realizados: 21.130

(5) Estrato 3: Prevalência igual a 12,7\%; total de testes realizados: 18.345

${ }^{(6)}$ Estrato 4: Prevalência igual a 24,4\%; total de testes realizados: 701 


\section{Anexo 16}

Tabela A19 - Memória de cálculo para a estimativa de custo do salário anual do microscopista e do agente comunitário de saúde que realiza o teste rápido segundo os cenários de análise: cenário 1 - área global,

$$
\text { cenário } 2 \text { - áreas com laboratórios e cenário } 3 \text { - áreas isoladas }
$$

\begin{tabular}{|c|c|c|c|c|c|}
\hline $\begin{array}{c}\text { Salário anual do } \\
\text { microscopista } \\
\text { para o cenário } 1 \text { - } \\
\text { área global } \\
\text { (1) } \\
\end{array}$ & $\begin{array}{l}\text { Salário anual do } \\
\text { microscopista } \\
\text { para o cenário } 2 \text { - } \\
\text { áreas com } \\
\text { laboratório } \\
(2)=(1) \times 0,70\end{array}$ & $\begin{array}{l}\text { Salário anual do } \\
\text { microscopista } \\
\text { para o cenário } 3 \text { - } \\
\text { áreas isoladas } \\
(3)=(1) \times 0,30\end{array}$ & $\begin{array}{l}\text { Salário anual do } \\
\text { agente } \\
\text { comunitário para } \\
\text { o cenário 1- } \\
\text { área global } \\
\text { (4) }\end{array}$ & $\begin{array}{l}\text { Salário anual } \\
\text { do agente } \\
\text { comunitário } \\
\text { para o cenário } \\
2 \text { - áreas com } \\
\text { laboratório } \\
(5)=(4) \times 0,70\end{array}$ & $\begin{array}{c}\text { Salário anual do } \\
\text { agente } \\
\text { comunitário } \\
\text { para o cenário } 3 \\
\text { - áreas isoladas } \\
(6)=(4) \times 0,30\end{array}$ \\
\hline $172.347,63^{(1)}$ & $120.643,34^{(2)}$ & $51.704,29^{(3)}$ & $126.999,60^{(4)}$ & $88.899,72^{(5)}$ & $38.099,88^{(6)}$ \\
\hline \multicolumn{6}{|c|}{$\begin{array}{l}\text { Notas: } \\
\text { (1) Conforme anexo } 14 \\
\text { (2) Considerando } 70 \% \text { dos exames } \\
{ }^{(3)} \text { Considerando } 30 \% \text { dos exames } \\
{ }^{(4)} \text { Conforme anexo } 15 \\
\text { (5) Considerando } 70 \% \text { dos exames } \\
{ }^{(6)} \text { Considerando } 30 \% \text { dos exames }\end{array}$} \\
\hline
\end{tabular}




\section{Anexo 17}

Tabela A20 - Memória de cálculo do salário global para realização de uma microscopia, considerando dois cenários de análise: cenário 1 - área global dos 12 municípios que contém 30\% dos exames realizados em áreas isoladas e cenário 3 -

áreas isoladas *

\begin{tabular}{|c|c|c|c|}
\hline Categorias profissionais ${ }^{(1)}$ & $\begin{array}{c}\text { Salário para } \\
111.637 \\
\text { exames - } \\
\text { cenário } 1\end{array}$ & $\begin{array}{c}\text { Salário } \\
\text { ponderado } \\
\text { para } 111.637 \\
\text { exames - } \\
\text { cenário } 1\end{array}$ & $\begin{array}{c}\text { Salário } \\
\text { ponderado por } \\
\text { lâmina - } \\
\text { cenário } 1\end{array}$ \\
\hline Microscopista & $172.347,6300$ & $172.347,63$ & \\
\hline Agentes comunitários de saúde (acs) & $126.9999,6000$ & $38.0999,88$ & \\
\hline TOTAL PARA CENÁRIO 1 & $299.347,2300$ & $210.447,51$ & $1,8851^{(5)}$ \\
\hline Categorias profissionais ${ }^{(1)}$ & $\begin{array}{c}\text { Salário para } \\
30 \% \text { dos } \\
\text { exames - } \\
\text { cenário } 3 \\
\end{array}$ & & $\begin{array}{c}\text { Salário } \\
\text { ponderado por } \\
\text { lâmina - } \\
\text { cenário } 3 \\
\end{array}$ \\
\hline Microscopista & $51.704,29^{(6)}$ & & \\
\hline Agentes comunitários de saúde (acs) & $38.099,88^{(6)}$ & & \\
\hline TOTAL PARA CENÁRIO 3 & $89.804,17$ & & $2,6814^{(7)}$ \\
\hline
\end{tabular}

Notas: * Foi assumido que o cenário 2 não utiliza ACS para coleta de exames; (1) Assumido que os ACS coletam o sangue em

$30 \%$ dos exames no cenário 1 (nas áreas isoladas) e todas as lâminas no cenário 3

(2) Conforme anexo 14

(3) Conforme anexo 15

(4) Ponderado o salário do ACS por $30 \%$

(5) R\$210.447,51/111.637 lâminas

(6) Conforme anexo 16

(7) $\mathrm{R} \$ 89.804,17 / 33.491$ lâminas 


\section{Anexo 18}

Tabela A21 - Memória de cálculo para a estimativa de custo de microscópio e de manutenção de microscópio segundo o número de profissionais necessários no cenário 1 - área global dos municípios

\begin{tabular}{|c|c|c|c|c|c|c|}
\hline $\begin{array}{l}\text { Estratos de } \\
\text { risco }\end{array}$ & $\begin{array}{c}\text { Número de } \\
\text { profissionais } \\
\text { necessários para o } \\
\text { total de testes/ano em } \\
\text { cada estrato } \\
\text { (1) }\end{array}$ & $\begin{array}{c}\text { Número de } \\
\text { microscópios } \\
\text { necessários para o } \\
\text { total de testes/ano } \\
\text { em cada estrato } \\
\text { (2) }\end{array}$ & $\begin{array}{c}\text { Custo dos } \\
\text { microscópios por } \\
\text { ano por estratos - } \\
\text { caso base } \\
(3)=R \$ 1.053,85 x \\
\text { (2) }\end{array}$ & $\begin{array}{c}\text { Custo do } \\
\text { microscópio por } \\
\text { lâmina - caso - } \\
\text { base } \\
(4)=(3) / 111.637 \\
\text { lâminas }\end{array}$ & $\begin{array}{c}\text { Custo da } \\
\text { manutenção dos } \\
\text { microscópios por } \\
\text { ano por estratos - } \\
\text { caso base } \\
(5)=R \$ 80,00 \times(2)\end{array}$ & $\begin{array}{c}\text { Custo da } \\
\text { manutenção de } \\
\text { microscópio por } \\
\text { lâmina - caso -base } \\
(6)=(5) / 111.637 \\
\text { lâminas }\end{array}$ \\
\hline $\mathbf{1}^{(3)}$ & 12 & 12 & $12.646,20$ & & 960,00 & \\
\hline $2^{(4)}$ & 4 & 4 & $4.215,40$ & & 320,00 & \\
\hline $\mathbf{3}^{(5)}$ & 4 & 4 & $4.215,40$ & & 320,00 & \\
\hline $4^{(6)}$ & 1 & 1 & $1.053,85$ & & 80,00 & \\
\hline $\begin{array}{l}\text { CUSTO } \\
\text { ANUAL } \\
\text { TOTAL }\end{array}$ & & & $22.130,85$ & 0,1982 & $1.680,00$ & 0,0150 \\
\hline
\end{tabular}

Notas:

(1) Com base no número de lâminas examinadas, conforme anexo 14

(2) Considerado um microscópio por profissional

(3) Estrato 1: Prevalência igual a 28,5\%; total de lâminas examinadas: 71.461

(4) Estrato 2: Prevalência igual a 22,0\%; total de lâminas examinadas: 21.130

(5) Estrato 3: Prevalência igual a 12,7\%; total de lâminas examinadas: 18.345

(6) Estrato 4: Prevalência igual a 24,4\%; total de lâminas examinadas: 701 


\section{Anexo 19}

Tabela A22 -Memória de cálculo para a estimativa de custo de transporte para a realização de teste rápido em áreas isoladas que correspondem a $30 \%$ dos casos examinados no cenário 1 - área global dos municípios, segundo a necessidade por estratos

\begin{tabular}{|c|c|c|c|c|c|}
\hline $\begin{array}{l}\text { Estratos de } \\
\text { risco }\end{array}$ & $\begin{array}{c}\text { Número de } \\
\text { profissionais } \\
\text { necessários } \\
\text { para o total de } \\
\text { testes/ano em } \\
\text { cada estrato } \\
\text { (1) }\end{array}$ & $\begin{array}{c}\text { Fator de } \\
\text { correção para } \\
\text { estimativa do } \\
\text { uso de } \\
\text { transporte } \\
\text { para ações de } \\
\text { malária em } \\
\text { cada estrato } \\
(2)=(1) / 12 \\
\end{array}$ & $\begin{array}{c}\text { Custo do transporte por ano por } \\
\text { estrato - caso base } \\
(3)=\mathrm{R} \$ \begin{array}{c}37.764,00 / \text { fator de correção } \\
\text { de cada estrato }\end{array} \\
\mathrm{R} \$\end{array}$ & $\begin{array}{l}\text { Custo do transporte por } \\
\text { ano para } 33.491 \text { exames } \\
(30 \%) \text { - caso - base } \\
\qquad \begin{array}{c}(4)=(3) \times 0,3^{(4)} \\
R \$\end{array}\end{array}$ & $\begin{array}{l}\text { Custo do transporte por } \\
\text { exame - caso - base } \\
(5)=(4) / 33.491 \text { exames } \\
\text { R\$ }\end{array}$ \\
\hline $\mathbf{1}^{(5)}$ & 12 & 1 & $37.764,00$ & & \\
\hline $2^{(6)}$ & 4 & 3 & $12.588,00$ & & \\
\hline $3^{(7)}$ & 4 & 3 & $12.588,00$ & & \\
\hline $4^{(8)}$ & 1 & 12 & $3.147,00$ & & \\
\hline $\begin{array}{l}\text { CUSTO } \\
\text { ANUAL } \\
\text { TOTAL }\end{array}$ & & & $66.087,00$ & $19.826,10$ & 0,5920 \\
\hline
\end{tabular}

Notas: (1) Mantida como base a quantidade de profissionais necessária para cada estrato e assumido o estrato 1 como base para correção dos demais

estratos - onde haveria o maior gasto com transporte - custo máximo

(2) O fator de correção teve o objetivo de estimar a carga de transporte a partir do número de profissionais (proxy), tendo como base o número de profissionais do estrato 1 (12)

(3) $\mathrm{R} \$ 37.764$ corresponde a $\mathrm{R} \$ 3.147,00 \times 12$ meses - é o custo do caso-base, com base no Município Novo Repartimento. Os mesmos cálculos foram aplicados aos valores da variação de custos: $R \$ 1.856,00$ e $R \$ 35.649,07$, assumindo estes valores para o estrato 1.

(4) Assumida a necessidade de transporte para $30 \%$ dos exames - áreas isoladas

(5) Estrato 1: Prevalência igual a $28,5 \%$; total de lâminas examinadas: 71.461

(6) Estrato 2: Prevalência igual a 22,0\%; total de lâminas examinadas: 21.130

(7) Estrato 3: Prevalência igual a 12,7\%; total de lâminas examinadas: 18.345

(8) Estrato 4: Prevalência igual a 24,4\%; total de lâminas examinadas: 701 


\section{Anexo 20}

Tabela A23 -Memória de cálculo para a estimativa de custo de transporte para a realização da gota espessa em áreas isoladas que correspondem a $30 \%$ dos casos examinados no cenário 1 - área global dos municípios, segundo a necessidade por estratos

\begin{tabular}{|c|c|c|c|c|c|}
\hline $\begin{array}{l}\text { Estratos de } \\
\text { risco }\end{array}$ & $\begin{array}{l}\text { Número de } \\
\text { profissionais } \\
\text { necessários } \\
\text { para o total de } \\
\text { testes/ano em } \\
\text { cada estrato } \\
\text { (1) }\end{array}$ & $\begin{array}{c}\text { Fator de } \\
\text { correção para } \\
\text { estimativa do } \\
\text { uso de } \\
\text { transporte } \\
\text { para ações de } \\
\text { malária em } \\
\text { cada estrato } \\
(2)=(1) / 12\end{array}$ & $\begin{array}{l}\text { Custo do transporte por ano por } \\
\text { estrato - caso base } \\
(3)=R \$ \begin{array}{l}75.528,00 / \text { fator de correção } \\
\text { de cada estrato }\end{array} \\
R \$\end{array}$ & $\begin{array}{l}\text { Custo do transporte por } \\
\text { ano para } 33.491 \text { exames } \\
\begin{array}{c}(30 \%) \text { - caso - base } \\
(4)=(3) \times 0,3^{(4)} \\
\text { R\$ }\end{array}\end{array}$ & $\begin{array}{l}\text { Custo do transporte por } \\
\text { exame - caso - base } \\
\begin{array}{c}(5)=(4) / 33.491 \text { exames } \\
\text { R\$ }\end{array}\end{array}$ \\
\hline $\mathbf{1}^{(5)}$ & 12 & 1 & $75.528,0000$ & & \\
\hline $2^{(6)}$ & 4 & 3 & $25.176,0000$ & & \\
\hline $3^{(7)}$ & 4 & 3 & $25.176,0000$ & & \\
\hline $4^{(8)}$ & 1 & 12 & $6.294,0000$ & & \\
\hline $\begin{array}{l}\text { CUSTO } \\
\text { ANUAL } \\
\text { TOTAL }\end{array}$ & & & $132.174,00$ & $39.652,20$ & 1,1840 \\
\hline
\end{tabular}

Notas: ${ }^{(1)}$ Mantida como base a quantidade de profissionais necessária para cada estrato e assumido o estrato 1 como base para correção dos demais

estratos - onde haveria o maior gasto com transporte - custo máximo

(2) $\mathrm{O}$ fator de correção teve o objetivo de estimar a carga de transporte a partir do número de profissionais (proxy), tendo como base o número de profissionais do estrato 1 (12)

(3) $\mathrm{R} \$ 75.528,00$ corresponde a $\mathrm{R} \$ 6.294,00$ x 12 meses - é o custo do caso-base, com base no Município Novo Repartimento. Os mesmos cálculos foram aplicados aos valores da variação de custos: $\mathrm{R} \$ 3.712,00$ e $\mathrm{R} \$ 71.298,13$, assumindo estes valores para o estrato 1.

(4) Assumida a necessidade de transporte para $30 \%$ dos exames - áreas isoladas

(5) Estrato 1: Prevalência igual a 28,5\%; total de lâminas examinadas: 71.461

(6) Estrato 2: Prevalência igual a 22,0\%; total de lâminas examinadas: 21.130

(7) Estrato 3: Prevalência igual a 12,7\%; total de lâminas examinadas: 18.345

(8) Estrato 4: Prevalência igual a 24,4\%; total de lâminas examinadas: 701 
Anexo 21

Tabela A24 -Memória de cálculo para a estimativa de custo de internação hospitalar, considerando custos conjuntos de diárias de enfermaria e diárias de UTI em três possibilidades de tempo de internação e para o conjunto dos casos positivos*

\begin{tabular}{|c|c|c|c|c|c|c|c|c|c|c|}
\hline $\begin{array}{c}\text { Custo da } \\
\text { Diária } \\
\text { hospitalar no } \\
\text { SUS - } 2006 \\
\text { R\$ }\end{array}$ & $\begin{array}{c}\text { Custo de diária } \\
\text { de CTI no SUS } \\
-2006 \\
\text { R\$ }\end{array}$ & 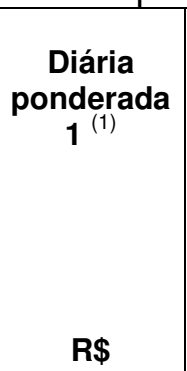 & $\begin{array}{c}\text { Diária } \\
\text { ponderada } \\
2^{(2)} \\
\\
\text { R\$ }\end{array}$ & $\begin{array}{c}\underset{3}{\text { Diária }} \\
\text { ponderada } \\
\\
\\
\text { R\$ }\end{array}$ & $\begin{array}{c}\text { Custos para } \\
\text { regime de } \\
\text { internação por } \\
10 \text { dias, } \\
\text { considerando } \\
27.488 \text { casos } \\
\text { positivos com a } \\
\text { Diária } 1^{(4)} \\
\text { R\$ }\end{array}$ & $\begin{array}{c}\text { Custos para } \\
\text { regime de } \\
\text { internação por } \\
07 \text { dias, } \\
\text { considerando } \\
27.488 \text { casos } \\
\text { positivos com a } \\
\text { Diária } 2{ }^{(4)} \\
\text { R\$ }\end{array}$ & $\begin{array}{c}\text { Custos para } \\
\text { regime de } \\
\text { internação por } \\
18 \text { dias, } \\
\text { considerando } \\
27.488 \text { casos } \\
\text { positivos com a }^{(4)} \\
{\text { Diária } 3^{(4)}}_{\text {R } \$}\end{array}$ & $\begin{array}{c}\text { Custo } \\
\text { estimado de } \\
\text { internação por } \\
\text { caso - Diária } 1 \\
\text { R\$ }\end{array}$ & $\begin{array}{c}\text { Custo } \\
\text { estimado de } \\
\text { internação } \\
\text { por caso - } \\
\text { Diária 2 } \\
\text { R\$ }\end{array}$ & $\begin{array}{c}\text { Custo } \\
\text { estimado de } \\
\text { internação } \\
\text { por caso - } \\
\text { Diária } 3 \\
\text { R\$ }\end{array}$ \\
\hline 60,98 & 213,71 & 137,34 & 106,80 & 167,89 & $37.752 .019,20$ & $20.550 .028,80$ & $83.069 .285,76$ & $1.373,45$ & 747,60 & $3.022,03$ \\
\hline & & & & & & & & & & \\
\hline
\end{tabular}

* Considerados todos os casos positivos devido à entrada do dado no modelo de custo-efetividade que ponderará pela freqüência de casos graves de malária falciparum

(1) Soma ponderada dos custos considerando 50\% em regime de UTI e 50\% em regime de enfermaria

(2) Soma ponderada dos custos considerando $30 \%$ em regime de UTI e $70 \%$ em regime de enfermaria

(3) Soma ponderada dos custos considerando $70 \%$ em regime de UTI e $30 \%$ em regime de enfermaria

(4) Assumidos de 7 a 18 dias de internação, sendo o caso-base de 10 dias 
